4twบ.d Tokomito 
- Digitized by the Internet Archive in 2008 with funding from Microsoft Corporation 


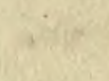





\section{CLIMATIC CYCLES AND TREE-GROWTH}

\section{A STUDY OF THE ANNUAL RINGS OF TREES IN RELATION TO CLIMATE AND SOLAR ACTIVITY}

BY

A. E. DOUGLASS

Director of Steward Observatory, University of Arizona

$$
\text { cvol.I. }
$$
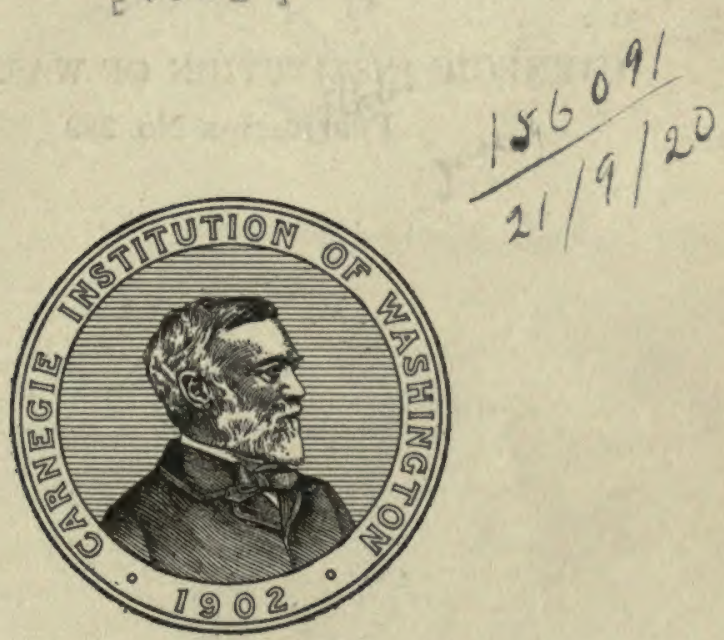

Published by the Carnegie Institution of Washington

Washiygton, 1919 


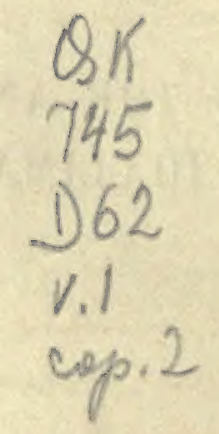

CARNEGIE INSTITUTION OF WASHINGTON

Publication No. 289 
PAGE.

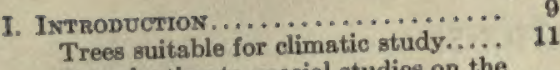

Introduction to special studies on the yellow pine................... 12

Location. .

Climate and seasonal conditions. 13

II. Preltminary studis on the yeliow PINE .

Yearly identity and the dating of rings 15

Crose-identification -... Cross-identification and climate. 17

Month of beginning annual means... 17

The time of year of ring formation... 18 Significance of subdivisions in rings...$\ldots \ldots \ldots \ldots \ldots$. $20 . \ldots$.

Number of trees necessary for reliable results,$\ldots \ldots \ldots . . . . . .$. . Direction of maximum growth..

Rate of growth and age........ Growth and soil.............

1II. Collection of Bections........... The first Flagstaff group of 25 sections Subgroups.................. First suggestion of cross-identifieation.................. The Flagataff 500-year record. ... The second Flagstaff group of $7 \mathrm{sec}$ tions ...................... The Prescott group.............. South of England group........... Outer cosst of Norway group....... Inner cosst of Norway group....... Christiania group............... Central Sweden group............. South Sweden group.............. Eberswalde (Prussia) group.......... Pilsen (Austria) group. ............ Southern Bavaria group............ Old European trees............... Windsor (Vermont) group.......... Oregon group................... The Sequois group .................

The Sequoia journey of $1918 . . . . .$.

IV. Detarla of curve production..... Preparation of radial samples....... Form of sample.............. Method of cutting............ Preparation for measurement...

Identification of rings............. Fire-scars .................. Cross-identificstion between distant points. . ...............

The difficult ring $1580 \ldots \ldots$

Measuring...................... Tabulating.................... Averaging. ................... Smoothing.................... Standardixing.................. Plotting..................... Problems in plotting...........

v. Comrelation with ratngali........ Result of study of curves........ Early tests of rainfall correlation. . . . . . . . . . . . . . . .

The Prescott correlation............ Accuracy..................

V. Correlation with mainfali-contd. BAGE. The Prescott correlation-continued.

Mathematical relation of rainfall and growth .............. 67

Character of the conservation term $\ldots \ldots \ldots \ldots \ldots \ldots \ldots, 67$

Summary ............... 70

Sequois correlation with rainfall. 70

Future work............... 72

Meteorologieal districts............ 72 Meteorological districts and growth of trees............ 72

Arizons and California........ 73

Meteorological distriots and solar correlation...............

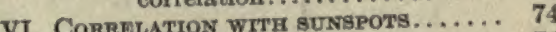

Dry-climate tests............ 74

Wet-climate reaction.......... 74

The European groups.......... 76

Windsor (Vermont) correlation. 79

The runspots and their possible causes 81

Appearance............... 81

Sugrested causes of sunspots... 82

Length of the sunspot period... 84

Tree-erowth and solar activity.. 84

VII. M PTTODS OF PERIODIC ANALYsTS.... 85

Need for such analysis......... 85

Proportional dividers.......... 85

The optical periodograph.......... 86

Schuster's periodogram........ 86

The optical periodogram...... 86

Application to length of sunspot period................. 88

Production of differential pattern 89

Theory ................ 90

The automatic optical periodograph. 92

The curve.............. 92

Track and moving mechsnism... 92

Differentisl pattern mechanism . 93

The periodogram mechanism... 94

Periodograms............... 96

Resolving power of the periodograph.................... 96

VIII. Crowess .................. 98

Significance of cycles.......... 98

Predominant cycles............ 98

Locality and solar cycles...... 99

Illustrations of cycles. ........ 101

Tlistrations of cycles............ 101

The 11-year cycle in sequoia.... 102

The 11-year cycle in sequoia..... 103

Double and triple cycles......... 103

A 2-year cycle................. 106

Periodograph analyses............ 107

Differential patterns.......... 107

The 11-year eycle............ 107

Changes in the 11-year tree-cycle

of Arizons................ 108

Sequoia pattern.............. 109

Other solar cycles............. 109

The 100-yesr cycle............. 110

Illustration by the periodograph. 110

Summary ................. 111

Sumpary . .................... 111

Addendum.................... 112

APPENDIX........................... 113

Tables of mean tree-growth by grougs 118
Bibliography ................. 124 


\section{ILLUSTRATIONS.}

PLATES.

PAGE.

Plate 1.

A. Bottomless pits near Flagstaff, illustrating drainage through limestone...................

B. Yellow pine forest of northern Ari-

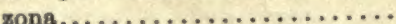

Plate 2.

Cross-identification of rings of growth Plate 3. in yellow pine ( $P$ inus ponderosa).

A. Section of Scotch pine from Southern

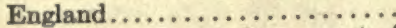

B. Section of Scotch pine from coast of Norway.................

Platio 4.

A. Section of Sooteh pine from Ös, Norway ...................

B. Section of Scotch pine from Dalarne, Sweden...................

Prate 5.

A. Upland contours, above Camp 6 in Sequoia Grove: D-19 . . . . . .

B. Basin contours, Indian Basin, looking $\mathrm{S} . \mathrm{E}$. : D-12 and 13 in center.

Plate 6.

A. Cutting radial sample from end of log, Converse Hoist, D-20, age 2800 years. ...............

B. Site of oldest tree, Converse Hoist, D-21, age 3200 years........

Plate 7.

A. Cutting sample from stump, Enterprise: D-22, age 3000 years.....

B. Centennial stump, Enterprise; cut in 1874 , D-23, age 3075 years.....

Plate 8.

A. Bection of Scotch pine from Eberswalde, Prussis, showing solar rhythm..................

B. Another section from the same forest, showing same rhythm.........

Plate 9.

A. Periodogram of the sunspot numbers, 1755-1911. Corrugations show periods. The numbers give length of period in years. The white line is the year 1830 and shows phase...................

PAOT.

Plate 9-continued.

B. Differential pattern used in making the periodogram, consisting of the sunspot curve mounted in multiple...................

C. Same pattern photographed out of focus to show discontinuities in the vertical lines..............

D. Sweep of sunspot numbers, 1755-1911

E. Differential pattern of sunspot numbers made by the periodograph process...................

Plate 10.

A. The automatic optical periodograph.

B. Differential patterns of Sequoia record, 3200 years at $11.4 \ldots \ldots \ldots$.

Prate 11.

A. Periodogram of standard 5-year period................... 96

B. Periodogram of mixed periods...... 96

C. Periodogram of sunspot numbers $1610-1910, \ldots \ldots \ldots \ldots \ldots . \ldots 96$

D. Periodogram of Flagstaff 500-year record to show cycles between 4 and 15 years of length........ 96

E. Periodogram of same continued to 25 years.................. 96

PuAte 12. Differential patterns:

a. Sunspot numbers, 1610-1910 at 11.4. 108

b. 57 European trees, 1830-1910 at 11.4. 108

c. 80 European trees, 1800-1910 at 11.4. 108

d. South Sweden, 1830-1910 at 12.0... 108

e. Vermont group, 1650-1910, at 11.3. 108

f. Flagstaff group, 500 years, at 11.4... 108

o. Flagstaff group at 23.5 years...... 108

h. Norway, 1740-1910, at 23.8 years... 108

i. Austria, $1830-1910$, at 22.0 years... 108

j. Norway, N-2 400 years, at $33.0 \ldots . .108$

$k$. Vermont, 250 years, at $32.5 \ldots \ldots \ldots 108$

$i$. Sweden, 1740-1910, at 37.0 ....... 108

$m$. Sequoia, 1300-250 B. C., at 33.0 ... 108

n. Flagstaff, 500 years, at $33.0 \ldots \ldots \ldots 108$

v. Sequoia, 3200 years at $101 \ldots \ldots \ldots 108$

p. Flagstaff, 500 years at $120 \ldots \ldots \ldots . . .108$

q. Standard 5-year period at 5.0 years. 108

q. 5 to 10 year logarithmio variablo period at $8.0 \ldots \ldots \ldots \ldots \ldots \ldots 108$ 


\section{TEXT-FIGURES.}

1. Effect of monthly distribution "of precipitation on thickness of rings of growth; Prescott, Arizona..........

2. Monthly and yearly precipitation at Prescott, and size and character of rings.......................

3. Annual growth of trees at Flagstaff from 1385 to $1906, A . D \ldots \ldots \ldots \ldots$

4. Comparison of two Flagstaff groups. Variations in annual rainfall according to month of beginning annual means.

5. Growth of individual trees compared with precipitation at Flagstaff......

6. Annual growth of trees near Prescott,

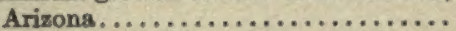

7. Annual rainfall and growth of trees (Group V) at Prescott. Dotted line $=$ rainfall. Solid line $=$ growth.....

8. The nine European groups..........

9. Sunspots and growth of trees at Eberswalde, Germany .................

10. Growth of old European trees. A. Six Norwegian trees, mostly from inner fjords. B. Eight trees from Dalarne, Sweden.......................

11. Oregon group. Curve No. 1, aetual tree growth; No. 2, trees growth departures, smoothed; No. 3, sunspot numbers displaced 2 years to left....

12. Cross-identification in first five sequoias and gross rings in No. 1...........

13. Correlation between tree growth and rainfall in smoothed curves; Flagataff.

14. Early test of correlation between tree growth and rainfall by years; Flagstaff

15. Relation of tree growth and rainfall at Prescott. Tree growth and rainfall uncorrected....................

16. Five-year smoothed curves of growth and rainfall $\ldots \ldots \ldots \ldots \ldots \ldots \ldots$.

17. Accumulated rain and smoothed tree growth.....................

18. Actual tree growth and growth calculated from rain ................

19. Actual rain and rain calculated from

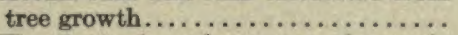

20. Huntington's early curves of sequoia growth and rainfall compared with growth calculated by a conservation formula.....................

21. Comparison of Fresno rainfall (after Huntington) and sequoias D-1 to 5 ..

22. Sunspot numbers and annual rings in spruce tree from south Sweden......
AQR.
23. Six European groups, standardized and smoothed............... 75

24. Three European groups, standardized and smoothed.................

25. Comparison between 57 north Europe trees (smoothed) and sunspot numbers. The trees are from England, Norway, Sweden, and north Germany

26. Dates of large rings in 80 European trees compared with sunspot curves. Ordinates give number of trees in total of 80 showing maxima in respective years....................

27. Tree growth at Windsor, Vermont, showing measures uncorrected: same standardized and smoothed, and sunspot numbers displaced 3 years to left

28. Smoothed quarterly rainfall (upper curve), sunspot numbers (center), and tree growth (lower) at Windsor, Vermont, 1835 to $1912 . . \ldots \ldots \ldots \ldots$.

29. Correlation curves of solar cycle, rainfall, and tree growth at Windsor, Vermont, 1835 to $1912 \ldots \ldots \ldots \ldots \ldots \ldots$.

30. Schuster's periodogram of the sunspot numbers.......................

31. Diagram of theory of differential pattern in periodograph analysis......

32. Smoothed curve of Arizona pines showing the half-sunspot period for 120 years............................ 102

33. Changes in the 11 -year period in 500 years. Solid line, Arizona pine; dotted line, sequoia............ 103

34. Correlation curves in the 11-year cycle 104

35. Early curve of Arizona oines from $\mathbf{1 7 0 0}$ to 1900 A. D. (No. 4) compared witb double and triple sunspot cycles combined (No. 3)................ 105

36. Douhle sunspot period in tree growth at inner fjords of Norway; lower curve a 22.8 -year cycle............... 105

37. Double sunspot rhythm in sequoia, D-12 about 300 A. D.......... 105

38. Triple sunspot cycle in a single tree from northern Norway. Lower curve, a 34 -year cycle................ 106

39. D-22 at 750 to 660 B. C., showing a 2-year period................. 106

40. Two differential patterns of Huntington s preliminary 2000 year sequois record. The most prominent cycle is about 105 years in length, shown in the upper diagram............ 109 



\title{
CLIMATIC CYCLES AND TREE-GROWTH
}

A STUDY OF THE ANNUAL RINGS OF TREES IN RELATION TO CLIMATE AND SOLAR ACTIVITY

\author{
By A. E. Douglass \\ Director of Steward Observatory, University of Arizona
}





\section{CLIMATIC CYCLES AND TREE-GROWTH.}

\section{INTRODUCTION.}

The investigation described in the subsequent pages bears close relation to three sciences. It was approached by the author from the standpoint of astronomy and a desire to understand the variations of the sun. It was hoped that these variations could be more accurately studied by correlation with climatic phenomena. But the science of meteorology is still comparatively new and supplies us only with a few decades of records on which to base our conclusions. So botanical aid was sought in order to extend our knowledge of weather changes over hundreds and even thousands of years by making use of the dependence of the annual rings of trees in dry climates on the annual rainfall. If the relationship sought proves to be real, the rings in the trunks of trees give us not only a means of studying climatic changes through long periods of years, but perhaps also of tracing changes in solar activity during the same time. Thus astronomy, meteorology, and botany join in a study to which each contributes' essential parts and from which, it is hoped, each may gain a small measure of benefit.

It is entirely natural that the yellow pine, Pinus ponderosa, common on the western Rockies, should have been the first tree studied, since it was an intimate and extensive acquaintance with the forest and with the climate of northern Arizona that led the writer to the thought of possible relation between the two. The climate had been sought for astronomical reasons because its limited rainfall of about 22 inches gave many clear nights and superb skies. The forest with its great extent and stately trees proved wonderfully attractive and the absence of undergrowth or of other species of trees was its most noticeable feature to anyone accustomed to moist climates. Evidently the absence of undergrowth was related to the dryness, and the critical problem of the tree was to survive periods of drought rather than to compete successfully with other species in the struggle to obtain food supply. The following argument, therefore, was naturally suggested: (1) the rings of trees measure the growth; (2) growth depends largely upon the amount of moisture, especially in a climate where the quantity of moisture is limited; (3) in such countries, therefore, the rings are likely to form a measure of precipitation. Relationship to temperature and other weather elements may be very important, but precipitation was thought to be the controlling factor in this region and for the sake of simplicity it is the element fundamentally considered throughout the present study.

In the very beginning of the work it was expected that only in large averages would a relationship be found between tree-growth and climate. Accordingly, something like 10,000 measures had been made 
on the pines of northern Arizona and the results all tabulated, when it occurred to the writer to compare the annual growth of Flagstaff trees directly with the 8 or 10 years of rainfall records taken at the United States Weather Bureau station recently established there. It was immediately seen that the accuracy with which tree-growth as shown in the rings may represent annual rainfall was far greater than anticipated. In a considerable number of cases, but especially in the dryclimate groups, this has been found to be in the neighborhood of 70 per cent, which is raised substantially by applying a formula to allow for some degree of moisture conservation. At the present time, therefore, it is possible to lay a foundation for this study directly in the fact that the rings of trees form an approximate measure of the rainfall.

When the studies were carried to northern Europe an equal exactness in following the rainfall was not found, but a direct correlation was discovered between tree-growth and solar activity. Subsequent groups have been obtained from moist regions of the United States, and one is led to believe that this altered reaction is a question of precipitation and that it must be kept well in mind in any application of the methods hereafter described.

Since the beginning of this investigation, in 1901, assistance has been received from several sources which it is a pleasure to acknowledge at this time. Mr. T. A. Riordian, of Flagstaff, had 24 sections of the early Flagstaff group cut from the ends of logs and shipped to me. Mr. Willard P. Steel assisted in the measuring of the first 25 sections and a number of friends helped in the tabulation. Mr. C. H. Hinderer, of the United States Forest Service, at Prescott, Arizona, assisted in procuring the Prescott groups. Mr. H. S. Graves, Chief of the United States Forest Service, gave me several letters of introduction to foresters in Europe, by which I was greatly assisted in procuring the 9 European groups. I am glad to express my obligation to Dr. H. H. Jelstrup of Christiania, Professor Gunnar Schotte of Stockholm, Professor Dr. A. Schwappach of Eberswalde, and Professor A. Cieslar of Vienna, for especial aid in this connection. Assistance in completing the Vermont group was given by Mr. M. H. Douglass and others, and for aid in procuring the Oregon group I am glad to mention the excellent work of Mr. Robert H. Weitknecht, who was for a time connected with the United States Forest Service at Portland, Oregon. I am indebted to Mr. George A. Hume, of the Sanger Lumber Company, for important help in connection with the sequoia groups. In 1914 a grant of $\$ 200$ was received from the Elizabeth Thompson Science Fund for study upon the correlation between tree-growth and solar variation. In 1918 a fund of $\$ 250$ was placed at my disposal by the American Association for the Advancement of Science. This was for the purpose of extending the sequoia ring-record from 2,200 years in length (the result of preceding collection) to 3,000 years. This material was collected in 
the summer of 1918 and the measurements and tabulation finished soon after. I wish gratefully to acknowledge the courtesy of the editors of the Astrophysical Journal and the Bulletin of the American Geographical Society for permission to use illustrations and extracts from articles of mine which they have published. Plate 9 and figure 31 in the text are from the former journal. Thanks are also extended to Professor Ellsworth Huntington for the use of several text-figures which first appeared in my chapter of his work (1914).'

\section{TREES SUITABLE FOR CLIMATIC STUDY.}

During the course of this investigation the wood and growth of numerous species of trees have been examined with reference to their adaptability to the purposes herein described. The collections visited include several in London; especially one in the South Kensington Museum, fossils in the Jermyn Street Museum, the lumber-yards of Messrs. W. W. Howard Bros. \& Company, tree sections and fossils in the geological museum at Berlin, fossils in the lignite beds of Grube Ilsa near Dresden, and fossils chiefly in Munich and Vienna. In

TABLE 1.-List of trees in the Jessup collection whose rings were counted.

\begin{tabular}{|c|c|c|c|c|c|}
\hline Scientific name. & Common name. & Locality. & $\begin{array}{c}\text { Approx- } \\
\text { imate } \\
\text { center, } \\
\text { A. D. }\end{array}$ & $\begin{array}{l}\text { Possible } \\
\text { periods. }\end{array}$ & $\begin{array}{l}\text { Quality } \\
\text { of ring } \\
\text { sequence. }\end{array}$ \\
\hline Pinus torreyana. & Torrey pine. & San Diego, Cal. & 1790 & 11 years.... & \\
\hline Pinus radiata... & Monterey pine.... & Monterey, Cal. . & 1855 & 22 years..... & \\
\hline Pinus monticola.. & Western white pine. & Oregon.......... & 1641 & $\begin{array}{l}11 \text { years: } \\
\text { Brückner. }\end{array}$ & \\
\hline Pinus strobiformis & Mexican white pine. & Southern Ari- & 1706 & 22 years.... & \\
\hline Pinus strobus. . & White pine.. & Nova Scotia.... & $1740 ?$ & $\begin{array}{l}22 \text { y ears; } \\
\text { Brückner. }\end{array}$ & Fair. \\
\hline Pinus treds...... & Loblolly pine...... & Florida... & 1731 & $\ldots \ldots \ldots \ldots$ & \\
\hline $\begin{array}{l}\text { Pinus echinata... } \\
\text { Tsuga hetero- } \\
\text { phylla. }\end{array}$ & $\begin{array}{l}\text { Short-leaved pine. } \\
\text { Western hemlock.. }\end{array}$ & Missouri........ & $\begin{array}{l}1650 \\
1700\end{array}$ & Uncertain.... & \\
\hline Tsuga caroliniana & Carolina hemlock. & Carolina......... & 1697 & $\begin{array}{r}\text { Poor, } 22 \text { yr.; } \\
\text { Brückner. }\end{array}$ & Good. \\
\hline Tsuga canadensis. & Canadian hemlock. & Nova Scotia... & 1525 & $\begin{array}{c}11 \text { years; } \\
\text { Brückner. }\end{array}$ & Good. \\
\hline $\begin{array}{l}\text { Pseudotsuga ma- } \\
\text { crocarpa. }\end{array}$ & Bigcone fir & $\begin{array}{l}\text { Southern Cali- } \\
\text { fornia. }\end{array}$ & $1480 ?$ & 11 years.... & Good. \\
\hline $\begin{array}{l}\text { Pseudotsuga mu- } \\
\text { cronata. }\end{array}$ & Douglas fir. & Oregon.......... & 1315 & 11 years.... & Good. \\
\hline $\begin{array}{l}\text { Picea sitchensis... } \\
\text { Pices rubens }\end{array}$ & Tideland spruce... & Northwest coast & 1798 & & Very good. \\
\hline $\begin{array}{l}\text { Pices rubens..... } \\
\text { Sequoia gigantea. }\end{array}$ & $\begin{array}{l}\text { Red spruce...... } \\
\text { Bigtree........ }\end{array}$ & $\begin{array}{l}\text { Nova Scotia..... } \\
\text { Californis...... }\end{array}$ & $\begin{array}{r}1610 \\
550\end{array}$ & Brückner... & Good...... \\
\hline $\begin{array}{l}\text { Taxodium dis- } \\
\text { tichum. }\end{array}$ & Bald cypress................. & Florids............ & $1670 ?$ & & \\
\hline $\begin{array}{l}\text { Cupressus mac- } \\
\text { nabiana. }\end{array}$ & Macnab cypress... & $\begin{array}{l}\text { Northern Cali- } \\
\text { fornia. }\end{array}$ & 1760 & & Very good. \\
\hline $\begin{array}{l}\text { Toxylon pomifer- } \\
\text { um. }\end{array}$ & Osage orange.... & $\begin{array}{l}\text { Southern Arkan- } \\
\text { sas. }\end{array}$ & 1765 & & Fair. \\
\hline Ulmus fulva...... & Slippery elm..... & Missouri........ & 1770 & 20 years .... & ‥ \\
\hline
\end{tabular}


America, collections were examined at the Smithsonian Institution in Washington, the horticultural exhibit at the Panama-Pacific Exposition in 1915, the museum at Chicago, but especially the Jessup collection in the American Museum of Natural History in New York City. Much careful counting of rings was done at the latter. ${ }^{1}$

Considering all the trees examined, the conclusion was reached that the conifers, by the great regions they cover, the great variety of climates they endure, and especially by the prominence of their rings, seem best adapted to the purpose in hand. The chief trees, used with approximate number of rings measured in each, are: the yellow pine (Pinus ponderosa) about 14,000 ; Scotch pine $(P$. silvestris) about 9,000 ; hemlock (T'suga canadensis) 2,500; Douglas fir (Pseudotsuga mucronata) 2,500; sequoia (Sequoia gigantea) 47,000.

\section{INTRODUCTION TO SPECIAL STUDIES ON THE YELLOW PINE.}

Before taking up the details of collection and measurement it is desirable to describe certain preliminary studies, such as those upon the yearly identity of the rings, time of the year of ring formation, and so forth. These studies were made chiefly upon the yellow pine of northern Arizona, but from the similarity between the pine and the other trees used it seems safe to say that the results apply equally to the Scotch pine, sequoia, hemlock and other species employed.

Location.-The yellow pines upon which the studies were made were obtained near Flagstaff, in the central part of northern Arizona, at an elevation of about 6,800 feet above the sea. The northern part of the State is largely a plateau forming the southern extension of the great Colorado Plateau. This high area is intersected some 65 miles north of Flagstaff by the Grand Canyon of the Colorado River. South of the town the high elevation extends 50 to 75 miles, varying only a few hundred feet from place to place, and then falls away abruptly at the "Rim." Oak Creek Canyon begins some 10 miles south of Flagstaff and flows to the south into the Verde River. The general drainage nearer town is gently to the northeast into the Little Colorado River some 40 miles away. Ten miles north of town the plateau culminates in the San Francisco Peaks, which reach an elevation of 12,700 feet. This mountain is a finely shaped volcanic mass with the old crater breaking away into a canyon toward the northeast. The town is in latitude $35^{\circ} \mathrm{N}$. and longitude $113^{\circ} \mathrm{W}$., and lies between two ancient lava streams 200 to 400 feet in height. It has a "wash" flowing through it from north to south, but this carries water only in time of severe storm or of rapidly melting snow.

\footnotetext{
1 The 17-foot section of sequoin was reviewed with some care and the dates on it checked. The dating is well done, as the errors are mostly under 15 years. The rings are large an do not show marked variations in width. Much repair work has been done on it, and the pieces of wood filling the drying cracks near the year $800 \mathrm{~A}$. D. almost completely interrupt the continuity of the ringe.
} 

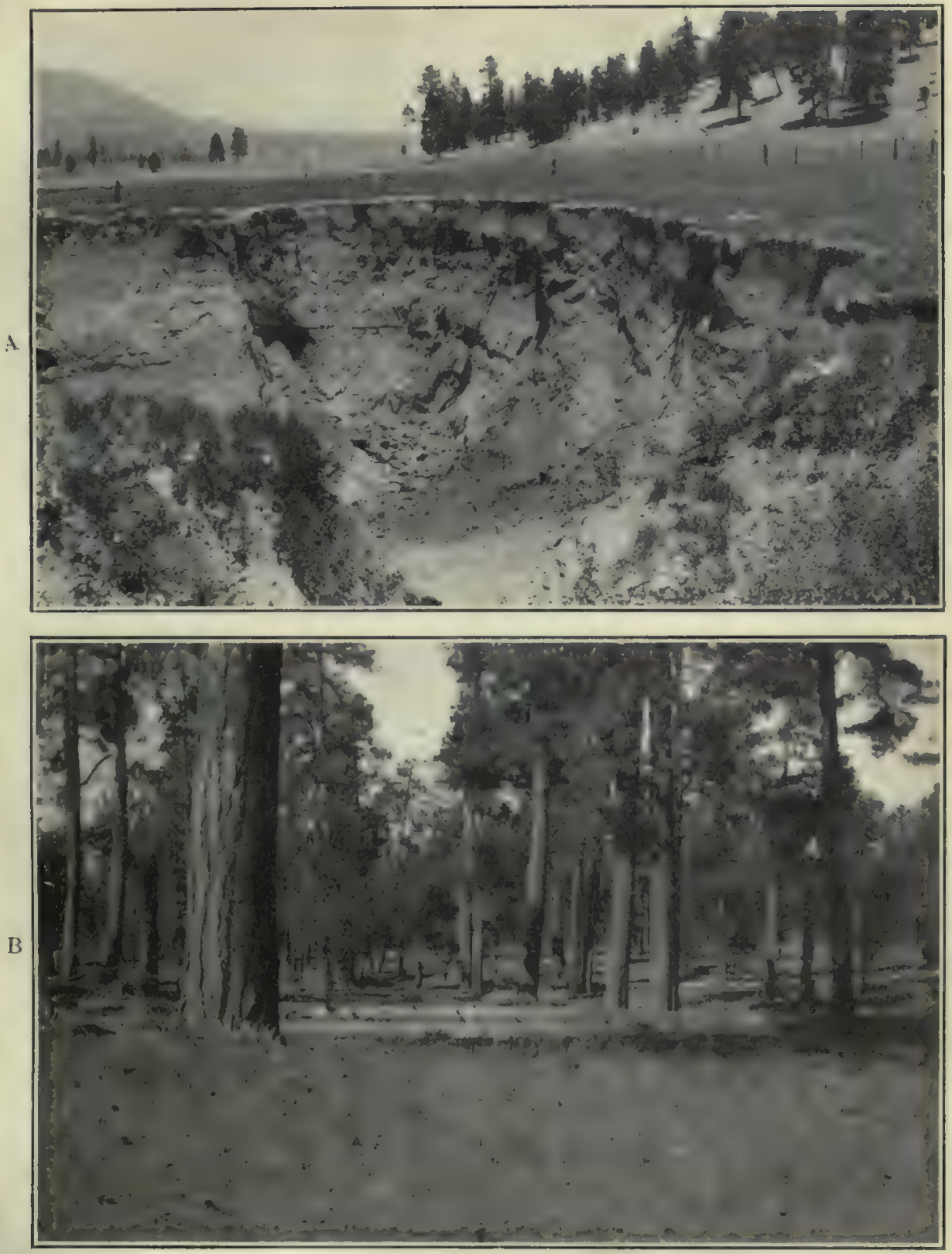

A. Bottomless pits near Flagstaff, illustrating drainage through limestone.

B. Yellow pine forest of northern Arizona. 

The general country rock is Kaibab limestone in horizontal layers forming the plateau, surmounted by lavas over extensive areas near the mountain. The bedrock is covered by a thin soil, largely formed in place. The soil over the limestones is porous, while that over the lavas has much clay and holds water. There is no swampy ground and therefore no conservation of moisture from year to year. Consequently variations in moisture-supply are qufckly felt by the trees. The pine forest is remarkable for the absence of other kinds of vegetation. It covers all parts of the plateau from about 5,000 feet in elevation to about 9,000. At the lower edge of the pine forest a belt of cedars, smaller than the pines and round in shape and with dark-green, thick foliage, makes an attractive landscape.

Climate and seasonal conditions.-The climate follows naturally from the latitude and altitude and the distance from the ocean. In the winters there may be from 1 to 6 feet of snow on the ground at one time. The storms are of the characteristic temperate-zone cyclonic types, but on account of the altitude the preliminary south or east winds are rarely observed. Storms come from the Pacific coast and rain occurs about a day later than in southern California. Spring and autumn are the dry seasons, and the warmest time of year is usually in June, just before the summer rains begin. The summer rains occur in July and August and often come in "spells" that last a week or two, with thunderstorms in the afternoons or at night, followed by clear mornings. Unlike the winter storms, the summer rains are local and apt to be torrential in character, with heavy run-off.

Meteorological records in northern Arizona are necessarily meager, yet not so deficient as might be expected. The country was first settled in the "fifties," when gold was discovered in Arizona as well as in California, and lines of travel were established from Santa $\mathrm{Fe}$ westward across the plateau. The "blazings" on the pine trees marking the earlier roads are still to be distinguished. Soon after the opening of the country the government located military camps at various places, and from that time records of rainfall and temperature were kept. The record at Whipple Barracks, near Preseott, begun in 1867, has been continued at Prescott to the present time. It is the longest consecutive record in the pine forest and is therefore used below.

The extreme range in temperature observed in Flagstaff is from about $20^{\circ} \mathrm{F}$. below zero to about $100^{\circ} \mathrm{F}$. above. But the town is in a peculiarly sheltered position and exhibits much lower night extremes than the "mesas" 200 to 400 feet above it. I have observed a difference of $26^{\circ} \mathrm{F}$. between the top and bottom of the hill west of town at sunrise on a winter morning. During the early years of the Lowell Observatory, which is located on the mesa 350 feet above the town, the lower minima were about $5^{\circ} \mathrm{F}$. These figures show the conditions to which the trees are subjected. 
The unobstructed topography of the plateau where the trees were collected is without doubt a very favorable feature. This leads to very similar conditions for the trees over many miles of country and doubtless greatly assisted in producing concordant tree-records. On the other hand, the San Francisco Peaks, 10 miles north of town, illustrate how meteorological data may vary in rugged localities. The west slopes of these mountains are exposed to the winter westerly storms and have an immense snowfall. Springs abound and all favorable localities are taken up as ranches. East of the mountain, however, the land is dry and barren, and long distances intervene between watering-places.

In a very rugged country like that about Prescott similar differences between east and west mountain slopes must constantly occur. This is the reason of an early difficulty with the Prescott groups. Nearly 60 trees from various localities were measured before a group was found close enough to Prescott to be compared minutely with records of precipitation at that place. 


\section{PRELIMINARY STUDIES ON THE YELLOW PINE.}

\section{YEARLY IDENTITY AND THE DATING OF RINGS.}

In comparing the growth of trees with rainfall and other data, it is essential that the date of formation of any individual ring shall be certain. This depends directly on the yearly identity of the rings or the certainty with which one ring and only one is formed each year. The fundamental starting-point in all identification is the ring partially formed at the time of cutting the tree. This is usually found with ease and has led to no uncertainty in the pine. In the sequoia this partial ring is exceedingly soft and had been rubbed off in nearly all trees examined. It was found unmistakably in a tree cut on the date of visit.

Superficial counting of rings is subject to errors due to omission and doubling of rings. In the first investigation of trees at Flagstaff it was supposed that the results were subject to an error of 2 per cent, most of which arose from double rings near the center of the tree. But the discovery and application of the method of cross-identification revolutionized the process of ring identification, and it was proved that the error of unchecked counting in the Arizona pines was 4 per cent and lay almost entirely in the recent years. It was due to the omission of rings or the fusion of several together.

Apart from cross-identification, confidence in the yearly identity of rings comes from the following sources:

(1) Belief that the well-marked seasons of the year cause absolute stoppage of growth in winter. The January mean temperature at Flagstaff is $29^{\circ} \mathrm{F}$. and that of July is $65^{\circ} \mathrm{F}$.

(2) The known time of cutting of nearly 100 different trees distributed through perhaps a dozen different years successfully and accurately checks cross-identification in the later years of the tree.

(3) The various identifications adopted for recent years check exactly with the neighboring rainfall records in Prescott and other places where such comparison can be made. This will have further illustration in connection with the chapter on rainfall and tree-growth.

(4) A check on the accuracy of the accepted identification of the Flagstaff trees was made by noting every statement of weather, freshets, or crop-failures mentioned by the historian Bancroft in his accounts of the settlements of Arizona and New Mexico. There were 14 cases in which the noted feature of the year agrees with the tree-record to one doubtful disagreement. The most striking correspondences occur with reference to the flood on the Rio Grande in 1680, the famines between 1680 and 1690, and the droughts in Arizona in 1748, 1780, and $1820-23$.

The effect of the undetected omission or the doubling of the rings in individual trees is to lessen the intensity of the variations in the curve of growth obtained by the averaging of many trees. T he 
may be divided into two classes: first, local errors of identity in small groups of rings in a few individual trees, which simply flatten the curve without affecting the final count; second, cases in which a given ring, in spite of attempts at cross-identification, is still in doubt, showing clearly in perhaps half of the trees and not in the other half. Such cases affect the final count, but do not flatten the curve. They leave a question of one year in the dating of all the earlier portions of the curve. Only two cases of this latter kind have been noted. One was the year 1822 in the Flagstaff pines (of which there is very little doubt) and the other is the ring 1580 in the sequoias, which was finally decided by material gathered in the special trip of 1919 .

\section{CROSS-IDENTIFICATION.}

Apart from care in measuring the rings, the details of which will be given in Chapter IV, the most fundamental and essential feature of the method of studying tree-growth is the cross-identification of rings among a group of trees. The ease and accuracy with which this can be done in a fairly homogeneous forest is remarkable. A group of 13 tree sections collected along a distance of a quarter of a mile in the forest of Eberswalde, near Berlin, show almost identical records. Two to ten rings in every decade have enough individuality to make them recognizable in every tree. A group of 12 sections from Central Sweden show such agreement that there is not a single questionable ring in the last 100 years or more. Especially marked combinations of rings can occasionally be traced across Europe between the groups hereafter mentioned. In Arizona the identification across 70 miles of country is unquestioned, and even at 200 miles the resemblance is apparent.

The value and accuracy of cross-identification was first observed in 1911 in connection with the Prescott trees. After measuring the first 18 sections, it became apparent that much the same succession of rings was occurring in each; therefore the other sections were examined and the appearance of some 60 or 70 rings memorized. All the sections were then reviewed and pinpricks placed in each against certain rings which had characteristics common to all. For example, the red ring of 1896 was nearly always double, while the rings of 1884 and 1885 were wider than their neighbors. In the 60 years investigated several obvious details in each decade appeared in every tree. After this success it was evident that the process should be applied to the Flagstaff trees which had been previously collected. Of the 25 , however, only 19 had been preserved. A minute comparison was made between these with complete satisfaction. Since then this process has been applied with great care to every group.

After the Flagstaff set was finished, it was compared with the Prescott group. It was interesting to find that the Flagstaff ring records 
could be identified at once in terms of the rings at Prescott; the narrow ring of 1851 was seen to correspond to one in the Prescott series. The compressed series from 1879 to 1885 likewise had its counterpart at Prescott and formed the portion of the sections which gave the most difficulties in identification. On the whole, so far as can be judged without minute study, the Prescott trees from relatively high elevations approximating the elevation at Flagstaff have a considerably closer resemblance to the Flagstaff sections than do those growing at lower altitudes.

Cross-identification and climate.-The process of cross-identification appears to be applicable to areas far removed from one another, but as the distances increase the resemblances between tree-growth records decrease, due to climatic differences. The correspondence between trees in different regions thus becomes a test of climate and we note a possible field for the application of this process in the delineation of similar climatic areas or meteorological districts. It seems to the author that in this way the growth of vegetation may easily be made of fundamental value in practical meteorology.

\section{MONTH OF BEGINNING ANNUAL MEANS.}

It is evident that it must take some time for the transmutation of rain into an important part of the organic tissue. There is evidence, as will be shown later, that the summer rains often have a prompt effect. The winter precipitation, however, is necessarily more remote in its action. Much of the first growth in the spring must come from the melting of the autumn and winter snows. It seems reasonable, therefore, to consider any snowfall as applying to the following yearly ring.

At Flagstaff the precipitation of November is almost always in the form of snow, and therefore that month should certainly be considered as falling after the arboreal New Year of that locality. In view of the uncertainty as to the exact month when the precipitation begins to have an influence upon the growth of the following season, and of probable variations in different years, it seemed wise to test the matter by a purely empirical method. The annual rainfall was ascertained for yearly periods beginning (1) with July 1 of the preceding year, (2) with August 1, and so on to (9) with March 1 of the current year. Another method involved a separating of the summer rains, one-half to apply on each adjacent winter, while a final method involved a similar division of the winter rains. This was done for 12 years at Flagstaff and 43 at Prescott. Part of the Flagstaff curves are given in the lower portion of figure 4 , where the rainfall can be compared with the growth of the trees. The curves plotted from these tests were found to have substantial disagreements, although of course the smoothed curves of all of them would be practically identical. A comparison of the growth of the tree with these various curves showed 
that the use of the year beginning November 1 at Flagstaff and September 1 at Prescott gave the closest agreement between growth and rainfall. At Flagstaff the majority of the trees came from a thin clay soil derived in place from decomposed lava, and so there was little depth for the storage of moisture. At Prescott the sections of group 5, shown in the solid line of figure 7, came from trees growing in a porous soil of decomposed granite in a rather flat depression with reaarded drainage, so that conservation would have a greater influence. Perhaps this explains why the year beginning September 1 gives the best results.

In the region of the great sequoias nearly all the precipitation in the mountains (and quite all in the valleys where comparative rain records are found) comes in the winter months. For these trees, therefore, the winter precipitation is compared with the growth for the succeeding year and the month of beginning annual means is in the autumn.

\section{THE TIME OF YEAR OF RING FORMATION.}

Among the problems connected with the relation of the growth of trees and the amount of rainfall, one of the most interesting was suggested by Director R. H. Forbes, formerly of the Arizona Experiment Station. This was to determine the time of formation of the red or autumn portion of the rings and the causes for the formation of double rings, which were very numerous in the Prescott group. It seems evident at once that the growth of red cells is related to the decreased absorption of moisture as winter approaches. A number of tests were made on the Prescott group. The first was designed to determine the character of the rainfall in the years producing double rings. The half-dozen most persistent cases were selected and in each of these the red ring was found double in the following number of cases: 4 out of 10 in $1896 ; 5$ out of 10 in $1891 ; 7$ out of 10 in $1881 ; 4$ out of 10 in 1878 , 1872 , and 1871. The average width of all the rings was $1.55 \mathrm{~mm}$. The mean rainfall by months for the years above selected was found and is plotted in the solid line of the upper diagram of figure 1. Six other rings showing one double in 10 trees in 1898, but no doubles in 1897, $1885,1884,1876$, and 1874, and averaging $1.54 \mathrm{~mm}$. in thickness, were then selected and the curve of rainfall by months for the year during which they grew has been plotted as the upper dotted line in figure 1. In each curve the 6 months preceding and the 2 months following the year are included. The curves seem to indicate clearly that the chief cause of doubling is a deficiency of snowfall in the winter months, December to March. This appears to mean that if the winter precipitation is sufficient to bridge over the usual spring drought, the growth continues through the season, giving a large single ring which ends only in the usual red growth as the severity of winter comes on. If, however, the preceding winter precipitation has not been entirely adequate, the spring drought taxes the resources of thetree and some red tissue is formed because of deficient absorption in the early summer before the rains begin. When these rains come the tree continues its growth. 
It appears further that if not only the winter snows are lacking, but the spring rains are unusually scanty, then the tree may close up shop for the year and produce its final red tissue in midsummer, gaining no immediate benefit from the summer rains. This appears to be the interpretation of the lower diagram of figure 1. Here the same 6 big

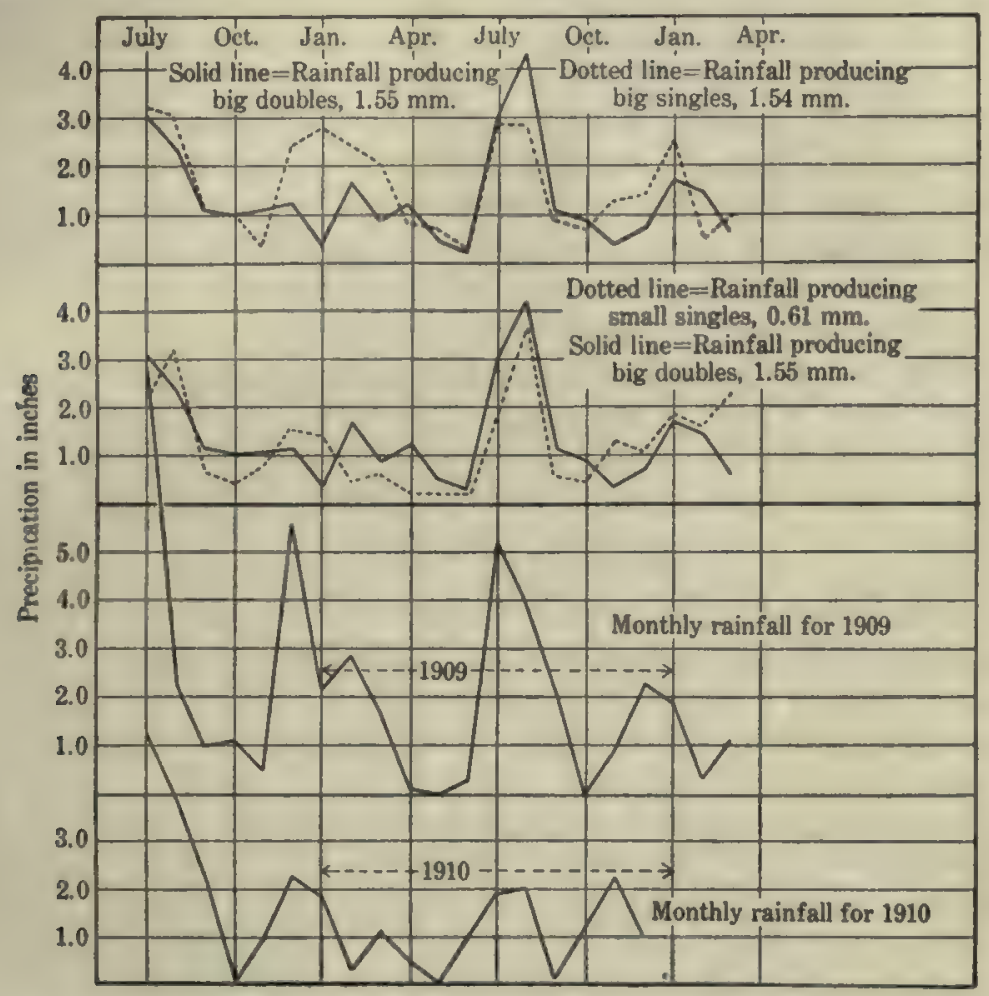

Fro. 1.-Efect of monthly distribution of precipitation on thickness of rings of growth; Prescott, Arisons.

doubles mentioned above are plotted, together with a selected list of 6 small singles particularly deficient in red tissues. They are, 1904 double once in 10, 1902 double once in 10, 1899 single, 1895 single, 1894 single, and 1880 double once in 10 . In these it is evident that drought in the spring stops the growth of the tree. The double ring, therefore, seems to be an intermediate form between the large normal single ring, growing through the warm parts of the year, and the small, deficient ring, ending its growth by midsummer. This occasional failure to benefit by the summer rains probably explains why the Prescott trees do not show an agreement of more than about 70 per cent between growth and rainfall. It suggests also that the Flagstaff trees, which grow under conditions of more rainfall and have very few double rings, give a more accurate record than those of Prescott.

Consistent with this view of the doubling is the condition of the outer ring in the Prescott sections collected by Mr. Hinderer. These trees 
were cut during various months from May to November. Naturally, those cut in May are in the midst of their most rapid growth, while those cut in summer may or may not show the double ring just forming. The conditions are shown in table 2.

TABLE 2.

\begin{tabular}{|c|c|c|c|c|}
\hline Group. & Altitude. & Date of cutting. & Cutting season. & Remarks. \\
\hline $\begin{array}{c}\stackrel{1}{2} \text { and } 4 \\
5 \\
3\end{array}$ & $\begin{array}{l}\text { feet. } \\
6,125 \\
6,420 \\
5,800 \\
6,800\end{array}$ & $\begin{array}{l}1911 \\
1909 \\
1909 \\
1910\end{array}$ & $\begin{array}{l}\text { May, June... } \\
\text { July to Sept... } \\
\text { Summer...... } \\
\text { Oot. and Nov. }\end{array}$ & $\begin{array}{l}9 \text { out of } 10 \text { show white tissue only. } \\
30 \text { out of } 33 \text { show red ring just form- } \\
\text { ing, probsbly s doubling. } \\
3 \text { or } 4 \text { out of } 10 \text { show red ring just } \\
\text { forming, probably a doubling. } \\
\text { All } 12 \text { show white without red, prob- } \\
\text { ably a large single. }\end{array}$ \\
\hline
\end{tabular}

By reference to figure 1, showing the curves of monthly rainfall for 1909 and 1910, it will be seen that 1910 would be likely to carry its growth through the year and produce a single line, as in group 3 above. The year 1909 is of intermediate character, having heavy winter precipitation and a severe spring drought of 3 months. In the groups cut at this time 33 out of 43 show a red ring forming in July, August, or September, doubtless the preliminary ring of a double. This lesser red ring is due to the spring drought, and its appearance at this time indicates a lag of a couple of months, more or less, in the response of the tree to rain. The whole matter of the relative thickness of the red and white portions of the rings is illustrated in figure 2. The heavy sinuous line shows the rainfall month by month at Prescott throughout the 43 years under consideration. The total rainfall for the year is indicated by the dotted rectangles while the size and character of the, rings is shown in the solid rectangles. In these the white portion indicates the white tissue and the shaded portion indicates red tissue.

Significance of subdivisions in rings. - The normal ring consists of a soft, light-colored tissue which forms in the spring, merging into a harder reddish portion which abruptly ends as the tree ceases growth for the year. The present subject (namely, the time of year of ring formation) indicates that the red tissue appears as the tree feels lack of sufficient moisture. Therefore, the great diversity in relative size of the red tissue and the occasional appearance of false rings undoubtedly has a real significance as to distribution of precipitation during the growing-season. This subject is a very promising one, but has received little attention in the present work. The trees of the Prescott group offer a few interesting examples of two or three false red rings in one year; they also have exceptionally many cases of omitted rings; both of these peculiarities are explained by the fact that these trees are close to the lowest elevation at which the climate permits them to live; they are therefore greatly affected by rainfall distribution and probably exaggerate its changes. 


\section{NUMBER OF TREES NECESSARY FOR RELIABLE RESULTS.}

In seeking the best curve of tree-growth which a given locality can supply, it might be thought at first that a very large number of trees must be obtained in order to get an average, but experience has shown that the number may be very small. In order to test the accuracy obtained from a small number of trees, a comparison was made between large groups and small. Of the original 25 trees in the first Flagstaff group, 19 were subjected to very careful cross-identification. Averages were then obtained of the oldest 5 , going back about 400 years, the oldest 10 (350 years), the oldest 15 (300 years), and the entire 19 reaching back only 200 years. Finally, the record of the oldest 2 was carried back fully 500 years. On plotting the groups of 15 , 10 , and 5 with its extension of 2 , it became immediately evident that 5 trees gavealmost the same growth as 15, even to small details. Between these 5 and the oldest 2 taken by themselves the agreement was not quite so perfect, yet was so close that errors thus intro. duced would not affect the curves. It must not be taken for granted. without test that this remarkable agreement between very small groups of trees is true necessarily for other trees or even for

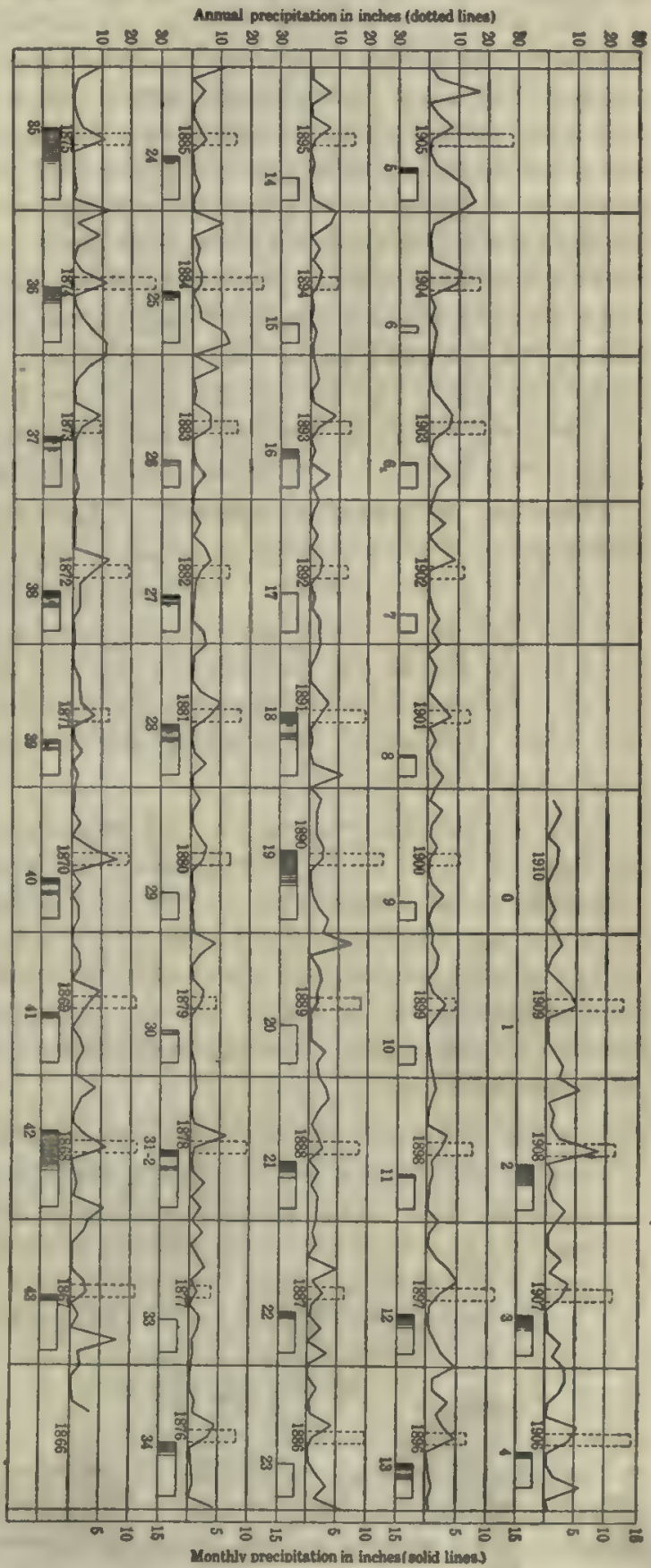

Fra. 2.-Monthly and yearly precipitation at Prescott and size and character of rings. 
this yellow pine under all conditions. Without doubt it is here due to homogeneous climatic conditions in a uniform topography and a tree sensitive to varying moisture-supply.

In a good many cases where the number of trees in a group has decreased in earlier years, it has been found (by carrying overlapping curves through a considerable period) that a few trees give essentially the asme curves as a large number. From the entire experience I have been led to assign a minimum preferably of 5 trees in any one group, while in some groups (notably the yellow pine of Arizona and the sequoias of California, together with the Seotch pine in central Sweden and in north Germany), 2 trees would give a very excellent record. In only one group have 5 failed to give a satisfactory record, and that was the set of Scotch pines from the outskirts of Christiania. The crossidentification of this group was not felt to be satisfactory, and a double number of trees from that locality would have been an advantage. This failure was thought to be due in part to therugged character of the region.

Direction of maximum growth.-The maximum trunk-growth was observed to occur a little east of north. The average difference between the radii was 12 per cent. An explanation of this increased growth to the north is to be found in the increased amount of moisture on that side, due to the slower melting of snow and decreased evaporation in the shade. For nearly all these trees the ground had a gentle slope toward the south, so that moisture working down hill reaches the north side of the root system first.

Rate of growth and age.-The relation of average ring-width to radius was found to be intermediate between an inverse proportion to the radius and an inverse proportion to the square of the radius. If the tree merely increased in diameter without growing upward, the width should be roughly inversely proportional to the radius. If the tree is increasing in height at the same time, we should expect an inverse proportion to the square of the radius. We find the relation to be between these.

Growth and soil.-In early studies of 25 yellow pines at Flagstaff it was noticed that a certain subgroup of 6 trees dropped to its strong minima in 1780 and 1880 more promptly than the others. This appears to be connected with the soil upon which the trees grew. This subgroup stood on a limestone formation where the soil is porous and the rock below full of cracks. The other two subgroups grew on recent lavas, very compact and unbroken, covered with a rather thin layer of clayey soil. With the former, therefore, the rain passed quickly through the soil and away, and we do not find so much conservation of moisture as in the latter, where the water could find no convenient outlet. On the whole, the growth seems to be more rapidly influenced by changes of moisture on limestone than on volcanic rocks. 


\section{COLLECTION OF SECTIONS.}

The material upon which the discussion of climatic cycles and treegrowth is based has been derived from 230 trees collected in the 15 years from 1904 to 1918 . The regions drawn upon comprise chiefly Arizona with its yellow pine, the Baltic drainage area of north Europe with its Scotch pine, and the high Sierras of California with their great sequoia. Two small collections come respectively from the northerst and northwest coast of the United States. The collections have been made in small, convenient groups as opportunity offered, to each of which a name has been given which will appear below.

The relative dimensions of the various groups may be expressed in terms of the number of measures of rings. In the first Flagstaff group there were about 10,000. In the second Flagstaff group of 1911 only a few hundred. The Prescott groups included about 4,000; the 9 European groups about 9,000. The Vermont group had between 2,500 and 3,000 , and the Oregon group about the same. The first collection of sequoias in 1915 had about 25,000 measures and the collection in 1918 embraced about 22,000.

Throughout the whole study it was desired to get as long records as possible and old trees were therefore selected. In nearly every case this meant large trees also. Apart from this no special selection of trees was made at any time, save only in the Christiania group, in which so many of the logs showed a "complacent" habit, with long successions of equal rings rather large in size, that some effort was there made to find the $\log s$ which showed variations in ring-size. A complacent ring-record without doubt means that the environment of the trees was well adapted for its best development.

\section{THE FIRST FLAGSTAFF GROUP OF TWENTY-FIVE SECTIONS.}

The plan of using tree-rings for the general purpose of a check on astronomical and meteorological phenomena was first formulated in 1901. The first measurements were made in January 1904, on a huge $\log$ in the yards of the Arizona Lumber and Timber Company at Flagstaff. This method of measuring was extremely inconvenient and the succeeding 5 sections were cut from logs and sent to town for more careful examination. Hence the exact location of these first 6 was never visited. The remaining 19 trees were selected in 1906 by myself in the forest while the logs were yet lying near their stumps, and I was able to mark on each section the points of the compass and otherwise describe the location. The measurements were completed in 1907 and published in the Monthly Weather Review of June 1909. They had not been subjected to cross-identification and, when the value of this 
process was recognized in 1911 , the 19 sections of which samples had been preserved were compared and a complete cross-identification carried through. Thus the errors of identity in the former tabulation were found (published in $1914^{3}$ ) and a complete new set of tables and averages made from the original measures. For a time it was thought that an error of one year might exist in the period of the great drought of $1820-23$, but the various checks made upon identity lead easily to the belief that there are no errors of identity in this 500-year series.

Subgroups.-The trees of this group were divided into three subgroups consisting of (1) 6 trees from 3 miles south of Flagstaff; (2) 9 trees from 11 miles southwest of Flagstaff; (3) 10 trees from a point 1 mile west of the last subgroup. A comparison of the 3 subgroups clearly reveals the general character of the longer periods hereafter to be discussed and shows lesser variations to be common to all. Interesting differences, depending on the location in which the trees grew, have been mentioned.

First suggestion of eross-identification.- Other interesting facts came to light. It was especially noticeable that a given year of marked peculiarity could be identified in different trees with surprising ease. This is illustrated in plate 2, where shavings from 5 of the Flagstaff trees have been photographed; the photographs have been enlarged to such a scale that the distance from the large ring 1898 (indicated by the upper line of black crosses) to the small ring 1851 at the lower line of crosses is equal in all cases. The other lines of crosses indicate the noticeably broad rings of 1868 and 1878. An examination of the photographs shows that a very characteristic feature is a group of narrow rings about the years 1879 to 1884 . These can be identified in practically every tree and an examination of many stumps which were not measured showed that it was easy to pick them out wherever one chose. Striking verification of this was found in the case of a stump near town which had been cut about 20 years previously. By finding this group of rings, the writer was able to name the year when the tree was felled and the date was verified by the owner of the land. In the more recent work this same group shows conspicuously among Prescott trees, and in general 95 per cent of these trees have rings so characteristically marked that the identification of the same series of rings can be made with little doubt, whether at Flagstaff or at Prescott.

The Flagstaff 500-year record.-Figure 3 shows the Flagstaff tree record from 1385 to $1906 \mathrm{~A}$. D., a period of 522 years. The table of measures from which the curve was plotted will be found on page 112. To give the record from 1503 to 1906,5 trees are used, and comparisons showed that these 5 gave as accurate a record as a larger number whose inclusion would have shortened the record or made awkward breaks in it. The earlier part of the record is from 2 trees 


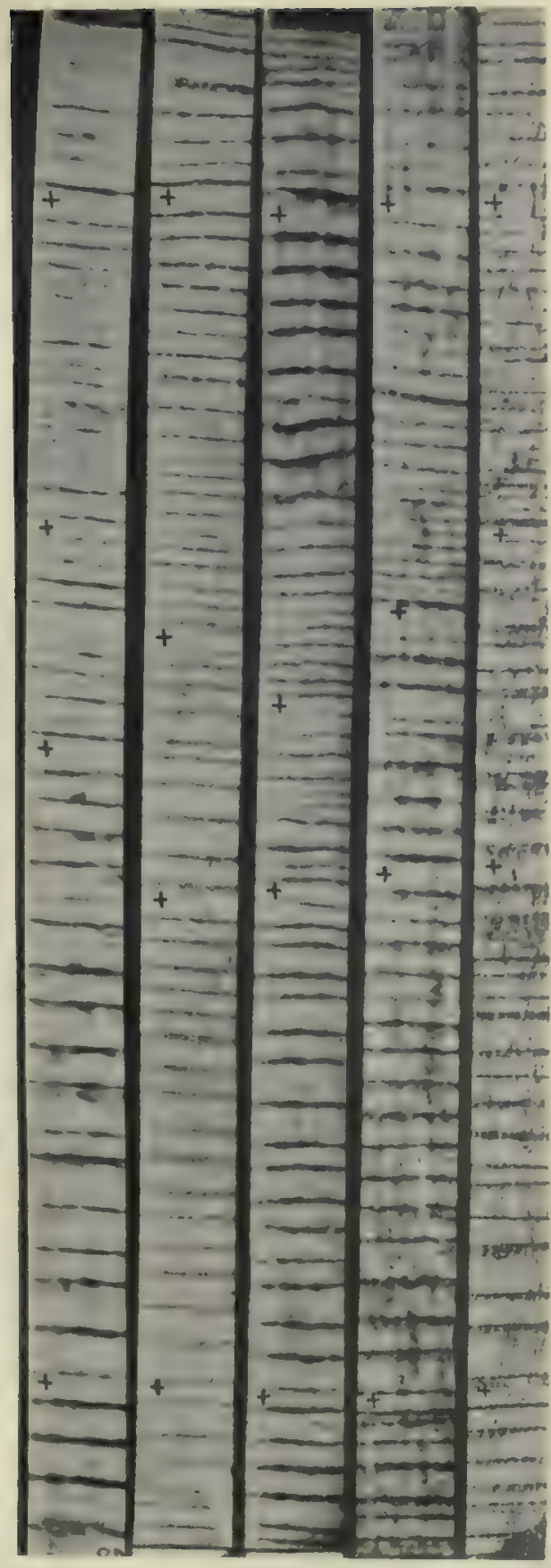

24

$i$

Cross-identification of rings of growth in yellow pine (Pinus ponderasa). 

COLLECTION OF SECTIONS.
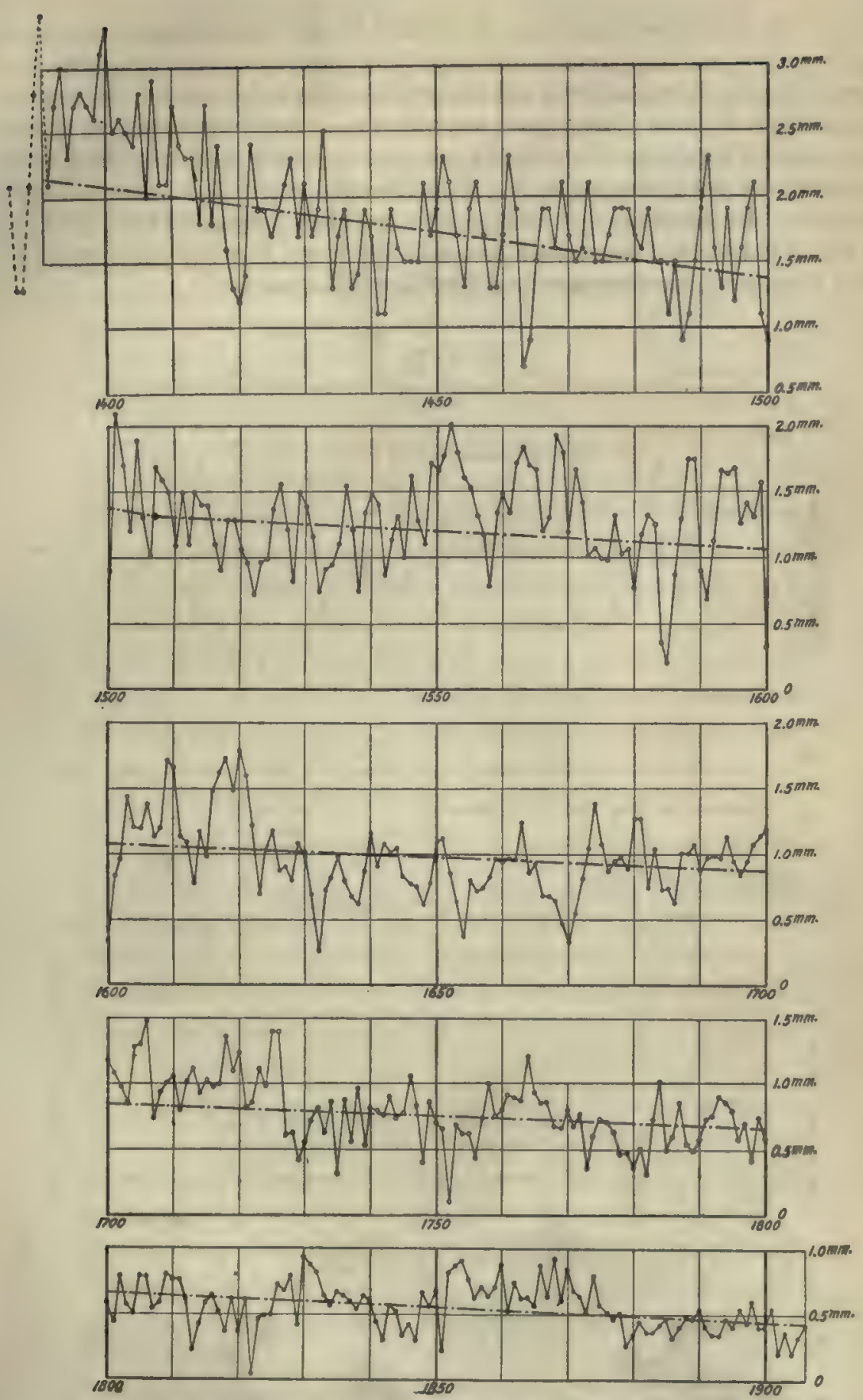

Fra. 3.-Annual growth of trees at Flagstaff from 1385 to 1906, A. D. 
only. A comparison between the 5 and these oldest 2 taken by themselves give an agreement not absolutely perfect, yet so close that errors thus introduced will not materially affect the curves. However, the oldest 2 were very slow-growing trees and they required on the average an increase of about 30 per cent in order to make their curve continuous with the whole 5 . Thus the tree-record is made to begin at 1385. In the recent years of the record also, between 1891 and 1896, a slight correction was made for omitted rings, the complete omission of a ring being an exaggeration that introduces error.

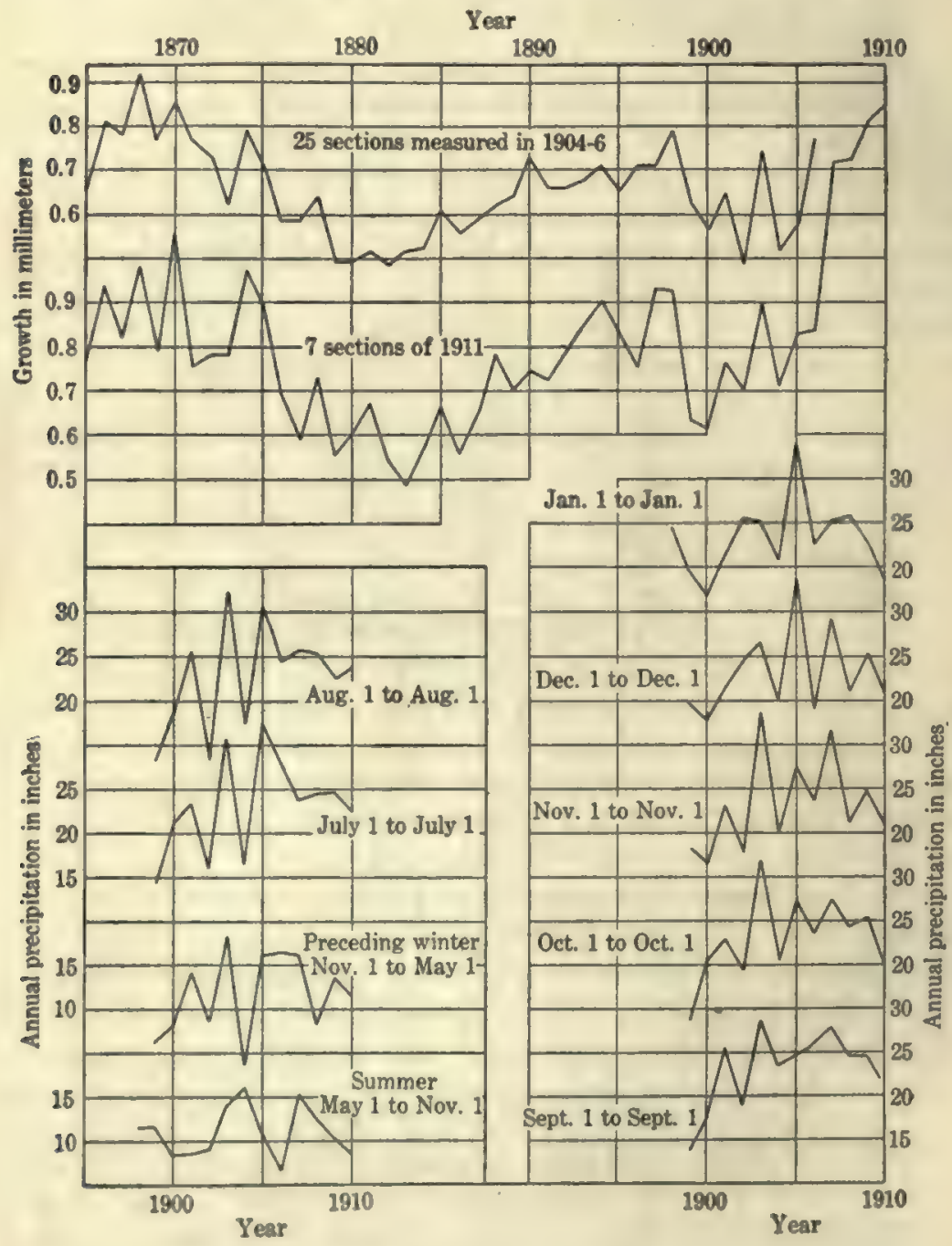

F1. 4.-Comparison of two Flagstaff groups. Variations in annual rainfall acoording to month of beginning annual means. 


\section{THE SECOND FLAGSTAFF GROUP OF SEVEN SECTIONS.}

In 1911 the writer visited Flagstaff again and made a trip into the forest where cutting was going on, in order to procure a few additional samples of the yellow pine which would check the recent part of the tree-record previously obtained and bring it up to date for comparison with rainfall values. The location was about 12 miles southeast of town and from 6 to 12 miles east of the region from which the first Flagstaff group was obtained. Seven cuttings were procured from the edges of stumps, thus bringing away a triangular pyramid of wood, which included the outer 50 to 100 rings.

Figure 4 shows how well the second group checks the first and indicates that even a small group of trees, no more than 7 in number, is sufficient to give results of considerable accuracy. Indeed, we may go further and say that a single tree under favorable conditions may give results of very great value. This is evident in figure 5 , where the 7 sections from the last Flagstaff group are plotted separately, the most rapid grower at the top, just below the rainfall curve, and the slowest-growing tree at the bottom. All rise alike because the conditions of rainfall in 1900-10 were more favorable than in the preceding decade, but all (especially the curve of section 4) show a more or less close relation to the rainfall at Flagstaff, even though that town was some 12 miles away. The great sinuosity which a quick-growing tree may show is well illustrated in section 4 in the great differences between successive years. A lack of sinuosity is shown in section 5 at the bottom. This difference supports the conclusion already reached that slow-growing trees are of less value than rapid ones in the determination of climatic

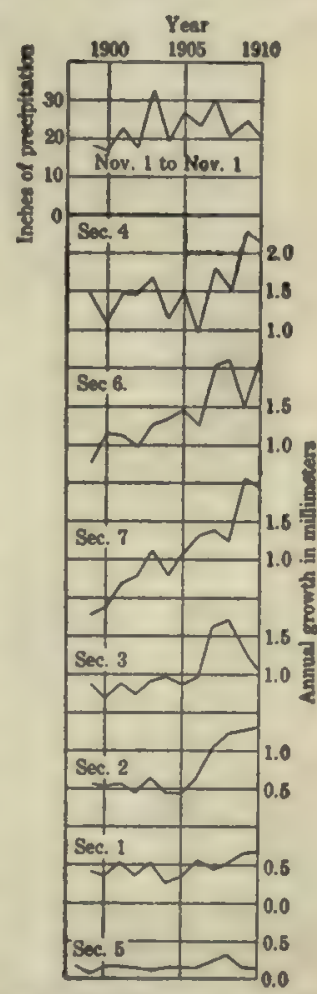

Fre. 5.-Growth of individual trees compared with precipitation at Flagstaff.

cycles. The results of the measures of this group serve as a check on the preceding measures and are shown in the figures just referred to. They are, therefore, not tabulated in this book.

\section{THE PRESCOTT GROUP.}

Prescott is located in the northerly part of the Bradshaw Mountains, at an elevation of 5,200 feet. The rocky subsoil is largely granite disintegrated at the surface and worn into steep hillsides, deep gorges, and picturesque masses of rounded boulders. The ridges are sharp and rugged, and the general contour is very irregular. There are very 
few isolated peaks. The mountains are covered with pines from their crests to a little below the level of the city.

This Prescott group was obtained in 1911 for the purpose of testing the conclusions derived from the Flagstaff trees some years earlier.

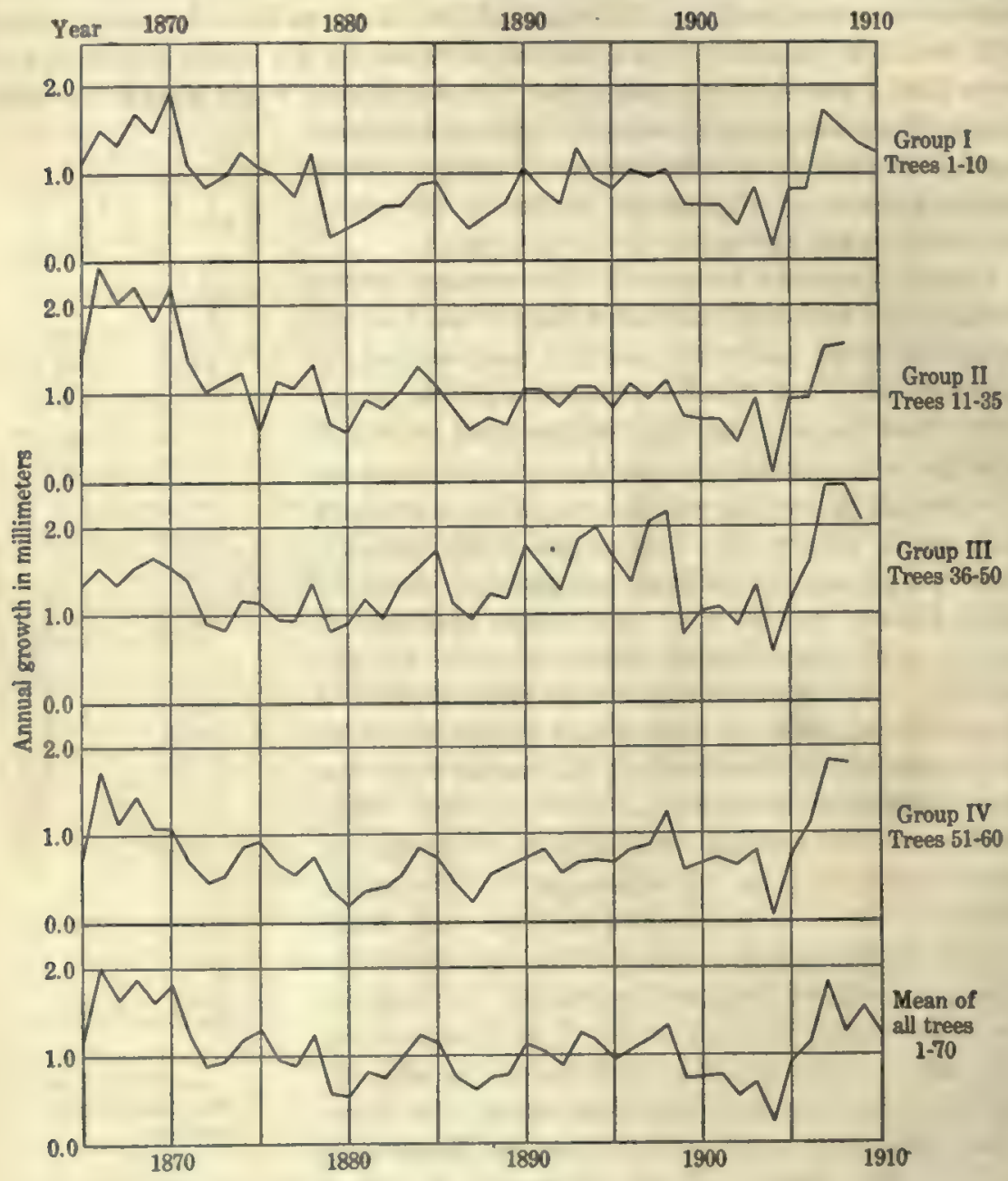

Fic. 0.-Annual growth of trees near Prescott, Arizona.

It consists of 67 trees selected in 5 subgroups depending on their nearness to town. The farthest was 10 miles southeast and the nearest was 1 mile south. It was apparent that the agreement between growth and precipitation increased as the location of the actual rainfall station was approached. The nearest subgroup, containing 10 
trees, shows so much greater agreement than the others that it has been used alone in drawing final conclusions. Its site was a small, poorly drained level space near the bottom of the valley.

In this group there was no necessity of duplicating the Flagstaff records, and therefore small $V$-shaped cuttings were made at the edges of the stumps, only triangular pieces of wood giving the outer half century of ring-growth being brought away. These were the samples on which the value of the cross-identification was discovered, as already described. Identical series of rings were observed in nearly every tree of the group.

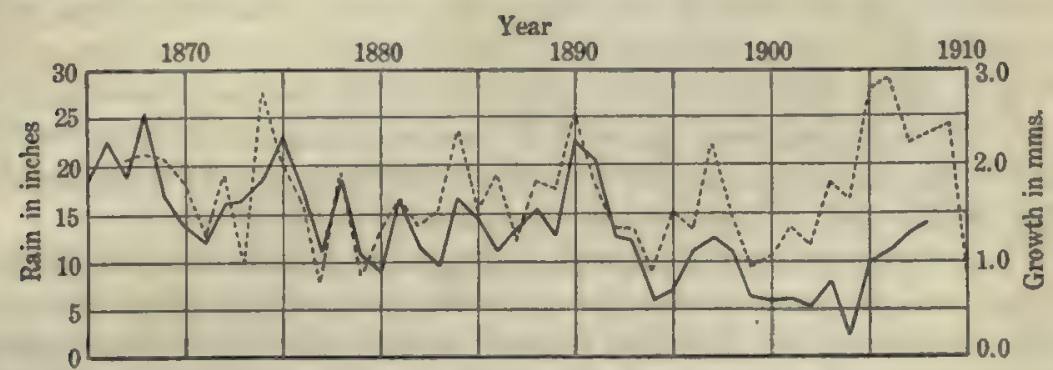

Fio. 7.-Annual rainfall and growth of trees (Group V) at Prescott. Dotted line: rainfall. Solid line: growth.

Out of 67 sections averaging 50 rings each, only 6 gave any identification trouble. In 2 of these, 2 rings were lacking, but when allowance was made for this defect the identification was satisfactory. Another section had 2 extra rings, and another had 2 extra and 3 lacking. The other 2 sections proved especially puzzling and were finally omitted from the means. Of these 6 troublesome sections, the first 5 were very slow growers. Hence it would seem advisable not to use extremely slow-growing trees any more than is necessary. It may be urged that trees do not grow continuously at the slow or fast rate and that we can not tell how much of the change is due to rainfall. On the whole, however, it seems advisable to exclude trees or parts of trees whose identification is extremely difficult. The inner rings if well identified may be extremely useful in carrying back early records, as the slow-growing trees are likely to be among the oldest.

The averages of 4 subgroups and the means of all the Prescott trees will be found plotted in figure 6 . The curve of the fifth subgroup is given in figure 7, where it may be compared with the rainfall of Prescott.

\section{SOUTH OF ENGLAND GROUP.}

This group of 11 sections was obtained in January 1913 at Fleet, near Aldershot, some 30 miles west-southwest of London. The trees were the common pine, Pinus silvestris, and averaged about a foot in diameter. The growth was very rapid and the wood was full of 
moisture. The trees had formed a border to a little plot of cultivated land with a southwesterly exposure. The average age was 54 years. The rings were all extremely plain, averaging 2 to $4 \mathrm{~mm}$. in size, and cross-identification was everywhere perfect. Of the 50 or 60 rings, about 10 had marked characteristics and were easily recognized in nearly every section. It was noted that a few sections had numerous rings more sharply defined on the summer side of the dense red portion than on the usual winter edge. One of the 11 sections is shown in plate 3, A.

The appendix contains a table of mean tree-growths of the 11 British sections; the years 1859 to 1863 inclusive show means of 6 trees only, as some did not extend back that far; of these, 2 had their centers about 1858,2 in 1857, and 2 in 1855. The owner of the land informed me that the trees had all been planted at the same time, and therefore this apparent discrepancy may be due to sections cut at different heights above the ground. These means are plotted in figure 8 .

For ready comparison it seemed desirable to standardize this British curve as well as each of the other European curves. Each curve is therefore corrected for changing rate of growth with age and also very slightly smoothed to get rid of the confusing effect of the 2-year "seesaw" described later. In the present group, after careful consideration, the standardizing line follows the tree-growth through a uniform curve in the earlier years and becomes straight in the later years. Percentage departures from this mean standard line give the standardized curve. These percentage departures smoothed by Hann's formula will be found plotted in figure 23, together with similar curves from the other European groups.

\section{OUTER COAST OF NORWAY GROUP.}

On the advice of Dr. H. H. Jelstrup of Christiania, I visited the Forest School of Sopteland, a small place located about 18 miles south of Bergen, near latitude $60^{\circ}$. The elevation is but little above sealevel, and irregular intervening hills give slight protection from the North Sea storms. This group of 10 Pinus silvestris sections was collected on January 3, 1913, from logs in the yard of the Forest School. The logs had been cut within a week or two in Os, 12 miles to the south, on an exposed part of the coast and probably close to sea-level. $\ddot{O} s$ is on the north shore of one of the larger inlets entering on the north side of Hardanger Fjord.

The average diameter was 6 to 8 inches and the average date of the center was about 1840 , but one extended back to about 1800 and another to 1700 . The average size of rings was about $1.25 \mathrm{~mm}$. The group cross-identified extremely well and on a preliminary inspection seemed to show somewhat rhythmic variations in growth. In these 

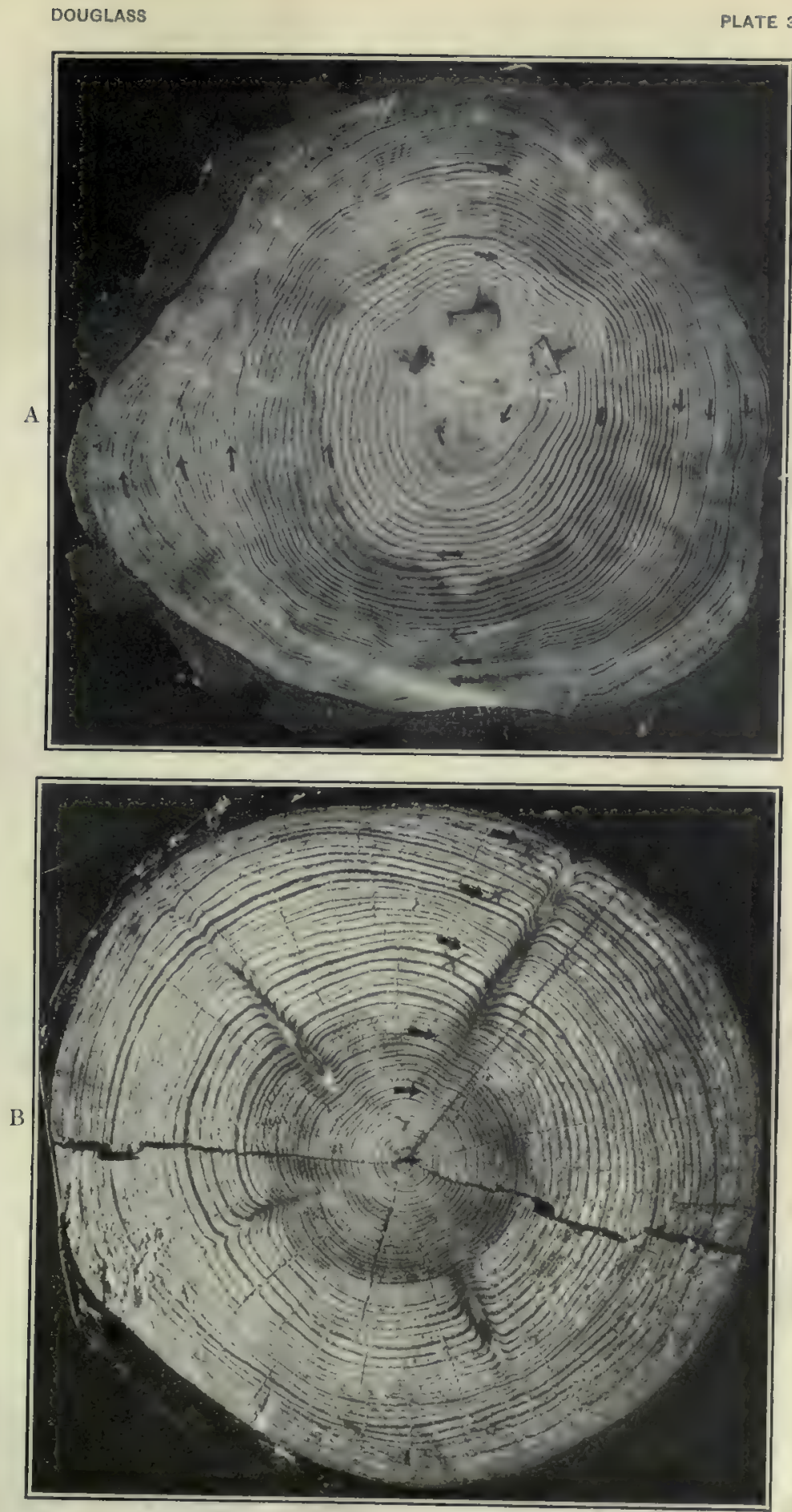



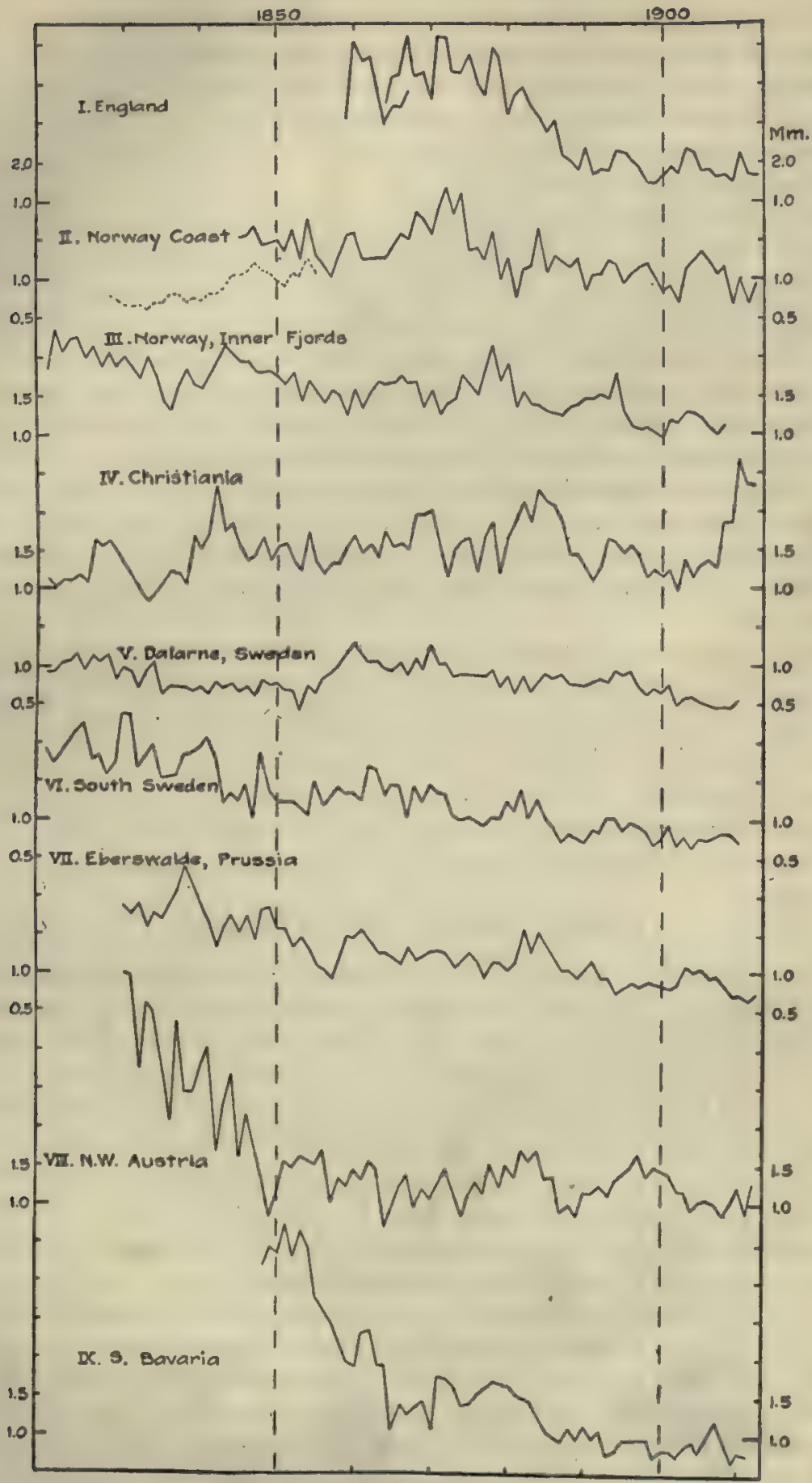

Fro. 8. The nine European groups. 
sections there is more than usual variation in different radii, an excess of growth starting in one direction and then slanting off in some other direction. Here it was found also that maxima were not always the same in different radii. It was suspected that some radii tried to follow a single cycle and others a double cycle. A photograph of one of these sections is shown in plate $4, \mathrm{~A}$.

The appendix presents a table of mean growth of this group from 1845 to 1912. No. 2 had its center in 1865, and between that date and 1845 extrapolated values have been used in forming the means. These extrapolated or artificial values preserve the average shown by the individual tree during its years of growth, but are made to vary from that average in accordance with the variation's of the rest of the trees in the group. From 1828 to 1844 the mean of 3 sections only is given. The actual mean has in this latter case been multiplied by 1.25 to bring the average into accord with the group, for the mean of these 3 for the 11 years from 1845 to 1855 inclusive is only 80 per cent of the mean of the group. In this group one center was in 1865, three in 1844, one in 1842 , one in 1840 , one in 1836 , one in 1827 , one in 1800 , and one in 1693.

These means are plotted in figure 8. The same corrected to a standard mean and smoothed by Hann's formula will be found in figure 23. No real correction for age has been made in this case, for there seems little change in rate of growth that can certainly be identified as such. The whole, therefore, has been simply reduced to scale for comparison with other groups by dividing every year by 1.25 , which is very nearly the average growth in millimeters.

\section{INNER COAST OF NORWAY GROUP.}

It is a great help to visit the exact locality in which the trees grew, or to get very near it, as in the groups already described, and especially to obtain personal information in a mountainous country like Norway, where meteorological conditions may vary enormously within a few miles. But it was impossible in the present group, whose sections had mostly been collected some years before for use in the forest service and schools. By courtesy of various officials I was permitted to examine and measure these sections in their offices, and whenever it was possible thin sections were cut off for me to add to my collection. In measuring sections of which samples were not retrined, for example $\mathrm{B} 15, \mathrm{~B} 16$, and $\mathrm{N} 2$, there was no opportunity of cross-identifying rings, and hence unusual precautions were observed in numbering the rings. If at any spot they seemed to be very close together with any chance whatever of mistake by omission or doubling, the numbering was carried to as many other radii as were necessary for a check, and worked over very carefully until the best possible result was obtained 
and all doubt seemed to be overcome. Nevertheless, judging by past experience, unchecked counting leaves a doubt wherever the rings are reduced to 0.1 to $0.2 \mathrm{~mm}$. in thickness.

Another disadvantage of this group is that the trees came from very diverse localities, and hence do not represent homogeneous conditions. Therefore, each section in the group will have special mention. The first number in the group, B 11, was cut from a $\log$ of Pinus silvestris lying on the woodpile in the yard of the forest school at Sopteland. The tree had been brought in for firewood late in 1912, but was undoubtedly dead at that time, for the outermost ring checked with the Ös group unmistakably as 1911 . This view was supported by the decayed bark and moldy trunk. This section was 9 by 14 inches in size and had the center (date 1734) some 3 inches from one end, producing one of the most uniform cases of eccentric growth which I have seen.

Nos. B 12, 13, and 14 cross-identify most satisfactorily with the Os group. From one to six individual characters or a most convincing sequence of characters were obvious in every decade. Section 12, a foot across, was cut in 1909, and the last complete ring was unmistakably of 1908 by comparison with the previous group. A section was cut for me at the school in Sopteland. The original was marked "No. 1, 1909, Knagenkjelm, Kaupanger," a location on Sogne Fjord, some 80 miles northeast of Bergen. My section shows the bark and very dense, handsome wood with strongly marked rings. Its center is at 1682 . No. B 13, center at 1807, is of about the same size and from the same place, and was marked "No. III, 1909." Its outer ring also identified as 1908. A portion of this section also was cut for me.

No. B 14, center 1779, was marked "No. 1, 1909, Lyster Sanatorium," on Sogne Fjord. As in the other two cases, its outer ring was plainly 1908. A thin section was cut for me. Its size was 12 by 14 inches. B 16 was marked "No. 3, 1909," from the same place. This huge section was 28 inches in diameter and 7 inches thick, and its center was about 1724 . There was a series of very small rings from 1787 to 1794 and another from 1806 to 1813 . I have no section of it and so no cross-identification could be attempted, but the measures of the recent years agree with No. 14 from the same place.

No. B 15, center at 1633 , was also measured at the school and no section retained for comparison with the others. It is the only one from its locality. It was marked "No. 1, 1909, Nestaas, Granvin," on Hardanger Fjord. It was cut in October and the first ring was considered to be of that same year. The rings were very clear back to 1680 and in fact to the center, but between the center and 1680 they were very small. 
All the sections so far in this group came from the west side of Norway near latitude $60^{\circ}$. The remaining two came from farther north and were first examined in the office of Dr. Jelstrup. No. N 1 was a small tree some 6 inches in diameter with its center in 1848. It grew in Mo i Ranen in latitude $66^{\circ} 15^{\prime}$, a 2 days' trip by boat from Trondjem. The rings show a rhythmic character, and a photograph of the thin section presented to me is given in plate $3, \mathbf{B}$. As in the other similar photographs, the years of sunspot maxima are marked with arrows. It was cut in 1907 and the outer incomplete ring was taken as of that year. The identification with trees from near Bergen is poor, as would be expected.

No. N 2 was an interesting cross-shaped section from beyond the Arctic Circle, latitude $68^{\circ} 45^{\prime}$. It had been damaged by forest fires at various times to such an extent that the injured parts of the trunk ceased growing while the rest kept on; hence it was of this extraordinary shape. It was cut in the winter of 1905-6, and the outer ring was taken as of 1905. As a rule the rings were very easy to follow until before the year 1600 , and even then by carrying the ring to other arms the identification seemed practically certain. The rings reached a suspiciously small size between the center at 1497 and 1512 .

The measuring of this 400-year section was done on December 31 , 1912. By noting ring after ring with care, tracing all rings a short distance and following the one case of suspected double across into another arm, there seemed to be no errors, certainly none of doubling and none suspected of disappearance. Letters B, BB, indicating maximum growth, were placed at the center of groups of large rings as the measuring progressed, without knowledge of any relation between them. That same day, on looking over the measures, a Brückner period seemed indicated. The maxima were marked as the measuring progressed. See table 3, on page 35 .

This series of maxima, 270 years long, from 1561 to 1830 , shown in figure 38 , permits the application of a 34 -year period with an average error of less than 3 years. If that case were alone, I would not include it here, but I believe I shall be able to show it in a number of very old trees in widely separated localities.

From the above description it is evident that we have in this group some very interesting trees, even though they grew far apart. They are probably worth more as individuals than as a group, but until more trees can be added from their various localities the usual method of presenting them here is used. So the group means are tabulated in the appendix, using an extrapolated value of $\mathrm{N} 1$ from its center in 1848 back to 1821 . These means will be found plotted in figure 8 . They have been corrected for age and reduced to standard size in the 
usual way by a straight sloping line reading $1.90 \mathrm{~mm}$. in 1820 and 1.15 mm. in 1910. The corrected means smoothed by Hann's formula will be found plotted in figure 24.

TABLE 3.

\begin{tabular}{|c|c|c|c|}
\hline $\begin{array}{l}\text { Date of maxima } \\
\text { as marked. }\end{array}$ & $\begin{array}{c}\text { Differences } \\
\text { in years. }\end{array}$ & $\begin{array}{l}\text { Suggested marima } \\
\text { on } 34 \text {-year period. }\end{array}$ & Residuals. \\
\hline 1830 & & 1831 & -1 \\
\hline 1797 & 33 & 1797 & 0 \\
\hline 1754 & 43 & 1763 & 9 \\
\hline 1696 & $\begin{array}{l}29 \\
29\end{array}$ & $\begin{array}{l}1729 \\
1695\end{array}$ & 1 \\
\hline 1657 & 39 & 1661 & -4 \\
\hline 1528 & 29 & 1627 & 1 \\
\hline 1661 & 33 & 1593 & 2 \\
\hline 1535 & $\begin{array}{l}34 \\
20 ?\end{array}$ & $\begin{array}{r}1559 \\
\text { - } 1525\end{array}$ & 109 \\
\hline
\end{tabular}

\section{CHRISTIANIA GROUP.}

This group of 5 Pinus silvestris sections was secured from logs at a little sawmill in the outskirts of Christiania. The logs cut in the neighborhood were in a large pile at the mill, and after the snow was brushed from them suitable ones were selected. Usually in such cases the largest and oldest were taken, but in this group the growth was exceptionally complacent. Accordingly, preference was given to those which showed variability in size of rings.

These sections were measured a month or two later. Cross-identification proved very unsatisfactory. Large variations were found in the 5 specimens. On this account it was felt that there might be several errors in this group which could perhaps have been removed by a larger number of trees for intercomparison. The centers of the 5 were respectively at $1848,1824,1797,1807$, and 1790 . The average diameter was about 1 foot. On page 114 will be found the mean growth of these sections and the plot of the same will be found in figure 8 . There seems no special change in growth with age, and the whole series was merely reduced to percentages by dividing each yearly value by $1.50 \mathrm{~mm}$. These values, smoothed by Hann's formula, will be found plotted in figure 23.

\section{CENTRAL SWEDEN GROUP.}

These 12 sections, showing an average diameter of about 11 inches and an average age of 190 years, were obtained from the sawmill near Gefle, on the coast, 60 miles north of Stockholm. The mill, one of the largest in Sweden, was some 4 miles from the town, on the river coming 
from the interior. The logs came from the vicinity of Dalarne in central Sweden, a large district. The bark is taken off as required by law and the logs are floated down to the mill. I visited the mill on Saturday, December 28, 1912. Twelve sections had been cut, but they were too thick and the whole 12 were cut a second time. These logs had been in the water a year and the last ring would therefore be of 1911 or possibly 1910 . Of the 12 , I think that all but 2 or 3 show the 1911 ring. Though these sections must have come from a considerable area (unless in the water and mid-afternoon darkness they accidentally secured original neighbors from thousands of logs), they identify among themselves extremely well. Cycles or pulsations were noticed and marked on all the sections of this group before identification. No. S 8 seems the most regular; a photograph of it is reproduced in plate 4, B. The cross-identification for the last 100 years hardly needs review, as it is entirely reliable and practically nowhere are there doubtful rings.

The means of the years 1820 to 1910 are given in the appendix and a plot of the same will be found in figure 8. The tree-growth in this group and others before 1820 will be taken up separately. There seems to be here no real change of growth with age, and the values were changed to standard by dividing by $0.8 \mathrm{~mm}$. These results were then smoothed by Hann's formula and plotted in figure 23 .

\section{SOUTH SWEDEN GROUP.}

This group of 6 sections was measured at Stockholm on December 27, 1912, in the office of Professor Gunnar Schotte, chief of the Swedish Forest Service. In my lists they are numbered from S 13 upward. They are all Pinus sitvestris save S14 and S 17, which are spruce, Picea excelsa. No. S 14 is noted particularly because it showed as perfect a sun-spot rhythm as G 8 from Eberswalde, whose photograph is given in plate 8, A. An entirely satisfactory cross-identification was made at the time of measurement.

The individual trees came from different localities and are therefore mentioned separately. No. S 13 was marked "4105-6" and was cut in May 1909. It grew about 100 miles southwest of Stockholm, in latitude $58^{\circ} 40^{\prime}$. About 1833 it has a doubtful ring which was settled by comparison with other measures. Its center was in 1763 . No. S 14, a Picea excelsa, marked "4105-14," was cut in July 1910 on the east side of Vetter Lake, less than 100 miles southwest of the preceding. Its center was in 1816. No. S 15, marked "4105-2," was cut in August 1909 , about latitude $64^{\circ} 30^{\prime}$, near Lycksele, Lapland. It showed clear and well-sized rings to its center in 1701. No. S 16, marked "4131-a1," was cut in August 1910, in Elfdals, in latitude $61^{\circ} 24^{\prime}$. Its center was about 1838 , but its inner 10 rings were uncertain and therefore not 

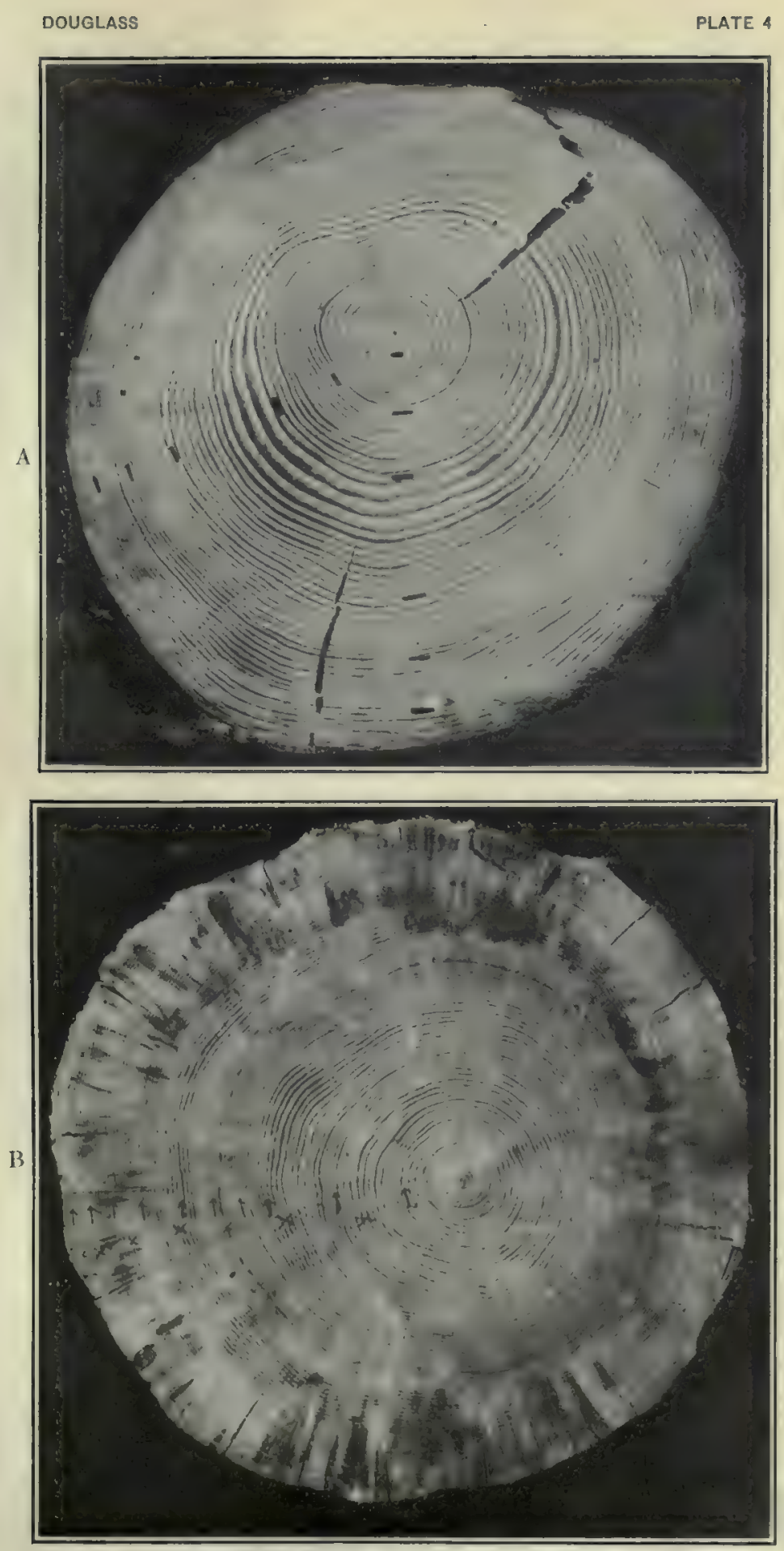

A. Section of Scoteh pine from Ös, Norway.

B. Section of Scotch pine from Dalarne, Sweden. 

used. No. S 17, Picea excelsa, marked "4105-5," was cut in May 1909, in the same locality as S 14 and shows a similar rhythm. Its center was in 1777. No. S 18 was a small section marked "4131-a-12." It was cut in October 1910 , in latitude $58^{\circ}$, well to the west of the others. Its radius measured only 2 inches. The average diameter of the other sections was about 12 inches.

On page 115 will be found the means of these sections, with two extrapolations, one from 1820 to 1848 and the other from 1820 to 1878 . This curve will be found plotted in figure 8. It has been corrected for age and reduced to percentages by dividing by the readings of a straight line extending from $1.90 \mathrm{~mm}$. in 1820 to $0.70 \mathrm{~mm}$. in 1910 . This corrected set has been smoothed by Hann's formula and will be found plotted in figure 23 .

\section{EBERSWALDE (PRUSSIA) GROUP.}

These 13 trees were cut and sections prepared for me by the kindness of Professor A. Schwappach of Eberswalde. They were all Pinus silvestris planted about 1820 to 1830 , exactly alike in height and size, with tall, straight, clear trunks about 10 inches in diameter and bushy tops. The land is a gently rolling country with a slight northerly slope, leaf-covered ground, a sandy soil with loam on top, and an elevation above the sea of 200 to 300 meters. The height above the city level was 200 feet or so; the locality was south and west of Eberswalde station. The trees cut were scattered along a quarter of a mile and so did not represent any close grouping. Their rings show almost identical records; 2 to 10 in every decade have enough individuality to make them recognizable in every tree.

On the first examination of these sections in November 1912, it was evident that their growth follows with fidelity the sunspot curve since 1830. This may be traced in the curves below and in the accompanying photographs of two of the sections in plate 8 . It will be seen at once that there is a rhythmic sway in the growth, groups of large rings alternating with small ones. The arrows pla'ced in the photographs mark the years of maximum sunspots. Taking the group as a whole, the maximum growth comes within 0.6 year of the sunspot maximum. To one maximum alone they fail to respond, namely, 1894; instead of rising, the curve drops in 1892,1893 , and 1894 . I have tried to find cause for this, but was informed by Professor Schwappach that therewere no fires, pests, or other known causes for it except climatic conditions. ${ }^{1}$

${ }^{1}$ Schwappach. Zeitschrift Forst- und Jagdwesen, September, 1904. A recent bulletin of the Mellon Institute, by J. F. Clavenger, entitled, "Effect of the soot in smoke on vegetation," ruggests at least a possibility. Clavenger shows photographs of tree sections in the neighborhood of iron mills, in which the growth is normal until the smoke from the mills pours over the forest, and then the rings rapidly decrease in size. It would solve the purzle if it could be shown that amoke from the iron and brass works in the neighboring city came over the forest of Eberswalde more abundantly at about this time. Dr. Schwappach writes that the manufactories and repair shops are $3 \mathrm{~km}$. distant and in his opinion the decrease in growth can not be due to smoke from them. 
On page 114 will be found the Eberswalde means from 1830 to 1912. Only one center occurs later than that date of beginning, namely, 1833. The others were mostly between 1821 and 1827. The means of this group are plotted in figure 8 and also shown more in detail in figure 9. These means have been corrected for age and reduced to

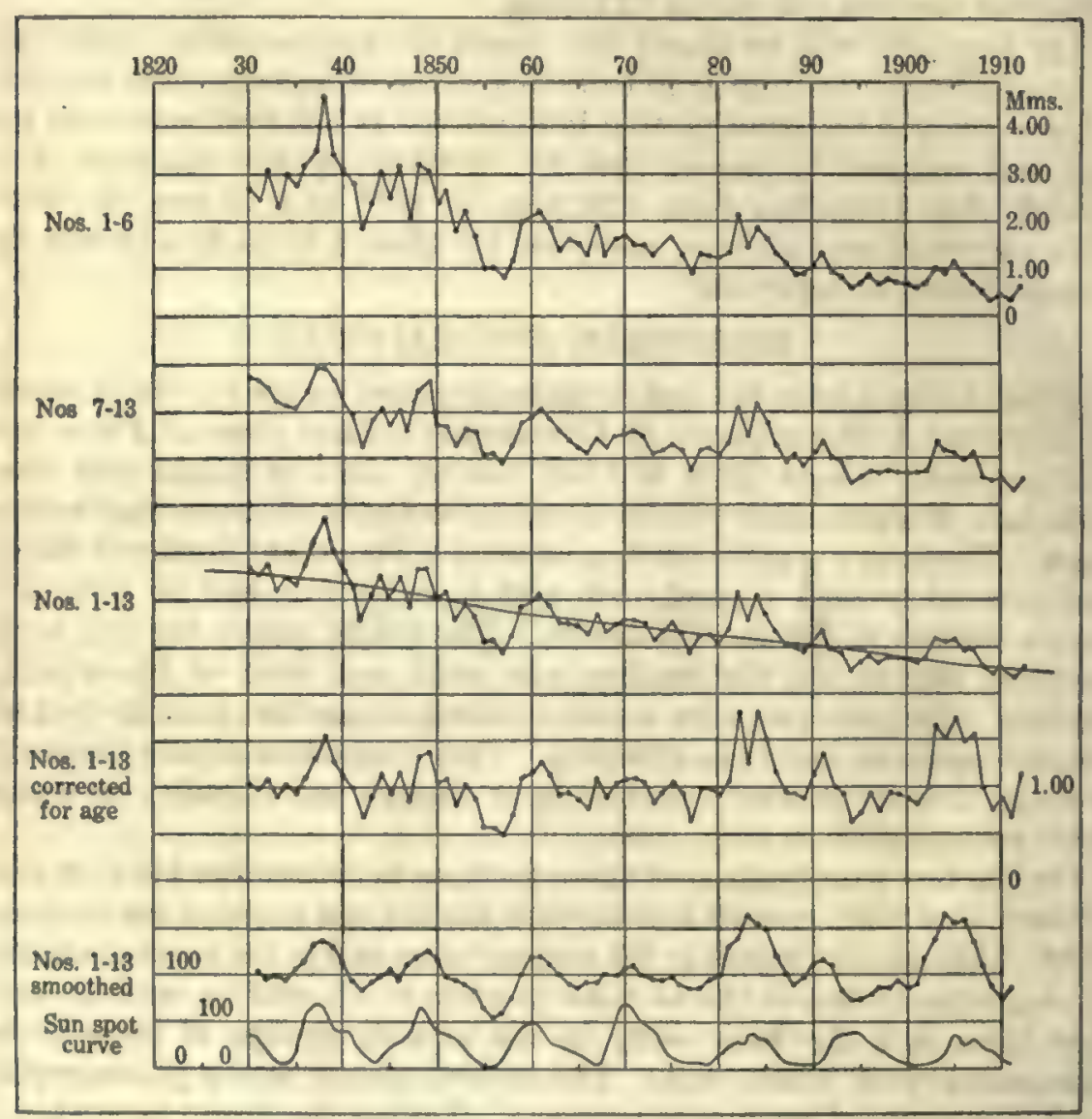

Fre. 9. - Sunspots and growth of trees at Ebergwalde, Germany.

percentages of a mean line reading $2.57 \mathrm{~mm}$. in 1830 and $0.54 \mathrm{~mm}$. in 1910. These in turn have been smoothed and plotted in figure 23.

In considering the significance of the agreement above noted, one should, in my opinion, keep in mind first the unusually homogeneous environment of these particular trees and the great care they have received, and second, the suggestion they contain of eventually defining distinct meteorological districts in which homogeneous effects are noted. A small pine of 60 rings from the Hartz Mountains was examined in the 
Geological Museum at Berlin, in which the same cycle was prominent. It was not measured, as the date of cutting was not known.

\section{PILSEN (AUSTRIA) GROUP.}

This group of 7 Pinus silvestris sections was measured in the office of Dr. A. Cieslar, in the Hochschule der Bodenkultur at Vienna. I have no samples of them in my collection, but they were carefully cross-identified before measuring. Two sections had the ring for $\mathbf{1 8 4 9}$ very doubtful, but its identity was verified by comparison with the others. The average date of the center was 1821 and the average size 11 inches in diameter. They all came from a forest station near Pilsen, in northwestern Austria. I have not seen the locality, but judging by the appearance of the country a little farther south the mountains are not rugged.

The mean measures upon this group from 1830 to 1912 are given on page 114; their plot is in figure 8. The curve is very peculiar, and it is hard to say how it should be corrected for age. It descends sharply from $3.62 \mathrm{~mm}$. in 1830 to $1.25 \mathrm{~mm}$. in 1851, and from that point on it remains 1.25. This bent line has been applied, and the resulting percentages have been smoothed and plotted in figure 24 .

\section{SOUTHERN BAVARIA GROUP.}

This group of 7 Pinus silvestris and 1 Picea excelsa sections was cut for me by the kindness of Messrs. Klöpfer and Konigen in Munich from logs in their yards. The trees had been cut in the winter of 1911-12 at Altotlinz, Ober Bayern, some 50 miles south, at a considerable altitude, in the northern valleys of the Alps. The rings in all these were clear and distinct and no doubtful cases were found except a very few near the center of two sections, which were omitted in the means; yet the cross-identification was not fully satisfactory. Sections numbered M 2, M 6, and M 8 in this group showed 1 to 2 entire discordances out of about 10 features in the last 60 years. The others agree fairly well. Possibly this condition results from the rugged and non-homogeneous region where they grew.

On page 116 will be found the means from 1848 to 1911 . In these, M 6 and M 7 are extrapolated for about 12 years, and M 8 for 2 . These means will be found plotted in figure 8. The curve shows apparently a very rapid decrease of growth with age. The correction line assumed is a line reading about $3.15 \mathrm{~mm}$. in $1850,2.10 \mathrm{~mm}$. in 1860 , then with decreasing slope reaching a nearly level line at 0.90 $\mathrm{mm}$. between 1895 and 1911 . The means have been reduced to percentages of this line and smoothed by Hann's formula and plotted in figure 24. 


\section{OLD EUROPEAN TREES.}

It is of course most desirable to carry the tree-records back as far as possible for verification of any feature observed in recent years and for additional information. But one is met by the rapidly diminishing number of specimens and the liability of obtaining records which are not representative of the regions on account of the increasing effect of individual and accidental variations. It is true that in the very homogeneous region about Flagstaff, Arizona, an average of 5 trees and even of 2 gave a valuable record corroborated by comparisons with larger numbers; but in these European groups the oldest trees are all from the Scandinavian peninsula, and probably the individual trees of which I have samples are representative of widely different localities in a rugged and mountainous country. Even though not homogeneous, the 15 oldest trees have been segregated in 2 groups covering the interval from 1740 to 1835 .

Group A represents the inner coast of Norway and includes the following trees: No. B 3, Ös, south of Bergen; No. B 11, Sopteland, south of Bergen; No. B 12, Sogne Fjord; No. B 15, Hardanger Fjord; No. B 16, Sogne Fjord; No. N 2, latitude $68^{\circ} 45^{\prime}$.

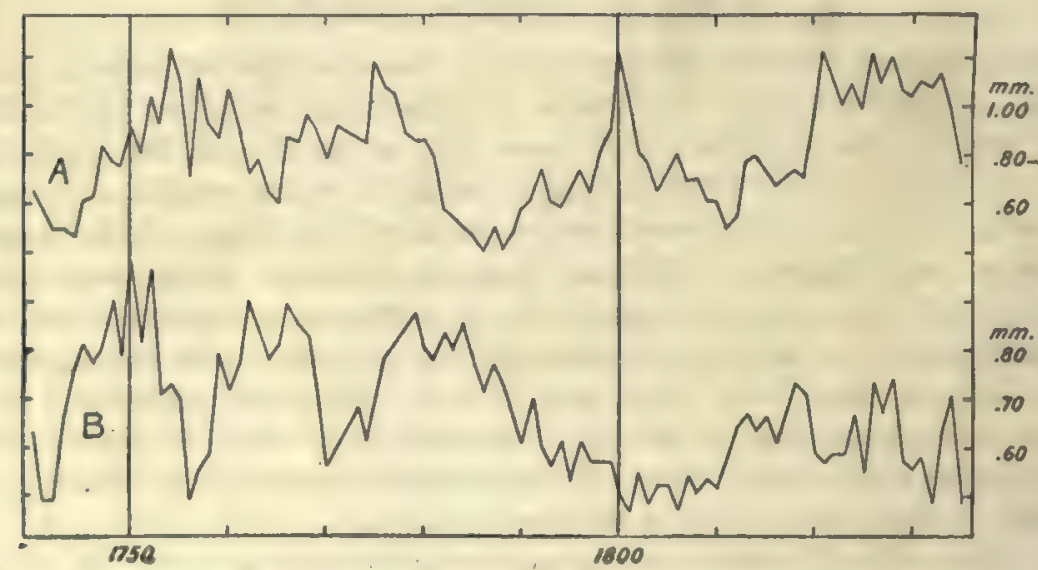

Fic. 10.-Growth of old European trees. A, six Norwegian trees, mostly from inner fjords. $B$, eight trees from Dalarne, Sweden.

Group B is made up of 8 trees from Dalarne, central Sweden, and 1 from Lapland, latitude $64^{\circ} 30^{\prime}$. This group, therefore, represents somewhat more homogeneous conditions, but yet it can not be well summarized in its larger fluctuations. When plotted with Group A, as in figure 10 , it shows the latter to have a considerable tendency to reversal, a characteristic already observed in this region. But there are discrepancies in Group B consisting of sudden depressions in growth 
which suggest injury, as in 1756 and 1769 and 1770. A very regular recovery from these depressions sustains this idea of their cause. The means of the 2 groups are given on page 116.

A few trees are perhaps available for periods antedating 1740. The centers of 5 are as follows: B 12 in 1682, B 15 in 1641, N 2 in 1497, $\mathrm{S} 4$ in 1510 , S 9 in 1660. But the first 3 are from separate localities in Norway and the other 2 are from central Sweden, so it seems hardly profitable to include them here in a group on account of the tendency to reversal between those localities. The section N 2, 400 years old, from high latitude on the Norwegian coast, presents a feature of interest as noted in connection with the Norwegian group, namely, a pronounced fluctuation very nearly 34 years in length. The measures on this tree have been plotted, a mean sinuous line drawn through them, and then this mean line transferred to a different scale, smoothed graphically, and photographed to form figure 38 on page 106. The more formal analysis of this interesting tree-record with the periodograph confirms this periodic fluctuation.

\section{WINDSOR (VERMONT) GROUP.}

On return from Europe it seemed desirable to learn how American trees react in similarly moist climates. But it was not easy to secure sections. There are very few large pines near the Eastern cities. One "pitch" pine from 50 miles south of Boston, with more than 100 rings, was secured, but there were no others in that immediate vicinity. Five white-pine sections from near Middleboro, Massachusetts, were obtained, but their rings were too few in number, being only 50 to 60 . Finally a satisfactory series of hemlock, Tsuga canadensis, from Windsor, was collected. Six sections came from the northwest slopes of Mount Ascutney at the lower and very steep end of the Brownsville trail. Five of these I cut from the stumps myself and preserved, and one was measured on the stump itself with full cross-identification. The remaining 5 of the 11 were cut from logs in a lumber-yard in Windsor; they came from across the river on a farm about 3 miles from town. Thus 7 or 8 miles separated these two subgroups. But the whole are here retained in one group, for the cross-identification, though difficult, was perfectly satisfactory. In order to be quite sure on this point, the subgroups were left separate until their curves could be compared. The Ascutney subgroup, with one extrapolation, extends back to 1695 , and from that date 2 trees were carried back to 1650. A comparison between the 2 and the whole 6 showed harmonious curves in their overlapping parts. This curve shows an average growth of considerably less than $1 \mathrm{~mm}$. in all its earlier years and up to the year 1808, when its yearly growth doubled. This sudden 
increase was interpreted to mean that at that time these hemlocks emerged from the shade of surrounding trees. The change was so rapid and great that it seemed likely to be due to the cutting down of the surrounding forest. In this subgroup, also, the years 1770 and 1821 were so extremely small that injury on those dates seemed likely. ${ }^{1}$ The other subgroup from east of Windsor extends easily to 1650 , with one extrapolation of 20 years and another of 3 . It shows no effects in 1770 or 1821 , but does show a temporary slight rise in 1807, and then a gradual increase to well over $2 \mathrm{~mm}$. by 1870 or 1880, as would be expected when light-loving trees gradually push their way out into preeminence above their neighbors. A comparison between these two curves in their minor details confirms the view that all 11 may be included in one group.

The means of the Windsor hemlock sections from 1651 to 1912 are given on page 116. In 1651 the figures give an average derived from only 6 sections. This increases to 9 sections in 1694, and from 1695 the whole 11 sections are used. These numbers have been smoothed and plotted, and their resulting curves will be found in figure 27 , together with the sunspot curve.

\section{OREGON GROUP.}

Following the New England group, a set of Douglas firs was obtained from a logging area about 25 miles northwest of Portland, Oregon. Several points of interest appear in connection with this group. In the first place, the samples were not radial specimens of the wood itself as heretofore, but were pieces of blotting-paper of suitable size which had been rubbed into the tops of the weathered tree stumps. These were made in 1912 by Mr. Robert H. Weinknecht, who writes as follows:

"The prevailing age on the tract is about 210 years on the stump. The trees selected were average with neither suppressed nor abnormally large growth. An average typical radius was selected on each stump. Twentythree impressions from this one locality were obtained and sent. Twenty-one came from stumps cut in the summer of 1908 , one from a stump cut in 1909, and one from a stump cut in 1912. The method of taking the impressions was one devised by Mr. Higgs and described by him in the Forest Quarterly for March, 1912. It was found that fresh stumps gave very poor results and especially poor for the last 50 years. This was attributed to pitch forming near the outer parts of the stump and to the fact that the weathering of the stump had not been sufficient to bring the rings out in relief. Some of the impressions were gone over with a pencil to bring out the rings where they were faint or broken. This was done carefully and checked by the number of rings counted on the stump."

During the course of identification and measurement, it was observed that only a small proportion of the ring impressions show distinctly

1 A letter was published in the local newspaper, asking if anyone had any information regarding forest fres in 1770 or 1821 or of lumbering in that locality in 1807 or 1808 , but no reply has been received. 
the ending of each year's growth, which is usually the best measuringpoint. In good reproductions the measures are satisfactory, different observers agreeing within 0.1 to $0.2 \mathrm{~mm}$. In others, however, there is much chance for judgment in selecting the measuring-point, and observers differ 0.3 to $0.5 \mathrm{~mm}$. Nevertheless it is easy to judge of the relative sizes of rings and the only injurious effect is to reduce variations.

The cross-identification was very. satisfactory, with practically no doubtful cases and only a few which required careful study. It is not likely that there is a single error in identity throughout the 17 sections in this group. Two other trees, one cut in 1909 and the other of

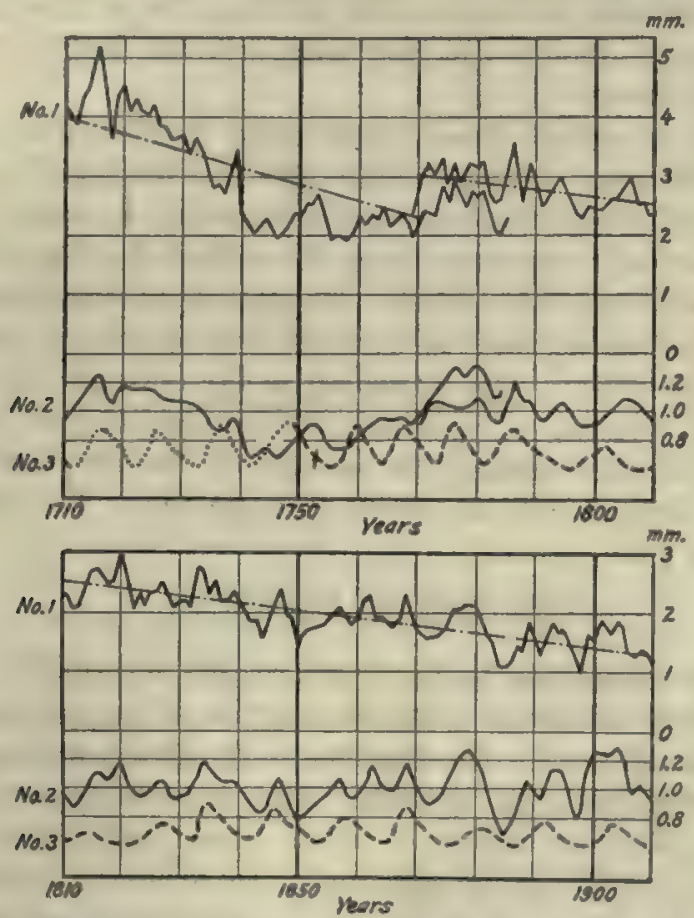

Fig. 11.-Oregon group. Curve No. 1, actual tree-growth; No. 2, tree-growth departures, smoothed; No. 3 , sunspot numbers displaced 2 years to left.

unknown date, but probably cut in 1902, were not included. They showed special characteristics, such as an evident injury in 1861-62, affecting the 1862 ring and several others following it. They show also small growth in 1886, and even in 1887 and 1888 following the minimum growth of 1884 and 1885 prominent in the large group. The tree (cut probably in 1902) shows a minute growth in the years 1779 to 1783 inclusive, evidently the result of injury. These two sections are full of character and may prove valuable.

Five other rubbings similar to the group of 17 were discarded because defective in some parts. The attempt to trace the lost lines with a pencil-mark gave no help. One of the 17 was defective since 
1835, and only the earlier part, ending in 1834, was used. Extrapolated values for the missing part were derived in the usual way. A few short, apparently doubtful, regions of rings required careful study and it was found that well-adjusted illumination of the rubbings was very necessary to their correct reading. When the ring impressions were deep in the paper, the end of the rubbing showing the tree center was held toward the source of light in order that the elevation corresponding to the beginning of the spring growth might be brightly illuminated. When the impressions were shallow and faint, it was noted that the rings became very distinct if the rubbing was held between the eyes and the light, thus giving a very faint and perfectly even illumination. If this did not bring out the individual rings, the rubbing was not used.

The location in which these trees grew was visited in 1918 and general contours were noted. The hills are low and comparatively flat-topped, with disintegrated rocks showing in railroad cuttings. The sides of the hills are steep, and the valley bottom is narrow and usually has a wash near its center. In general the drainage is toward the east, but there is no high and sharp ridge between this region and the ocean on the west. The situation is far enough north to have a good snowfall in winter. It is about 800 feet above sea-level.

The tabular matter giving the results of the measures on the 17 Douglas firs of Oregon will be found on page 117. The plotted values appear in figure 11.

\section{THE SEQUOIA GROUP.}

In 1911, after examining the writer's results obtained on the yellow pines, Huntington made an extensive series of measurements on the big tree, Sequoia gigantea. He did this work on the stumps themselves by direct counting from the outside. This introduced errors of beginning due to removal or injury of outer rings, and errors of omission which of course could not be checked. In order to correct for large errors of omission, he worked out an approximate correction on the grounds of probability which depended upon a comparison between two or more radii of the tree, and in that way many errors were compensated. In the vast majority of cases, his measures were not of individual rings but of successive groups of ten. I have collected seven of his trees, and after complete cross-identification verify his centers as shown in table 4.

But Huntington's method of working directly on the stump enabled him to get data from a very large number of trees, some 450 , in a way that served his purpose very admirably. He was searching for general effects, and accuracy to a year or two was less essential. He wished to approximate absolute values of rainfall in past climates, in contrast with which my chief aim is to get relative and periodic values. These 
two different purposes supplement each other in a highly valuable manner. Therefore, for him, the determination of the general curve, with an allowance for larger growth near the center, was most important. For that purpose he used both young and old trees. Necessarily he visited places where the trees had been cut. The two chief regions of his measurement were in the King's River Canyon district close to the General Grant National Park, and in an old lumber region near Springville, which is south of the Sequoia National Park.

Following Huntington's route, I visited the former region in August 1915. The town of Hume, the mill-site of the Sanger Lumber Company, is reached from Sanger by daily auto stage and formed, therefore, an excellent base of operations. Hume is at an elevation of about 5,500 feet, on the shore of a large artificial pond, into which the logs are dumped as they are brought down from the camps. A narrow-

TABLE 4.

\begin{tabular}{|c|c|c|c|c|c|}
\hline $\begin{array}{c}\text { Sequois } \\
\text { No. }\end{array}$ & $\begin{array}{l}\text { Huntington's } \\
\text { No. }\end{array}$ & $\begin{array}{l}\text { Huntington's } \\
\text { first year } \\
\text { of tree. }\end{array}$ & $\begin{array}{l}\text { Identified } \\
\text { first ring. }\end{array}$ & $\begin{array}{c}\text { Distance } \\
\text { from center } \\
\text { in inches. }\end{array}$ & $\begin{array}{l}\text { Probable } \\
\text { date of } \\
\text { center. }\end{array}$ \\
\hline 12 & 92 & 17 A. D. & Not ident. & $8(?)$ & \\
\hline 13 & 91 & 585 A. D. & 588 A. D. & 0 & \\
\hline 14 & 96 & 387 A. D. & 389 A. D. & 0 & \\
\hline 16 & 59 & $121 \mathrm{~B} . \mathrm{C}$. & 159 B. C. & 0 & \\
\hline 21 & 74 & 1318 B. C. & 1304 B. C. & 1 & $1316 \mathrm{~B} \cdot \mathrm{C}$. \\
\hline 22 & 195 & $1141 \mathrm{~B} . \mathrm{C}$. & 1086 B. C. & 7 & 1160 B. C. \\
\hline 23 & 116 & $1191 \mathrm{~B} . \mathrm{C}$. & $1121 \mathrm{~B}, \mathrm{C}$. & 10 & 1200 B. C. \\
\hline
\end{tabular}

gage logging road extends in an easterly direction from Hume, high up on the southern side of King's River Canyon. It winds in and out of the various small canyons or basins that empty into the large ravine. The elevation of the log road increases gradually from Hume until it reaches 7,000 feet at Camp 6 and Camp 7, which are about 7 and 9 miles distant respectively.

Camp 6 and Camp 7 are the names of the two recent logging stations. Camp 6 was occupied in 1915 and was located on the eastern side of Redwood Basin. The camp sites are usually chosen in such localities, for in each basin there is an enormous collection of accessible timber. In general the tops of the mountains are very rugged and the slopes exceedingly steep. The upper ridges are apt to be very sharp, but in the higher altitudes there is a tendency for the weathering of the mountain to produce this basin type of contour. From the accumulation of soil and the enormous snowfall in winter these become exceedingly swampy. Below the basin the water is carried by sharp, narrow canyons down very steep grades to the river far below. These groves of sequoias are between 6,000 and 7,000 feet above the sea. The climate at this elevation presents a contrast between an intensely cold winter season with 10 to 15 feet of snow and 
delightfully mild summers. The latter have occasional thunder-storms whose waters quickly run down the mountain slope. Thus conservation plays an important part in the growth of these trees by rendering the winter precipitation more important than the summer and by permitting the moisture to remain long in the swampy places.

Three groups were obtained from this general region in 1915. The first of these came from the uplands above Camp 6 close to the west line of section 17, township 13 south, range 29 east. This region may be found on the Tehipite Quadrangle of the United States Geological Survey. The group includes Nos. 1 to 5 . No. 1 was a splendid tree, about 19 feet in its greatest diameter, growing at the uppermost limit of the logging area. Its growth was rapid, and yet it was an extremely sensitive tree, showing beautiful variations from year to year. No. 2 was obtained a little lower down and is mentioned here because it has been used as the standard of the whole sequoia group, having probably a more perfect record than any other tree measured. Its center was about $300 \mathrm{~B}$. C. No. 5 was a small tree which was cut just at the time I came within hearing distance. I thought that two blasts of dynamite were set off and found afterwards that only one charge of dynamite had been used to break through the last support of the mighty tree; the other report was the tree itself crashing to the ground. Yet this was a small tree, only some 12 feet in diameter, and its age was about 700 years. It proved of particular value to the whole sequoia group, because it was the only tree on which was obtained the ring of the current year, thus permitting a very important correction to be made in the dating of rings. This had an important bearing on the relationship of rings to rainfall.

The second group included Nos. 6 to 11, and was made about a mile to the north and 700 feet lower altitude in the swampy basin whose outlet was similarly toward the northeast. No. 6 grew at the edge of the little brook running through the basin and its rings proved later very uncertain in identity, because its habit was complacent, $i . e$., the rings were nearly all alike in size. ${ }^{1}$ No. 7 was an improvement on it, and No. 8, which was still farther from the creek, was perhaps the best of this group of 6 . It gave a very fine cross-identification with the first group. No. 11 was also very close to the creek near the outlet of the basin and, as with No. 6, it was impossible to be sure of the identification, owing to its complacent character.

The third group consisted of 4 trees from Indian Basin, about 10 miles northwest of the Redwood Basin and 3 miles north of Hume. This basin is a broad, flat, fertile area with an outlet toward the northeast. Four trees were obtained there which Huntington had already counted. Nos. 12 and 13 came from the flat middle area of the basin. No. 12 was not included in the final averaging because its rings

${ }^{1}$ Since the trip of 1919 the identification of No. 6 has been fully established. 

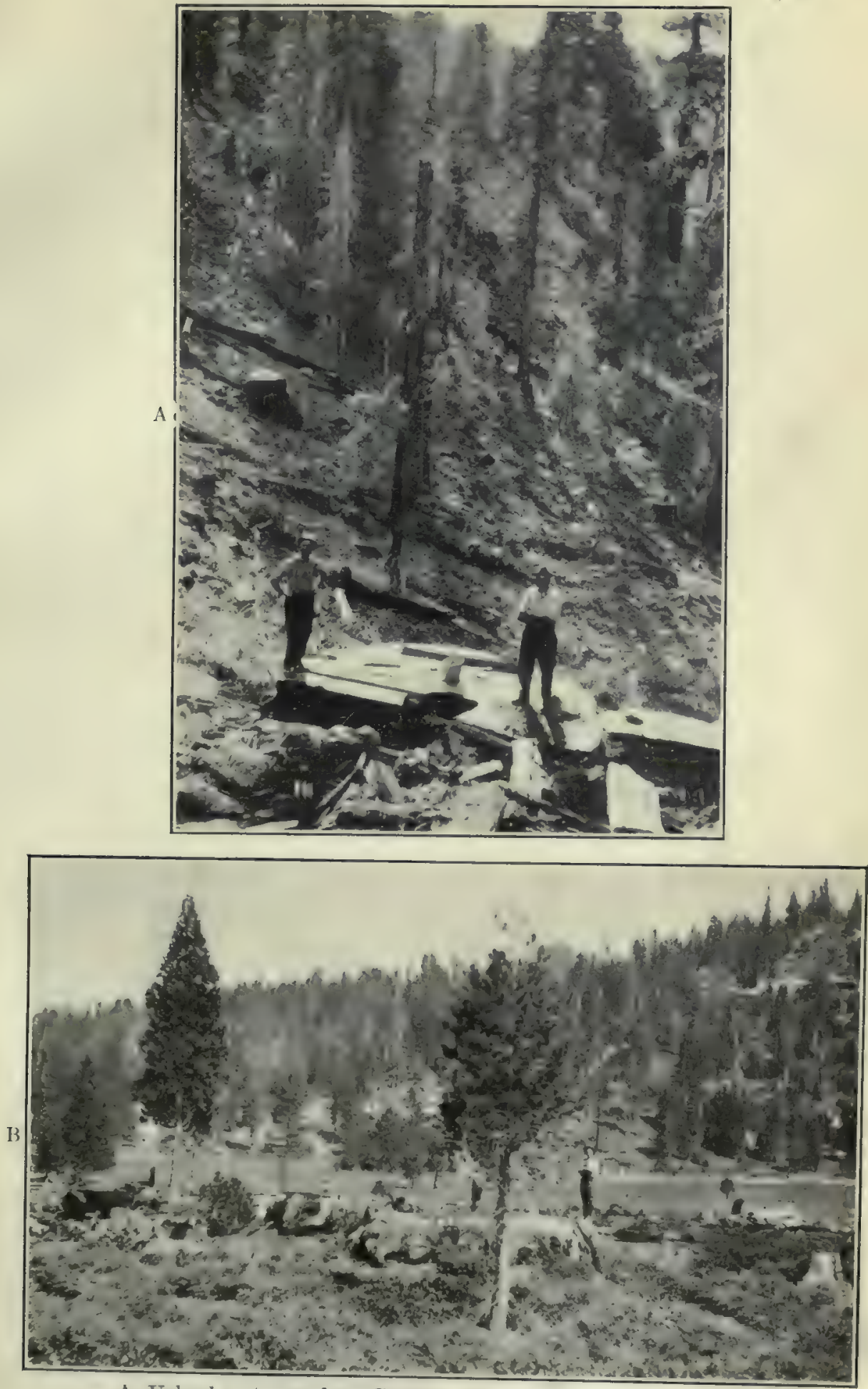

A. Upland contours, above Camp 6 in Sequoia Grove: D-19.

B. Busin contours, Indian Basin, looking S. E. : D-12 and D-13 in center. 

could not be identified at all, chiefly owing to large numbers of compressed rings in the last 500 years or more, and to several heavy firescars and its generally complacent character. In 1919 a short radial sample was cut from another part of the stump and a complete and satisfactory identification obtained. It shows very fine rhythmic growth in places. No. 13 was not included in the final averages, because its rings were very complacent and perfect identification was not obtained. Nos. 14 and 15 were obtained from the northern side of the valley and their identification was entirely satisfactory. The agreement which they give with Huntington's "first year of tree" has already been quoted.

The three groups whose collection has been described above showed on examination certain interesting relationships to the location in which they were found. The first group was obtained high up on a hillside, where the slope of the ground was $15^{\circ}$ to $25^{\circ}$. It was not very far from the top of a sharp ridge and there was no opportunity for moisture to collect and remain for long periods on the soil. Therefore one would expect these trees to show variation related to the amount of snowfall each winter, if any did. The growth of some of these trees was large but full of constant variation, and they were therefore of the type which I have called "sensitive." They do in fact show best of any the relationship to precipitation which will be described in a later chapter. The second group came from a characteristic feature of the country, namely, a basin with thoroughly water-soaked soil.

The luxuriance of vegetation in these basins before lumbering was wonderful. The sequoias grew often within a few feet of each other, and even between them were pines, firs, and cedars. Lumbermen often point out the bottom of a basin and say that such a place ran over 1,000,000 board feet to the acre. To-day nearly all the trees are gone and débris and rubbish are scattered about everywhere. The constant supply of water in the basin made the trees less dependent upon the annual precipitation and they show, in fact, large rings with very slight variation from year to year. They are typical examples of the "complacent" habit. Complacent trees contribute much less to a knowledge of climatic variations, and some of them have to be discarded because of uncertainty in the dating of their rings.

The third group, Nos. 12 to 15, came from Indian Basin, where logging had been done about 1903. Its outlet, like the others, was toward the northeast. It had, however, a much larger flat area, now covered by extensive fields of hay and by forage. The characteristics of the trees found here were the same as in the groups already described.

No. 1 (with a 7 -foot radius) was first counted and marked with provisional dates. The rings were coarse and the numbering seemed promising, but proved later to have 6 to 8 errors in the last 700 years. No. 5, which was the tree cut down during my visit, was then dated 
provisionally. It was 700 years old, with coarse, sensitive rings, and was the only one of the group showing the ring for 1915. In comparing these two for larger variations no accordance was recognized and in details cross-identification failed also, due (as afterwards found) to accumulated errors in No. 1.

No. 2 was then counted and compared with No. 5 with apparent certrinty and satisfaction. The former was nearly 6 feet in radius, with small rings, 2,200 years old, and with all but 3 years represented. The last 700 years were thus compared minutely with No. 5 and the earlier parts with No. 1, and one ring (later identified as 699 A. D.) was found to have been overlooked. The earlier parts were later all checked

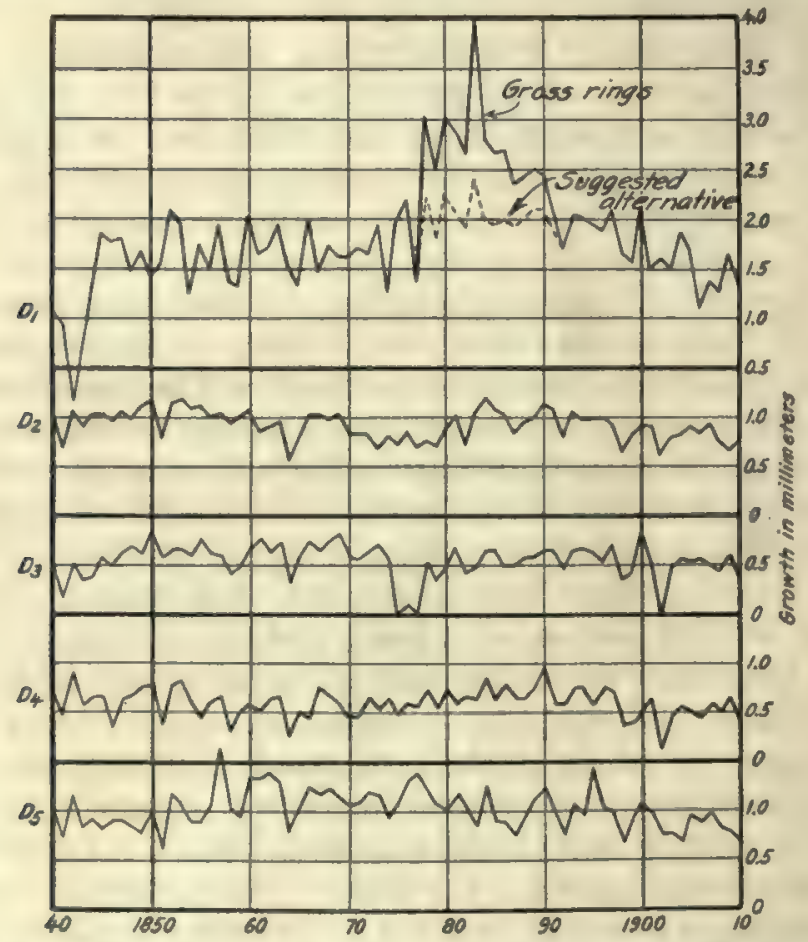

Fra. 12.-Crose-identification in first five sequoias and gross rings in No. 1.

against No. 3 and no suspicion of error was discovered. This number was, therefore, taken as the best type of specimen of this group. Large fluctuations of size rarely occur in it.

No. 3 was next counted by comparison with No. 2. No. 3 has few large fluctuations and large portions of it match No. 2 with the greatest accuracy. Nevertheless, as a standard with which to compare others, it would be misleading, for it frequently omitted rings; in one place 7 rings and in another 6 rings are entirely missing, and half a dozen more in singles and in pairs. Yet cross-identification with No. 2 was easy and perfectly convincing as to the location of the missing rings. 
No. 4 proved to have fairly large rings with 3 to 4 single ones missing and some hard to find, but the identification was easy and entirely satisfactory. No. 1, which was by this time recognized as the most difficult of the group, was reexamined in detail by comparison with No. 5, which proved difficult, with No. 2, which was somewhat better, but especially with No. 4, which proved to have the closest similarity, and all apparent errors were removed. It was very apt to drop out completely rings which were a little below the average. No. 5 seemed to have no tendency to subdue or drop rings. This, with its disclosures of the ring for 1915, showed the necessity of including younger trees in any new group to avoid mistakes in the outer slow-growing parts of the older trees. A comparison of the last 70 years' growth of sections 1 to 5 is given in figure 12. An illustration of "gross" rings is seen in the upper curve.

When the second subgroup was compared with the first, two complete omissions from No. 2 and the others of that first subgroup were discovered. This necessitated the complete renumbering of the first five sections.

The sections were measured at this stage of the dating process. The final renumbering was made after the 1919 trip, the purpose of which was settling the identity of a doubtful ring occasionally found between 1580 and 1581. The existence of this ring was established and the necessary corrections on the sections and in the tabular matter in this book have been made. All subsequent comparisons have verified this identification.

\section{THE SEQUOIA JOURNEY OF 1918.}

The visit to the Big Trees in 1918 was for the purpose of procuring material so that the tree-record from the 2,200 years already secured could be extended to 3,000 years. It was expected to do this without great difficulty, for Huntington had enumerated 3 trees over 3,000 years of age, and he had placed numbers on the tops of stumps so that these could be readily identified. Nevertheless, in consequence of the occasional absence of a number on the top of a large stump which had been counted by him, a little more care proved to be necessary than was anticipated.

After procuring an outfit in San Francisco, I selected Hume as a base and immediately went out on the $\log$ road to Camp 6, the old location of the groups obtained in 1915. All the stumps from which samples had been taken (including Nos. 1 to 15) were visited and each was marked with its respective number preceded by the letter $\mathrm{D}$. This marking was done by a chisel, and the figures were usually about 4 inches in height. Placing the capital D before each number made it certain that no number would be accidentally read upside-down. Naturally the stumps from which samples have been taken show the large cut from center to outside, and there is no doubt about their 
belonging to the group. But if other samples are taken in future years, this numbering will prevent confusion. All the 23 stumps are thus identified by a number in this series.

I had hoped on this trip to find other trees as old as Huntington's three, and therefore searched carefully for the largest stumps. All those over 20 feet in diameter and a number of less size were estimated for age. This was done by measuring the average width of rings here and there along a radius and multiplying by the length of the radius. About 50 were thus tested. In many cases the result has proved to be within 50 years and sometimes much closer, but these estimations were not very reliable, there being several large mistakes in them. In attempting to pick out the oldest stumps among several thousand without spending much time or getting very far from camp, it is impossible to make these estimates with very great care. It was felt that much help would have been obtained from a small range-finder and telescope, the former to give the distance of the stump and the latter its diameter. In the course of a few days this would have saved many miles of tramping and the oldest trees would have been found more readily.

On the steep upland slopes above Camp 6, two trees were estimated at about 2,500 years in age. These were afterwards numbered D 18 and D 19. D 18 was an immense tree which was cut down in 1914 at the time a motion-picture company was operating in the sequoia forest. It is referred to by the lumbermen as the "Moving Picture Tree." It had to be blasted from the stump before it fell, and the stump was so completely shattered that no sample could be cut from it. In falling, the trunk of the tree split in halves through a large part of its length, and most of it remains where it fell. About 40 feet of logs were cut away between the ruins of the stump and the rest of the tree. Accordingly my sample was cut from the lower end of the broken top and at a point which had been about 50 feet above the ground.

Close by the location of No. 18, and on the steep upper hillside just below the track which extends on to Camp 7, is No. 19. A log from it rests uphill with its upper end at the railroad embankment. The section was taken from the stump nearly 60 feet below (see plate 5). Camp 7 was visited and used as a base for two days. It is 2 miles beyond Camp 6 on the ridge at the farther side of Windy Gulch. There are some very fine stumps close to the road that goes down from the camp into the basin, which were estimated to be 2,300 or 2,400 years old.

No. 16 was found high up in the gulch that extends toward the top of the mountain just south of the camp. The gulch faces toward the east and at the location of the tree has a slope of $15^{\circ}$. No. 17 comes from the basin some hundreds of feet below the camp. It was a windfall and the lumberman thought it might have been lying there a great many years. As it was a very large tree and of slow growth, it was 

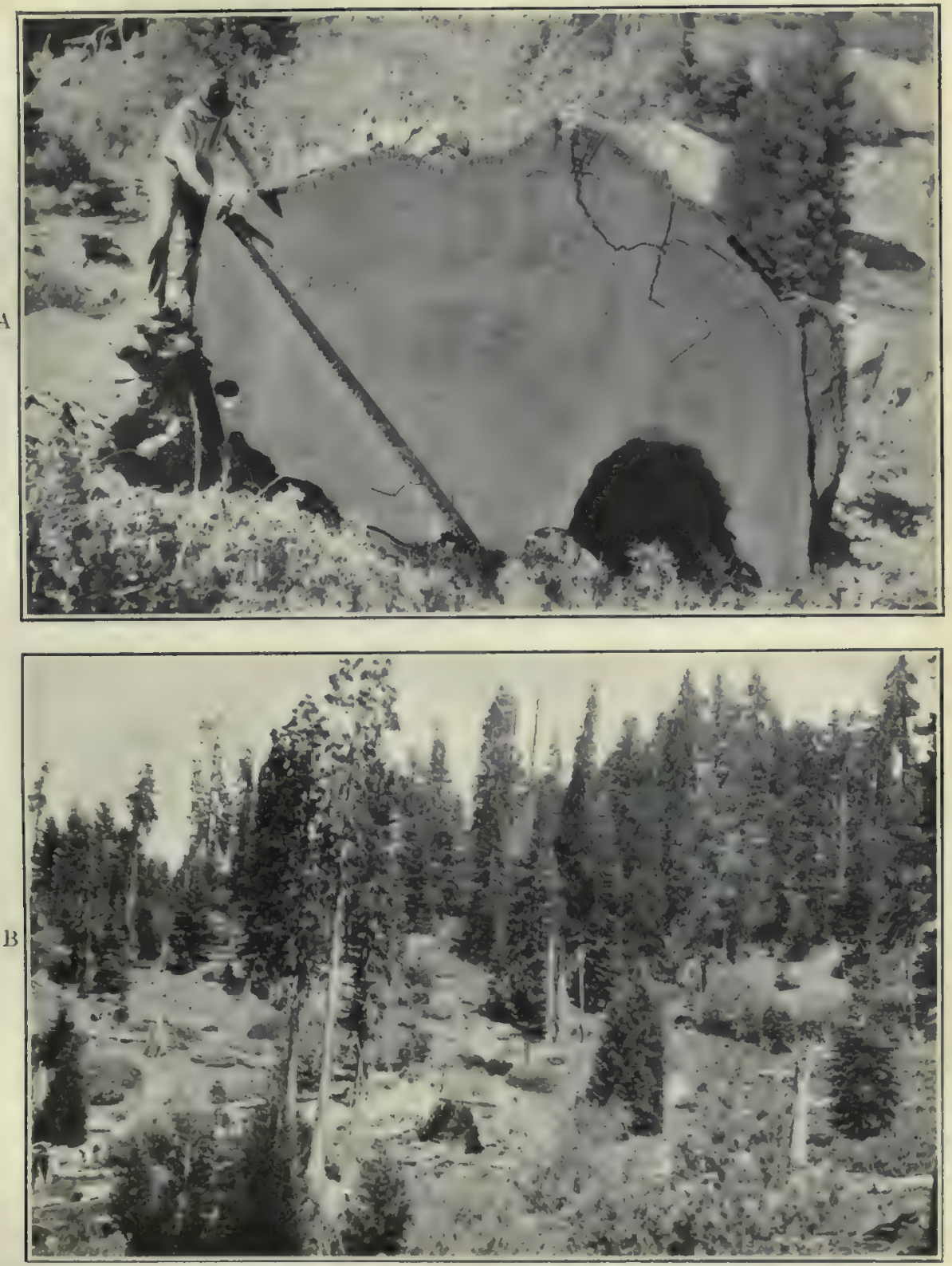

A. Cutting radial sample from end of $\log$, Converse Hoist: D-20, age 2800 years.

B. Site of oldest tree, Converse Hoist: D-21, age 3200 years. 

hoped that its center would prove of very great age. But the results were disappointing, for it turned out that it had fallen only a few years before the logging began and that its age was only 2,200 years. It had so many compressed rings in its outer parts that the last 800 years were not considered worth measuring.

On leaving the vicinity of Hume several days were spent at the General Grant National Park. It formed an ideal center for a considerable region. Horseback trips were made to the area which Huntington calls the "World's Fair District," "Converse Hoist," and by other names. No. 20 was a fallen tree with a northerly exposure, on the west side of the upper basin, not far from the old hoist at the top of the ridge. It was on the west side of the abandoned railroad. It was found that the tree fell only 6 years before the logging was done. A log had been taken out and the sample was cut from the top of the fallen stump. No. 21 is the most interesting of all, because it gives the oldest record by nearly 200 years. It is on the east side of the railroad and brook in the lower part of the upper basin, and some 30 feet above the level of the brook. It is not at all impossible that during its long life the topographic character of the ground about it has altered materially. It is somewhat complacent in its later growth, but this does not persist throughout its record. The top of the stump had carbonized, become extremely brittle and very hard to cut. Though bits of wood broke off and clogged the saw, every piece was marked and preserved. The radial sample has been glued together in the laboratory and is now 9 feet long. The original center of the stump was badly cracked through contraction in drying, but there were lacking only about 2 inches at the center. The central portion, perhaps a foot in diameter, was not firm enough to be cut out with the saw. It was therefore removed very carefully and is now mounted in a special box in the laboratory. The oldest complete ring in good condition was identified as $1305 \mathrm{~B}$. C. Possibly two more rings may be added. A hundred yards to the south and slightly higher up the hillside is the "World's Fair Stump." This was cut in 1892 at a height of more than 20 feet above the ground, and to-day the stump is very difficult to climb, as the scaffold built around it has broken away.

A trip was made from the General Grant National Park to the upper part of the Comstock millsite, known also as Wigger's. The stage road goes near it and the point is known as "Big Stump." The stump, easily seen from the road, is some 25 feet in diameter with a raised square in the center. The location is in a side basin close to a small brook. An examination of the rings showed that the tree had grown with the greatest rapidity, as the rings were of enormous size. It was estimated to be 1,500 years old. No sample was taken of it.

A trip was also made from the park to visit the General Grant Tree and if possible estimate its age. There is an extensive burnt area on 
the upper side of the tree in which the rings may be observed. These rings are large, and various estimations of the age of the tree obtained in two different visits gave an average of 2,500 years. Near the General Grant Tree is the stump of what was known as the Centennial Tree. It was said that a section of this tree was exhibited in 1876. Since then the stump has been badly burned and is in poor condition for cutting a sample. Some estimate of the rings showed their size to be large, and the age of the tree, therefore, was not very great, perhaps 1,800 years. This confirms the estimate of the General Grant Tree near by.

Tabie 5.-Sequoia list.

\begin{tabular}{|c|c|c|c|c|c|c|c|c|c|c|}
\hline 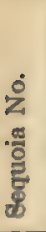 & 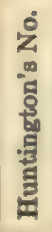 & $\begin{array}{l}\text { Huntington's } \\
\text { first year } \\
\text { of tree. }\end{array}$ & $\begin{array}{l}\text { Identified } \\
\text { central com- } \\
\text { plete ring. }\end{array}$ & $\begin{array}{c}\text { First } \\
\text { complete ring } \\
\text { not central. }\end{array}$ & 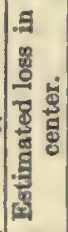 & 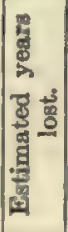 & $\begin{array}{l}\text { Probable } \\
\text { center of } \\
\text { tree. }\end{array}$ & 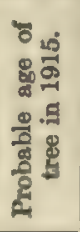 & 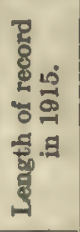 & Location. \\
\hline & & & 592 A. D. & & $\mathrm{cm}$. & & & $\begin{array}{l}\text { yre. } \\
1323\end{array}$ & $\begin{array}{c}y r s . \\
1323\end{array}$ & Camp 6, Uplands. \\
\hline 2 & $\ldots>>>>$ & & & 274 B. C. & 4.5 & is & 289 B. C. & 2204 & 2189 & Do. \\
\hline 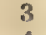 & & & 310 B. C & & & $\cdots$ & n........ & 2225 & 2225 & Do. \\
\hline 4 & ... & .. & 425 A. D. & & & $\ldots$ & $\cdots \cdots$ & 1490 & 1490 & Do. \\
\hline 5 & & 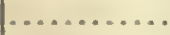 & 1202 A. D. & & & & & 713 & 713 & Do. \\
\hline $6^{1}$ & & $\ldots$ & 1125 A. D. ${ }^{2}$ & & & & & $790^{2}$ & $790^{2}$ & Camp 6, Basin. \\
\hline 7 & & & & 594 A. D. & 13.5 & 75 & 519 A. D. & 1396 & 1321 & Do. \\
\hline 8 & & & 294 B. C. & 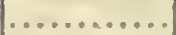 & & .. & ….... & 2209 & 2209 & Do. \\
\hline 9 & & & $311 \mathrm{~A} . \mathrm{D}$ & & & & & 1604 & 1604 & Do. \\
\hline 10 & . & & 362 A. D. & & & & & 1553 & 1653 & Do. \\
\hline $11^{8}$ & & & 然 & 697 A. D. & 7.5 & 46 & 651 A. D. & 1264 & 1218 & Do. \\
\hline $12^{1}$ & 92 & 17 A. D. & & 135 A. D. & 14 & 65 & 70 A. D. & 1845 & 1780 & Indian Basin. \\
\hline $13^{\mathbb{1}}$ & 91 & 585 A. D. & 688 A. D. ${ }^{2}$ & 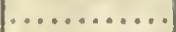 & &. & $\ldots$. & $1327^{2}$ & $1327^{2}$ & Do. \\
\hline 14 & 96 & 387 A. D. & 388 A. D. & & & & & 1527 & 1527 & Do. \\
\hline 15 & 59 & $121 \mathrm{~A} . \mathrm{D}$. & 160 B. C. & & & ... & & 2075 & 2075 & Do. \\
\hline 16 & & & 506 B. C. & & & & & 2421 & 2421 & Camp 7, Uplands. \\
\hline 17 & & $\ldots \ldots \ldots$ & $308 \mathrm{~B} . \mathrm{C}$. & & & . & & 2223 & $1438^{3}$ & Camp 7, Basin. \\
\hline 18 & & & 294 B. C. & & & & & 2209 & 2209 & Camp 6, Uplands. \\
\hline 19 & & & & 242 B. C. & 8 & 35 & 277 B. C. & 2192 & 2157 & Do. \\
\hline 20 & & & 902 B. C. & & & & & 2817 & 2817 & Converse Hoist. \\
\hline 21 & 74 & 1318 B. C. & $\cdots$ & 1305 B. C. & 2.3 & 12 & 1317 B. C. & 3232 & 3220 & Do. \\
\hline 22 & 195 & 1141 B. C. & & $1087 \mathrm{~B}, \mathrm{C}$. & 12.0 & 75 & 1162 B. C. & 3077 & 3002 & Enterprise. \\
\hline 23 & 116 & 1191 B. C. & & 1122 B. C. & 14 & 80 & 1202 B. C. & 3117 & 3037 & Do. \\
\hline
\end{tabular}

1 Omitted from the means on account of some deficiency in identification.

"Identification very nearly right.

- Not identified after 1130 A. D.

Leaving the vicinity of the General Grant National Park and going south to Porterville, thence by rail to Springville, a 3 days' trip was arranged to the old Enterprise millsite. Camp was made at the cabins, about 10 minutes' walk below the millsite. On going up from the camp, No. 23, known as the Centennial Stump, was found at once, as it is of enormous size, high in the center, and covered with names of visitors. It is located close beside the road and near the wash, about 100 yards from the clear space once occupied by the Enterprise Mill. The oldest tree which Huntington found at this locality had been 

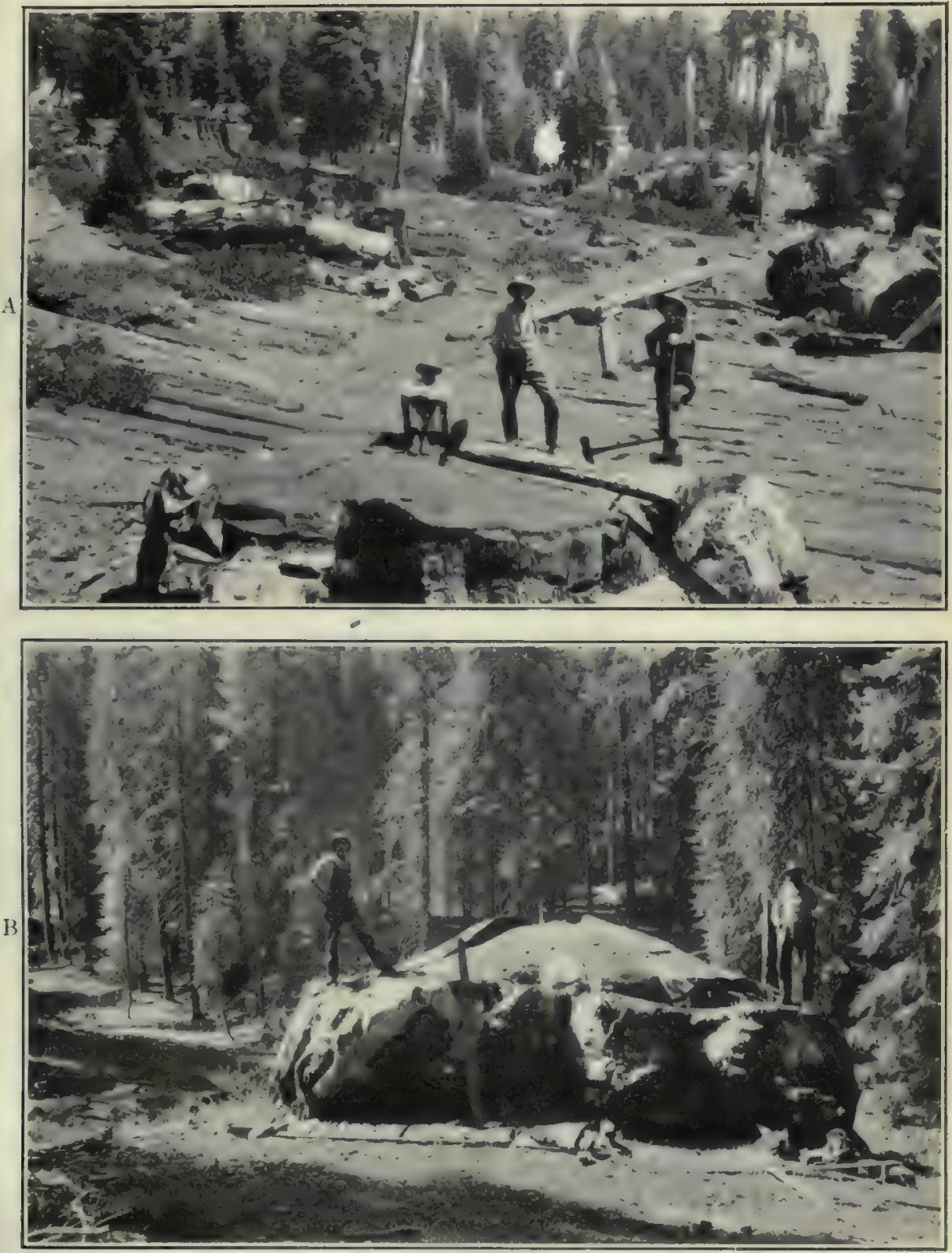

A. Cutting sample from stump, Enterprise: D-22, age 3000 years.

13. Centennial stump, Enterprise, Cut in 1874: D-23, age 3075 years. 

numbered 116 in his lists. This stump had no number on it, but from the date of its cutting and its age of nearly 3,100 years, it is without doubt the one he refers to. The tree was cut in the winter of 1874-75 for exhibition at the Centennial. The trunk was hollowed out and prepared for transportation in pieces to Philadelphia, where it was said to have been erected, making a sort of hut. In consequence of the uneven surface left, it was very difficult to cut a sample from this stump. However, one was at last secured, which is $\mathbf{1 2}$ feet long as it lies on the table in the laboratory.

No. 22 was Huntington's No. 195 and grew near the center of the millsite. Its cutting was extremely easy and its cross-identification with No. 23 and the other trees farther north proved entirely reliable.

The location from which these two interesting trees were obtained is at the very top of a ridge with a steep descent on the east to the North Fork of the Middle Fork of the Tule River and a similar descent on the west to the Tule Valley. The top of the ridge is several hundred yards wide, with opportunity for considerable snow to collect there in winter. It receives little drainage from any source. Just north of it is Mount Moses, high and rugged, and to the south are high ridges extending toward Bear Valley.

All the sections obtained in these various trips were shipped to Tucson, and four weeks of continuous work were spent in crossidentification. All the identifications were satisfactory except the year 1580, which was finally determined by the special trip in 1919 . The general method of measuring and marking these sections will be found in the next chapter and the tabulation of averages at the back of the book. Owing to the interest in these trees of remarkable size and age, a list of the 23 collected in these two trips is given in table 5 . 


\section{DETAILS OF CURVE PRODUCTION.}

\section{PREPARATION OF RADIAL SAMPLES.}

Form of sample.-Nearly all of the 230 trees used in this investigation are represented by portions preserved in my collection. Wherever possible the entire section, 1 to 3 inches or more in thickness, was brought to the laboratory for examination. Unless the section was light and easily handled, it was found convenient to cut from it a radial piece showing the complete series of rings from center to bark. Naturally the enormous trees of the sequoia groups could be obtained only in radial form. The paper rubbings from Oregon and the small cuttings of the Prescott and second Flagstaff groups were also of this type. Hence the radial sample is regarded as the usual or type form in which the material appears in the laboratory. If the original section was small the radial piece appears as a bit of wood cut across the grain, square or triangular in cross-section and a foot, more or less, in length.

Method of Cutting.-The partial radials, such as used in the Prescott group, were secured from the stumps in place by making saw cuts at the edge of the stump in two directions, meeting a few inches below the surface. In this manner a piece of wood in the form of a triangular pyramid was secured and was sent to the laboratory. The radials of the sequoias were cut altogether from the tops of stumps or from the ends of logs that lay on the ground. From the manner in which the trees were cut down it was usually possible to get a clear surface of stump or log from the bark on one side to somewhat past the center where the under-cut had been made. After a minute examination of the surface exposed, a radius was selected which would give the greatest freedom from fire-sears and other irregularities of ring distribution. Two lines about 8 inches apart were drawn with blue chalk along this radius. Then two men with a saw 8 to 14 feet in length made a slanting cut on one of the lines of sufficient depth and in the right direction to meet a similar slanting cut from the other chalk line. In this way a long piece of wood of $V$-shape in cross-section was obtained, extending from the center to the outside and giving the full ring record.

In sequoias recently felled this cutting of the radials was extremely easy, but many of the sections obtained were from stumps which had been standing and weathering for 25 years and in one case 43 years. The exposure carbonizes the top of the stump and makes it extremely brittle and difficult to cut; small pieces break off and wedge the saw. Thus it often becomes a very difficult task to extract the radial section. The pieces into which the radial section breaks are marked for identification immediately, photographed and listed in notebook, and then carefully packed for shipment. On arriving at the laboratory, they are pieced together with the greatest care and then glued together in groups, making the entire radial section a series of convenient pieces about 2 to 3 feet in length. 
Preparation for measurement.-These pieces were then examined to find the longest sequences of clear and large rings, and guide-lines for the subsequent identification and measurement were selected as nearly as possible perpendicular to the rings. Such lines having been decided on, two straight pencil lines, half an inch apart, were drawn and the surface between these was "shaved." For this purpose, after the trial of many other methods, a common safety-razor blade was clamped to a short brass handle. With this very sharp blade the rough surface of the wood is removed and the rings stand out very clear and distinct. Besides the space between the lines, the region close outside is usually shaved also for a preliminary trial at cross-identification, the final marks being the only ones permitted between the guide-lines.

The best light for observing the rings is a somewhat diffused light coming sharply from the side. A light falling on the wood perpendicularly is apt to be very poor, either for visual work or photography. Light from each side must be tried, for there is often a great difference between the two directions, due probably to the way in which the knife passed over the wood and bent the ragged edges of the cells. In photographing, the colors involved and the result sought $(i . e .$, to show the red rings as black) require an ordinary plate and a blue colorscreen.

When the surface is well prepared it is placed in a suitable light and wet with kerosene applied by means of a bit of cotton on the end of a small stick. This deadens the undesired details of the surface, and brings the rings into greater prominence. The identified section is now supported over the unknown and with watchmaker's glass in eye and long needle in hand, the observer can make rapid comparison and quickly put on the required marks.

\section{IDENTIFICATION OF RINGS.}

In the early Flagstaff work the rings were first numbered, beginning at the outside without regard to the year in which they grew. But this was found to add complexity and involve the use of a separate reduction from the provisional numbers to the true dates of the rings. Accordingly the rings are dated at once as well as possible on some selected section that gives promise of an accurate record. The identification mark is a pin-prick or very small hole placed on the last ring of each decade. The middle year of each century has 2 pin-pricks and the centuries are marked with 3 ; the 1,000-year mark is 4. Marks found in error are "erased" by a scratch through them.

After the selected section is dated with the greatest care not to overlook or mistake any rings, others are dated by direct comparison with it. The common practical test in such comparison is the relation of width of a ring to its half-dozen near neighbors. For some unknown reason, rings of diminished size seem to carry more individuality than enlarged rings, and so they are usually picked out for cross-comparison. 
In nearly every decade some are thus distinguished, and in each century there are usually 3 to 4 conspicuously small rings which give very important aid.

In the first work on the 2,200-year sequoia record, the identification was a laborious task involving all the writer's spare time for a year. The only real difficulty was with the ring for the year 1580 . This was temporarily called $1580 \mathrm{~A}$, but the material collected in 1919 showed it to represent a year and a final and complete renumbering included it as such. In the end the comparisons gave entire confidence as to the identity of every ring. Section No. 2 gave the most nearly perfect long record, beginning at $274 \mathrm{~B}$. C., and is used as a standard with which to compare all new ones.

The most difficult parts to identify are the compressed rings. Over long periods, varying from 5 or 10 up to 100 years, the rings are sometimes so crowded together that large numbers of them seem to be merged into one and their identification becomes extremely difficult and in a few cases impossible. The great variations in sizes so produced also exaggerate effects. These groups of compressed rings are considered as of little value, and in fact in many trees their measurement is omitted altogether. Tree No. 12 of the sequoias obtained from the Indian Basin had such bad groups of compressed rings that it proved practically impossible to identify them without a large expenditure of time not then available. Tree No. 17, also, from Camp 7, was found so full of compressed rings in the last few hundred years that all measurements were omitted after the year $1130 \mathrm{~A}$. D.

Fire-scars.--Most of the big trees show fire-scars at some time in their history, and the process of the tree's regeneration is very interesting to observe. If the scar is small the woody growth quickly comes in from each side and covers it. If the scar is very large, occupying perhaps one-quarter or one-third of the circumference, the tree is likely never to recover and the burnt place remains permanently on its side. In cases of less extensive burns, the wood from each side year by year grows toward and over the injured spot, and if the injury has not been too great the approaching sides may meet and imprison their own bark within the tree. Thus one often sees the tops of the stumps marked here and there by a hole as large as a foot in diameter, filled with bark in perfectly good condition.

No. 12 had several fire-scars that interfered with the identification of rings. No. 18 also had one or two fire-scars and in particular showed a fire in the year 1781. The latter evidently stopped the growth at that point completely, yet was not large enough to interfere with recovery. In the sample in the laboratory the usual reddish-colored heartwood changes about the year 1700 to the white sapwood, which ends with the ring 1781 and shows a surface that was once covered with bark. However, immediately outside of that surface, the red heart- 
wood begins again with the year 1791 in a thick, rapid growth. The heartwood continues for some 20 years before changing again into the white sapwood, which persists to the outside. In order to make sure that this gap would not prevent satisfactory identification, a small portion was cut from another part of the outside of the tree, showing some 300 rings without interruption; but this additional piece $I$ found in that case to be unnecessary.

In sections numbered 22 and 23, from the old Enterprise millsite, there are injuries which do not greatly alter the appearance of the rings, yet are sufficiently great to weaken the wood and cause it to break at several points. If the break in such case is across the rings, it is easy to carry the identity of rings past the injured point. But when the break in any wood sample is all in one ring there may be a doubt as to whether the break is between two rings or in the middle of one. In the latter case there will apparently be an extra ring at that point. If the break is obviously between two complete rings, then an unknown number of rings may be lost at the broken point. The only way to carry the correct dating of the rings past such broken places is to secure samples from other parts of the same tree or from other trees, which show 100 to 200 rings on each side of the uncertain place without serious interruption. A simple cross-identification will show whether any rings are lost. However, in Nos. 22 and 23 just referred to, nearly all lines of breakage crossed the rings in a way that left no uncertainty. But No. 22 had an injury and a break between complete rings at about 1020 B. C. and a pronounced injury at about 1060 B. C. No. 23 had an extensive decayed place with the loss of about 35 rings at 1060 B. C. An extra piece cut from the stump of No. 23 carried the dating across these gaps with perfect satisfaction and in complete accord with No. 21 which had been secured 50 miles to the north.

Cross-identification between distant points.-The sequoias collected in $1915 \mathrm{had}$ come from the immediate vicinity of Camp 6, about 7 miles east of Hume, and from Indian Basin, which is 3 to 4 miles north of Hume. The total extent of country covered was about 10 miles. All these were identified and found to be very similar in their characteristics. In 1918 the country represented was extended by sections from the new Camp 7, some 2 miles east of Camp 6. Nos. 20 and 21 were then obtained from the old Converse Hoist, 4 miles from Indian Basin and 15 miles from the Camp 7 district. Finally, 2 trees were obtained from the old Enterprise millsite, 50 miles from the other localities. It was realized at the time that there might be difficulties of cross-identification between these 2 trees at Enterprise and the other well-known and well-identified groups near Hume and the General Grant National Park. However, it was very gratifying to observe on close examination of these sections that no uncertainty was introduced in the identity of the rings. One realizes from this that, so far 
as sequoias are concerned, a distance of $\mathbf{5 0}$ miles between groups is likely to be no particular obstacle in cross-identification.

The difficult ring 1580 .- The small ring $699 \mathrm{~A}$. D. and several other difficult ones were absent in comparatively few trees and any uncertainty regarding them was removed in the early part of the work, but it was not so with the ring of the year 1580 . The best of the tree records were from the uplands and usually omitted it, while many of the basin trees which showed it were at first very uncertain in identification. The ring was therefore provisionally called $1580 \mathrm{~A}$ and held in doubt for several years. The question of its reality was finally settled in the affirmative by a special trip to the sequoias in 1919 and the collection of a dozen carefully selected radial samples. The final review of all the tree-records has resulted in satisfactory identification of some previously doubtful cases and in complete conviction regarding the ring for $1580 \mathrm{~A}$. D. No other uncertain cases were discovered. Considering the 35 sequoia records now (1919) made use of, it seems possible that all errors of dating have been removed.

\section{MEASURING.}

Having prepared and identified the wood samples, the first method of measuring was to lay a steel rule on edge across the series of rings in a radial direction and to read off from the rule the position of the outside of every red ring. These were either recorded at once by the person measuring or were noted by a clerical assistant. This method applied to the Flagstaff and Prescott trees and to the European and Vermont groups. In nearly all of them the steel rule used was a meter in length. It was ascertained by tests that the errors in readings of this kind were less than $0.1 \mathrm{~mm}$. on the average for a single reading. For the Oregon group a microscope slide was used with a vernier which gave at once readings to $0.01 \mathrm{~mm}$. The readings obtained by either of these methods were recorded in two columns on a page, and the subtractions were performed afterwards, giving the actual width of the ring in millimeters and fractions. Thus any error in the original reading would affect two rings only. Very great numbers of readings have been done a second time and vast numbers have been checked over approximately; hence it is believed that errors of this kind are extremely rare; out of 20,000 measures, perhaps 4 or 5 have been discovered. Errors of subtraction may have occurred, but it is thought that these also are extremely rare indeed, since practically all of the work has been checked over a second time.

In the case of the sequoias, however, the method of measuring was much more highly developed. It required a cathetometer with a thread micrometer and adding machine. The cathetometer is placed horizontally on the table and the wood to be measured is also put 
horizontally on the table at a distance of about 33 inches. The cathetometer telescope has a lens of such a focus that $1 \mathrm{~mm}$. on the wood section becomes $0.25 \mathrm{~mm}$. in the focus. The micrometer has a screwthread with a pitch of $0.25 \mathrm{~mm}$., so that one revolution of the micrometer head moves the thread through exactly $1 \mathrm{~mm}$. as seen on the wood. The individual measures of rings are made on the micrometer screw by reading the graduation of the head to revolutions and hundredths, giving directly millimeters and hundredths. On commencing a set of readings the stationary thread of the micrometer is first placed on the zero-year ring of each decade, and the reading of the cathetometer is made and this is entered on the adding machine. A space is then inserted on the adding machine and thereafter the micrometer reading of each ring in the decade is added in column as fast as made. Then another space is made on the adding machine and the total is entered without clearing the machine. Immediately below this total the reading of the cathetometer in the new position 10 years advanced is made and inserted on the machine without addition. Then another space on the machine is given, followed by the individual readings of the next decade. In this way all the years are read individually by the micrometer and every 10 years the sum of these readings is checked against the cathetometer reading, which should come to the same amount.

The reading of the micrometer screw to $0.01 \mathrm{~mm}$. is closer than the average setting can be obtained. The rule has been generally observed that in every decade the agreement between the sum of the readings obtained and the cathetometer reading should check within $0.20 \mathrm{~mm}$. In the earlier measures, where the rings were irregular or the surface of the wood uneven, this accuracy of check was not obtained in a few cases. Yet even there the error in checking was not much larger than the figure mentioned, and it is expected that the results are sufficiently close for all purposes desired. The 25,000 measures on the first group of sequoias were begun by the writer, but after 2,000 had been done they were continued by Mr. Edward H. Estill, who did them with great care. In the second group, with 22,000 rings, the measuring had been done by Mr. J. F. Freeman, who has made some slight alterations in the method above described by which an increased accuracy is obtained. As a result, the check between the decades by measure and by cathetometer is nearly always within $0.10 \mathrm{~mm}$.

\section{TABULATING.}

The paper used for the tables throughout has been a cross-ruled paper with squares about three-eighths of an inch in size. This paper is 8 by 10 inches in size and suffices admirably for small tables. Usually 20 numbers are placed on a horizontal line with the beginning year at the left and with numbers from 1 to 20 at the top. Thus 1820,1840 , etc., will be placed at the left, and 1821 will be the first date given in 
that line. When it is desired to make longer tables, the pages are pasted together side by side or end to end, and then given a zigzag fold, so that two pages are open at once. In the case of the sequoias, with their 2,000 to 3,000 rings, no attempt has been made to paste the pages together, but enough loose sheets are used to cover the entire series at the rate of 20 years to a page. This gives sufficient vertical space to include all the necessary trees in a group and to use subgroups which may be summarized and averaged by themselves. An attempt has been made to check the addition of these numbers throughout.

\section{AVERAGING.}

In simple averaging the sums are placed in ink on the table and divided by the number of trees, using the slide rule for the process. There are several questions in connection with this subject. The first is whether straight averages of trees of widely different size give the best report of the evidence of the trees. It is evident that in taking averages of trees of mixed sizes the larger trees will carry more weight and their variations will be more pronounced in the result. But it is often the case that the smaller trees are the ones which show the greatest relative variations in the rings. This can be so much the case that the omission of a ring becomes a gross exaggeration. It is possible to use the relative values by taking the logarithm of each ring measure, averaging the logarithms, and then coming back to the number. This could be called a geometrical averaging, since it would be the equivalent of multiplying all the values together and then extracting the root equal to the number of values. In this way the small trees of the series would receive more importance. However, this plan is so long that it has not been used in practice.

One of the most common and puzzling problems is the proper method of handling the decrease in the number of trees in a group as the center is approached. A group of 5 may be selected, for example, and perhaps a century from the average center of the trees some one tree whose rings differ from the average may come to its end. It means that for 100 years near the center only 4 trees supply the data and at the point where the 5 change to 4 there is a discontinuity in the curve. In actual practice this lacking tree has usually been supplied by an extrapolation from its subsequent curve. That is, the variations assumed in the non-existent part of the tree follow precisely the variations in the remaining trees, altered to the average size of the missing tree by means of a constant factor, determined by overlapping periods. Thus, if 5 trees carried easily back to 1820 , but only 4 of them extended to 1720 , and it was desired to carry the full group to 1720 , the period from 1820 to 1840 would be taken both for the 4 and for the 1 alone and the ratio between them determined. Now, averages for the 4 are carried back to 1720 , and then the factor found in 
overlapping periods is applied to the mean of the 4, producing a probable value of the fifth between the years 1720 and 1820 . This probable value is inserted in parenthesis in the table and all 5 values added up for an average. As a rule, groups are carried back only far enough to make assumed values of this kind a minimum in number.

There is one other problem in this immediate connection, namely, that of "gross rings." By gross rings I mean certain regions in a section where the average size of the rings becomes 2 to 5 times as great as normal. This is a problem by itself, both as to cause and as to method of treatment. Some study of its prevalence in different trees has been made, and it is usually safe to say that where an epoch is shown to have gross rings in one tree, the chances are at least even that the same years will have gross rings in the next tree. Since gross rings may not come oftener than once in several hundred years and last only 10 to 15 years, it is evident that we are dealing with something more than mere accident. The phenomenon probably has a climatic character. Yet, gross rings are not universal at any one time, and while one epoch may show gross rings in half the trees of a group it does not show it in the other half, judging by the groups examined. It is considered best to allow the ring values to enter the curves just as they are found, for while the gross rings disturb very greatly the size of a series of 10 to 20 rings, they do not seriously disturb the relation in size between a ring and its immediate neighbors. They therefore, as a rule, do not render the rings unidentifiable. It is likely, therefore, that they should be included in the means, and if some better way of handling them is discovered later it will not be difficult to apply it.

\section{SMOOTHING.}

In general the smoothing of a curve means removing some of the minor variations, so that the larger variations may be perceived. In the early part of the work the use of overlapping means was adopted. At the very start, overlapping means of a considerable number, such as 11 or 9 , were used. This was quickly changed to overlapping means of 3. These overlapping means were done by the calculating machine (Brunswiga). On this machine three were added and then continuously the one next in sequence was added, while one at the other end of the three was dropped. However, this was changed to Hann's formula, because his formula is normally easier to apply and it gives a little more individuality to each observation. The method of applying Hann's formula consisted in adding to a table two columns consisting of, respectively, first and second intermediate values. This can be done rapidly and without taking too much space. To express the differences between overlapping means and Hann's formula graphically, we only need to say that if we take successive groups of three in any curve, forming a triangle, the center of gravity of the triangle is the value 
from overlapping means, but the point midway between the vertex and the middle of the base is the point from Hann's formula. In the present work Hann's formula has been used frequently, and in order to shorten description of processes the word "Hann" has been used as a verb.

In the analysis of curves already performed by the periodograph, the curves have sometimes been smoothed by Hann's formula before plotting and photographing. But a trifling error in the focus immediately smooths the curve, and therefore it is evident that the preliminary smoothing of a curve before plotting need not be done. ${ }^{1}$ Such preliminary smoothing helps the eye to judge variations in the curve. The effect of out-of-focus position in a photograph may be called optical smoothing. It is evident that optical smoothing may be done in two directions, vertically and horizontally. In plotting a curve it is evident that the desired smoothing must be in a horizontal direction, but in the differential photographs made with the periodograph, the directions of optical smoothing may have a very important bearing on the judgment of the significance of the photograph. Of course, in the differential pattern, long interference fringes are sought and these are emphasized by optical smoothing parallel to them. Some illustrations of this will be given under the subject of the periodograph.

Perhaps no feature of this subject of tree-growth and climatic and solar variation has received more adverse comment than the matter of smoothing curves. The author is entirely open to conviction as to the advantage and disadvantage of such process, but it seems well to remember that our views as to this are likely to be a matter of convention rather than of actual thought in relation to the subject in hand. For instance, a monthly mean is a smoothed result. The rainfall, instead of being taken as it came, mostly in a few days, especially in the summer, is treated as if it were the same for every day in the month. Yearly means are smoothed values. The ordinary method of plotting yearly means is a smoothed representation of those quantities. The unsmoothed representation consists of what one may call a columnar plot. Examples of plots of that type may be found in connection with some rainfall records published by the United States Weather Bureau and in a representation of the London rainfall for more than 100 years published by the British Rainfall Association, and elsewhere. In this kind of plot the rain for a year is not represented by a dot, but by a block column which extends from the base-line up to the required amount and it has a width equal to the interval of one year according to the scale of the plot. Now, the ordinary way of representing rainfall places a dot at the middle of the top of this column, and these dots are connected together by straight lines. It is immediately

\footnotetext{
1The three-score of curves which are now specially prepared for examination with the periodoeraph carry the mean values without smoothing.
} 
seen that this cuts off each corner of the high column of any maximum year and contributes those corners to the adjacent lower column, so that the ordinary bent line of the rainfall record has thus been twice smoothed-once in the yearly sum and once in the method of plotting.

In speaking of the above records, I have in mind the smoothing in time intervals, but I would like to note also that whenever a district is averaged as a whole the average thereof is a smoothing in space. The temperature at any one time in a city station is a single definite record; but if the mean temperature in a valley or a State, for example, is tabulated, there is at once a spacial smoothing. In the minds of many students of solar variation and weather, the reason why a large group of meteorologists fail to get evidence of the relationship is because they take the average of the whole earth at once in their test of temperature changes or of rainfall. It is evident, therefore, that the reason they do not get results is because they do too much smoothing of the curves. Studies in connection with the present investigation have given some indication that small districts balance each other in their reaction to solar stimuli.

STANDARDIZING.

The fundamental data tabulated in the appendix are the means of the actual measures of the various groups. They, therefore, contain the effects of the two chief arboreal constants, which are (1) the nearly universal big growth at the center of the tree and (2) the increased size in some entire trees due to specially favorable environment. In producing a perfectly normal record of tree-growth over long periods, one desires to have it expressed throughout in terms of the normal adult growth of an average tree. This is the kind of record most suitable for analytical study. In the present study, in which so much time has been spent in finding how the work should be done, on account of the great labor involved no attempt has been made to apply these corrections to individual trees; but in comparing groups with one another it has seemed worth while to apply both corrections in a simple manner. Each group supplies an approximate curve of its decreasing growth with age. So, after plotting the means, a long average line as nearly straight as possible is drawn through them. This gives the factor by which individual rings may be reduced to the standard adult growth; at the same time this line enables us to reduce the different groups to a common standard of size. Both corrections are done at once by calculating for each year the percentage departure of the plotted mean from this line. In actual tabulation this works out very easily, for under each mean is placed the reading of this line, and below that the quotient obtained by dividing the former by the latter. The line of quotients then becomes the desired group curve corrected for age and for mixed sizes. This process is the standardizing process referred to in previous descriptions. 


\section{PLOTTING.}

So many curves have been made in connection with this study that a practically uniform system throughout has been adopted. The paper used is a cross-section paper with the smallest divisions $2 \mathrm{~mm}$. in extent and with heavy lines at every centimeter. The smallest divisions are uniformly used for one year unless in some special study. For the illustrations, these plots are traced and drawings made from which the engravings are reproduced. For use in the periodograph, the plot is made on the same scale and continued in length to any amount up to about 40 inches. The space between the base-line and the curve has then been cut through with a sharp knife, usually a razor blade, and the curves have been mounted in long strips some 4 inches wide and 50 inches long, and the backs painted with opaque paint. In this way they are mounted for analysis. A mirror behind reflects light of the sky overhead through the curve and supplies the necessary illumination for photography.

Problems in plotting.-In connection with the plotting of the curves used in this study, certain problems have arisen which seem worthy of consideration. The ordinary plot and the ordinary averaging seem extremely good and appropriate when the variations are small in comparison with the mean values, but when the variations are large in comparison with the mean values it does not seem to the writer certain that the usual plotting conveys an accurate idea or gives a suitable basis for further work. This may be illustrated by the plotting of rainfall. If the rainfall doubles in some unusual year, it produces an immensely greater change in the area of the curve than when it goes to one-half of the mean. Doubling the mean produces the same changes as going down to zero, though in proportion the latter is infinitely greater.

The enormous exaggeration, therefore, of excessive rain values was felt to introduce misleading material in the ordinary form of a plot. In order to overcome this at least one experiment has been made with what is called a bilateral plot. In this the quantities from 0 to 100 per cent of the mean are plotted as before, but the quantities over 100 per cent of the mean are inverted in percentage and plotted above the mean line on an inverted scale. It is recognized that this is not the perfect way of making a plot of this sort, for by this plan the mean value of the new curve will not be at the same point as before, but will be somewhat below it. However, the matter is only in the experimental stage and it has not been thought necessary to work out a correct procedure. 


\section{CORRELATION WITH RAINFALL.}

Result of study of curves.- On completing numerous curves of treegrowth in the manner already described, three characteristics were observed: (1) in arid-climate groups the annual rings are approximately proportional to rainfall; (2) in moist-climate groups they vary with the changes of solar activity; (3) in each they are subject to certain cycles or periodic variation. The first of these is the subject of the present chapter.

Early tests of rainfall correlation.-The earliest comparison with rainfall in this investigation was made between the first Flagstaff subgroup of 6 trees and 43 years of precipitation records at Prescott, 67 miles distant. It was not expected that agreement in individual years would be found; accordingly smoothed curves were used, consisting of overlapping means of 9-year groups. This produced curves of gentle variation, but similarity in the curves was evident. These early curves are presented in figure 13 . The best agreement was found

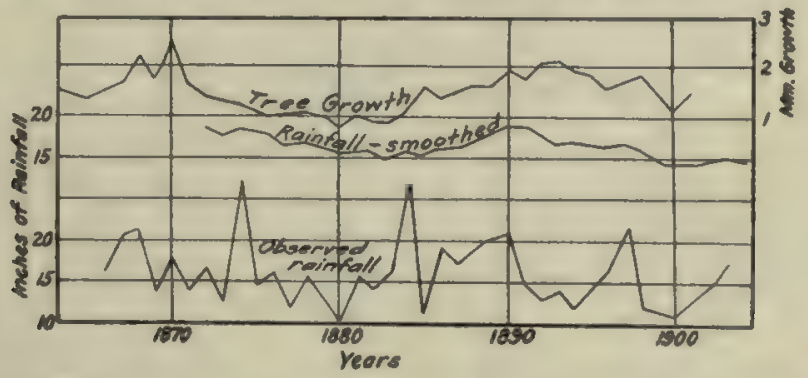

Fro. 13. Correlation between tree-growth and rainfall in smoothed curves; Flagstaff.

by placing each mean of 9 years of rainfall at the end of the 9 years as in this figure instead of in its center. This lag of four years seemed inconsistent with the later results of yearly agreement without lag, and in fact for years it has been accepted with some hesitation by the writer. Yet in the present consideration of the subject it appears to have a special significance. This existence of the lag in long periods agrees in principle with the "accumulated moisture" effects observed in the Prescott trees and with the idea of a tree exhibiting a reserve power or vitality which may run low or be built up by varying environment. The principle will be referred to again below; it is sufficient now to state that it seems quite reasonable to find no lag in yearly correlation with rainfall and at the same time a very considerable lag in the slower variations.

The comparison in figure 13 was made with Prescott records because there were not at that time enough Flagstaff records to be of service. But later, when a Weather Bureau station had been established in Flagstaff for several years, the striking comparison shown in figure 14 
was made. In this the lower curve represents the average annual growth of 25 trees and the upper curve is the precipitation 12 miles distant. The latter is taken from November 1 to November 1 in order to carry the snowfall into the following season of growth. This study suggested the investigation of the time of year to begin annual means of rainfall, which has already been presented in Chapter II. Figure 4 gives a comparison between Flagstaff rain and the two Flagstaff groups, and also shows how the best time of beginning the year was determined. It proved to be November 1 at Flagstaff and September 1 at Prescott, where the nature of the ground gives more chance of conserving moisture. The

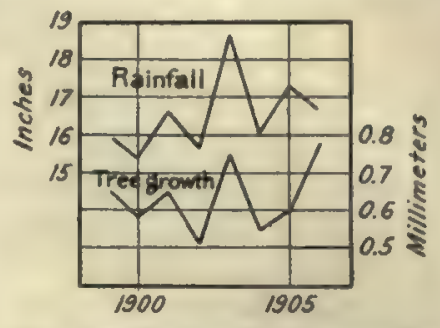

Fig. 14.-Early test of correlation between tree-growth and rainfall by years; Flagstaff.

great difference between individual trees in response to rain is also shown in figure 5. It is evident that quick-growing trees serve as better indicators.

\section{THE PRESCOTT CORRELATION.}

Five subgroups, numbering in all 67 trees, were obtained from different points in the vicinity of Prescott. These all cross-identified among themselves with entire success, both as individuals and as groups. The group curves are shown in figures 6 and 7 , but in comparison with the Prescott rainfall they differed greatly, the group nearest the city showing much the best accordance. Accordingly this group is plotted by itself in figures 7 and 15 with the rainfall curve. On the whole there is much agreement, as may be seen by comparing the crests and troughs of one with those of the other. The most conspicuous discrepancy is in 1886, where the rainfall decreases and the growth of the trees increases. In 1873 the growth seems to have responded to the decrease in rainfall, but to a greatly diminished degree. The tree maximum of 1875 , one year behind the extreme maximum of 1874 in the rainfall, is entirely reasonable, since the ground may become so saturated that the effects last until the following year. On the whole, the curves shown in figure 7 support the idea of a proportional relation between annual rainfall and annual growth.

Accuracy.-The accuracy with which the pine trees near Prescott represent the rainfall recorded in that city for 43 years is, without correction, about 70 per cent. By a provisional correction for conservation of moisture by the soil this accuracy rises to about 82 per cent. The nature of this conservation correction is very simple; it makes use of the "accumulated moisture" of the meteorologist. It signifies that the rings in these dry-climate trees vary not merely in proportion to the rainfall of the year, but also in proportion to the sum 
of the profits and losses of the preceding years. The "credit balance" in their books at the beginning of the year has only somewhat less importance than the income during the current year.

Mathematical relation of rainfall and growth.-In order to formulate the relation between rainfall and tree-growth, an effort was made to construct a mathematical formula for calculating the annual growth of trees when the rainfall is known. Any such formula must perform three principal functions: (1) reduce the mean rainfall to the mean tree-growth; (2) provide a correction to offset the decreasing growth with increasing age of the tree; and (3) express the degree of conservation by which the rain of any one year has an influence for several years. In a formula of universal application other factors will play a part, but for a limited group of trees in one locality they can be neglected.

The first process, namely, the reduction of the mean rainfall to the mean tree-growth, is a division by 250 . This is the general factor $K$ in the formula below. The second part, namely, the correction for the age of the tree, was practically omitted in forming the curves shown, since judging by the Flagstaff curves its effect would be very slight in the interval under discussion. In long periods it is an immensely important correction and its effect should always be investigated. Over the short periods used in this rainfall discussion the decrease of annual growth with age may be regarded as linear and an approximate formula is

$$
\frac{G_{n}}{G_{y}}=1-c(n-y)
$$

Where $G_{n}$ represents growth in any year $n ; G_{y}$ is growth in middle year of series $y$, and $c$ is the rate of change per year, a constant which was 0.0043 in the last half century of the Flagstaff series. Over the whole interval from 1700 to 1900 , in the first Flagstaff curve, the growth was approximately an inverse proportion to the square root of the time elapsed since the year 1690 and may be closely expressed in millimeters by the formula

$$
T_{n}=\frac{10}{\sqrt{n-1690}}
$$

$T_{n}$ is here the mean tree-growth for the year $n$. If $G$ be the mean size of rings, then the factor to be introduced in a general formula becomes

$$
\frac{10}{G \sqrt{n-1690}}
$$

Character of the conservation term.-This factor has two important features: (1) in this arid climate it applies better as a coefficient than as an additive term, and (2) it gives a prominent place to "accumulated moisture" as commonly used in meteorology. 
The first assumption in regard to conservation was that the ringgrowth in any one year was built up by contributions from the current year and previous years in diminishing proportion. For example, it would be proportional to

$$
R_{n}+\frac{1}{2} R_{n-1}+\frac{1}{4} R_{n-2} \text { etc. }
$$

in which $R_{n}$ is the rainfall for the current year, $R_{n-1}$ that for the year preceding, etc. This may be called an additive correction. It did not

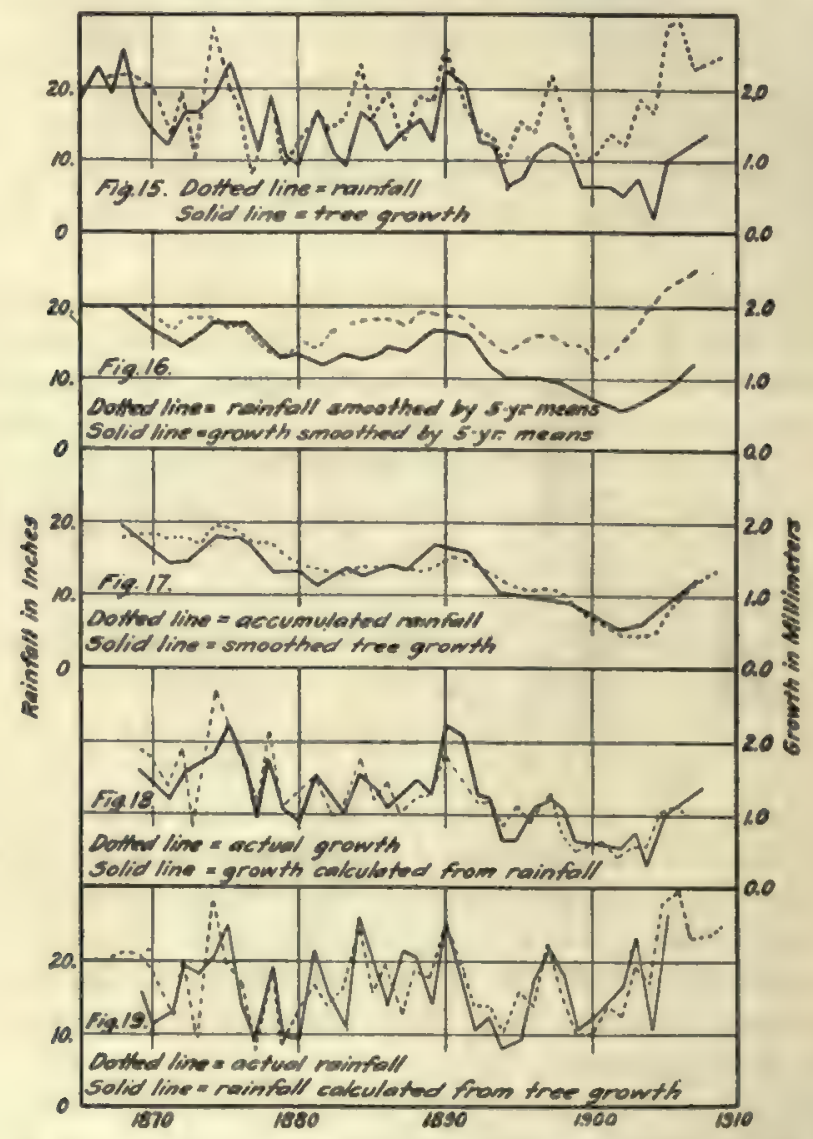

Fro. 15.-Relation of treo-growth and rainfall at Prescott, Arizona. Tree-growth and rainfall uncorrected.

Fre. 16. - Five-year smoothed curves of growth and rainfall.

Fro. 17.-Accumulated rain and smoothed tree-growth.

Fro. 18.-Actual tree-growth and growth calculated from rain.

Fre. 19.-Actual rain and rain calculated from tree-growth.

give satisfactory results for the Prescott trees, although a formula of this general type has been applied with some success to the sequoia, which grows in more moist soil.

The variations in the Prescott trees were seen to be proportional both to the rainfall of the year and to the average growth or activity 
which the trees had exhibited in the preceding few years. But this average growth bore the same relation to the average or smoothed rainfall that the accumulated moisture bore to the smoothed rainfall. Hence the ratio between accumulated moisture and smoothed rainfall gave at once the required ratio between smoothed tree-growth and smoothed rainfall. These relations are shown in figures $\mathbf{1 6}$ and $\mathbf{1 7 .}$

Accumulated moisture is simply the algebraic sum of the amounts by which all the years in a series from the start to and including the year desired depart from the mean. It may be expressed by a formula, thus

$$
A_{n}=\left(R_{1}-M\right)+\left(R_{2}-M\right)+\ldots\left(R_{n}-M\right)=R_{1}+R_{2}+R_{3}+\ldots R_{n}-n M
$$

and conversely

$$
R_{n}=M+A_{n}-A_{n-1}
$$

In this formula $A_{n}$ is the accumluated moisture for the $n$th year of a series of consecutive years whose mean rainfall is $M$.

The simple empirical formula for the tree-growth $T_{n}$ for the $n$th year of this series thus was found to be:

$$
T_{n}=K \cdot \frac{c M+d A_{n}}{S_{n}} \cdot R_{n}
$$

in which $c$ and $d$ are small constants found advantageous in reducing the accumulated moisture curve to proper scale. $S_{n}$ is the reading of the smoothed rainfall curve and the term $c M+d A_{n}$ is the accumulated moisture expressed in values above a base-line instead of departures from a mean. In actual numbers this becomes

$$
T_{n}(\text { in inches })=\frac{1}{250} \cdot \frac{0.90 M+\frac{1}{4} A_{n}}{S_{n}} \cdot R_{n} \text { (in inches) }
$$

The mean value of the rainfall $M$ is 17.1 inches. The application of this formula in calculating tree-growth at Prescott from the rainfall is shown in figure 18.

The reversal of the process in order to ascertain rainfall from treegrowth seems to be fully as accurate over this limited period, and its result is shown in figure 19, where the curve has an average accuracy of 82 per cent for individual years. In producing this reversal the following operations were performed:

1. A 5-year smoothed curve was made of the tree-growth. This gives us the term $\frac{0.90 M+\frac{1}{4} A_{n}}{250}$ in the reversed formula

$$
R_{n}=\frac{S_{n}}{\frac{0.90 M+\frac{1}{4} A_{n}}{250}} \cdot T_{n}
$$

2. This term is multiplied by 1,000 and $3.6 M$ subtracted, leaving $A_{\text {, in inches. }}$ 
3. From $A_{n}$ an approximate $R_{n}$ is found by the formula

$$
R_{n}=M+A_{n}-A_{n-1}
$$

4. This series of approximate rainfall $R_{n}$ is smoothed and becomes the $S_{n}$ of the formula.

5. Final values are then found by the proportion

$$
\frac{0.90 M+\frac{1}{4} A_{n}}{250}: S_{n}:: T_{n}: R_{n}
$$

It should be emphasized that the above formula for conservation is the one found to apply under dry climatic conditions. In moist climates the trees, so far as observed, seem to depend on other meteorological elements or combinations of elements.

The Prescott trees, as we have seen, even without correction give a record of rainfall with an accuracy of about 70 per cent. It is possible that the Flagstaff trees with their higher elevation, more certain rainfall, and more central location in the zone occupied by this species give somewhat more accurate records. They are probably much less often subjected to extremes of dryness, which throw the tree out of its equilibrium and cause it to produce an abnormally small set of rings. It seems likely, also, that the less compact soil, combined with a more abundant precipitation, produces a yearly growth more nearly proportional to the rainfall than at Prescott.

Summary.-In considering this reduction it seems fairly clear that (1) there is a strong correlation between rainfall and tree-growth; (2) the accuracy may be increased by introducing a conservation correction; (3) in dry soils this factor enters as a coefficient; (4) this coefficient depends on the state of activity of the tree; (5) in the Prescott trees this state of activity follows the curve of accumulated moisture.

Although the moisture-content of apparently dry ground may be a most important item, it is by no means certain that the observed accumulated moisture effects consist in actual moisture in the ground. It may be that they represent some vital condition of the tree. The matter is a very interesting one for future study.

Sequoia correlation with rainfall.- On his return from the big trees in 1912, Professor Huntington supplied me with a curve of sequoia growth obtained from many comparatively young trees which had been cut in the lower edge of Redwood Basin near Camp 6. On comparing these with his curve of rainfall in the San Joaquin Valley, compiled from records at Fresno and San Francisco, a close relation was not evident, but an additive formula

$$
T_{n}=k \cdot \frac{R_{n}^{2}+R_{n-1}^{2}+R_{n-2}^{2}}{R_{n}+R_{n-1}+R_{n-2}}
$$

was used with encouraging results. This formula was designed to allow for strong conservation in the soil, not of the static type as in a 
pond, but of the moving type, as if a belated supply from the snows came to hand and then passed on. The tree was assumed to receive moisture from the current year and from the first and second preceding years; and whichever of the three was greater, that one had the more effect. The application of this formula is shown in figure 20.

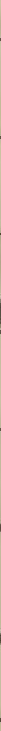

Fro. 20.-Huntington's early curves of sequoia-growth and rainfall compared with growth calculated by a conservation formula.

But on identifying the rings in the trees collected from that locality in 1915, and especially on finding the soft, delicate parts of the 1915 ring on D-5, it seemed fairly certain that the curve of growth given in figure 20 is one year in error through the omission of a final ring. The growth, then, which appeared to be 1902, for example, and for which a pronounced conservation was necessary, really came the year before,

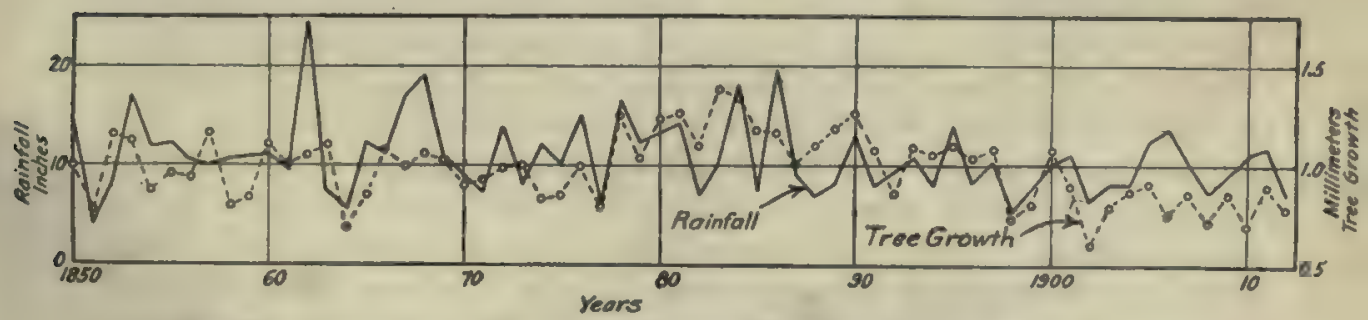

Fre. 21.-Comparison of Fresno rainfall (after Huntington) and sequoiss D-1 to 5 .

and less conservation or none was needed. The comparison of the same rainfall curve with the old sequoias of the present series is given in figure 21. In this the agreement is not as good as at Prescott, but there is marked similarity in many details. My curve from very old 
trees is probably not as good in details as Huntington's samples from young and sensitive trees. His material is well worth cross-identifying and dating with care, and then comparing with any records of snowfall which can be obtained from the sequoia groves. It is greatly to be regretted that Fresno, 65 miles away and at 5,000 feet lower elevation, is the nearest point where precipitation records can be obtained for a period long enough to be of value.

Future work.-It will be very interesting to find whether the characteristics of the correlation at Prescott are general in arid climates and dry soils and whether practical formulas for conservation in moist soils or climates can be worked out. When this is done the significance of the study of annual rings will be greatly increased.

\section{METEOROLOGICAL DISTRICTS.}

The study above described raised emphatically the question as to the extent of the region or district from which comparative rain records should be selected. Such a meteorological district could be defined as one in which homogeneous weather elements are found. But we immediately ask ourselves the questions: must all weather elements be alike in it or is it sufficient to have only rainfall (for example) essentially the same throughout; will the district remain constant through indefinite time or will it change; is the district for short-period weather changes the same as the district covered by secular changes. In the present discussion I have understood by meteorological districts such regions as may show similar or identical variations in some one weather element. It seems likely that a region which may show unity in small or rapid variations may not do so in large and slow variations, or more likely may be a small fraction of a region which will show unity in large variations.

Meteorological districts and growth of trees.-The cross-identification of trees over large areas has already suggested the use of annual rings as a possible aid in delineating meteorological districts. This function of the rings has received some exemplification in the present study. For instance, the pine trees of Norway differed in such a way that it was necessary to divide them into two classes, one of which came from the outer coast near sea-level and the other from the inner fjords and mountains. The trees from these different regions show strong reversal with reference to each other. Again, the trees from the lowlands about the Baltic Sea show marked similarity in their variations and indicate, as we would expect, a homogeneous district. Furthermore, groups from near the Alps show strong differences from the other European groups, as we might expect from our experience with the five groups from the mountainous country about Prescott. A rugged and mountainous region is very difficult to divide satisfactorily 
into meteorological districts. Yet, in spite of local differences, mountain regions may be alike in major characteristics, for all the Prescott groups, though differing among themselves, cross-identify excellently with the Flagstaff trees 60 miles away. The sequoias also crossidentify perfectly in mountain localities 50 miles apart, showing that there is enough similarity in different parts of the high Sierras to cause the trees to agree in many variations.

Arizona and California.-Fully 450 miles intervene between the sequoias of California and the pines of Arizona, yet there are strong points of identity between them in the last 300 years. The dates of notably small rings are much alike in each. The details of this comparison have not yet been fully studied, but they support the idea long since expressed (1909) that Arizona and California, especially its southern half, form parts of a large district which has similarity in certain variations. A long acquaintance with this region throws light on the details of this similarity. The winter precipitation, which is largely in the form of snow at the altitude of the trees studied, has the major influence on tree-growth, for it is largely conserved near the trees, whereas the summer rains are usually torrential and the water quickly flows away. The winter storms moving in an easterly direction reach the coast region first and after about 24 hours are felt in Arizona. Thus, in spite of the coast range of mountains and the intervening low-level deserts, each winter storm passes over both regions and causes an evident similarity between them. In a large view they belong to a single meteorological district.

Meteorological districts and solar correlation.-In searching for a link of connection between solar variation and meteorological changes, we must bear in mind the effect of possible reversals in neighboring meteorological districts, such as noted above in Norway. It may be the lack of such precaution which has caused many meteorologists to condemn at once the suggested connection between the distant cause and the nearby effect. We must remember that districts may be small in area, and in combining many together we may neutralize the result for which we are in search. Some illustration of correlation found in small districts will be given in the final chapter. 


\section{CORRELATION WITH SUNSPOTS.}

Dry-elimate tests.- In the work of 1907 (published 1909) upon the first group of 25 yellow pines from 1700 to 1900 A. D., several long sequences of variation in a 5 to 6 year period were noted. These were compared with rainfall records at Prescott and in southern California and the crests of rainfall and growth appeared to coincide in date. It was then seen that the temperature curve of southern California had a period and phase corresponding to the rainfall curve, but with the second minimum almost entirely suppressed, and that finally this temperature curve resembled in form and phase the inverted curve of sunspot numbers. In connection with the publication referred to (1909), a set of curves was prepared to show these relationships. This set is partly reproduced in figure 34 , page 104 . In the original drawing the tree-curve was the least satisfactory, which was to be expected, as no real certainty in the dating of rings existed at that time. After crossidentification the tree-curve was again integrated for the 11-year period and far better results were obtained. This new curve is given in the figure referred to.

This type of integrated curve gives many facts in a very condensed form. A differential or detailed form of presentation should accompany it, as in figure 25, showing the full series of individual observations and beside it the curve with which it is to be compared. The differential study of the Arizona trees will be taken up in connection with cycles, but can be summarized in the statement that in the last 160 years 10 of the 14 sunspot maxima and minima have been followed about four years later by pronounced maxima and minims in the tree-growth. Also, during some 250 years of the early growth of these trees, they show a strongly marked double-crested 11-year variation.

Wet-climate reaction.- In the very first group of continental trees studied, those obtained at Eberswalde near Berlin, the remarkable fact was recognized at once that 13 trees from one of those carefully tended German forests show the 11-year sunspot curve since 1830 with accuracy. The variation in the trees is shown in plate 8 . The arrows on the photographs are not to call attention to the larger growth, but to mark the years of maximum sunspots. The other trees of that group do not show quite so perfect rhythm as do the marked radii shown, but are like the other parts of these sections, showing strongly a majority of the maxima. Taking the group as a whole, the agreement is highly conspicuous, and the maximum growth comes within 0.6 year of the sunspot maximum. The Eberswalde curves arranged in two groups and compared with the sunspot curve were shown in figure 9, page 38.

In the group of six sections from south Sweden, which were measured subsequently in Stockholm, a spruce (Picea excelsa) was discovered which shows the sunspot rhythm with the same striking clarity as the 

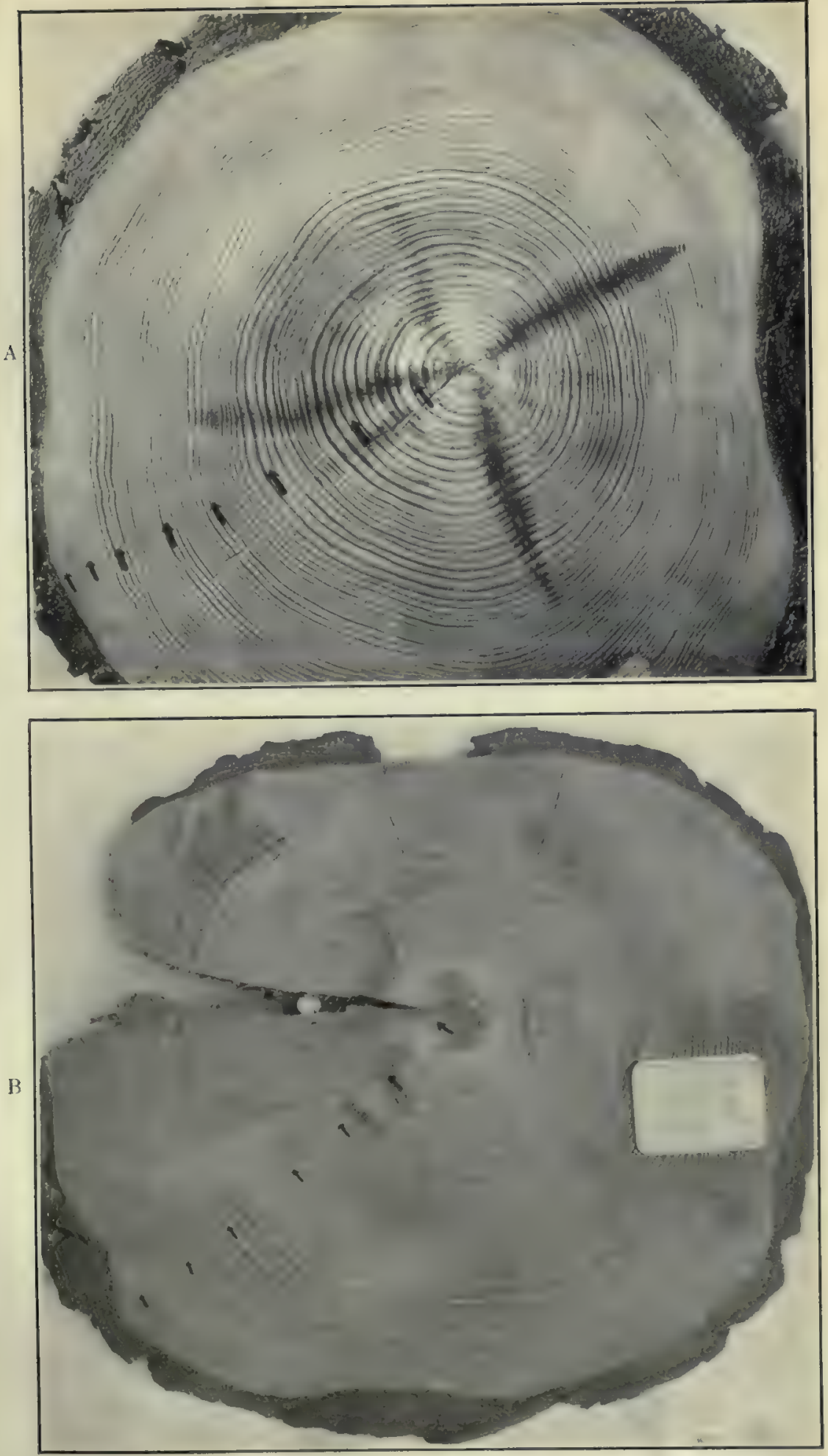

A. Section of Scotch pine from Fberswalde, Prussia, showing solar rhythm. B. Another section from the same forest, showing same rhythm. 



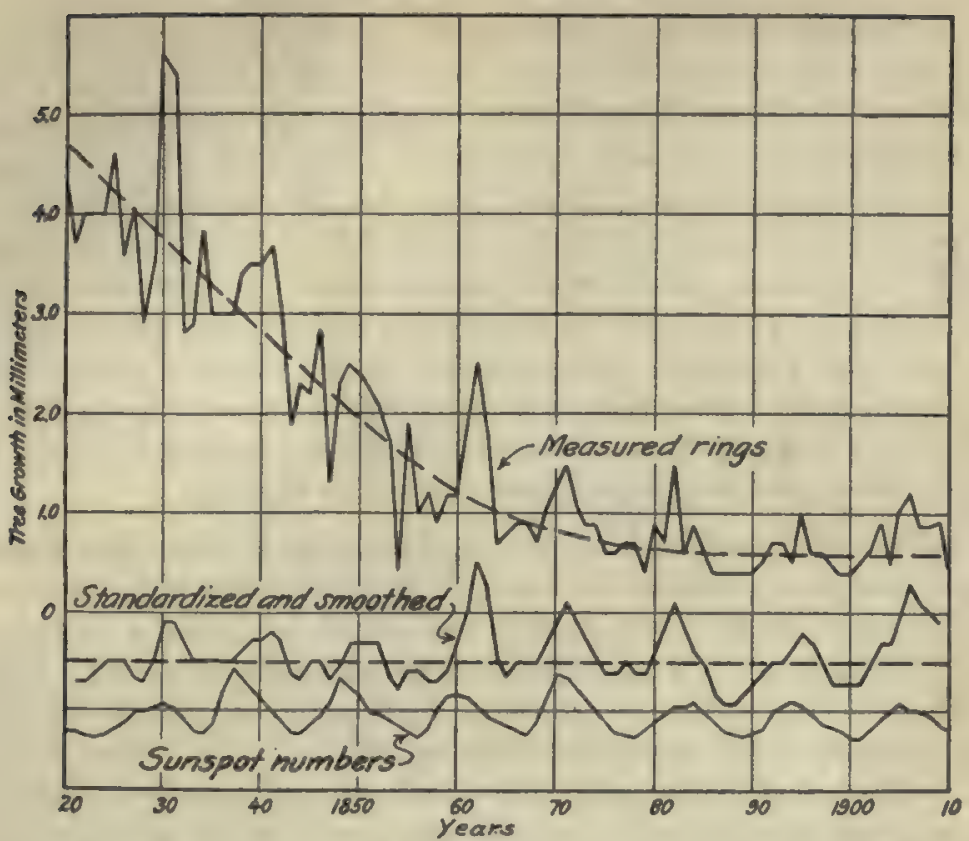

Fra. 22.-Sunspot numbers and annual rings in spruce tree from south Sweden.

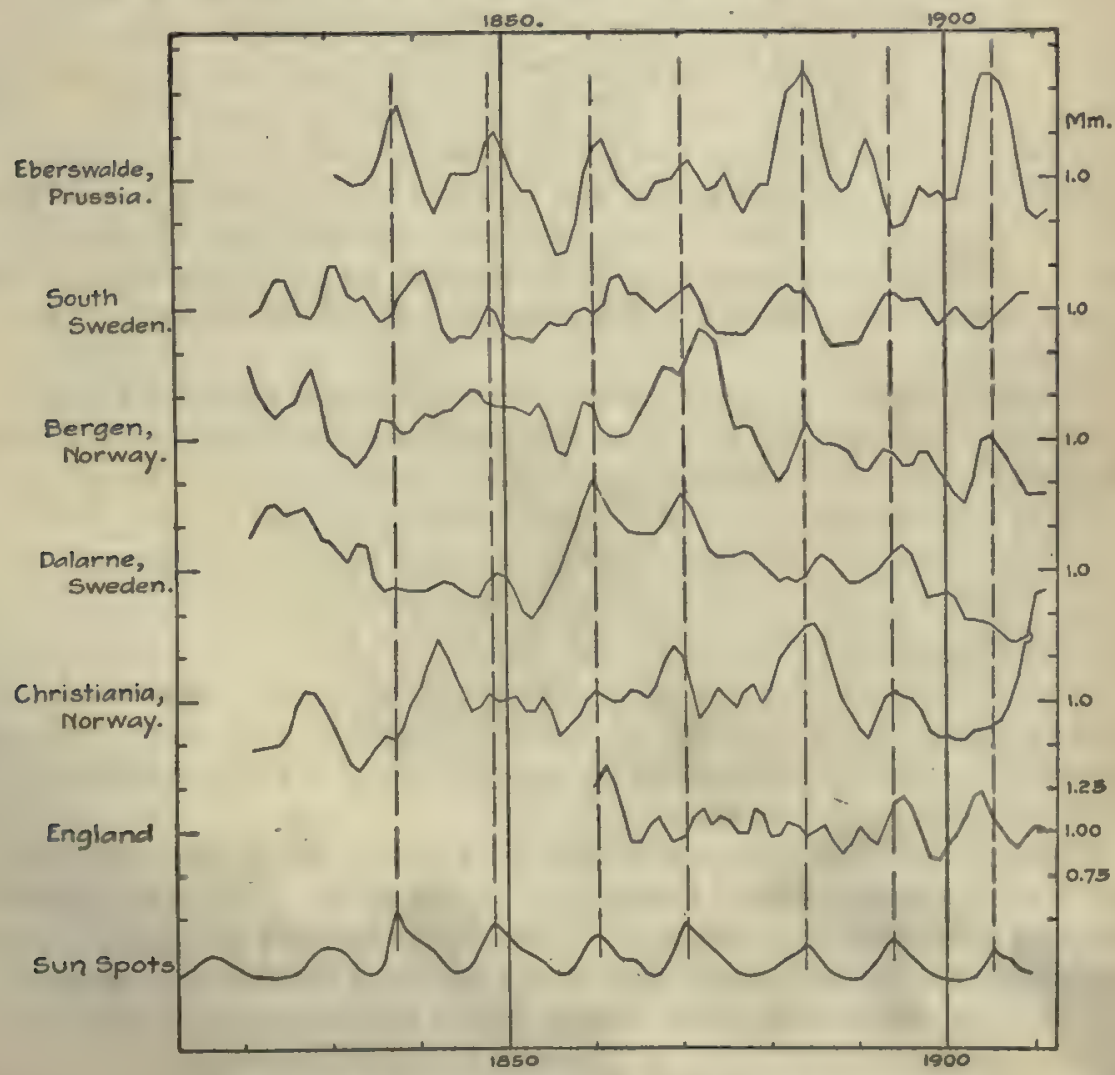

Fra. 23.-Sir European groups, standardized and smoothed. 
best Eberswalde sections. In view of the as yet unsuccessful efforts to obtain a photograph of this section, its measures have been plotted and are found in figure 22 with the sunspot curve for comparison. In the figure the upper curve gives the actual measures with the standardizing line drawn through them. The middle curve shows the same measures reduced to percentage departures from the line and smoothed by Hann's formula. The lowest curve shows the corresponding sunspot numbers. It would be highly interesting to know the exact conditions under which a tree produced such a curve of growth as this. In the opinion of the writer, it would not be impossible to find other trees of this type, and even to identify them without real injury to the tree, so that surrounding conditions could be studied.

The European groups.-For better comparison, the nine European groups have been corrected for change of growth-rate with age, reduced to percentages of their own means, smoothed by Hann's formula, and plotted in figures 23 and 24 together with the sunspot curve. They do not all follow the sunspot numbers with equal accuracy, and the six groups showing best agreement are segregated in the first of the two figures. The north German and south Sweden groups around the Baltic Sea are the most satisfactory; the group from the west coast of Norway is almost as good. Then come the Dalarne, Christiania, and south of England groups. These six in figure 23 have the times of sunspot maxima indicated by broken lines carried straight upward from the sunspot curve at the bottom. Of the other three groups, the trees from the inner coast of Norway as a whole appear to show a reversed cycle, probably because they were in deep inland valleys, while the southern groups, northwest Austria, and southern Bavaria close to the Alps have combined agreement and disagreement, so that they can not as yet be considered to give a definite result. They are shown by themselves in figure 24.

However, in the 6 groups representing the triangle between England, northern Germany, and the lower Scandinavian peninsula, a variation in growth since 1820 showing pronounced agreement with the sunspot curve is unmistakable. Every sunspot maximum and minimum since that date appears in the trees with an average variation of 20 per cent. This is shown in figure 25, which contains the mean of the 57 trees of the six groups, with the sunspot curve placed below for comparison. The agreement is at once evident. The apparent increase of tree-growth with increase in the number of sunspots becomes still more striking when the means are summated in a period of 11.4 years, as shown in the lower part of the figure.

A second important feature of figure 25 is that five of the eight minima show a small and brief increase in tree-growth. This suggestion of a second maximum is of interest, because in it we find agreement with Hann and Hellmann in their studies of European rainfall and sunspots, and it lends added weight to results which each author obtained but 
which neither allowed himself to regard as conclusive. In the immense work of Hellmann (1906) upon the rainfall of the North German drainage area, it is this inconspicuous maximum which he finds the more important of the two.

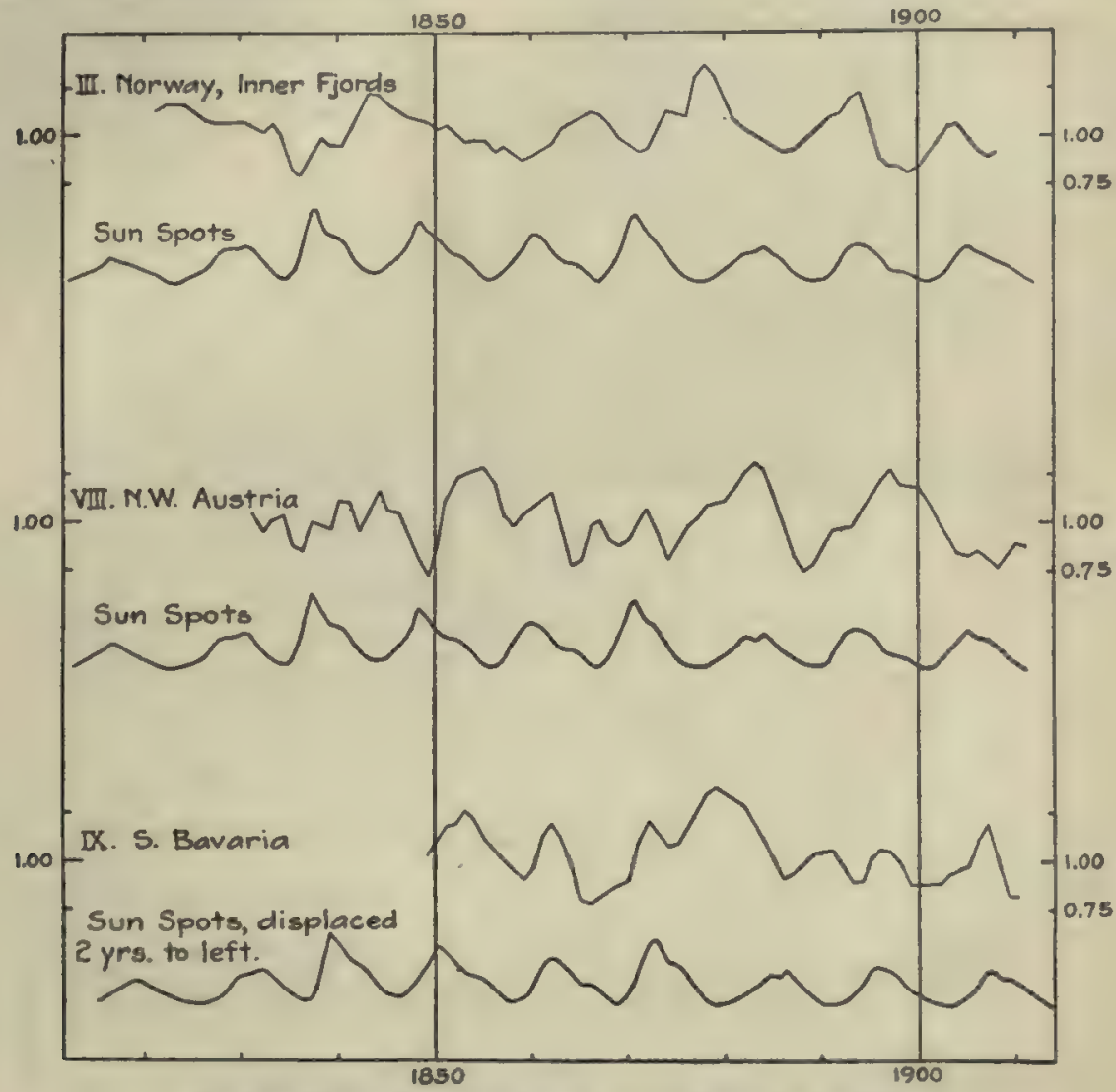

Fra. 24. -Three European groups, standardized and smoothed.

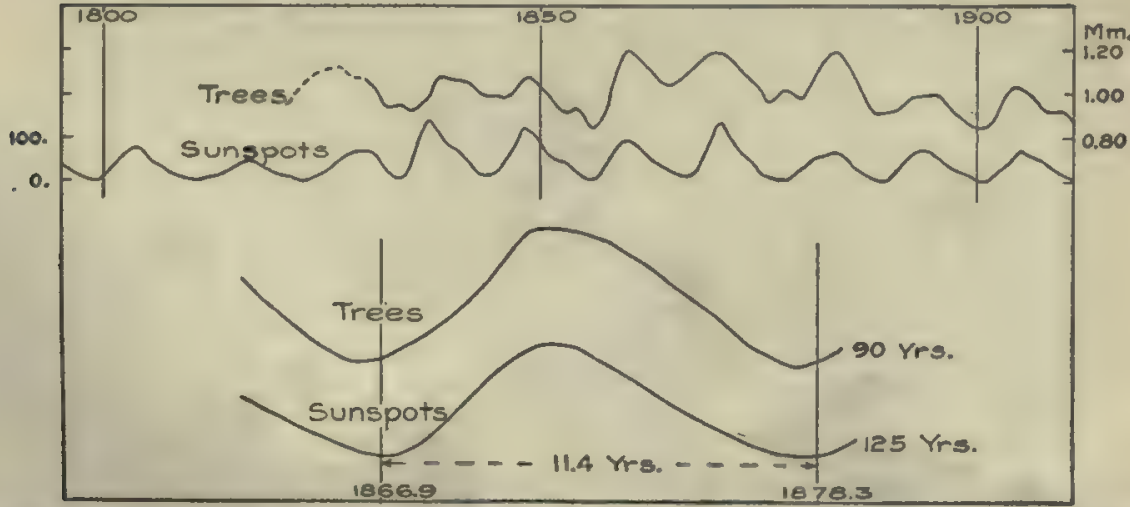

F10. 25. -Comparison between 57 north Europe trees (smoothed) and sunspot numbers. The trees are from England, Norway, Sweden, and north Germany. 
In seeking further evidence of sunspot correlation, advantage was taken of certain statistics recorded while measuring the various sections. Before making the measures or identifying the rings in any way, the groups of rings larger than the average were sought out and

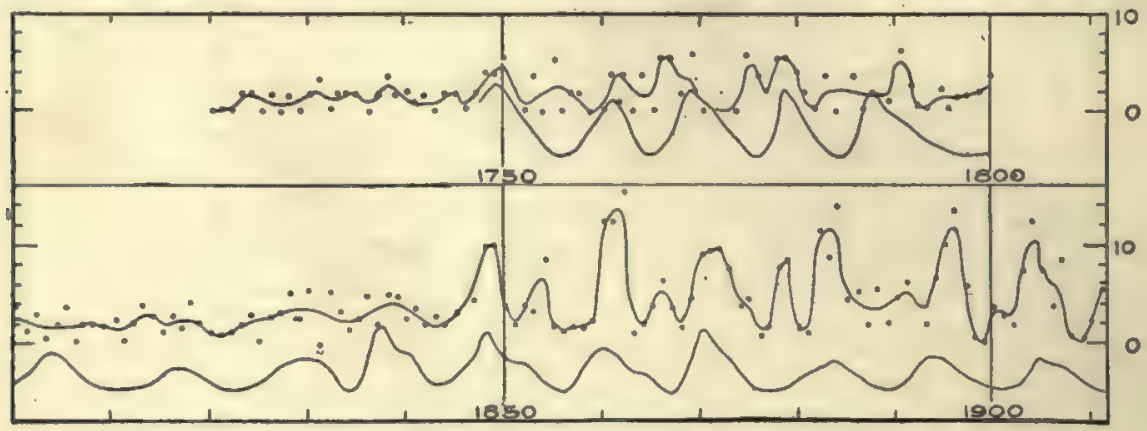

Fra. 26.-Dates of large rings in 80 Europenn trees compared with sunspot curves. Ordinates give number of trees in total of 80 showing maxima in respective years.

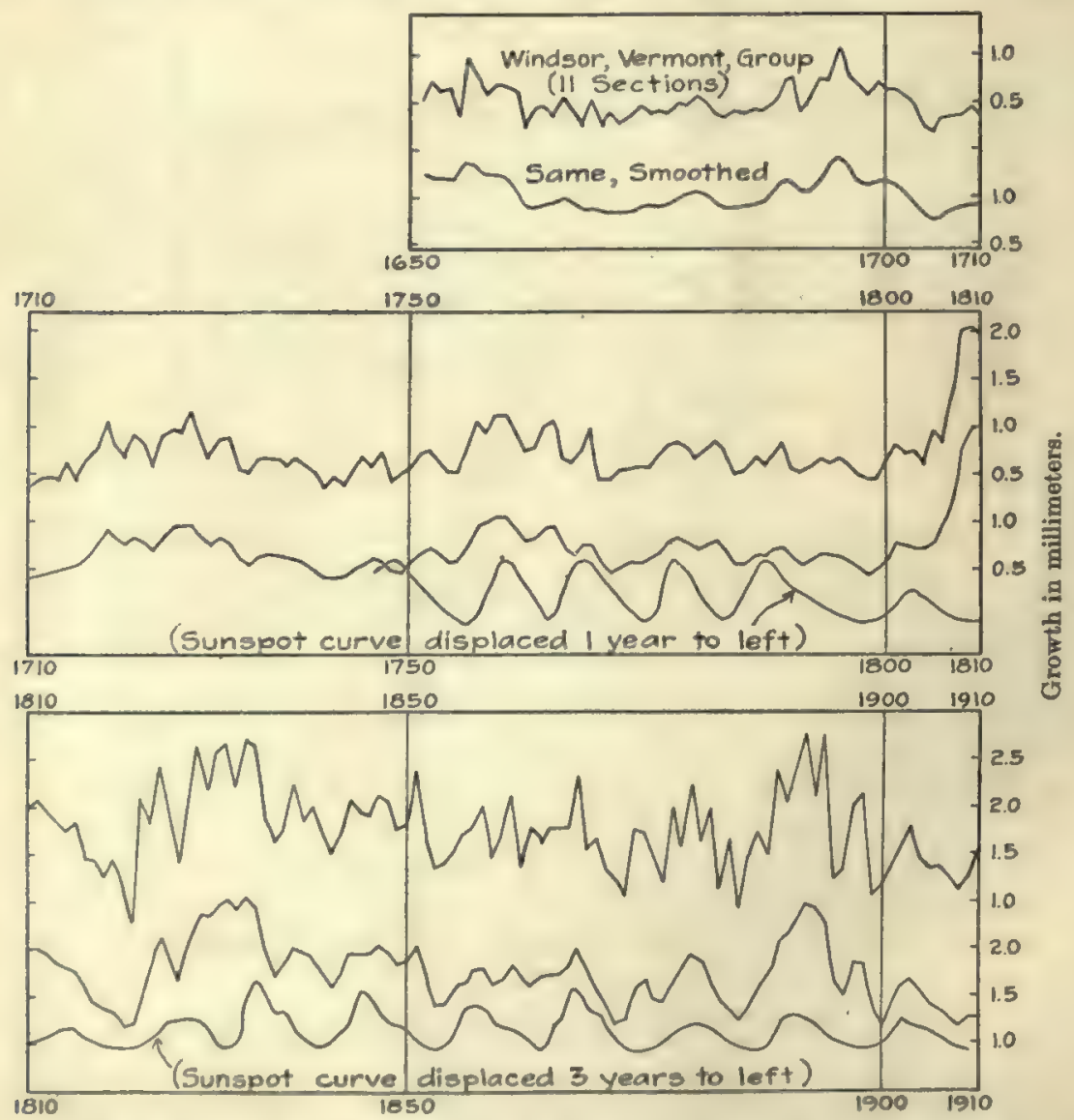

Fic. 27.-Tree-growth at Windsor, Vermont, showing measures uncorrected; same standardized and smoothed, and sunspot numbers displaced 3 years to left. 
crosses were placed upon the central ring, which was usually the largest of the group. These crosses are well shown in plate 4, B. Their dates were noted during the measuring. In figure 26 the ordinates give the number of maximum marks found in each date throughout the whole
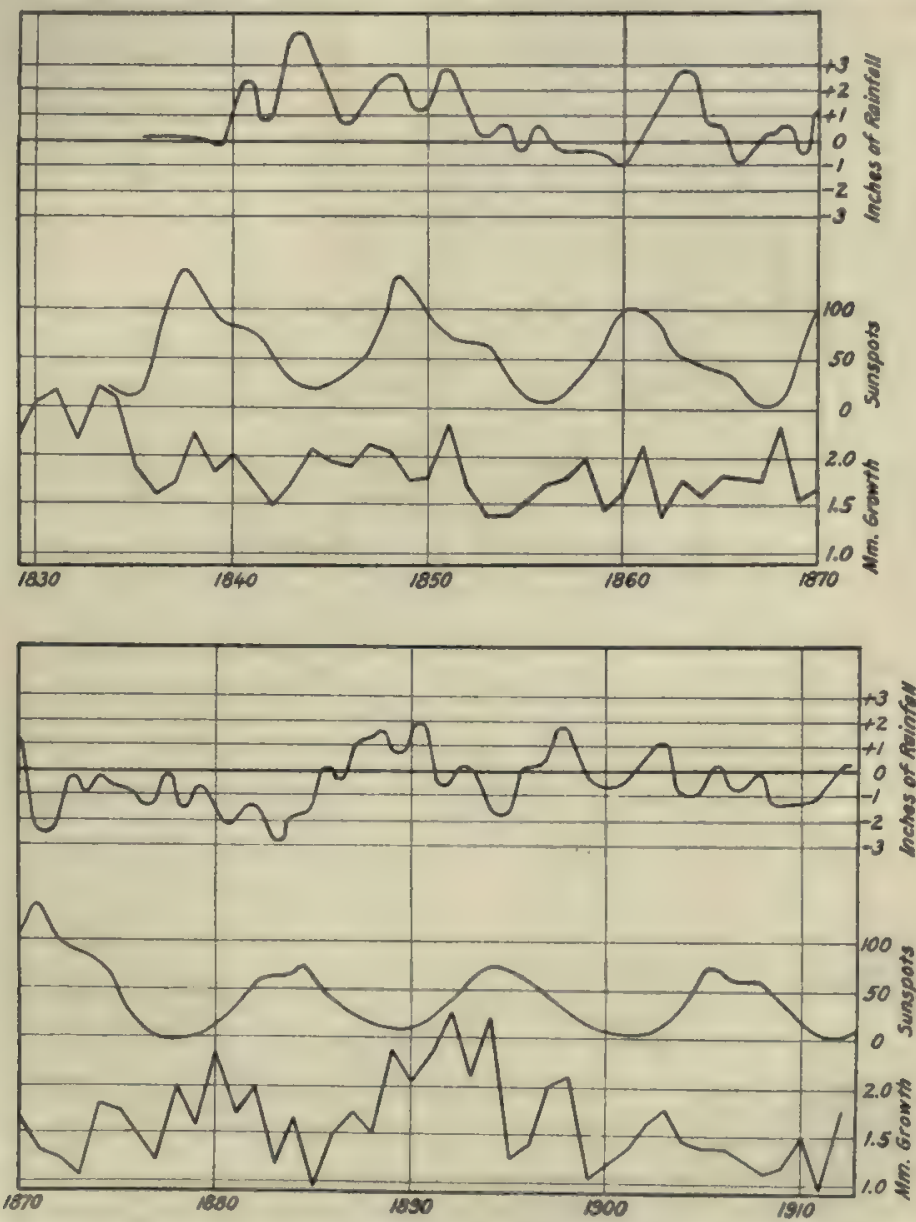

Fro. 28.-Smoothed quarterly rainfall (upper curve), sunspot numbers (center), and tree growth (lower) at Windsor, Vermont, 1835 to 1912.

80 sections. The more recent dates show higher crests because there are more trees. In the second line is the sunspot curve. The matching of the crests of the two curves is unmistakable. The secondary treecrest at sunspot minimum is very regular, as would be expected from the inclusion of the three groups of figure 24, some of which are evident reversals. This test is only qualitative, but seems to the writer to offer substantial support to the quantitative relation shown in figure 25.

Windsor (Vermont) correlation.-An interesting sidelight is thrown on this type of correlation by the American curves from Windsor, Vermont. 
The original means of 11 trees are given in the upper line of figure 27. In the middle line these are smoothed by Hann's formula and in the lower line is the sunspot curve, displaced three years to the left in the portions since 1810 and one year in the same direction before that date. The tree crests anticipated the solar crests by three years when the trees were large and making good growth, but when small this anticipa-

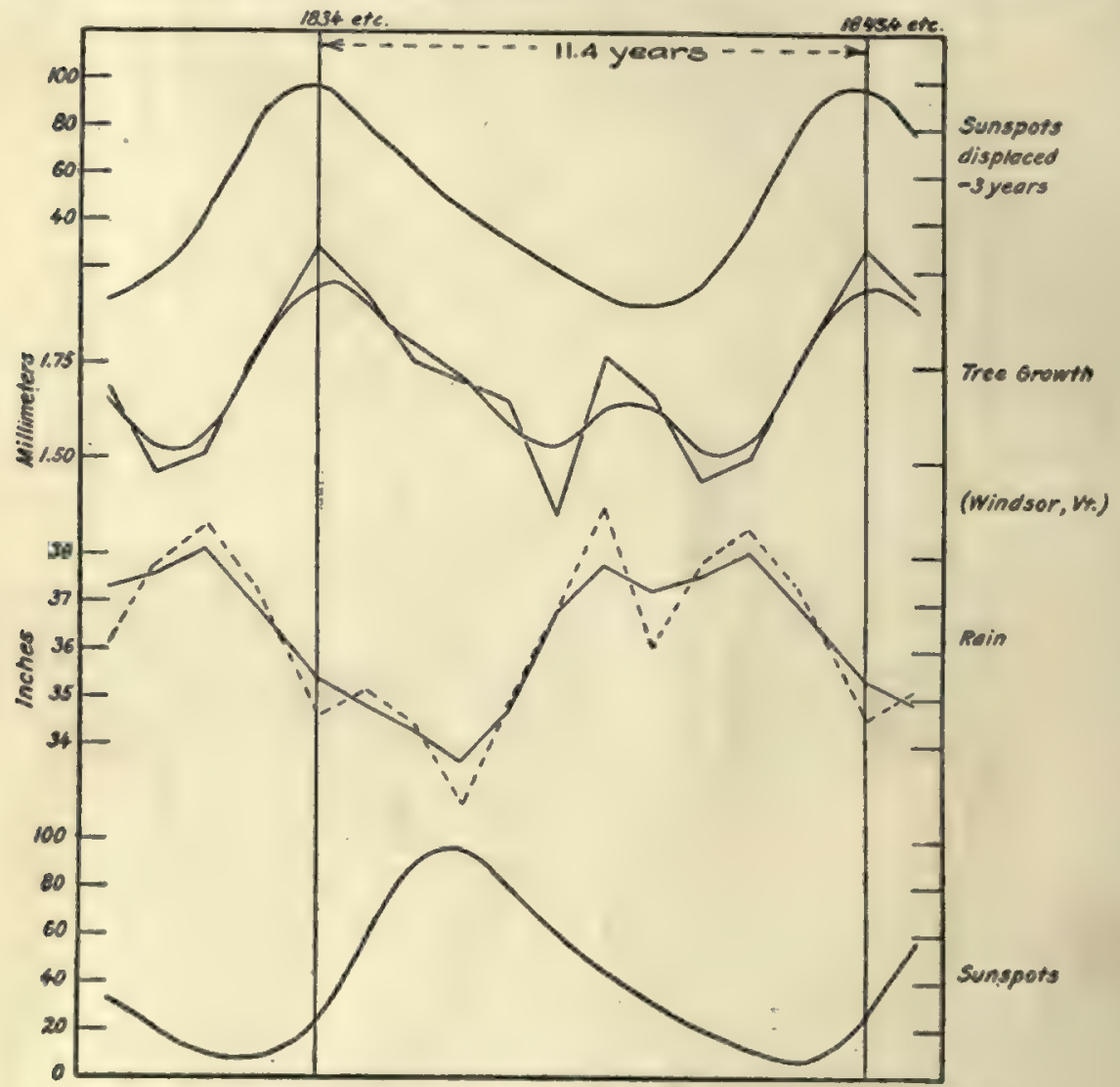

F1e. 29.-Correlation curves of solar oycle, rainfall, and tree-growth at Windsor, Vermont, 1835-1912.

tion of the sunspot maximum was considerably less. A correlation is evident, but it is hard to give a satisfactory explanation of the phase displacement. Figure 28 gives details of the time relation between tree-growth, rainfall, and solar activity. In figure 29 the curves of figure 28 have been summated on an 11.4-year period, as was done in figure 25. At the bottom is the sunspot curve from 1834 to 1912 inclusive; directly above it is the curve of rainfall for the vicinity of Windsor, compiled chiefly from records at Hanover and Concord and covering 1835 to 1912 ; above that is the tree-growth from 1834 to 1912 , and in the upper line the sunspot curve is repeated with a displacement of -3 years. 


\section{THE SUNSPOTS AND THEIR POSSIBLE CAUSES.}

If the sunspots are an index of some solar activity so far reaching as to affect our climate and vegetation, it is well to note very briefly their appearance and the suggested causes of their periodic character.

Appearance.-At first view sunspots are small black areas appearing from time to time on the sun. In actual size they vary from a few hundred miles in diameter to more than a hundred thousand. Rarely seen by the naked eye, the vast majority are only discovered through the telescope; hence it was only after the invention of that instrument that records of them were kept and their nature investigated. As Hale (1908) has found, they are cooling places; they merely look black by contrast with their more intensely bright background. His remarkable photographs show that they often have a rotation about their own center. They usually come in groups between latitude $5^{\circ}$ and $25^{\circ}$ in each hemisphere of the sun and are almost continuously changing in small details. Their life is usually less than one rotation of the sun.

Schwabe in 1851 announced their periodic character with maxima every 11 years. During sunspot maximum a small telescope will show 5 to 20 spots, but during the minimum one may search for weeks without finding a spot that can be certainly recognized. Records of the numbers of spots were specially collected by Wolf for many years and later by Wolfer of Zurich. At the present day many observatories are taking daily photographs of them. The term relative sunspot number was invented to convey an idea of the average number of spots visible at any one time under favorable circumstances. The number actually counted receives a simple correction for unfavorable weather or small telescope, so that the published numbers shall be as nearly standard as possible.

While the spot appears black and may possibly be sinking into the sun, it is usually attended by intensely bright areas or faculæ and even by prominences which are often violently explosive, ejecting matter hundreds of thousands of miles from the sun's surface. Thus the sunspot maximum indicates increased activity at the surface of the sun, which, according to Abbot (1913 and $1913^{2}$ ), is actually sending us increased heat radiation. During the maximum the magnetic condition of the earth is profoundly affected, as evidenced by northern lights, magnetic storms, earth currents, and variations of the earth's magnetic constants. This relation to the earth's magnetism has been recognized from the first discovery of the periodicity of sunspots. But the effect of the change of solar radiation on climate and ordinary weather elements is more obscure. General effects on climatic conditions have been admitted as probable by Penck (1914), but in general the great weight of opinion has been against a traceable effect of solar activity on weather or climate. 
From the description above it is easily seen that the sunspots are not likely to be in themselves the fundamental solar activity, but rather an index of something else, and possibly a very sensitive index, for the percentage change in spot numbers is hundreds of times as great as the percentage changes in measured radiation between sunspot maxima and minima.

Suggested causes of sunspots.-The cause of sunspots is still a matter of conjecture, and there is no generally accepted hypothesis to explain them. There is analogy to our clouds in that both indicate decreased temperature. In their limitation to certain latitudes they resemble the belts of Jupiter. The belts of Jupiter are roughly the lines of division between the powerful easterly equatorial current and the slower moving zones on either hand; and indeed this has been suggested as an explanation of the particular location in latitude of the sunspots, for there is an increase in speed of rotation of the sun's surface as the equator is approached. Their periodic character is very difficult to explain. Fundamental periodic changes in the body of the sun have been suggested and, in the absence of better explanations, some such statement hazily indicating the direction in which explanation is to be sought, is perhaps the best that we can do. Planetary influence, however, has often been proposed as the cause. The near agreement between the revolution period of Jupiter and the sunspot period has naturally attracted attention. Stratton (1911-1912) has made a very interesting study of the appearance, continuance, and disappearance of spots on portions of the sun facing toward or away from Jupiter and Venurs. A few per cent more spots do originate and disappear on the "afternoon" of the side facing Venus than on other longitudes, but he considers the case of physical relationship not proven.

Planetary influence is sought in a theory proposed by W. J. Spillman (1915). In this theory gravitation is assumed to be due to pressure variations in the ether arising from electronic rotation in the attracting body. The varying speed of a planet in its orbit between perihelion and aphelion, involving varying quantities of energy, requires, he says, an interchange between the kinetic energy of the plant and the atomic energy of the central attracting body. This atomic energy is in the vibrations of the electrons, but he thinks it is likely to affect both the temperature and the electric activity of the central body. The effect in this way of Jupiter and Saturn would exceed the sum of all the other planets combined and is therefore the only one considered. The effect of Jupiter with its substantial variations in distance between perihelion and aphelion predominates, and we have a marked resemblance between the sunspot curves since 1770 and the differential planetary effect. One notices that this interchange of energy would presumably affect all parts of the sun alike and that therefore we could not expect an excess of sunspots on the side facing Jupiter. 
H. H. Turner (1913; cf. Sampson, 1914) has worked out an hypothesis which is stimulating, even if not yet acceptable. He supposes that the Leonid swarm of meteors, revolving once in about 33 years in a very eccentric orbit, is at the basis of the sunspot recurrence. These meteors were observed in countless swarms, filling the sky for a few nights in November 1799, and again in 1833 and 1866. In 1899 they were expected, but failed to appear in large numbers, having probably been swerved to one side through the attraction of some planet. Turner finds that they have passed near Saturn several times in the last 2,000 years. At some of these encounters a quantity of meteors may have been detached and losing their own velocity may have fallen nearly straight toward the sun, grazing its outer surface in their circuit at a velocity of 400 miles per second, then swinging out to aphelion near their place of encounter, and completing their revolution in about 11 years. Successive returns of the main Leonid swarm, approaches of Saturn, and perhaps even the influence of other planets would be sufficient to perturb this meteoric swarm and cause the variations in period observed. On their terrific flight close to the sun many would be caught in the sun's outer atmosphere, thus in some way causing sunspots.

This hypothesis attempts to explain the period and its irregularities, including the double and triple period. I refer to it at some length because the investigation of trees gives evidence not only of climatic variations in the sunspot period, but of double and triple sunspot periods and possibly of still larger fluctuations. Turner's hypothesis warrants further discussion to explain why the spots appear in subtropical latitudes but not at the solar equator. In the planetesimal hypothesis of Chamberlin and Moulton, the rotation of the sun on its axis is attributed to the material falling back upon it after receiving a slight orbital motion from the visiting star. The authors state that the process may still be going on. This view is sustained by arguments based on the zodiacal light and on meteors, both of which seem best explained as planetesimal matter not yet returned to the solar mass. Matter as yet unabsorbed would very likely consist of particles which had been given just enough orbital motion to escape the surface of the sun on their periodic return. The particles for the most part would then have extremely eccentrie orbits and pass close to the sun's surface at tremendous velocity. They would be moving largely in the plane of the solar system and consequently would pass close to the sun's equator. If finally caught in the sun's atmosphere, friction would reduce their motion, turning a large part of it into heat and a part into forward movement of the sun's atmosphere. Thus the planetesimal hypothesis explains the equatorial acceleration. A large meteoric group, as suggested by Turner, is therefore consistent with the hypothesis. The undefined zone between the accelerated equator and the 
slower-moving latitudes on each side would present much mechanical disturbance and favor the formation of local vortices. Such a process as this would be accompanied by the increased radiation in sunspot maximum which has been observed. If this hypothesis has a basis of fact, it is probable that the increased radiation at that time would come from the sun's equator, where there are no spots. Increased rotational movement of the equatorial zone at the sunspot maximum should be susceptible of observation by spectroscopic means. The meaning of the slow movement of this spot-forming zone toward the equator, as sunspot maximum changes to minimum, is not clear under this hypothesis; nor does one see why the secondary spot described by Hale (1919) should have its definite location following the principal spot, nor why the magnetic polarity of spots changed near the last sunspot minimum. These phenomena, recently observed by Hale and his collaborators, point toward causes within the sun.

Length of the sunspot period.-For many years Newcomb's figure of 11.13 years has been commonly quoted. However, recently some of the best authorities say frankly that it may be anywhere from 11 years to nearly 12 years. Schuster (1898-1906) discussed analytically the best known sunspot numbers, those since 1750. This has been followed by the work of Kimura (1913), and especially Turner (1913) and Michelson (1913). In general, the analyses by Schuster and Kimura, and by Turner in his earlier papers, produce a large number of possible periods of small amplitude. Michelson, however, goes to the other extreme. "Indeed," he says, "it would seem that with the exception of the 11-year period and possibly a very long period (of the order of 100 years) the many periods found by previous investigators are illusory." Turner in his hypothesis referred to above reduces the number to a few, which supply a basis for his reasoning. Michelson had favored a period of about 11.4 years and Turner says that only this 11.4-year period is sensible at the present time.

Tree-growth and solar activity.-The correlation shown in this chapter suggests a possible use of the annual rings of trees in the study of solar activity. There are two lines which such a study might take. An intensive line already mentioned includes the search for wet-climate trees showing the solar rhythm in their growth and the determination of the conditions under which they produce this curve. An extensive line of study is obviously possible also in reconstructing, as far as possible, a history of the sunspot cycle from very old trees. The yellow pines of Arizona give evidence that 500 years ago the cycle was operating very much as now. The sequoias, if correctly interpreted, already carry the history back over 3,000 years, and beyond that fossil trees may stretch the time covered in part at least into millions of years. 


\section{METHODS OF PERIODIC ANALYSIS.}

Need for such analysis.-During these modern times of rainfall and sunspot records we may compare such records with tree-growth and obtain the interesting correlations exhibited in the last two chapters; but the tree records extend centuries and even thousands of years back of the first systematic weather or sun records of any kind. Without being over-precise or exhaustive, it is interesting to note that California weather records began about 1851. Records on the Atlantic coast began largely in the half-century before that date. London has a rainfall record since 1726, Paris since 1690, and Padua since 1725 . Good sunspot records began about 1750 , but the number of maxima and minima is known between 1610 and 1750 , although the exact dates are uncertain. All this does not carry us very far back, but it serves as an excellent basis for the correct interpretation of the record in the trees.

It would be possible to apply correlation formulas to the Arizona tree records and perhaps to the sequoias and construct a probable rainfall record for long periods of time, but apart from Huntington's study of the "Climatic Factor in History," the chief use of such a record would be in studying the laws which govern rainfall; and this is best done through cycles. We shall find that the sunspot cycle plays an important rôle in rainfall. But we find traces of the solar cycle in nearly all of our tree groups, and evidently the way to read the trees is to study first of all their alphabet of cycles. Hence the best methods of identifying cycles must be used.

Proportional dividers.-If a short series of observations is to be tested for a single period, it can be done by mathematics, but it will take many hours and give a result in terms so precise as often to deceive. This, for example, has been the difficulty with the mathematical solution of the sunspot curve. It seems to the writer that the safer way to solve such a curve is by a graphic process, plotting the curve and applying equal intervals along it. An extremely good instrument for this purpose is the multiple-point proportional dividers. By a system of pivots and bars, 16 or more points are maintained in a straight line and at equal intervals, while the space between two successive points may be drawn out from one-eighth inch to one inch. The remarkable persistence of the half sunspot period in the early Flagstaff trees was detected in this way.

The projection of equal spacing on curves as long as 12 to 15 feet has been done by a 10-foot india-rubber band with small metal clips pinched on at regular intervals. As the band was stretched all the intervals were enlarged by equal amounts, and periodic phenomena were detected. Similar use could be made of the sharp shadows cast by the glowing carbon of an arc-light. The shadow of a transparent 
scale could easily be cast in all sizes upon a plotted curve. But all these methods of equal spacing on a plotted curve leave far too much to the individual judgment of the investigator.

\section{THE OPTICAL PERIODOGRAPH.}

A method of periodic analysis well adapted to the work in hand has been developed by the writer as the need for it became more and more evident. Along with the feeling of need for rapid analysis was the increasing recognition of the desirability of some process which would place mere individual judgment and personal equation as far in the background as possible.

Schuster's periodogram.-In 1898, Schuster suggested the use of the word "periodogram" as analogous to the word spectrogram; that is, a periodogram is a curve or a photograph which indicates the intensity of time periods just as the spectrogram indicates intensity of spaceperiods or wave-lengths. The spectrogram commonly gives its intensities by varying photographic density along a band of progressive wave-lengths. For the periodogram Schuster made simply a plotted curve, of which the abscissæ represented progressive time-periods and the ordinates represented intensities. He made a mathematical analysis of the sunspot numbers and constructed a periodogram which is reproduced in figure 30 . It shows periods at its crest at $4.38,4.80$, $8.36,11.125$, and 13.50 years.

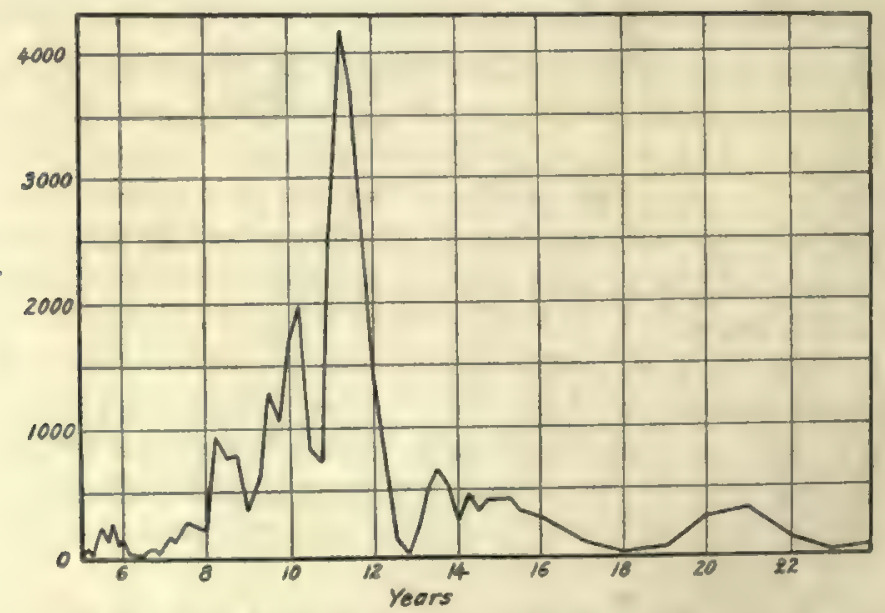

Fre. 30.-Schuster's periodogram of the sunspot numbers.

The optical periodogram.--It is, of course, not necessary that the periodogram should take the form of a plotted curve with intensities represented by ordinates, nor yet need it be exactly like a spectrogram showing intensities by density. The first periodogram produced by the writer is shown in plate $9, \mathbf{A}$. It is an analysis of the sunspot num- 
bers from 1755 to 1911 . The existence of a rhythm in any specified period is indicated by a beaded or corrugated effect. A line across the corrugations gives in fact the rhythmic vibrations of the cycle. On a moment's examination this periodogram shows much of the information which has been under discussion for many years. The 11-year period is the most pronounced, but it is not so superior to all others as would be expected. It may be of any duration from 11.0 to 11.8 years, but 11.4 is a good average. There is obviously a period somewhere between 9.5 and 10.5 years and one between 8.0 and 8.8 , but it is less conspicuous. Faint indications of periods are found near 14 years. The double of 8.4 is seen between 16 and 17 years. The double of the 10-year period shows near the 20 and at 22 the double of the 11 begins.

The preliminary part of producing this periodogram is the construction of the "differential pattern" shown in plate 9 , B. This pattern is the optical counterpart of a set of columns of numbers arranged for addition, as when one summates a series of annual measures on a 10-year period, for example. The series is arranged in order with the first 10 years in the first line, the second 10 in the second line, and so on. In the case of the pattern the lines are made indefinitely long, so that the optical addition may be done in other directions than merely straight downward, for by making the additions on a slant a different period comes under test.

In order to produce this pattern the sunspot curve was cut out in white paper and pasted in multiple on a black background. The left end of each of the upper lines is the date 1755. Each successive line is moved 10 years to the left, so that passing from above vertically downward each line represents a date 10 years later than its predecessor. This continues from 1755 to 1911, and the lower 10 lines show the latter date at their right ends. It is not necessary that any of the lines should be full length, as we use only a part of each. By passing the eye downward from the top, a period near 10 years will show itself at once by a succession of crests in vertical alinement. If the crests form a line at some angle to the vertical, then the period they indicate is not exactly 10 years. It is more if the slant is to the right and less if to the left. The horizontal lines are spaced the equivalent of 5 years. Hence, if we measure the angle made between a vertical line and a line joining two crests in successive horizontal lines, we may easily calculate by simple formulas the period indicated.

Since the photometric values of all the curves in the diagram are proportional to the plotted ordinates, the photographic summation of the whole pattern in a vertical direction is almost an exact analogue of a numerical summation. This summation is simply done by a positive cylindrical lens with vertical axis. This brings down on the plate a series of vertical lines or stripes. If, now, we cut across these lines with a horizontal slit, the light coming through this slit from one end to the other will be the summation of the diagram in the vertical. 
But the photographic summation may be done at any slant instead of only in the vertical, and therefore the sensitive plate may be made to summate these curves through a long range of periods. In order to get a long range of periods, the diagram was mounted on an axis with clock-work and slowly rotated in front of a camera with a cylindrical lens for objective, a horizontal slit in the focal plane, and a sensitive plate passing slowly downward across the slit by clock mechanism. In this way a full range of possible periods come under the summing process, and when a real period is vertical the crests of the curves form vertical lines which come down as a series of dots or beads in the slit. When no period is in the vertical the light coming through the slit is uniform. Of course, there is a practical limit to the different angles at which the diagram may be viewed. An angle too far in one direction, making the tested period very small, would require a great number of duplications of the curve, while too great an angle the other way, making the tested period very large, catches the curve in the nonsymmetrical form and introduces errors. In the periodograms actually made of the sunspot curve the minimum period tested was 7 years and the maximum 24. One notes especially that this is a continuous process and that all periods from the minimum to the maximum are tested.

Application to length of sunspot period.-The interest in the sunspot period makes a special consideration of plate 9 , c, worth while. This figure is a photograph of plate $9, \mathbf{B}$, taken out of focus for the purpose of calling attention to certain general features. In $\mathrm{B}$ the eye naturally turns to the sharp outlines and notes its minute details. In C the crests of $\mathbf{B}$ are changed into large blotches connecting somewhat with their nearest neighbors and varying in intensity. The alinement which they form in a nearly vertical direction is a graphic representation of the period. If the line were exactly vertical the period would be 10 years. The slant to the right shows more than 11 . If the line were straight the period would be constant. It is evident that there are several irregularities in it. Having a number of exactly similar lines side by side, the irregularities are repeated in each and thus strike the consciousness with the effect of repeated blows. These irregularities are the discontinuities referred to by Turner in connection with his hypothesis. It is evident at a glance that the sunspot sequence divides itself into three parts, namely, a 9.3-year period, 1750-1790; then an interval of readjustment, 1800-1830, with a 13-year period; and lastly an 11.4-year period lasting to the present time (values approximate). ${ }^{1}$ But the latter is not perfectly constant, for after 1870 there is a change in intensity. The breaks thus shown and Turner's dates of discontinuity are compared in table 6.

In discussing the periodicities of sunspots (1906\%, pp. 75-78) Schuster divided his 150 years, from 1750 to 1900 , into two nearly equal parts. He found in the first part two periods of 9.25 and 13.75 years acting successively, and in the second part, a period of 11.1 years. 

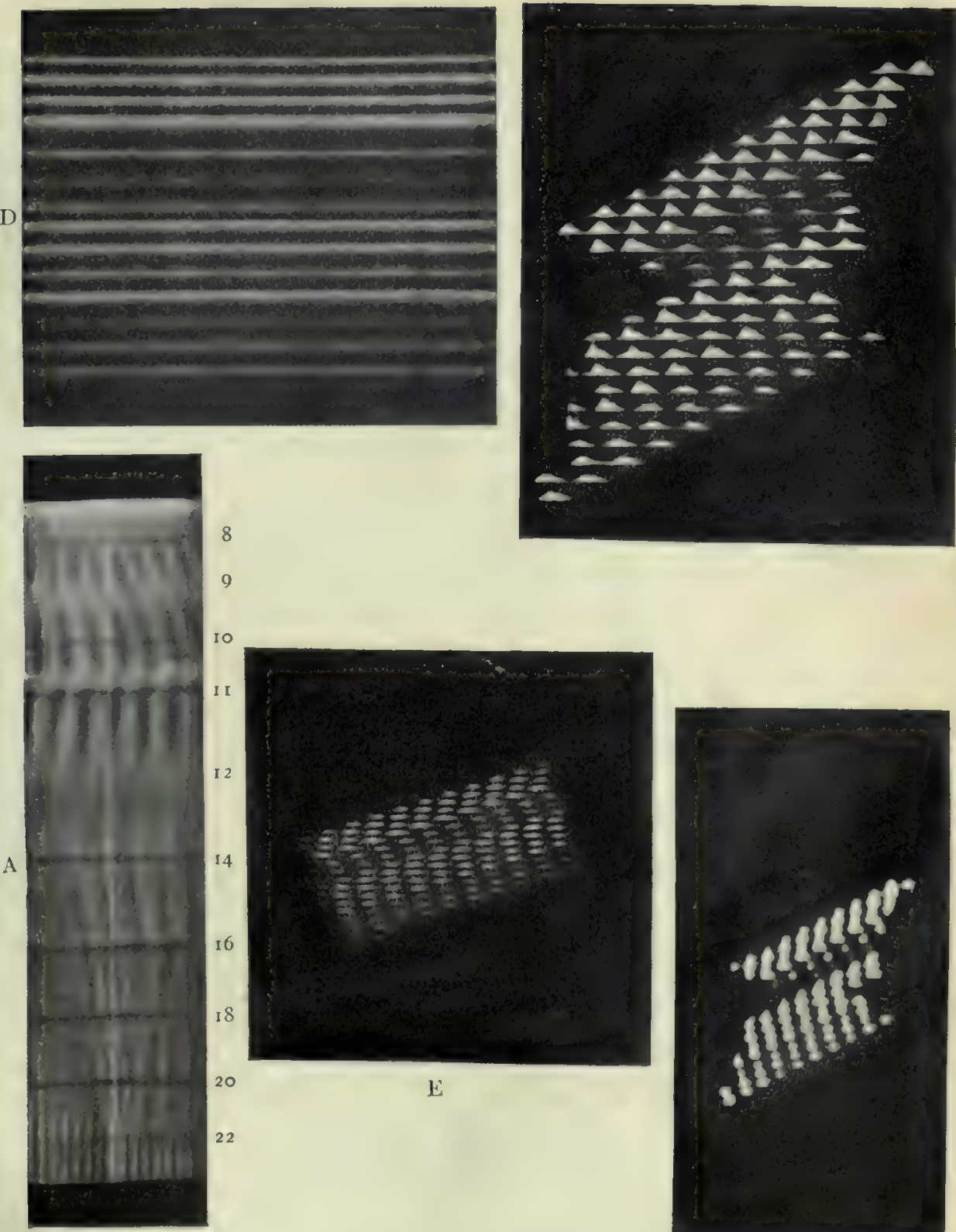

\section{8}

9

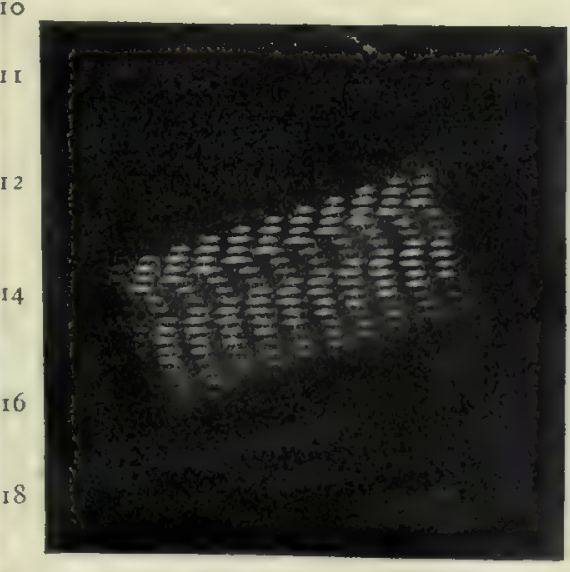

$\mathrm{E}$

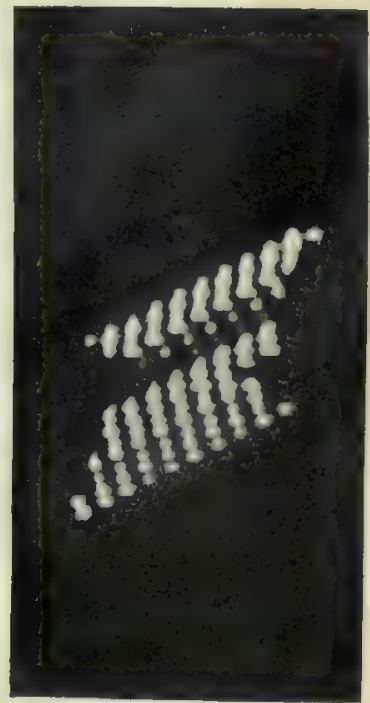

A. Periodogram of the sunspot numbers, 1755-1911. Corrugations show periods. The numbers give length of period in years. The white line is the year 1830 and shows phase.

B. Differential pattern used in making the periodogram, consisting of the sunspot curve mounted in multiple.

C. Sime pattern photographed out of focus to show discontinuities in the vertical lines.

D. Sweep of sunspot numbers, 1755-1911.

E. Differential pattern of sunspot numbers made by the periorlograph process. 

By means of this diagram one can discover at a glance the origin of many of the periods which Michelson thought were illusory and in which opinion he was largely right. We can plainly see a 9.3-year period in the early part of the curve. Let us call this part of the sequence $A_{n}$ and its broken continuation near the center $B_{n}$ and the lower and later part giving the 11.4-year period $C_{n}$. Thus we get at once three periods, $9.3,11.4$, and something over 13 years. If, now, we bring the average $A_{n}$ into line with the average $C_{n}$ as the periodograph does, we

TABLE 6.-Discontinuities in the sunspot cycle.

\begin{tabular}{|c|c|}
\hline Periodogram. & Turner. \\
\hline & 1766 \\
Between 1788 and 1804. & 1796 \\
Between 1830 and 1837. & 1838 \\
Between 1870 and 1884. & 1868 \\
& 1895 \\
\hline
\end{tabular}
get 11.4 years. If we bring the average $A_{n}$ into line with the $C_{n-1}$, we get close to 10 years. If we bring into line $A_{n}$ and the heavier parts of $C_{n-2}$, we get 8.4 years or thereabouts. And at 5.6 years we find a period which is just half of $C_{n}$ and at 4.7 the half of $A_{n}$, and so on. It is like a checker-board of trees in an orchard; they line up in many directions with attractive intensity. But plate $9, \mathrm{c}$, helps remove some of the complexity of the sunspot problem. It shows us that while these various periods are apparent, they are improbable and needless complications. The diagram supplies a basis for profitable judgment in the matter. Hence to avoid just such awkward cases as the sunspot curve, a differential pattern is considered to be a necessary accompaniment of the periodogram in doubtful cases.

Production of differential pattern.-The work described above, consisting particularly in the production of a periodogram from the differential pattern, was done at Harvard College Observatory in 1913. The next fundamental improvement in the apparatus was in 1914, and consisted in a method of producing the differential pattern without all the labor of cutting out the curves. It was simply the combination of a certain kind of focal image called a "sweep" and an analyzing plate. A single white or transparent curve on a black background is all that is now needed as a source of light. An image of this is formed by a positive cylindrical lens with vertical axis. In the focal plane image so produced each crest of the curve is represented by a vertical line or stripe and the whole collection of vertical lines looks as if it has been swept with a brush unevenly filled with paint and producing heavy and faint parallel lines. Each of these lines represents in its brightness the ordinate of the corresponding crest. The sweep of the sunspot numbers is shown in plate 9, D. Any straight line whatever in any direction across this sweep truly represents the original curve, not as a rising and falling line but in varying light-intensity. A plate with equally spaced parallel opaque lines, called the analyzer or analyzing plate, is placed in the plane of this sweep. These lines may be seen in 
plate 9, E. When the analyzer is furned at a small angle to the lines of the sweep, each transparent line shows the full curve or a substantial part of it in its varying light intensities. 'These numerous reproductions are all parallel to each other, separated by equal dark lines, and each one is displaced longitudinally with reference to its neighbors, thus presenting the characteristics of the differential pattern. By twisting the analyzer with reference to the sweep while the two remain in parallel planes, different periods may be tested; for as the analyzer twists, each reproduction varies in respect to its length and its displacement from its adjoining neighbors above and below. When a period is formed it shows itself, just as in the original differential pattern, by rows of dark and light spots in alinement more or less perpendicular to the analyzing lines, as in plate 9 , в. These light and dark rows are analogous to interference fringes and are identical with the elaborate but provokingly useless designs on a wire screen in front of its reflection in a window, or with the parallel fringes when two sets of parallel lines are held at a slight inclination to each other. ${ }^{1}$ Alinements are always best recognized by holding the paper edgewise and looking at the diagram at a low angle rather than in a perpendicular direction.

The analyzing plate resembles a coarse grating with equally spaced parallel lines. Much difficulty was experienced in making it. It is most satisfactory if made on glass with strong contrast between the opaque and transparent parts. The grating now in use was produced by photographing a 10-foot sheet of coordinate paper upon which 165 lines of black gummed paper had been carefully fastened. The coordinate lines permitted the spacing to be done with exactness. The width of the transparent space throughout was three-tenths of the distance from center to center. This was carefully photographed by a good lens at different distances. Glass prints were made from each negative and are still in use. ${ }^{2}$

Theory.-The formula for the period is very simple:

Let $y=$ length of curve in years or other time-unit employed.

$l=$ length of curve image across sweep lines in centimeter or other unit of length.

$8=$ spacing center to center of analyzing lines in unit of length.

Then $\frac{l}{s}=$ number of analyzing lines in curve when lines are parallel to

$\frac{y 8}{l}=$ number of years in 1 line when lines are parallel to sweep.

\footnotetext{
1 Roever (1914), has used somewhat similar interference patterns to illustrate very beautif .lly certain lines of force.

A very superior analyzing plate has recently been made from a ruled screon such as is commonly employed in half-tone engraving.
} 
Now, taking analyzing lines $\overline{a a^{1}}$ and $\overline{b b^{1}}$ in figure 31 as horizontal, and letting the sweep be inclined as a small angle $\delta$ with the analyzing lines, the number of lines required to cross the sweep in the direction $a b$ perpendicular to analyzing lines will be increased and hence the value in years between two analyzing lines will be decreased; hence

$$
\frac{y s}{l} \cos \delta=\text { years per line from } a \text { to } b \text {. }
$$

If the fringe is perpendicular to the analyzing lines, its period is the distance $\overline{a b}$ in years and we have for this special case:

$$
p_{1}=\frac{y s}{l} \cos \delta \text {. }
$$

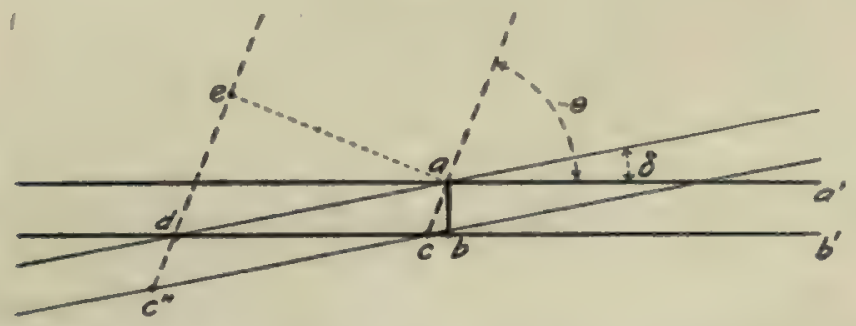

Fro. 31.-Diagram of theory of differential pattern in periodograph analysis.

If, however, the fringe takes some other slant, as the direction $\overline{a c}$, making the angle $\theta$ with the analyzing lines, then the period desired is the time in years between $a$ and $c$. That equals the time between $a$ and $b$ less the time from $b$ to $c$. Now $\overline{b c}$ in years would equal $\overline{a b} \cot \theta$ except for the fact that the horizontal scale along $\overline{b c}$ is greater than the vertical scale along $\overline{a b}$ in the ratio $\frac{\cos \delta}{\sin \delta}$ and therefore a definite space interval along it means fewer years in the ratio of $\frac{\sin \delta}{\cos \delta}$. Hence we have:

or

$$
\overrightarrow{b c} \text { (in years) }=\overline{a b} \text { (in years) } \tan \delta \cot \theta
$$

$$
P=p_{1}(1-\tan \delta \cot \theta)
$$

which is the period required.

The separation of the fringes needs to be known at times in order to find whether one or more actual cycles are appearing in the period under test. In figure 31

$$
\overline{a b}=8 \quad \overline{a d}=\frac{8}{\sin \delta} \quad \overline{a e}=\frac{s \sin (\theta-\delta)}{\sin \delta}
$$

which is the width required. 


\section{THE AUTOMATIC OPTICAL PERIODOGRAPH.}

The present apparatus combines the two processes whose development has been described above. The second process developed is really the first one in the present instrument.

The curve.-The curve is prepared by cutting it out in a thick coordinate paper. The space between the curved line and the base is entirely removed and the curve becomes represented by area. In order to make the density still greater, the paper is painted with an opaque paint so that the brilliant light passing through will come through only the curve itself and not the paper. A special windowshutter is made to occupy the lower 2 feet of the window, whose width is some 50 inches. The curtain can be drawn down to the top of this, excluding the light around the edges. This window-shutter has a door in the upper part to give access to the interior. Within this box is a sloping platform upon which a mirror 8 by 46 inches is placed. This mirror is about $35^{\circ}$ from the horizontal position and when looked at from a horizontal direction it reflects the sky from near the zenith. On the side of this box toward the room is a slit 45 by 3 inches in size. This extends horizontally and is on a level with the mirror. Below this slit is a narrow groove for taking the lower edge of the curve paper and above this slit is a strip of wood on hinges, so that when the lower edge of the curve is placed in the narrow groove below, this hinged strip closes down on the top and holds the curve in place directly in front of the mirror. Looked at from a horizontal direction within the room, the curve is seen brightly illuminated by light from the sky not far from overhead.

Track and moving mechanism.-About 7 feet from the curve the track begins and extends back 45 feet in a perpendicular direction. The track consists of 3 rails. The center rail is of uniform height and takes the single rear wheel, whose motion controls the movement of the film at the back of the camera. The right-hand rail is also uniform in height and supports one of the front wheels. The left rail is variable in height and supports the driving-cone, which serves as the other front wheel. The cone is 6 inches long and 3 inches in greatest diameter. It rests on a side rail whose elevation and distance from the center can be altered. The purpose of this particular mechanism is to vary the speed with which the camera travels along the track, for the time of exposure is approximately proportional to the square of the distance from the curve, and therefore when the camera travels from the near position to the far position it must slow down in rate as it goes along. The left rail, therefore, at the near position is close to the center and low down; in the middle and outer parts of the track it gets farther away and higher up, since the parts of the cone near the vertex travel on it. The axis of the cone carries a bevel gear meshing with another 
bevel attached to a vertical axis with a worm gear at the top, which the electric motor drives with a belt connection. In order to aid the motion of the camera, a cord passes from its back to the outer end of the track and by a system of pulleys and weights exerts a slight constant force. The motor is so connected that the camera travels away from the curve. The details here described may be seen in plate 10.

The differential pattern mechanism.-The camera is divided into three separate compartments, to each of which access is obtained by a sliding door moving in grooves on the side. The front compartment produces the differential pattern. It is about 7 inches long by 5 inches wide in the clear and 4 inches high. It is nearly divided into two parts by a partition which comes down from the top at about 2 inches from the front end. This partition does not go down to the floor of the compartment, but leaves a space of about an inch. A hole 1.5 inches in diameter is cut through the front of this compartment a little above its center, and another hole of the same size to match is cut through this partition, while at the back of this compartment a large opening is made a little over 2.5 inches wide and about 2 inches high. The lens is carried on a special carriage consisting of a horizontal and a vertical part. The vertical piece has a hole 1.5 inches in diameter cut in it, and the lens is mounted over the hole. The lens now in use consists of a spherical lens concavo-convex 2 inches in diameter and 12 inches in focus placed on the inside, and a positive cylindrical lens of the same size and focus placed on the outside with axis vertical. The convex side of each lens is placed outward. The lens carriage is placed partly under the partial partition and the lens in its holder comes directly between the two holes mentioned. When the sliding door of the compartment is down, the compartment is sufficiently light-tight to fulfill all the requirements of a camera. The movable carriage of the lens is mounted on two small glass tubes and runs between guides. A spring at its back end pulls it toward the position of focus for distant objects, where its motion is stopped by a pin. A long screw is passed through a hole in the bottom of the camera box and enters the bottom of this lens carriage, so that an automatic arrangement outside and underneath the camera can regulate the focus. This consists of a vertical axis with two lever arms. The upper lever arm is a short one connected to the screw which comes from the lens board. The lower lever arm is some 4 inches below the upper and goes off in a direction nearly at right angles; it carries on its end a wheel in a horizontal position. This wheel is so placed that it runs on an especially arranged track attached to the side of the center rail of the main track. By varying the elevation of this special focussing track in different parts of the main track, the focus of the lens can be automatically controlled.

At the back of this first compartment is the analyzing plate, the same plate used in previous work. The spacing of its lines is $0.5 \mathrm{~mm}$. from 
center to center. The proportionate transparent part is about threetenths of the center-to-center measurement. The area covered by these lines is 1 by 3 inches, making about 156 lines. The photograph is transparent with dense black lines in it. The glass has been cut down to a convenient size, and this plate is mounted at the back of the first compartment with the film side of the plate toward the back. This plate is over the large opening at the back of the first compartment. The differential pattern is formed automatically by the lens on this plate. The plate is held in a fixed position with its lines nearly vertical but inclined about $12^{\circ}$ to the lines of the sweep formed by the lens. This produces fringes more or less horizontal in direction. Varying periods are tested by changing the distance from the curve which alters the scale of the sweep while the analyzing lines are unchanged. As the scale of the sweep changes, the fringes appear to rotate about the center of the differential pattern. Immediately behind the analyzing plate are two condensing lenses described in the next topic. They bring the general beam of light to a focus about 6 inches back of the plate. For visual work a movable mirror, just back of the plate, reflects the beam outside the camera box, through an eyepiece to the eye. For photographic work a small total-reflection prism and simple lens are inserted about 5 inches back of the analyzing plate. These throw the beam outside into a special camera attachment in which ordinary films or plates may be used.

The periodogram mechanism.-The remainder of the camera is especially for the purpose of producing the periodogram from the differential pattern. Almost in contact with the analyzing plate is a condensing lens consisting of two cylindrical lenses about 2 inches in diameter and 6 inches focus; these are mounted with vertical axes and with their convex sides toward each other. The aperture of the condenser is about 0.75 inch in vertical height and 1.75 inches in length. The purpose of these condensers is to coverge the light which comes through the analyzing plate on the slit at the back. The second compartment is nearly the same size as the first, namely, about 6.5 inches long. At its front end is the analyzing plate with the condensers and at its back in the same optical axis is a vertical slit about 1 inch long and $1 \mathrm{~mm}$. wide. The sides of this slit are beveled so that the slit itself is at the back. In the middle of this compartment is a powerful cylindrical lens or combination of lenses with horizontal axis. This lens is made up of 4 separate positive cylindrical lenses, each 2 inches in diameter and 6 inches focus. These all have their convex sides toward the common center. They are mounted on a movable carriage of wood which slips in place or may be removed entirely. The aperture of this lens system is about 1.5 inches long by 0.75 inch high. The effect of the condensing lens and of this cylindrical lens is to cast in the plane of the slit an area of light whose size is essentially a repro- 


\section{DOUGLASS}
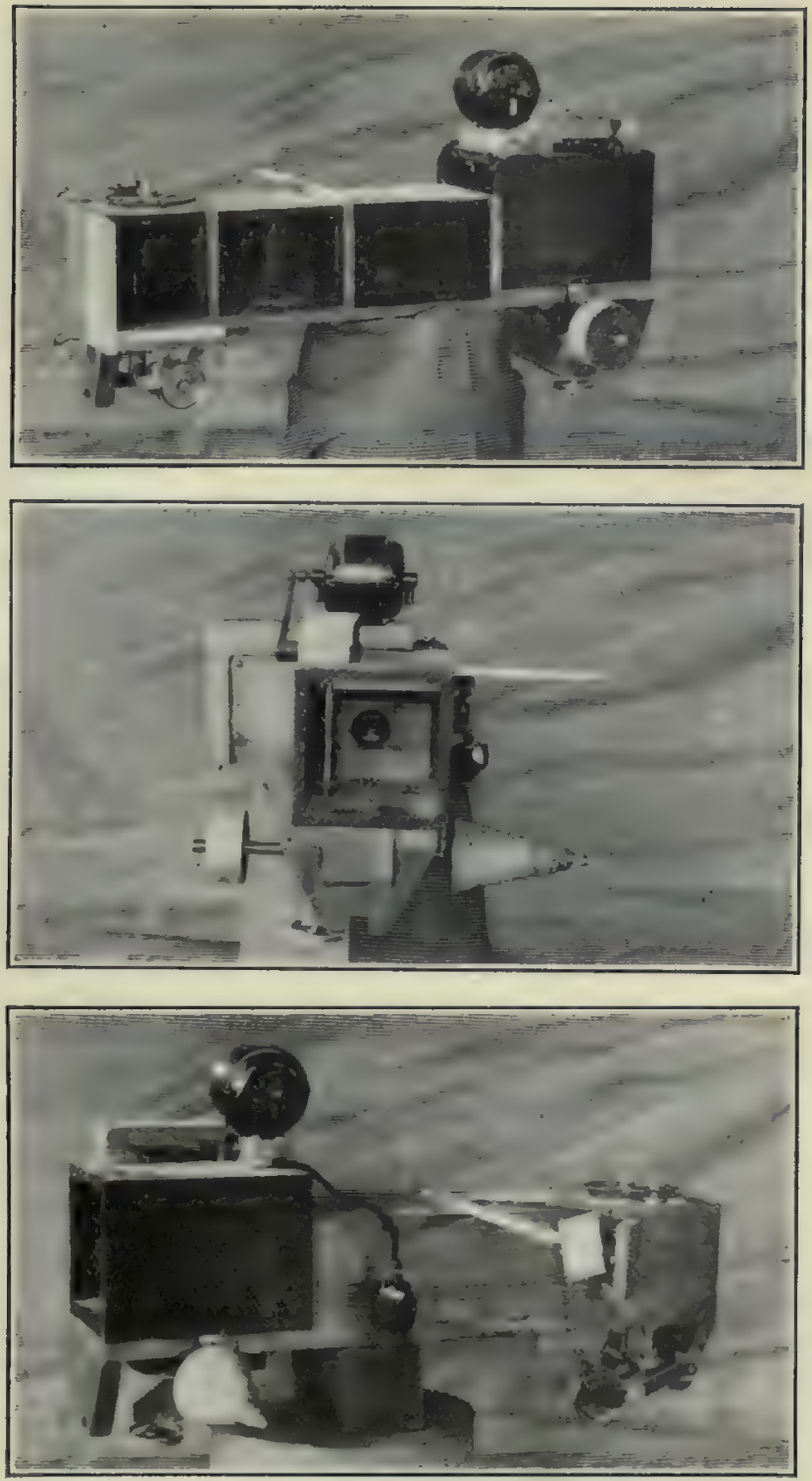

A.
PLATE 10

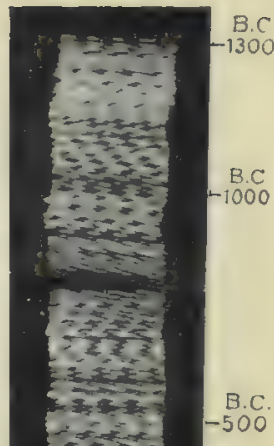

$-500$

$-0$

$A D$

$1,=2$

$-1=$

$y^{2}=$

$c+2$

Lis

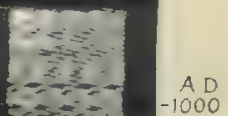

$=7=$

sty

के है

a $=$

$z=5$

$\therefore=$

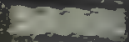

$25=3$

$2 \div$

C. 50.

$A D$

$-1500$

$-1$

$\Rightarrow$

$\cos x=1$

A.D.

$-1900$

A. The automatic optical periodograph.

B. Differential patterns of Sequoia record, 3200 years at 11.4 . 

duction of the aperture of the objective, namely, 1 inch high by 0.25 inch wide, but the detail in this area of light is brought in focus by the cylindrical lens and integrates the horizontal lines of the differential pattern. When, therefore, the differential pattern shows a series of horizontal fringes, they become reproduced by a series of horizontal lines crossing the slit, while in the slit itself they appear as a series of dots. When a period is disclosed by proper position of the camera, it will produce horizontal lines on the analyzing plate. A series of black and white dots, therefore, go through the slit into the final compartment; but when the distance is such that the lines on the differential pattern are at some slant, then, the integration carried into the slit being still horizontal, the illumination in the slit is uniform. In this way the beaded or corrugated effect in the slit indicates a period at that particular distance from the curve.

In order to read off periods directly in the final result without the necessity of making exact measures, an automatic signal or period indicator is introduced in this second compartment. Above the upper and lower ends of the slit are placed small pieces of mirror at $45^{\circ}$, and corresponding to these there are two small holes 0.25 inch in diameter in the side of the box. Outside of these holes again is a mirror at $45^{\circ}$ reflecting light from the curve in the window. So long as the holes are open, direct light from the curve is reflected by the two sets of mirrors through the slit on to the film beyond, as will be described. A shutter is placed over the outer holes in the box with a lever carried down to the vicinity of the central rail. On the end of the lever arm is a wheel. At proper intervals small pieces of wood are placed in the side of the track, so that as the wheel passes over them the shutter is opened and light passes to the mirrors and makes a dot or a line on each side of the film in the third compartment. In this way marks can be placed on the film independent of the periodogram, and yet they can be spaced exactly to represent the different periods tested. Special periods, for example 5 or 10 years, etc., are indicated by the extra length and density of the marks produced. These appear on the margins of the periodograms in plate 11 .

The final compartment at the rear contains a drum on a vertical axis which is slowly rotated as the whole mechanism moves along the track. The rear wheel resting on the center rail is connected by gearing to the drum, so that $1 \mathrm{~mm}$. on the drum represents $42.7 \mathrm{~mm}$. or 1.7 inches on the track. This makes a convenient length for the final periodogram. The drum can be detached, carried to a dark room to have a film pinned to its periphery, returned in a special light-tight box, and mounted on its axis for an exposure. The times of exposure depend on characteristics of the curve under test, but it is necessary to allow about 35 minutes for the range from 4 to 15 years, and several times that for the range from 15 to 25 years. Plates 10,11 , and 12 illustrate the apparatus and the periodic analysis produced. 
Periodograms.-Plate 11, which has been arranged to illustrate the work of the periodograph, shows several of the early periodograms which are comparatively free from obvious instrumental defects. In each the range of periods is marked on the left margin. Periods are indicated by the vertical band or ribbon breaking up into a series of horizontal dots or beads. For example, plate 11, $\mathrm{A}$, is a periodogram of the 5-year standard period made for the purpose of calibrating the work of the periodograph. The 5-year period is very prominent near the top of the diagram in the plate. At 10 years its first harmonic appears with double crest, showing still that it is a 5-year period. At 15 years the second harmonic shows with a triple crest, and at 7.5 years the $3 / 2$ overtone is evident with $3 / 2$ crests. These overtones are always readily distinguished from the fundamental on the differential pattern. The differential pattern of this 5-year standard is shown in plate $12, Q$. The instrument is set for analysis at 5.0 years. In this position the integrating lens sums up the rows of light crests as a series of dots on the periodogram.

Plate 11, B, is the analysis of a mixed standard used for calibrating the instrument. The curve contains sharp triangular crests at intervals representing periods of $7,9,11,13$, and 17 years, all mixed together and no two starting intentionally from the same point. These are all separated in the periodogram and the overtones of some may be seen. Such overtones can be distinguished from the fundamental on the differential pattern.

Plate 11, c, gives a periodogram of the sunspot numbers from 1610 to 1910 , using before 1750 the probable times of maxima suggested by Wolfer. The best period is at 11.1 as usually quoted. If the variation from 1750 only is taken, the best period comes at 11.4. This periodogram shows a period at about 8.6. The degree of accuracy with which one can pick out the periodic point is a real criterion of the accuracy of the result selected. The differential pattern of this same series of sunspot numbers will be found in plate $12, \mathrm{~A}$, in which the vertical rows of crests are readily distinguished. The sudden change in direction of the lines a little below the center of this and the two following periodograms is an instrumental defect due to slight unevenness in the track and therefore is without significance.

Plate 11, D and E, give an analysis of the Arizona 500-year record. The chief points of interest are the well-defined double-crested 11.6year period and the 19-year and 22-year periods. Other weaker periods may be seen from place to place.

Resolving power of the periodograph.-The accuracy with which a period can be determined by the periodograph may be readily observed in the differential pattern and the periodogram. The pattern indicates a period by showing a row of light spots or crests in line. The accuracy 


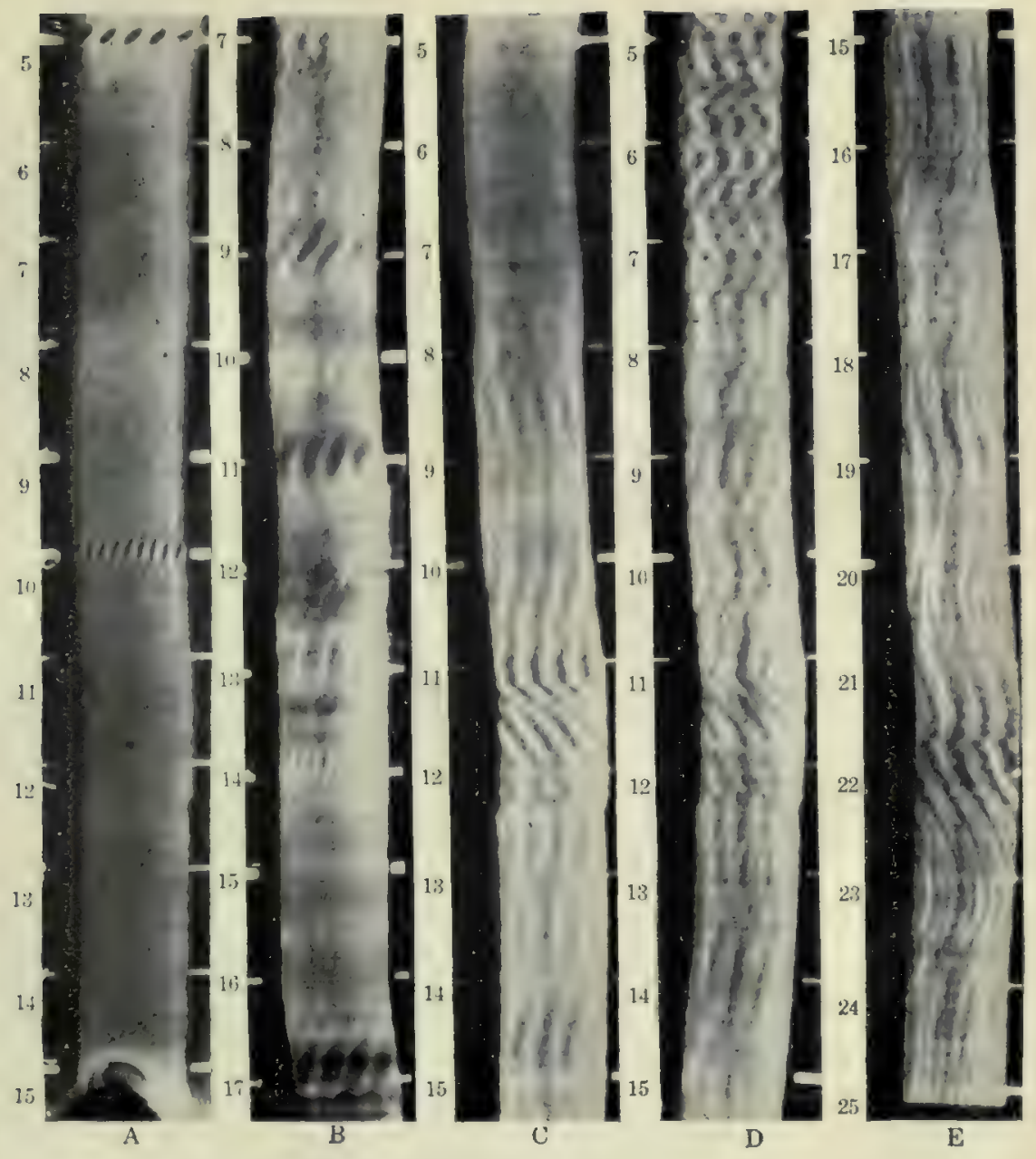
A. Periodogram of standard 5-year period.
B. Periodogram of mixed periods.
C. Periodogram of sunspot numbers, 1610-1910.
D. Periodogram of Flagstaff 500-year record, to show eycles between 4 and 15 years of length.
E. Periodogram of same continued to 25 years. 

of the period is the accuracy with which the direction of this line can be ascertained. This depends on the length of the row of crests, on the shortness of each crest, and on their individual regularity or alinement. These characteristics may be noted in the plates and especially in plate 12, Q. Expressed in other terms, these resolving features are respectively as follows: (1) Number of cycles covered by the given curve. (2) Shortness of maxima in relation to length of cycle; if the maximum is sudden and sharp, as in rainfall, the accuracy may be very great; if the maximum is long, as in a sine curve, the accuracy is less. (3) Regularity in the maxima and freedom from interference. These features all appear in the differential pattern and hence the accuracy of any period is its most evident feature and all observers can judge it equally well. It is exactly analogous to the accuracy of a straight line passed through a series of plotted points which theoretically ought to form a straight line but which do not do so exactly.

The most important part of the constructed instrument which may alter the accuracy of analysis is the analyzing plate. The accurate spacing and parallelism of the lines is a mechanical feature and can be produced with care and attention to details, but the relation of width of transparent line to center-to-center spacing of the lines is a matter of judgment and the necessities of photography. As this relative width increases, the length of each crest in the pattern becomes longer and the row of crests becomes wider and less definite in direction. If the maxima in the curve under test are of the sine-curve type this relation is less important, for the light crests in the pattern will be long in any case, but for sharp, isolated maxima resolution is lost if the width of the transparent line is too great. In the instrument now constructed the ratio of transparent line to center-to-center spacing is $3: 10$, but a smaller ratio such as 1:10 could advantageously be used in certain cases if there is sufficient light to make photography easy.

The accuracy in reading a periodogram is at once apparent on its face. When the number of cycles is great as in plate 11, A, the rhythmic or beaded effect is short and very limited in extent, as in the 5-year period there indicated, and the period is accurately told. But if the number of cycles is reduced (as in plate 11, B or c) the periodic effect in the photograph extends over a greater range and its center can not be told with the same precision. The accuracy of estimation in the periodogram is therefore the actual accuracy of the result. 


\section{CYCLES.}

Significance of cycles.-It has already been stated that three characteristics were observed in the curves of tree-growth: (1) correlation with rainfall; (2) correlation with sunspots; (3) general periodic variation. In the first and second of these the trees are compared directly with existing records, but in the third the tree record is available over hundreds and even thousands of years during which no human observations were recorded. Thus, if previous inferences are correct, the trees may reasonably be expected to give us some knowledge of prehistoric conditions. In the first attempt to secure such knowledge, the method which promises the most certain results is the analysis of ring variations in terms of cycles.

Correlatively, the study of cycles is of special value in climatic investigations. Such studies are undertaken for the purpose of predicting the future. The basis of daily or short-distance prediction is found in the conditions existing about the country at a given moment and a knowledge of the usual movement of storm areas. A basis for long-distance prediction is now generally sought in climatic cycles. Such cycles may or may not be permanent. Perhaps they are nothing more enduring than a series of wave systems on a water surface. Yet for the navigator a knowledge of the existing system is important, and so for the purpose of weather prediction we need to know the nature of the pulsations actually operating, and each one should be studied minutely. For this purpose the very long tree records and their presumably fair accuracy seem especially advantageous, since they give us a range in centuries which the meteorological records, with few exceptions, give only in decades.

A special and rapid method of carrying on the study of cycles has been developed in the periodograph which has been used in checking fully all the results in the present chapter. But after its recent completion and trial the fact became clear to the writer that its real service will be in a complete and thorough examination of all curves obtained, in order to derive a quantitative statement of the extension in time and space shown by each cycle. This in itself is a long process. Moreover, preliminary analysis of many tree curves reveals a very complex system of short-period variations in the trees, some of evident significance and some of little-known value as yet. The study of this complex of short periods together with other problems naturally suggested in the course of the work is reserved for the future; we shall now touch upon a few of the most important results reached in the analyses already accomplished.

Predominant cycles.-With the understanding that the study of cycles is not yet complete, it may be stated at once that the more 
conspicuous and general cycles at once apparent in the trees are directly related to the solar period. They are as follows:

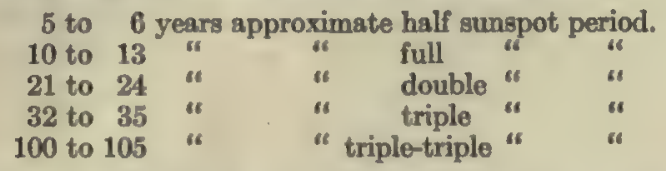

There are few if any periods over 20 years not in this list, but under 20 years several are fairly persistent, such as 19-, 14-, 10-, and 7-year periods. There is also a period of about 2 years which causes a frequent alternation of size in successive rings, giving a "see-saw" or "zig-zag" effect in the appearance of the curve. The discussion in this chapter, however, will be confined to the solar group of periods above listed and to a preliminary statement regarding the 2-year period. As the larger of these solar periods are very nearly simple multiples of the 11-year period, it is naturally suspected that they are or should be real multiples of the sunspot period. Hence I feel at liberty to speak of the "double sunspot period" or the "triple sunspot period" without committing myself to its exact length.

Locality and solar cycles.-Compared to the multitudes of meteorological districts about the world, the few isolated localities which have here been investigated seem very insignificant. The wet-climate trees near the Baltic Sea show variations following almost perfectly. the curve of sunspot numbers. The Scotch pines just south of the sea have had good care since they were planted about 90 years ago. This care has prevented the excessive competition between individuals which characterize natural forests, and perhaps for that reason they give this remarkable record of external conditions. The trees to the north of the Baltic include spruces as well as Scotch pines, and show the same reaction. Both these groups are in comparatively level country and far from mountains. The group of pines from the Swedish province of Dalarne show the 11-year period somewhat less clearly. They were nearer the backbone of mountains which extends down the Scandinavian peninsula. The older trees of this group show evidence of a triple sunspot period. The groups growing in the mountains and in the inner fjords of Norway show extensive variations and even reversals. Some of the individual trees exhibit the sunspot period very well, while some show it inverted and some divide it into two crests. The older trees show evidence of an inverted double period.

The trees near sea-level, both at Christiania and on the outer coast of Norway, return again to the 11-year period. The former do not cross-identify well and the latter show occasional variations, such as double-crested period, inversion, etc. Variations of this kind were noted in different radii of the same tree. The trees from the south of 
England show slight relation to the solar cycle. They show more prominently other variations, which, taken between 1870 and 1900 , may have given rise to Lockyer's 3.8-year period $(1905,1906)$. The full tree record becomes more accordant on a 3.5-year period. In this group there appears to be a slight relation to London rainfall of a direct character, that is, the growth is larger with increased rain. Naturally in such a well-cultivated region there may have been large differences due to treatment of the soil, drainage, and so forth. The other two European groups, one from Pilsen in Bohemia and one from the north slopes of the Alps in southern Bavaria, do not show consistent agreement with the solar variation. Yet the former shows a double sunspot period which is illustrated below.

Coming to the American continent, the Vermont group may also be considered as growing in a wet climate. It shows a very strong single-creasted solar period, but the maxima come 3 years early during the last century. During the preceding century, when the trees were younger, the tree maximum is only 1 year early. The rainfall in this region shows the solar period also, but it is roughly inverted with respect to the tree curve. The Oregon group must be considered as in the wet climate of the temperate zone. It is near the Pacific coast and has abundant rain or snow. The solar cycle is probably in it, but it is not so conspicuous as other short cycles. When these trees are summed up on the 11-year period, they show about 10 per cent total variation with maximum and minimum coinciding with the Vermont group and therefore anticipating the sunspot maximum by 3 years.

The sequoias grow farther south and experience the heavy precipitation of the temperate-zone winter combined with dry-climate summer conditions-that is, the summers are mostly clear, but have occasional sharp local showers, often with lightning The tree-growth shows a relation to the rainfall in the great valley below and therefore we could expect some similarity to the Arizona pines. This does exist, but the exact 11.4-year cycle shown in the pines is less evident in the sequoiss, though unmistakably there. The analysis of the long sequoia record will be shown below. In it several cycles between 7 and 15 years predominate in places. The 11-year period is plainly evident through most of the record and for some centuries is the predominant cycle, but for long periods other slightly differing cycles, such as 10 years, 12.6 years, or 13 years, are more evident. It is as yet impossible to say whether at these times there was a real change in the sunspot period, whether some subordinate period is operating in the sun, or whether only local conditions of some kind are the controlling factor.

The yellow pines of northern Arizona are dry-climate trees. They have a modified winter precipitation of the temperate zone. Spring and autumn have the complete dryness of the "horse latitudes," and the summers have the characteristic subtropical torrential thunder- 
storms. Rain is the controlling factor in these trees. The trees show a double-crested 11.4-year period through nearly all the 500 years of their record. This will be illustrated below. A 7-year period is also frequently observed, and the combination of the 7-year and 11-year periods may be the cause of these trees showing the double sunspot period prominently through most of their record by interfering to suppress alternate 11-year maxima. A triple sunspot period is very evident in the last 200 years, but is practically lost in the preceding 300 . The pines and sequoias agree in showing a long period of about 100 years. The record of the pines is not long enough to give it much precision, and 120 years fits it more nearly. The 3,200 years of the sequoias analyze best at 101 years.

Illustrations of cycles.-Two methods of illustrating cycles in the tree curves are used here. One is the usual method of showing the plotted curves together with another curve indicating the cycle, so that agreements and disagreements may be noted. To this method also belongs the integrated or summated curve, which shows the mean variation in the desired period. The other method is by aid of various periodograph diagrams. These diagrams may similarly be divided into the differential pattern, in which variations from the cycle at any time may be noted, and the periodogram proper, which gives roughly the mean form of the cycles in a considerable range of periods. This form of presentation, being new and yet carrying more information than the former, will be given with some explanation after the curves themselves have been shown.

The 11-year cycle.-Only two tree records, the yellow pine and the sequoia, extend back of the first telescopic observations of sunspots. It is of peculiar interest to see whether the trees which carry the rainfall record back so far with a comparatively high degree of accuracy show the same cycle. In nearly all parts of the yellow-pine curve there are suggestions of an 11-year cycle. By tracing this throughout the record, the period is found to have a lengtb of about 11.4 years, which is sufficiently close to the length of the sunspot cycle to be considered identical with it. This exact figure is not yet considered final, as future intensive study of the short-period variations in the trees may throw more light upon it. Taking 11.4 years as the probable length, the average total variation is found to be some 16 per cent of the mean growth. The period is generally double-crested with two well-developed maxima and minima, but they are rarely symmetrical. During the 120 years from 1410 to 1530 it shows most remarkable regularity. This feature, which was observed as soon as the smoothed curve was examined, is shown in figure 32 . The tree curve in this diagram has been reduced to departures from its own mean and smoothed by Hann's formula. The short period is immediately evident, even without the 5.7-year cycle plotted below. This bit of record in the yellow pines 
and the 90 years of record in the wet-climate Scotch pines near the Baltic Sea give the finest examples of rhythmic growth yet found in the trees.

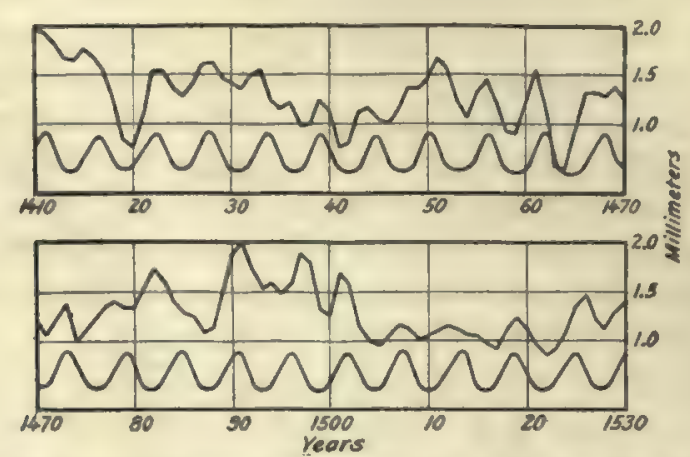

Fic. 32.-Smoothed curve of Arizona pines showing the half-sunspot period for 120 years.

In order to test for possible variations in the sunspot curve during these 500 years, the tree record from 1420 to 1909 has been divided into 8 periods of approximately 60 years each and the form of the 11-year period obtained in each. This is shown in figure 33. From this it appears that the 11-year cycle is not uniform throughout the whole 490 years covered by the curve. In general the cycle shows 2 maxima and 2 minima. From 1420 to 1660 the second minimum is generally the deeper. For the next 60 years the curve flattens out in a striking manner. From 1730 to 1790 the curve again shows variations, but they are not well related to this cycle. After 1790 there are again 2 minima, but on the whole the first is more conspicuous.

The 11-year cycle in sequoia.- The question of agreement between the sequoia and the yellow pine is a vital one. Although the sequoias grow in a locality some 450 miles distant, there is a similarity in the rainfall of the two places. Some attempt has been made to crossidentify the rings in the two groups, and the puzzling fact was revealed that from 1400 to about 1580 no certain identity could be found, though after that date it was evident in many places. The difficulty has been partly removed by applying this same method of analysis to the last 500 years of the sequoia. The result is shown in the dotted lines of figure 33 . It is evident that from 1420 to 1476 the second maximum of the pines is almost entirely lacking in the sequoias. The same is true of the interval from 1602 to 1658. The sequoias show strikingly the flattening of the curve from 1670 or 1680 to 1727 . In the remainder of the curves the sequoias show better rhythm in the sunspot cycle than do the pines.

Taking the evidence as a whole, it seems likely that the sunspot cycle has been operating since $1400 \mathrm{~A}$. D., with some possible interference for a considerable interval about the end of the seventeenth century. 
Correlation eurves.-Figure 34 is arranged to show certain relations of special interest in this connection. At the top was found the mean pine and sequoia curves for 490 years averaged on an 11.4-year period. Below these the mean 11.4-year period for the last 60-year interval is given for each tree. This is required for proper comparison with the short interval of climatic records. Next the rainfall and temperature observed on the southern California coast are plotted, and last of all the inverted sunspot curve for a corresponding period. There appears to be a marked relationship between these curves. Even the subordinate crest, which sometimes shows in the change from maximum to mini-

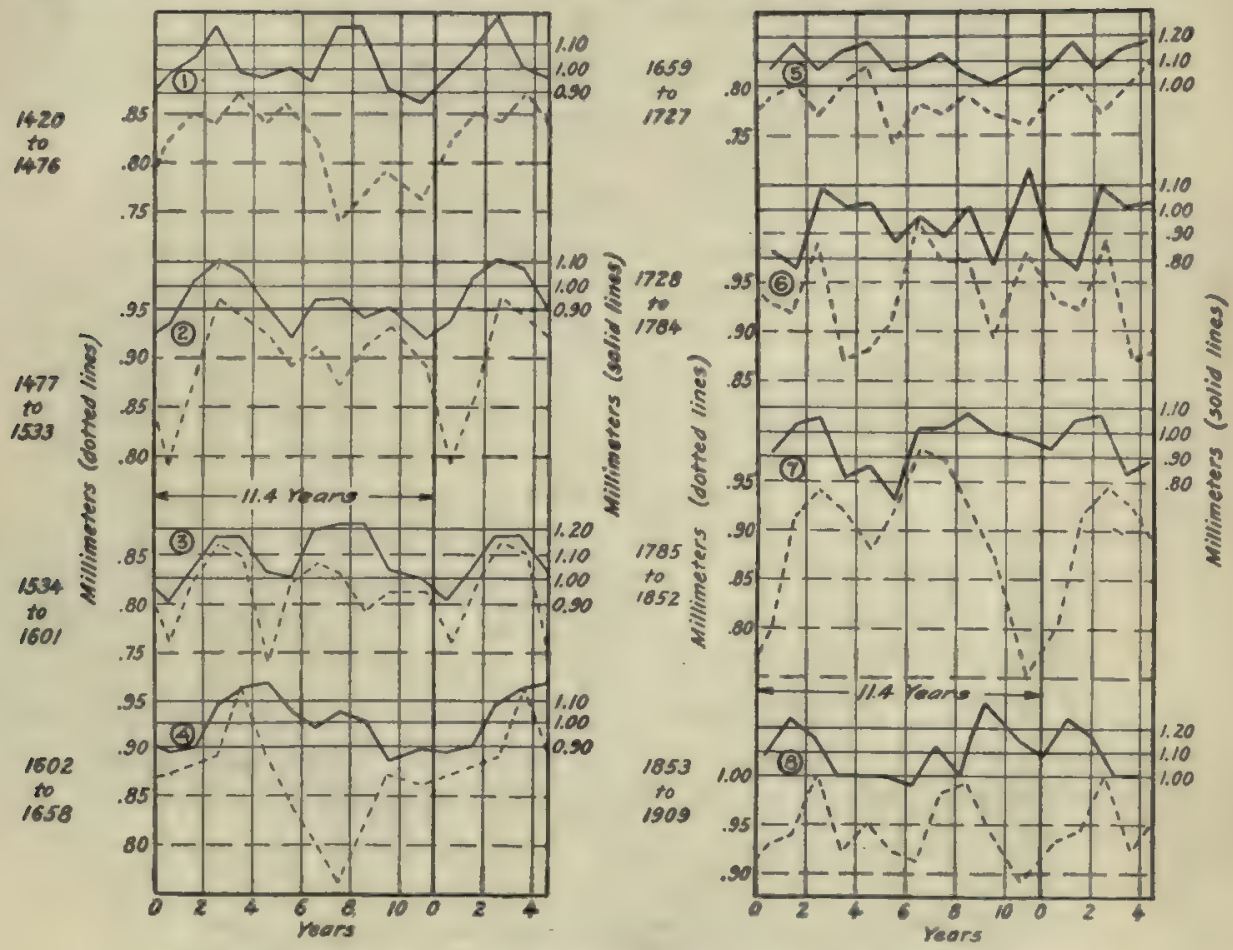

Fra. 33. - Changes in the 11-year period in 500 years. Solid line, Arizona pine; dotted line, sequois. ${ }^{1}$

mum of sunspots, matches the suppressed second crest of temperature and the full second crest of rainfall and tree-growth. This would seem impossible in the absence of a physical relation between them.

Double and triple eycles.-The first tabulation of the Arizona pines covered a period of only 200 years and included 25 trees. There were a few errors of identification in some of these trees, sufficient to flatten

\footnotetext{
1 The correction for the ring 1580 was made too late for insertion in this figure. The two dotted curves between 1420 and 1533 , therefore, should be moved one year to the left, while the third dotted curve between 1534 and $160 \mathrm{l}$ becomes slightly modified. A slight change in the first Arizons curve is required by a correction at 1463 A. D.
} 
the curve a little but not enough to change the pronounced fluctuations amply shown in recent analysis. This 200 -year record showed a very clear combination of the double and triple sun-spot periods. This was illustrated at the time in a drawing which is largely reproduced in figure 35. Curve No. 1 is a triple solar cycle 32.8 years in length;

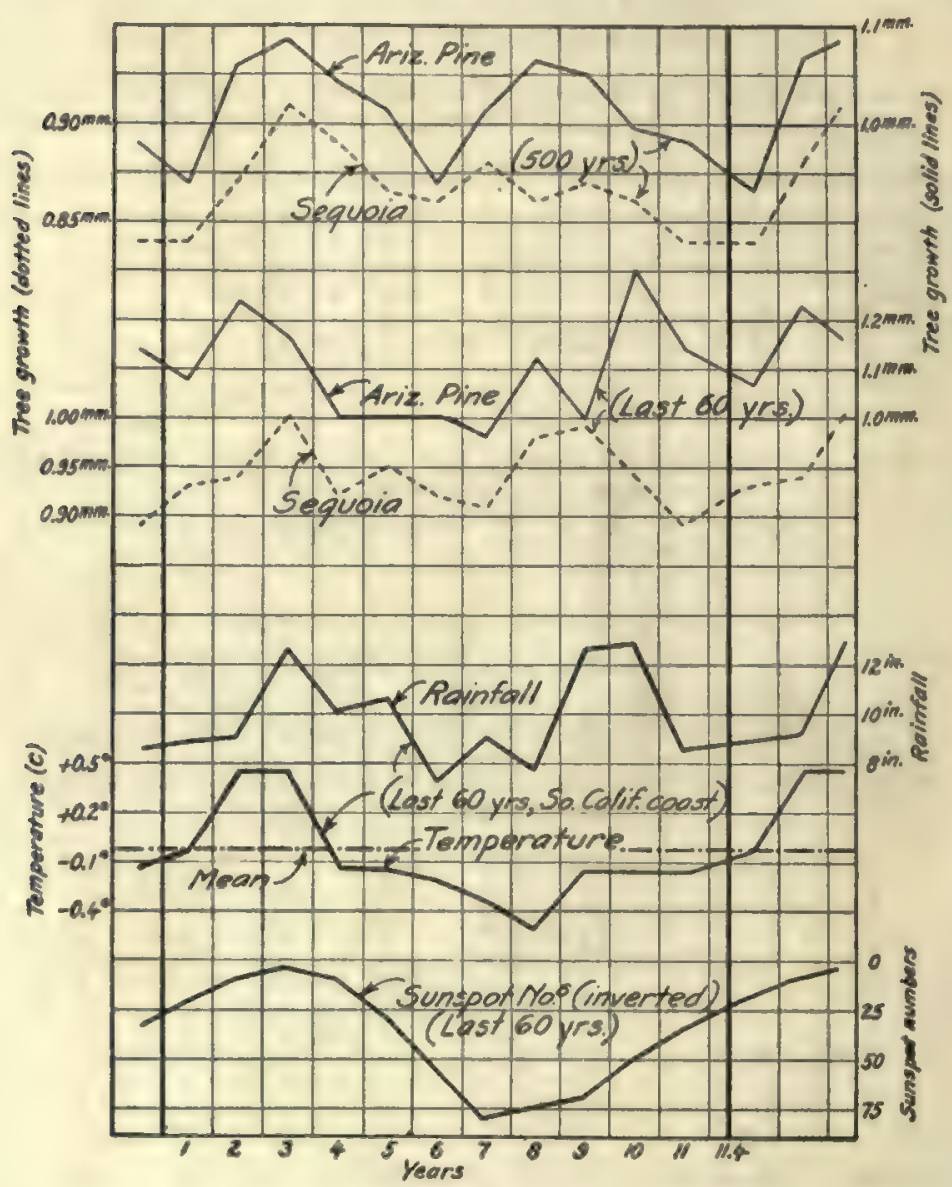

Fro. 34.-Correlation curves in the 11-year cycle.

No. 2 is a double cycle 21.2 years long, and the third curve is a simple combination of the two. The fourth curve is the tree-growth, showing fluctuations which admirably combine these two periods. All subsequent analysis of these trees has entirely supported this result, as shown in the periodograph work below. When the length of curve was extended from 200 years to 500 years, the double solar period was found to prevail through almost the entire length, but the triple period does not appear to have affected the tree-growth in the earlier 300 years.

Two other plain examples of the double solar type are illustrated in figures 36 and 37 . The former gives the double cycle shown in a scat- 
tered group of trees of considerable age from the inner fjords and mountains of Norway. The earlier half of the curve includes 6 trees and the later half 8 . The cycle beneath makes evident a well-developed rhythm in these trees. Figure 37 shows a very regular double sun-spot rhythm in the sequoias. There are many similar rhythms apparent in the sequoias, but as yet little study has been made of them. This one shows 80 years of the section D-12, whose identification was for a

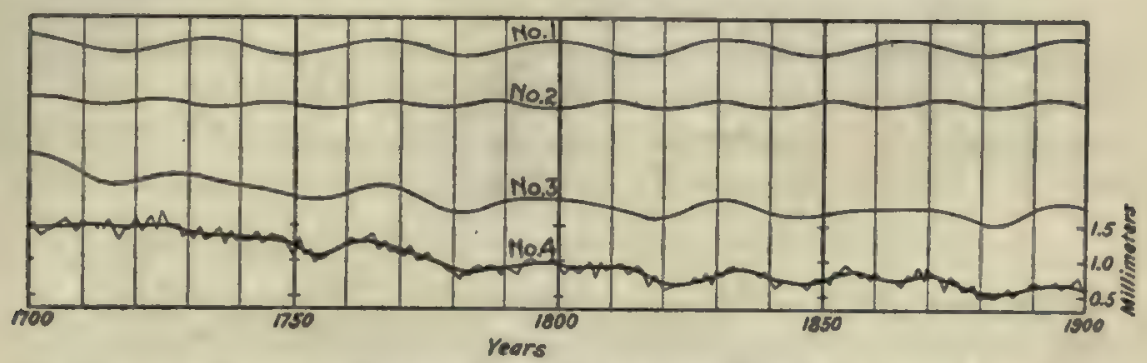

F1G. 35.-Early curve of Arizona pines from 1700 to 1900 A. D. (No. 4), compared with double and triple sunspot cycles combined (No. 3).

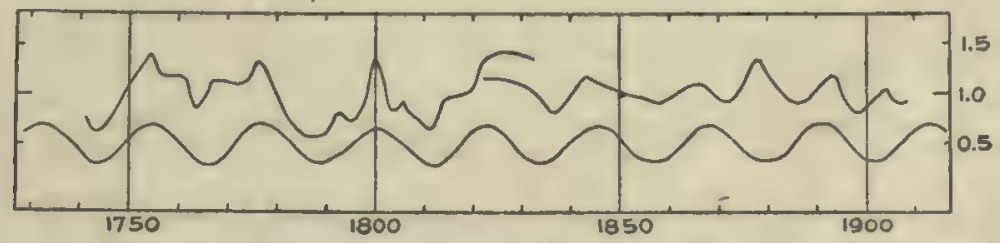

Fic. 36.-Double sunspot period in tree-growth at inner fjords of Norway; lower curve a 22.8 year cycle.

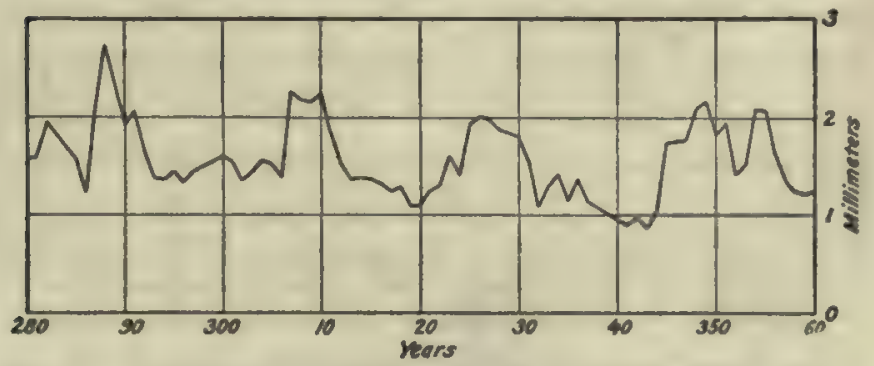

Fro. 37.-Double sunspot rhythm in sequoia, D-12 about $300 \mathrm{~A} . \mathrm{D}$.

(Material obtained in 1919 shows the dates in this figure to be too large by 27 years.)

long time uncertain on account of its complacent character and badly compressed rings. The rhythmic character is so evident that no cycle needs to be placed below the curve. The period is estimated at 20 to 22 years.

A triple solar cycle is shown in figure 38 , giving the condensed curve of a single 400-year-old Norwegian tree. The upper curve gives the mean growth, and the lower curve is a simple 34-year cycle. The rhythmic character of the growth was clearly seen in the measures 
immediately after their completion, and the period at once suggested the Brückner cycle of $\mathbf{3 5}$ years. This interesting tree has been mentioned on pages 34 and 41.

A 2-year cycle.-In the cross-identification of the trees used in this investigation, a constantly recurring feature has been a marked alternation in size of successive rings, giving them an appearance of being arranged in pairs. In the plotted curves this produces a zig-zag or see-saw effect. Usually such effect lasts a few years and then disappears or reverses, but the example illustrated in figure 39 shows unusual persistence. It is taken from D-22 from $750 \mathrm{~B}$. C. to $660 \mathrm{~B}$. C. The even dates show less growth than the odd almost continuously for 60 years, but for the next 30 years the reverse is the case. This is

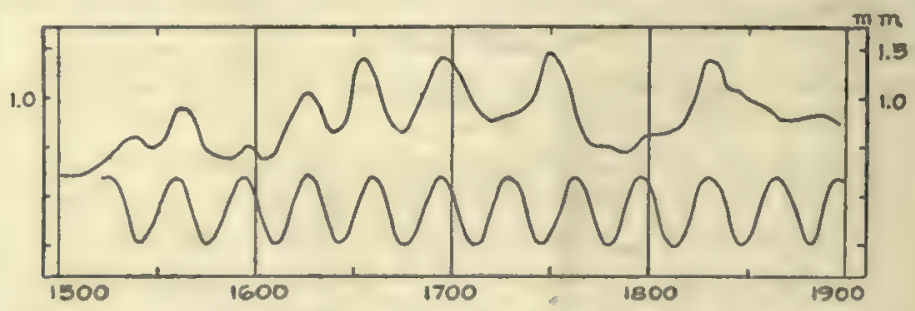

Fro. 38.-Triple sunspot cycle in a single tree from northern Norway. Lower curve, a 34-year cycle.

evidently due to a short period of about 2 years in length. It has not yet been fully studied, but it is prominent in the European groups and in the Vermont group. It frequently shows a duration of a little less than 7 years in one phase, with odd dates greater in growth than even dates, and then for the next 7 years reverses its phase. This 14-year cycle is the series of beats the 2 -year cycle produces by interfering with

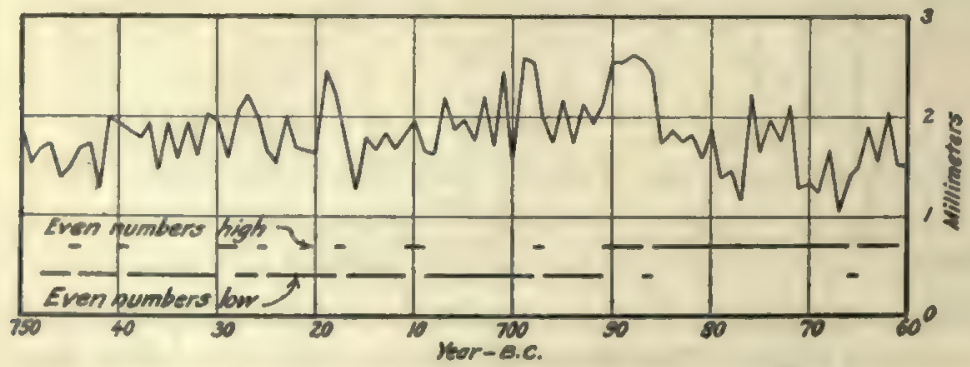

Fro. 39. -D-22 at 750 to 660 B. C., showing \& 2-year period."

the exact annual and biennial effects in the tree. Hence, by a simple process, its length is found to be in effect frequently 21 or 28 months. Comparison has been made with the rainfall records near the Vermont group (Douglass, 1915:181) and a variable period has been found 
averaging near the larger figure. It should more properly be called a "broken" period perhaps, since it is made up of different periods for different intervals, first one and then another predominating. The methods used in the search for this 2-year period have revealed frequently a solar cycle also, and there seems to be some obscure connection between the two.

\section{PERIODOGRAPH ANALYSES.}

Differential patterns.- The periodograms, as already shown, indicate the different cycles operating within a certain range. Any one cycle together with others close to it may be studied more minutely on the differential pattern produced when the instrument is set at the desired period. Plates 12 and 10, B, are arranged to illustrate this and at the same time show the solar cycles in several of the groups. A periodic effect equal in length to the setting of the instrument is indicated by a vertical row of light crests or dark spaces. These rows may be seen in any of the patterns. If the row of crests points downward to the right, its period is greater than the setting of the instrument; if to the left, the period is less. The straightness of the row indicates the regularity of the period. Plate 12, $\mathrm{Q}$, is made from the standard 5-year period with a setting at 5.0 years. The first pattern in plate 12 shows the regularity of the sunspot period since $1610 \mathrm{~A}$. D. The interval in the latter part of the eighteenth century, when the cycle was reduced to less than 10 years, is distinguished by a bending of the row toward the left. This is followed by a deflection toward the right during the interval of readjustment from 1790 to 1830 . The direction of any row becomes an exact measure of its period.

If a period is constant, the row of crests is straight. A zigzag row made up of short, straight parts means that one period after another becomes predominant. A curved row means a constantly changing period. Some examples of apparent curved rows may be picked out in the sequoia pattern. A curved row may indicate some other function than a simple period. Pattern $R$ in plate 12 is made to illustrate a logarithmic variable, beginning at the top as a 5-year period and changing by a constant percentage increase to a 10 -year period at the bottom. The instrument is set at 8.0 years.

The 11-year cycle.--The first 6 patterns in plate 12 illustrate this cycle. The first gives the sunspot numbers from 1610 to 1910 , including the uncertain ones from 1610 to 1750 . Pattern $B$ gives the fine vertical row shown by the 6 groups of trees from north Europe. This was shown as a curve in figure 25, page 77 . The qualitative test of the entire 80 European trees is shown in pattern $C$. This may be seen as a curve in figure 26 . The small secondary maxima at several of the minima show as light crests between the main rows. Pattern $D$ shows a 12-year period in south Sweden during the past 50 years, preceded by 
several maxima at about 8.5-year intervals. Pattern $E$ gives the Vermont analysis. The solar cycle shows well for the last 150 years, but is preceded by a 9.2-year cycle for about 50 years, and then by the solar cycle again. This tree curve is shown in figure 27 , page 78 .

The Arizona pines are given in pattern $F$. The double-crested solar cycle shows in the larger part of it, but is best developed in the upper and lower thirds. By sighting along these vertical rows, a dark line in the upper third, indicating the more pronounced minimum, comes in straight line with the lesser dark minimum line in the lower third, indicating a transfer of emphasis from one-half of the 11-year cycle to the other half in passing the seventeenth century. This was noted above in connection with the analysis of the same record by a series of curves in figure 33, page 103. Further study of this pattern, however, gives information as to how and when that change took place.

Changes in the 11-year tree-cycle of Arizona-A careful examination of an early differential pattern of the Flagstaff tree record gave the following probable history of the 11-year variation in Arizona:

TABLE 7.-Changes in the 11-year tree-cycle of Arizona.

\begin{tabular}{|c|c|c|}
\hline Yeara & Period. & Remarks. \\
\hline $1395-1550$ & 11.3 & $\begin{array}{l}\text { Double crests throughout, except } 1476 \text { and } \\
1487 \text {, where the second crest fails. }\end{array}$ \\
\hline $1550-1595$ & 14.3 & Heavy double orest. \\
\hline $1595-1661$ & $11.0=0.5$ & $\begin{array}{l}\text { Heavy single crests with trace of double } \\
\text { diminishing to small variable singles. }\end{array}$ \\
\hline $1661-1677$ & $16.0(?)$ & Possibly 1 long interval. \\
\hline $1677-1770$ & 12.5 & $\begin{array}{l}\text { Double crests mostly; going to } 10.8 \text { from } \\
1702 \text { to } 1722 \text {. }\end{array}$ \\
\hline $1770-1793$ & 9.0 & $\begin{array}{l}\text { Sharp single crest continuing second crest } \\
\text { of preceding double. }\end{array}$ \\
\hline $1793-1817$ & & Doubtful. \\
\hline $1817-1910$ & 11.6 & $\begin{array}{l}\text { Rather broad, heavy orests, sometimes } \\
\text { double; } 1864 \text { has too little and } 1875 \text { too } \\
\text { much crest. }\end{array}$ \\
\hline
\end{tabular}

The interval from 1830 to the present time divides also extremely well on a 21.0-year period, and fairly well in one of 7.3 years.

In obtaining this result no comparison was made with the sunspot record. So the following is of interest:

TABLE 8. - Changes in tree and sunspot cycles compared.

\begin{tabular}{|c|l|c|c|}
\hline \multicolumn{2}{|c|}{ Trees. } & \multicolumn{3}{c|}{ Sunspots. } \\
\hline Year. & \multicolumn{1}{|c|}{ Period. } & Year. & \multicolumn{1}{c|}{ Period. } \\
\hline $1505-1661$ & $11.0 \pm 0.8$ years. & 1615.6 to 1660.0 & 11.1 (?) years. \\
$1661-1677$ & $16(?)$ & 1660.0 to 1675.0 & 15.0 \\
$1677-1770$ & 12.5 mostly and 10.8 & 1675.0 to 1769.7 & 10.5 \\
$1770-1793$ & 9.0 & 1769.7 to 1788.1 & 9.2 \\
$1793-1817$ & Doubtful. & 1788.1 to 1816.4 & 14.15 \\
$1817-1910$ & $11.6,21.0$, or 7.3 & 1816.4 to 1905 & 11.08 \\
\hline
\end{tabular}


DOUGLASS
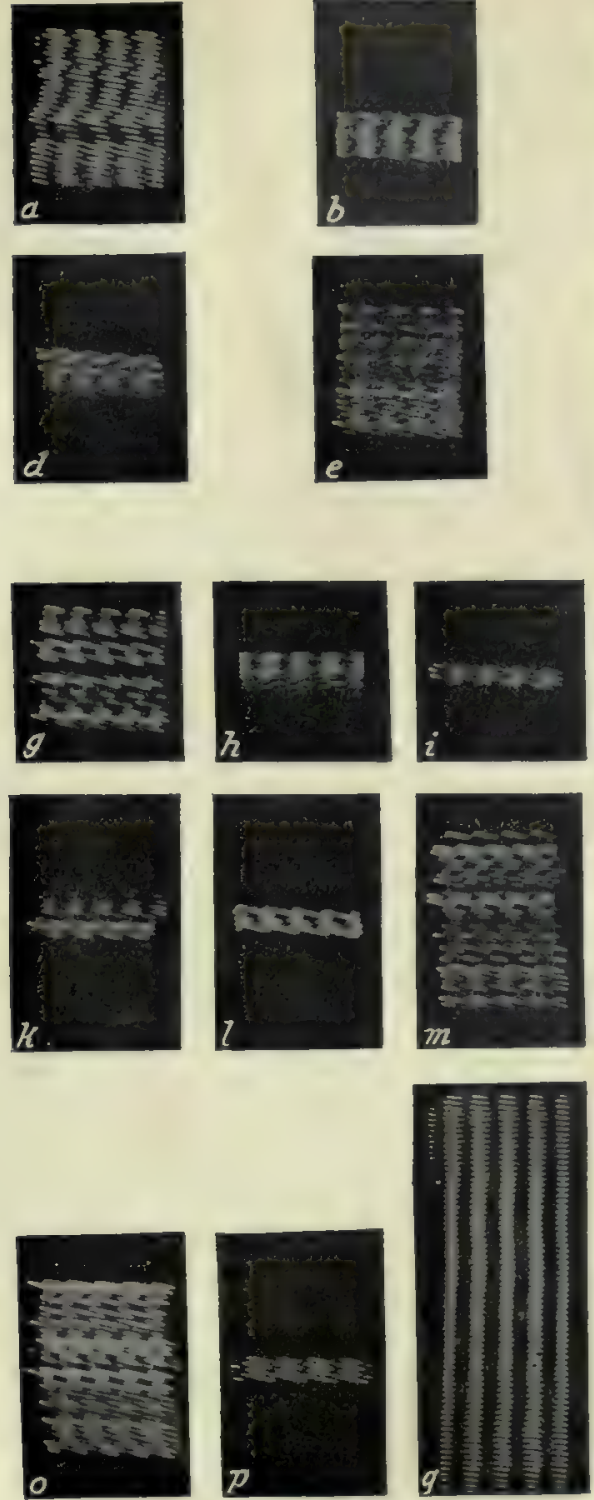

PLATE 12
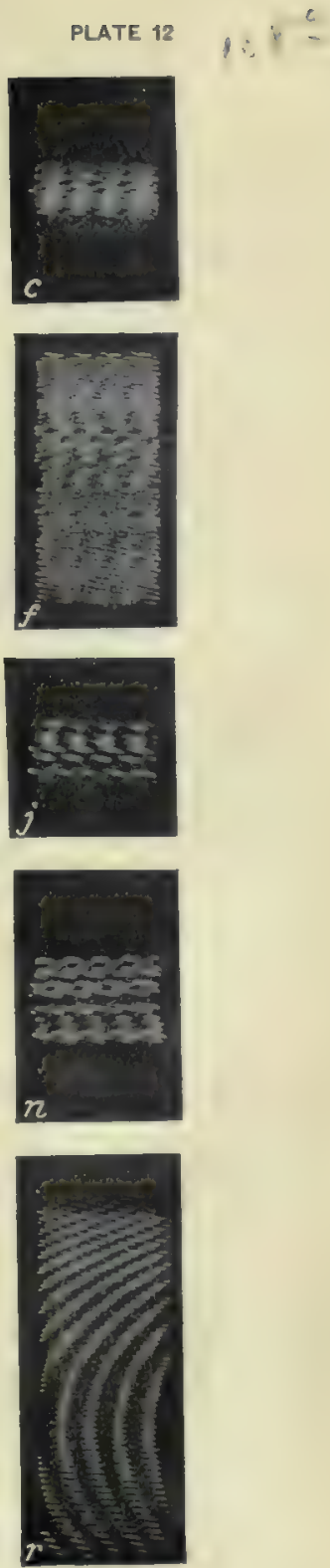

DIFFERENTIAL PATTERNS.

a. Sunspot Nos. 1610-1910 at 11.4 .

b. 57 European trees, 1830-1910 at 11.4.

c. 80 European trees, $1800-1910$ at 11.4.

d. South Sweden, 1830-1910 at 12.0.

e. Vermont group, 1650-1910 at 11.3.

f. Flagstaff group, 500 years at 11.4 .

g. Flagstaff group at 23.5 years.

h. Norway, $1740-1910$ at 23.8 years.

i. Austria, $1830-1910$ at 22.0 years. j. Norway, $\mathbf{N}-2,400$ years at 33.0

$k$. Vermont, 250 years at 32.5 .

l. Sweden, $1740-1910$ at 37.0 .

$m$. Sequoia, 1300-250 B. C. at 33.0.

$n$. Flagstaff, 500 years at 33.0 .

o. Sequoia, 3200 years at 101 .

p. Flagstaff, 500 years at 120 .

$q$. Standard 5-year period at 5.0 years.

$r$. 5 to 10 year logarithmic variable period at 8.0. 


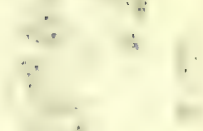

$\therefore$ 
The agreement seems to the writer to justify the conclusion that the tree record may indicate a possible sunspot period of 11.3 years from 1400 to 1550 and of 14.3 from the latter date to 1600 .

Sequoia pattern.-Pattern $B$ in plate 10 , opposite page 94 , is naturally the most interesting in respect to age, as it gives the sequoia analysis for 3,200 years. The solar cycle subject to slight variations may be dimly seen in large parts of it. It shows with some prominence during the first 500 years of our era, then for a few hundred years near the year $1000 \mathrm{~A}$. D., and for a long interval in the first 500 years of the record. There is opportunity for extensive study of these short periods, interpreting them by the aid of more widely scattered groups and other kinds of trees, and when possible by weather records.
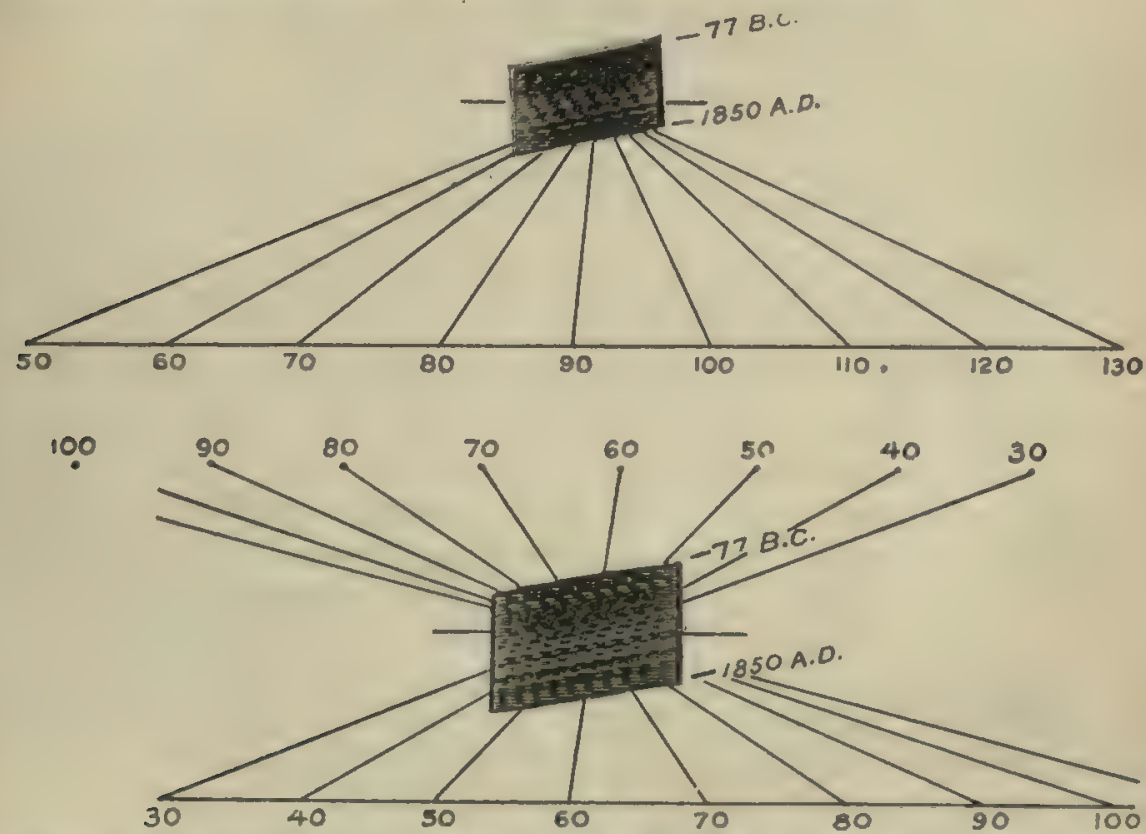

Frg. 40.-Two differential patterns of Huntington's preliminary 2000-year sequoia record. The most prominent eycle is about 105 years in length, shown in the upper disgram.

Other solar cycles.-Plate 12, G to $\mathrm{P}$, shows the multiples of the solar cycle. Pattern $G$ gives the Arizona tree record analyzed at 23.5 years. It shows a slightly irregular vertical row of crests. This is best seen by tipping the pattern so that the eye views it from a low angle instead of perpendicularly as in ordinary reading. A line slanting down to the left giving a period at nearly 22.2 years would answer quite as well. The lower third is somewhat broken by the triple sunspot period showing in it. The same record is analyzed at 33.0 years in pattern $N$. In this pattern the lower third shows the triple cycle in vertical rows and the double cycle shows in rows slanting strongly down to the left. Patterns $H$ and $I$ in plate 12 show the excellent double sunspot 
rhythm in the long Norwegian and shorter Austrian records, whose curves were given in figures 36 and 24 respectively, pages 105 and 77. Pattern $J$ shows the 33-year cycle of the 400-year tree, N-2, from near the Arctic Circle in Norway. The Vermont hemlocks are shown in pattern $K$. Here is found a good rhythm with a change in phase about 100 years ago. The Swedish curve shows a good rhythm at 37 years. Several intervals of triple solar cycle appear in the 1,000 years of early sequoia growth in pattern $M$. All the 8 patterns $G$ to $N$ are taken from special curves prepared on a one-fifth scale, using 5 -year sums in the plot.

The 100-year cycle.- Only two tree records are long enough to be tested for a cycle of this length. The sequoia gives a very excellent alinement at a period of 101 years, shown even better in the upper pattern of figure 40. The pattern of the present plate shows an increase to about 125 years in the last 600 years, which corresponds to the best analysis of the 500-year Arizona curve. This latter is at 120 years as shown in pattern $P$. Both of these are made from special curves plotted on one twenty-fifth of the usual scale.

Illustration by the periodograph.-The illustrations of periodograph analysis given above are practically the first made with this instrument and are therefore crude in many respects. Its advantage in the study of simple and obvious cycles such as the sunspot numbers is not at once apparent to the eye and its efficiency becomes evident only when one tries to select the exact period and state its accuracy. But one can foresee a useful application of this instrument in the study of mixed periods, such as appear in tree-growth here considered or in rainfall and other meteorological elements, a field as yet almost untouched on account of its complexity. However, in the brief presentation of its work given above, it is evident that the periodograph is found to corroborate and extend the results of the previous direct study of curves and to confirm the evidence there given of the great extent and importance of the solar cycles in the growth of trees. 


\section{SUMMARY.}

In the foregoing investigation the following conclusions have been reached:

(1) The variations in the annual rings of individual trees over considerable areas exhibit such uniformity that the same rings can be identified in nearly every tree and the dates of their formation established with practical certainty.

(2) In dry climates the ring thicknesses are proportional to the rainfall with an accuracy of 70 per cent in recent years and this accuracy presumably extends over centuries; an empirical formula can be made to express still more closely this relationship between tree-growth and rainfall; the tree records therefore give us reliable indications of climatic cycles and of past climatic conditions.

(3) The tree's years for such records begins in the autumn.

(4) Double rings are caused by spring drought and are indicative of the distribution of rainfall throughout the year.

(5) Tree records may be used in the intensive study of the location of homogeneous meteorological conditions and in outlining meteorological districts.

(6) Certain areas of wet-climate trees in northern Europe give an admirable record of the sunspot numbers and some American wet-climate trees give a similar record, but with their maxima 1 to 3 years in advance of the solar maxima. It is possible to identify living trees giving this remarkable record and to ascertain the exact conditions under which they grow.

(7) Practically all the groups of trees investigated show the sunspot cycle or its multiples; the solar cycle becomes more certain and accurate as the area of homogeneous region increases or the time of a tree record extends farther back; this suggests the possibility of determining the climatic and vegetational reaction to the solar cycle in different parts of the world.

(8) A most suggestive correlation exists in the dates of maxima and minima found in tree-growth, rainfall, temperature and solar phenomena. The prevalence of the solar cycle or its multiples, the greater accuracy as area or time are extended, and this correlation in dates point toward a physical connection between solar activity and terrestrial weather.

(9) The tree curves indicate a complex combination of short periods including a prominent cycle of about 2 years.

(10) An instrument has been constructed which promises special facility in the analysis of such periods.

The items enumerated above point to the general conclusion that near at hand and readily available in our forest areas is written a story of climatic cycles and solar relationship which in part at least is interpreted by the methods illustrated in the foregoing pages. 


\section{ADDENDUM.}

In the summer of 1919 a trip was made to the sequoia groves with three objects in view: (1) settling an uncertainty regarding the ring provisionally called $1580 \mathrm{~A}$; (2) gathering material bearing on the relation of short-period cycles to topography; (3) investigating the causes of enlarged or gross rings. It is only the first of these topies which has an important bearing on the foregoing chapters.

The region near the General Grant National Park was visited and 12 new trees were very carefully selected as to their water-supply, drainage, and distance from other trees, and short radial samples were cut from them. It did not seem necessary to have these include more than the last 500 years of growth. The radial piece, therefore, was made very small, but especial attention was given to procuring a continuous and reliable record. Critical examination showed at once that occurrence of the ring $1580 \mathrm{~A}$ was dependent on locality. The trees from the uplands, where identification was easy, largely failed to show the ring, but in specimens from swampy'basins, where crossidentification was difficult and sometimes uncertain, the ring was nearly always present. A complete decision, therefore, in favor of its real existence was satisfactorily obtained and the necessary corrections were made in the foregoing text and in the tabular matter which follows. It seems likely that the year 1580, which this ring represents, was phenomenally deficient in moisture in the locality of these giant trees.

In addition to the 12 new trees added to the sequoia group, a cutting was made from the stump D-12, which had hitherto defied all attempts at satisfactory dating. A small piece going back about 800 years was cut from a part of the circumference, entirely free from compressed rings, about 4 feet away from the full sample cut in 1915. At the time of cutting, great care was taken to insure proper crossidentification between the inner end of the new piece and the former sample. But in the laboratory the new piece proved to carry a very excellent series of rings and the identification was everywhere very easy and sure, and all doubt about the dating of that particular tree to its earliest ring in $135 \mathrm{~A}$. D., several inches away from its original center, was removed; therefore, it may now be included among those whose dating is entirely reliable.

A new group of 5 very old trees from near Flagstaff, has settled an uncertainty regarding the years 1463 and 1464 in the yellow pines (too late, however, to rectify figure 3 on page 25). It is now possible to carry a very fair cross-identification between the pines of Arizona and the sequoias of California through the whole five centuries of the former. 


\section{APPENDIX.}

TABLES OF MEAN TREE-GROWTH, BY GROUPS.

The tables give the mean growth of the group for each year in millimeters. The decade number in the left column applies to the growth in the adjacent column, and the succeeding 9 years follow along the horizontal line.

Flagstaff 500-year mearures: 8 to 19 trees.

\begin{tabular}{|c|c|c|c|c|c|c|c|c|c|c|}
\hline A. D. & 0 & 1 & 2 & 3 & 4 & 5 & 6 & 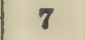 & 8 & 9 \\
\hline 1390 & & & 1.55 & 2.25 & 2.50 & 1.75 & 2.20 & 2. 30 & 2.20 & 2.10 \\
\hline 1400 & 2.55 & 2.75 & 2.00 & 2.10 & 1.95 & 1.80 & 2.30 & 1.50 & 2.35 & 1.65 \\
\hline 1410 & 1.65 & 2.25 & 1.90 & 1.80 & 1.85 & 1.30 & 2.25 & 1.30 & 1.90 & 1.10 \\
\hline 1420 & 0.80 & 0.70 & 0.90 & 1.90 & 1.45 & 1.40 & 1.20 & 1.35 & 1.55 & 1.80 \\
\hline 1430 & 1.25 & 1.65 & 1.15 & 1.45 & 1.95 & 0.75 & 1.20 & 1.35 & 0.80 & 0.90 \\
\hline 1440 & 1.35 & 1.25 & 0.60 & 0.65 & 1.40 & 1.10 & 1.00 & 1.05 & 0.95 & 1.60 \\
\hline 1450 & 1.25 & 1.40 & 1.85 & 1.60 & 1.15 & 0.85 & 1.35 & 1.65 & 1.20 & 0.80 \\
\hline 1460 & 0.80 & 1.25 & 1.75 & 1.40 & 0.55 & 0.95 & 1.40 & 1.45 & 1.10 & 1.60 \\
\hline 1470 & 1.25 & 1.05 & 1.10 & 1.65 & 1.00 & 1.00 & 1.25 & 1.40 & 1.40 & 1.45 \\
\hline 1480 & 1.20 & 1.10 & 1.35 & 1.00 & 1.05 & 0.60 & 1.05 & 0.40 & 0.60 & 1.05 \\
\hline 1490 & 1.40 & 1.80 & 1.10 & 0.85 & 1.40 & 0.70 & 1.10 & 1.35 & 1.65 & 0.60 \\
\hline 1500 & 0.40 & 1.55 & 1.15 & 0.70 & 1.35 & 0.80 & 0.50 & 1.25 & 1.10 & 1.05 \\
\hline 1510 & 0.55 & 1.05 & 0.55 & 1.05 & 0.90 & 0.90 & 0.65 & 0.45 & 0.75 & 1.32 \\
\hline 1520 & 1.06 & 0.96 & 0.72 & 0.96 & 0.98 & 1.36 & 1.56 & 1.22 & 0.82 & 1.50 \\
\hline 1530 & 1.38 & 1.16 & 0.74 & 0.82 & 0.94 & 1.10 & 1.54 & 1.22 & 0.74 & 1.34 \\
\hline 1540 & 1.50 & 1.40 & 0.86 & 1.14 & 1.32 & 1.00 & 1.62 & 1.28 & 1.10 & 1.72 \\
\hline 1550 & 1.66 & 1.76 & 2.02 & 1.80 & 1.60 & 1.56 & 1.32 & 1.18 & 0.78 & 1.34 \\
\hline 1560 & 1.48 & 1.34 & 1.72 & 1.84 & 1.70 & 1.68 & 1.20 & 1.30 & 1.94 & 1.80 \\
\hline 1570 & 1.20 & 1.68 & 1.44 & 1.0 & 1.08 & 1.00 & & 1.34 & & 1.08 \\
\hline 1580 & 0.78 & 1.18 & 1.34 & 1.2 & 0.36 & 0.22 & 0.88 & 1.30 & 1.76 & 1.76 \\
\hline 1590 & 0.92 & 0.70 & 1.14 & 1.68 & 1.66 & 1.70 & 1. & 1.44 & 1.34 & 1.60 \\
\hline 1600 & 0.34 & 0.84 & 0.96 & 1.44 & 1.22 & 1.20 & 1.38 & 1.14 & 1.20 & 1.72 \\
\hline 1610 & 1.6 & 1. 14 & 1.10 & 0.7 & 1. 18 & 0.98 & 1. & 1.62 & 1.72 & 1.48 \\
\hline 1620 & 1.7 & 1.60 & 1.2 & 0.7 & 1.04 & 1.18 & 0. & 0.90 & 0.80 & 1.08 \\
\hline 1630 & 0.98 & 0.70 & 0.26 & 0.7 & 0.8 & 0.9 & 0.80 & 0.68 & 0.62 & 0.86 \\
\hline 1640 & 1.16 & 0.90 & 1.08 & 1.0 & $1 .($ & 0.8 & 0. & 0.76 & 0. & 0.78 \\
\hline 1650 & 1.10 & 1.12 & 0.8 & 0. & & & & 0.74 & & 0.96 \\
\hline 1660 & 0.9 & 0.96 & 0.96 & 1.24 & 0.86 & 0.92 & 0.68 & 0.68 & 0.64 & 0.46 \\
\hline 1670 & 0.3 & 0.54 & 0.80 & 1.04 & 1.3 & 1.0 & 0.8 & 0 . & & 0.88 \\
\hline 1680 & 1.26 & 1.26 & 0.74 & 1.0 & 0.72 & 0.74 & 0.62 & 1.00 & 1.00 & 1.06 \\
\hline & 0.8 & 0,96 & 0.9 & & & & 0.8 & & & \\
\hline 1700 & 1.18 & 1.08 & 0.9 & 0.8 & 1.2 & 1.30 & 1.4 & 0.7 & 0.94 & 1.02 \\
\hline & 1.0 & 0.8 & 1.0 & 1.1 & & 1.0 & 0.8 & & & 1.10 \\
\hline 1720 & 1.24 & 0.82 & 0.86 & 1.12 & 0.9 & 1.40 & 1.40 & 0.1 & 0.64 & 0.42 \\
\hline 1730 & 0.5 & 0.72 & 0.82 & 0.6 & & 0.3 & & & & 0.54 \\
\hline 1740 & 0.8 & 0.80 & 0.76 & 0.9 & 0.74 & 0.78 & 1.06 & 0.84 & 0.40 & 0.86 \\
\hline 1750 & 0.7 & 0.66 & 0.10 & 0.6 & 0. & 0.6 & & & 1.00 & 0.76 \\
\hline 1760 & 0.80 & 0.92 & 0.90 & 0.8 & 1.22 & 0.94 & 0.86 & 0.86 & 0.68 & 0.66 \\
\hline 1770 & 0.8 & 0.6 & 0.7 & 0.3 & 0.6 & 0.7 & 0 . & & 0.48 & 0.48 \\
\hline 1780 & 0.36 & 0.52 & 0.32 & 0.74 & 1.02 & 0.50 & 0.60 & 0.86 & 0.54 & 0.50 \\
\hline 179 & 0.5 & 0.7 & 0.7 & 0.9 & 0.86 & 0.8 & 0.58 & 0.70 & 0.42 & 0.74 \\
\hline is & 0.5 & 0.4 & 0.7 & 0.5 & 0.5 & 0 . & & 0. & 0. & 0.80 \\
\hline & 0.7 & 0.7 & 0.8 & 0.2 & 0.4 & 0. & 0. & 0. & 0.36 & 0.62 \\
\hline 1820 & 0.3 & 0.62 & 0.0 & 0.4 & 0.4 & 0. & & 0. & 0. & 0.42 \\
\hline 1830 & 0.9 & 0.8 & 0.8 & 0.6 & 0.56 & 0.66 & 0. & 0. & 0 . & 0.64 \\
\hline 1840 & 0.6 & 0.44 & 0.30 & 0.5 & 0.52 & 0.34 & 0. & 0.36 & 0.68 & 0.56 \\
\hline 1850 & 0.6 & 0.2 & 0.8 & 0.8 & 0.90 & 0.76 & 0.62 & 0.70 & 0.64 & 0.70 \\
\hline 1860 & 0.88 & 0.52 & 0.7 & 0.6 & 0.6 & 0. & 0. & 0.64 & 0.94 & 0.62 \\
\hline 1870 & 0.8 & 0.68 & 0.6 & 0.5 & & 0.56 & 0.52 & 0.46 & 0.52 & 0.26 \\
\hline 1880 & 0.34 & 0.44 & 0.3 & 0.3 & 0.42 & 0.46 & 0.32 & 0.40 & 0.48 & 0.46 \\
\hline 1890 & 0.54 & $(0.47)$ & $(0.35)$ & $(0.35)$ & $(0.45)$ & $(0.40)$ & $(0.54)$ & 0.40 & 0.60 & 0.40 \\
\hline 1900 & 0.40 & 0.54 & 0.20 & 0.36 & 0.20 & 0.32 & 0.42 & $(0.53)$ & $(0.60)$ & $(0.66)$ \\
\hline 1910 & $(0.73)$ & & & & & & & & & \\
\hline
\end{tabular}


South of England: 11 trees.

\begin{tabular}{|c|c|c|c|c|c|c|c|c|c|c|}
\hline A. D. & 0 & 1 & 2 & 3 & 4 & 5 & 6 & 7 & 8 & 9 \\
\hline 185 & & & & & & & & & & .1 \\
\hline 18 & 5.1 & 4.6 & 4.7 & 3.8 & 3.53 & 4.18 & 4.29 & 5.25 & 4.27 & 4.32 \\
\hline 1870 & 3.65 & 5.19 & 5.21 & 4.32 & 4.34 & 4.87 & 4.04 & 3.79 & 4.94 & 4.72 \\
\hline 18 & 3.26 & 3.75 & 3.93 & 3. & 3.12 & 2.78 & 3.08 & 2. & 2.06 & 1.75 \\
\hline 1890 & 2.41 & 1.74 & 1.81 & 1.81 & 2.30 & 2.22 & 2.06 & 1.83 & 1.48 & 1.45 \\
\hline 190 & 1.71 & 1.90 & 1.63 & 2.35 & 2.29 & 1.83 & 1.84 & 1.65 & 1.72 & 1.51 \\
\hline 1910 & 2.28 & 1.71 & 1.65 & $\ldots$ & 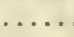 & $\ldots \ldots$ & ....... & -1 & $\ldots$ & 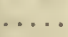 \\
\hline
\end{tabular}

Outer Coast of Norway: 10 trees.

\begin{tabular}{|c|c|c|c|c|c|c|c|c|c|c|}
\hline A. D. & 0 & 1 & 2 & 3 & 4 & 5 & 6 & 7 & 8 & 9 \\
\hline 1820 & & & & & & & & & 0.75 & 0.62 \\
\hline 1830 & 0.38 & 0.38 & 0.38 & 0.25 & 0.50 & 0.50 & 0.75 & 0.75 & 0. & 0.62 \\
\hline 1840 & 0.50 & 0.75 & 0.75 & 0.88 & 1.38 & 1.53 & 1.57 & 1.68 & 1.44 & 1.47 \\
\hline 1850 & 1.50 & 1. 39 & 1.59 & 1.22 & 1.74 & 1.29 & 1.17 & 1.01 & 1.28 & 1.57 \\
\hline 1860 & 1.57 & 1.24 & 1.26 & 1.28 & 1.27 & 1.40 & 1.54 & 1.52 & 1.85 & 1.77 \\
\hline 1870 & 1.5 & 1.87 & 2.18 & 1.83 & 2.10 & 1.35 & 1.38 & 1.22 & & 0.98 \\
\hline 1880 & 1.25 & 0.73 & 1.11 & 1.14 & 1.64 & 1.09 & 1.29 & 1.20 & 1.17 & 1.27 \\
\hline 1890 & 0.86 & 1.07 & 1.05 & 1.21 & 1.18 & 0.97 & 1.07 & 1.16 & 1.20 & 1.02 \\
\hline 1900 & 0.85 & 0.90 & 0.69 & 1.14 & 1.24 & 1.34 & 1.20 & 1.05 & 1.13 & 0.66 \\
\hline 1910 & 1.03 & 0.70 & 0.94 & & & & & & & \\
\hline
\end{tabular}

Inner Coast of Norway: 8 trees.

\begin{tabular}{|c|c|c|c|c|c|c|c|c|c|c|}
\hline A. D. & $\mathbf{0}$ & $\mathbf{1}$ & $\mathbf{2}$ & $\mathbf{3}$ & $\mathbf{4}$ & $\mathbf{5}$ & $\mathbf{6}$ & $\mathbf{7}$ & $\mathbf{8}$ & $\mathbf{9}$ \\
\hline 1820 & 1.81 & 2.38 & 2.09 & 2.22 & 2.25 & 2.00 & 2.12 & 1.89 & 2.04 & 1.88 \\
1830 & 2.00 & 1.89 & 1.72 & 2.01 & 1.80 & 1.45 & 1.30 & 1.64 & 1.81 & 1.65 \\
1840 & 1.60 & 1.78 & 1.92 & 2.15 & 2.08 & 1.94 & 1.94 & 1.81 & 1.81 & 1.81 \\
1850 & 1.71 & 1.66 & 1.79 & 1.40 & 1.69 & 1.58 & 1.40 & 1.54 & 1.49 & 1.22 \\
1860 & 1.56 & 1.31 & 1.52 & 1.65 & 1.62 & 1.68 & 1.74 & 1.65 & 1.66 & 1.34 \\
1870 & 1.56 & 1.26 & 1.38 & 1.44 & 1.75 & 1.60 & 1.48 & 1.76 & 2.16 & 1.68 \\
1880 & 1.89 & 1.34 & 1.52 & 1.38 & 1.36 & 1.29 & 1.25 & 1.22 & 1.34 & 1.36 \\
1890 & 1.44 & 1.44 & 1.51 & 1.45 & 1.79 & 1.30 & 1.10 & 1.05 & 1.08 & 1.00 \\
1900 & 0.95 & 1.19 & 1.14 & 1.30 & 1.29 & 1.20 & 1.10 & 1.00 & 1.14 & $\ldots$. \\
\hline
\end{tabular}

Christiania: 5 trees.

\begin{tabular}{|c|c|c|c|c|c|c|c|c|c|c|}
\hline A. D. & 0 & 1 & 2 & 3 & 4 & 5 & 6 & 7 & 8 & 9 \\
\hline 1820 & 1.12 & 1.06 & 1.10 & 1.10 & 1.16 & 1.10 & 1.60 & 1.54 & 1.60 & 1.48 \\
\hline 1830 & 1.28 & 1.12 & 0.94 & 0.86 & 0.96 & 1.12 & 1.22 & 1.20 & 1.08 & 1.68 \\
\hline 1840 & 1.52 & 1.70 & 2.32 & 1.76 & 1.82 & 1.58 & 1.36 & 1.44 & 1.66 & 1.40 \\
\hline 1850 & 1.54 & 1.60 & 1.36 & 1.26 & 1.72 & 1.36 & 1.20 & 1.32 & 1.32 & 1.52 \\
\hline 1860 & 1.66 & 1.48 & 1.58 & 1.40 & 1.72 & 1. 52 & 1.58 & 1.50 & 1.96 & 1.94 \\
\hline 1870 & 2.00 & 1.60 & 1.14 & 1.50 & 1.62 & 1.64 & 1.20 & 1.68 & 1.84 & 1.18 \\
\hline 1880 & 1.70 & 1.84 & 2.10 & 1.86 & 2.26 & 2.12 & 2.08 & 1.88 & 1.42 & 1.42 \\
\hline 1890 & 1.24 & 1.10 & 1.28 & 1.62 & 1.60 & 1.48 & 1.56 & 1.44 & 1.14 & 1.22 \\
\hline 1900 & 1.14 & 1.24 & 1.00 & 1.36 & 1.16 & 1.30 & 1.36 & 1.28 & 1.86 & 1.88 \\
\hline 1910 & 2.68 & 2.38 & 2.34 & & & & & & & . \\
\hline
\end{tabular}


APPENDIX.

Central Sweden: 18 trees.

\begin{tabular}{|c|c|c|c|c|c|c|c|c|c|c|}
\hline A. D. & 0 & 1 & 2 & 3 & 4 & 5 & 6 & 7 & 8 & 9 \\
\hline 1820 & 0.92 & 0.92 & 1.05 & 1.08 & 1.16 & 0.98 & 1.12 & 1.08 & 1.12 & 0.84 \\
\hline 1830 & 0.97 & 0.92 & 0.74 & 0.93 & 1.04 & 0.65 & 0.72 & 0.72 & 0.72 & 0.69 \\
\hline 1840 & 0.71 & 0.65 & 0.78 & 0.71 & 0.77 & 0.66 & 0.72 & 0.62 & 0.81 & 0.77 \\
\hline 1850 & 0.78 & 0.70 & 0.66 & 0.46 & 0.73 & 0.62 & 0.82 & 0.89 & 0.98 & 1.12 \\
\hline 1860 & 1.30 & 1.14 & 1.04 & 1.04 & 0.96 & 0.95 & 1.02 & 0.87 & 1.09 & 0.97 \\
\hline 1870 & 1.28 & 1.03 & 1.02 & 0.85 & 0.88 & 0.87 & 0.87 & 0.86 & 0.93 & 0.76 \\
\hline 1880 & 0.84 & 0.66 & 0.86 & 0.68 & 0.77 & 0.88 & 0.84 & 0.88 & 0.76 & 0.74 \\
\hline 1890 & 0.74 & 0.76 & 0.81 & 0.78 & 0.92 & 0.89 & 0.92 & 0.77 & 0.62 & 0.70 \\
\hline 1900 & 0.67 & 0.74 & 0.50 & 0.59 & 0.58 & 0.53 & 0.51 & 0.47 & 0.47 & 0.46 \\
\hline 1910 & 0.55 & & & & & & & & & - . \\
\hline
\end{tabular}

South Sweden: 6 trees.

\begin{tabular}{|c|c|c|c|c|c|c|c|c|c|c|}
\hline A. D. & 0 & 1 & 2 & 3 & 4 & $\mathbf{5}$ & 6 & 7 & 8 & 9 \\
\hline 1820 & 1.90 & 1.75 & 1.85 & 1.98 & 2.15 & 2.25 & 1.78 & 1.82 & 1.58 & 1.72 \\
\hline $\mathbf{1 8 3 0}$ & 2.37 & 2.37 & 1.68 & 1.8 & 1.9 & 1.58 & 1.55 & 1.58 & 1.85 & 1.87 \\
\hline 1840 & 1.93 & 2.07 & 1.82 & 1. 2 & 1.35 & 1.27 & 1.45 & 1.02 & 1.87 & 1.38 \\
\hline 1850 & 1.25 & 1.23 & 1.23 & 1.20 & 1.08 & 1.48 & 1.20 & 1.28 & 1.42 & 1.35 \\
\hline 1860 & 1.35 & 1.28 & 1.68 & 1.65 & 1.35 & 1.43 & 1.42 & 1.07 & 1.42 & 1.23 \\
\hline 1870 & 1.45 & 1.37 & 1.32 & 1.08 & 1.00 & 1.03 & 0.95 & 0.93 & 1.03 & 1.02 \\
\hline 1880 & 1.23 & 1.12 & 1.38 & 1.02 & 1.28 & 1.02 & 0.90 & 0.72 & 0.82 & 0.78 \\
\hline 1890 & 0.72 & 0.88 & 0.88 & 1.03 & 1.02 & 0.90 & 0.97 & 0.92 & 0.87 & 0.70 \\
\hline 1900 & 0.78 & 0.93 & 0.68 & 0.77 & 0.63 & 0.72 & 0.73 & 0.77 & 0.82 & 0.80 \\
\hline 1910 & 0.70 & & & & & & & & & $\ldots$ \\
\hline
\end{tabular}

Eberswalde, Prussia: 13 trees.

\begin{tabular}{|c|c|c|c|c|c|c|c|c|c|c|}
\hline A. D. & 0 & 1 & 2 & 3 & 4 & 5 & 6 & 7 & 8 & 9 \\
\hline 1830 & 2.70 & 2.56 & 2.78 & 2.26 & 2.52 & 2.38 & 2.79 & 3.22 & 3.74 & 3.04 \\
\hline 1840 & 2.63 & 2.38 & 1.56 & 2.11 & 2.55 & 2.06 & 2.55 & 1.82 & 2.82 & 2.88 \\
\hline 1850 & 2.08 & 2.15 & 1.55 & 1.96 & 1.66 & 1.05 & 1.06 & 0.87 & \begin{tabular}{|l|}
1.28 \\
\end{tabular} & 1.92 \\
\hline 1860 & 1.98 & 2.15 & 1.88 & 1.51 & 1.49 & 1.40 & 1.22 & 1.68 & 1.33 & 1.54 \\
\hline 1870 & 1.59 & 1.58 & 1.52 & 1.16 & 1.35 & 1.46 & 1.25 & 0.83 & 1.25 & 1.23 \\
\hline 1880 & 1.12 & 1.31 & 2.13 & 1.47 & 2.06 & 1.68 & 1.29 & 1.05 & 0.99 & 0.91 \\
\hline 1890 & 1.12 & 1.37 & 0.87 & 0.85 & 0.55 & 0.63 & 0.79 & 0.63 & 0.78 & 0.73 \\
\hline 1900 & 0.69 & 0.62 & 0.73 & 1.17 & 1.03 & 1.12 & 0.91 & 0.93 & 0.67 & 0.42 \\
\hline 1910 & 0.47 & 0.35 & 0.58 & & & & & & & \\
\hline
\end{tabular}

Pilsen, Austria: 7 trees.

\begin{tabular}{|c|c|c|c|c|c|c|c|c|c|c|}
\hline A. D. & 0 & 1 & 2 & 3 & 4 & 5 & 6 & 7 & 8 & 9 \\
\hline 1830 & 4.03 & 3.99 & 2.74 & 3.60 & 3.49 & 2.59 & 2.06 & 3.36 & 2.47 & 2.43 \\
\hline 1840 & 2.79 & 3.01 & 1.66 & 2.29 & 2.66 & 1.63 & 2.17 & 1.64 & 1.34 & 0.89 \\
\hline 1850 & 1.13 & 1.54 & 1.50 & 1.60 & 1.59 & 1.54 & 1.70 & 1.06 & 1.33 & 1. 23 \\
\hline 1860 & 1.44 & 1.31 & 1.54 & 1.43 & 0.74 & 0.99 & 1.27 & 1.39 & 0.99 & 1.20 \\
\hline 1870 & 1.09 & 1.29 & 1.44 & 1.19 & 0.87 & 1.14 & 1.30 & 1.14 & 1.51 & 1. 24 \\
\hline 1880 & 1. 50 & 1.37 & 1.70 & 1.56 & 1.70 & 1.33 & 1.37 & 0.93 & 1.00 & 0.87 \\
\hline 1890 & 1.17 & 1.16 & 1.26 & 1.16 & 1.31 & 1.41 & 1.49 & 1.70 & 1.40 & 1. 50 \\
\hline 1900 & 1.47 & 1.40 & 1. 20 & 1. 19 & 0.97 & 1.04 & 1.09 & 1.04 & 0.89 & 1. 03 \\
\hline 1910 & 1.23 & 0.91 & 1.31 & & & & & & & \\
\hline
\end{tabular}


Southern Bavaria: 8 trees.

\begin{tabular}{|c|c|c|c|c|c|c|c|c|c|c|}
\hline A. D. & 0 & 1 & 2 & 3 & 4 & 5 & 6 & 7 & 8 & 9 \\
\hline 1840 & & & & & & & & & 3.20 & 3.42 \\
\hline 1850 & 3.36 & 3.71 & 3.31 & 3.64 & 3.41 & 2.80 & 2.62 & 2.42 & 2.14 & 1.95 \\
\hline 1860 & 1.91 & 2.35 & 2.38 & 1.98 & 1.90 & 1.08 & 1.38 & 1.28 & 1.35 & 1.42 \\
\hline 1870 & 1.09 & 1.75 & 1.71 & 1.62 & 1.39 & 1.39 & 1. 52 & 1.58 & 1.68 & 1.66 \\
\hline 1880 & 1.65 & 1.55 & 1.50 & 1.44 & 1.26 & 1.05 & 1.00 & 0.92 & 1.09 & 0.96 \\
\hline 1890 & 1.11 & 0.99 & 1.04 & 0.76 & 0.81 & 0.96 & 0.95 & 0.96 & 0.95 & 0.72 \\
\hline 1900 & 0.81 & 0.82 & 0.74 & 0.86 & 0.90 & 0.81 & 1.02 & 1.19 & 0.92 & 0.66 \\
\hline 1910 & 0.79 & 0.76 & & & & & & & ... & \\
\hline
\end{tabular}

Six old Norway trees: Group A; inner coast.

\begin{tabular}{|c|c|c|c|c|c|c|c|c|c|c|}
\hline A. D. & 0 & 1 & 2 & 3 & 4 & 5 & 6 & 7 & 8 & 9 \\
\hline 1740 & 1.10 & 0.98 & 0.82 & 0.84 & 0.78 & 1.00 & 1.03 & 1.40 & 1.30 & 1.25 \\
\hline 1750 & 1.52 & 1.35 & 1.73 & 1.55 & 2.07 & 1.83 & 1.15 & 1.85 & 1.55 & 1.45 \\
\hline 1760 & 1.77 & 1.48 & 1.20 & 1.30 & 1.11 & 0.98 & 1.45 & 1.43 & 1.60 & 1.52 \\
\hline 1770 & 1.30 & 1.52 & 1.48 & 1.45 & 1.42 & 1.95 & 1.80 & 1.75 & 1.47 & 1.43 \\
\hline 1780 & 1.43 & 1.30 & 0.97 & 0.87 & 0.82 & 0.78 & 0.68 & 0.82 & 0.72 & 0.80 \\
\hline 1790 & 0.97 & 1.02 & 1.23 & 1.02 & 0.97 & 1.08 & 122 & 1.07 & 1.35 & 1.50 \\
\hline 1800 & 2.03 & 1.70 & 1.35 & 1.27 & 1.08 & 1.23 & 1.33 & 1.15 & 1.17 & 1.02 \\
\hline 1810 & 1.00 & 0.82 & 0.90 & 1.28 & 1.32 & 1. 22 & 1.13 & 1.58 & 1.23 & 1.18 \\
\hline 1820 & 1.73 & 2.05 & 1.77 & 1.67 & 1.82 & 1.63 & 2.02 & 1.82 & 2.00 & 1.77 \\
\hline 1830 & 1.73 & 1.84 & 1.80 & 1.88 & 1.64 & 1.28 & & & & \\
\hline
\end{tabular}

Eight old Sweden trees; Group B; Dalarne.

\begin{tabular}{|c|c|c|c|c|c|c|c|c|c|c|}
\hline A. D. & o & 1 & 2 & 3 & 4 & 5 & 6 & 7 & 8 & 9 \\
\hline 1740 & 0.70 & 0.54 & 0.54 & 0.73 & 0.85 & 0.90 & 0.87 & 0.90 & 1.00 & 0.87 \\
\hline 1750 & 1.09 & 0.90 & 1.07 & 0.79 & 0.80 & 0.78 & 0.55 & 0.61 & 0.65 & 0.87 \\
\hline 1760 & 0.80 & 0.86 & 1.00 & 0.92 & 0.87 & 0.90 & 0.99 & 0.95 & 0.92 & 0.76 \\
\hline 1770 & 0.62 & 0.66 & 0.71 & 0.75 & 0.68 & 0.82 & 0.88 & 0.90 & 0.93 & 0.97 \\
\hline 1780 & 0.89 & 0.86 & 0.92 & 0.89 & 0.95 & 0.86 & 0.79 & 0.86 & 0.81 & 0.68 \\
\hline 1790 & 0.68 & 0.78 & 0.67 & 0.62 & 0.68 & 0.59 & 0.68 & 0.63 & 0.63 & 0.63 \\
\hline 1800 & 0.56 & 0.52 & 0.61 & 0.55 & 0.58 & 0.58 & 0.52 & 0.60 & 0.57 & 0.59 \\
\hline 1810 & 0.58 & 0.65 & 0.71 & 0.74 & 0.71 & 0.73 & 0.68 & 0.73 & 0.81 & 0.79 \\
\hline 1820 & 0.66 & 0.63 & 0.66 & 0.66 & 0.75 & 0.81 & 0.81 & 0.75 & 0.82 & 0.65 \\
\hline 1830 & 0.62 & 0.65 & 0.55 & 0.70 & 0.79 & 0.55 & & & ....... & .... \\
\hline
\end{tabular}

Windsor, Vermont; 11 trees.

\begin{tabular}{|c|c|c|c|c|c|c|c|c|c|c|}
\hline A. D. & 0 & 1 & 2 & 3 & 4 & 5 & 6 & 7 & 8 & 9 \\
\hline 1650 & $\ldots .$. & 0.6 & 0.8 & 0.7 & 0.72 & 0.47 & 1.03 & 0.77 & 0.67 & 0.75 \\
1660 & 0.68 & 0.62 & 0.28 & 0.38 & 0.45 & 0.35 & $\mathbf{0 . 5 5}$ & 0.40 & 0.28 & 0.53 \\
1670 & 0.22 & 0.38 & 0.29 & 0.35 & $\mathbf{0 . 4 5}$ & 0.37 & $\mathbf{0 . 4 0}$ & 0.39 & 0.50 & 0.48 \\
1680 & 0.57 & 0.52 & 0.38 & 0.35 & 0.40 & 0.37 & 0.42 & 0.41 & 0.49 & 0.72 \\
1690 & 0.76 & 0.40 & 0.57 & 0.73 & 0.73 & 1.06 & 0.79 & 0.65 & 0.57 & 0.72 \\
1700 & 0.67 & 0.64 & 0.54 & 0.50 & 0.26 & 0.20 & 0.34 & 0.36 & 0.37 & 0.45 \\
1710 & 0.37 & 0.47 & 0.49 & 0.45 & 0.60 & 0.47 & 0.66 & 0.75 & 1.03 & 0.84 \\
1720 & 0.70 & 0.90 & 0.83 & 0.57 & 0.88 & 0.89 & 0.92 & 1.15 & 0.79 & 0.68 \\
1730 & 0.87 & 0.89 & 0.54 & 0.51 & 0.66 & 0.69 & 0.68 & 0.60 & 0.67 & 0.56 \\
1740 & 0.51 & 0.34 & 0.47 & 0.37 & 0.52 & 0.65 & 0.56 & 0.72 & 0.41 & 0.47 \\
1750 & 0.55 & 0.71 & 0.76 & 0.62 & 0.53 & 0.51 & 0.81 & 1.04 & 0.92 & 1.12 \\
\hline
\end{tabular}


Windsor, Vermont; 11 trees-continued.

\begin{tabular}{|c|c|c|c|c|c|c|c|c|c|c|}
\hline A. D. & 0 & 1 & 2 & 3 & 4 & 5 & 6 & 7 & 8 & 9 \\
\hline 1760 & 1.12 & 0.96 & 0.73 & 0.78 & 1.00 & 1.05 & 0.65 & 0.62 & 0.74 & 0.91 \\
\hline 1770 & 0.44 & 0.45 & 0.53 & 0.54 & 0.59 & 0.58 & 0.67 & 0.81 & 0.86 & 0.80 \\
\hline 1780 & 0.67 & 0.77 & 0.86 & 0.75 & 0.51 & 0.53 & 0.74 & 0.60 & 0.71 & 0.81 \\
\hline 1790 & 0.57 & 0.54 & 0.58 & 0.69 & 0.63 & 0.69 & 0.61 & 0.50 & 0.46 & 0.47 \\
\hline 1800 & 0.66 & 0.82 & 0.72 & 0.77 & 0.61 & 0.96 & 0.82 & 1.25 & 1.94 & 2.02 \\
\hline 1810 & 1.96 & 2.09 & 1.95 & 1.85 & 1.75 & 1.86 & 1.47 & 1.46 & 1.28 & 1.43 \\
\hline 1820 & 1.21 & 0.79 & 2.06 & 1.81 & 2.41 & 1.88 & 1.40 & 2.05 & 2.62 & 2.18 \\
\hline 1830 & 2.56 & 2.66 & 2.17 & 2.71 & 2.65 & 1.85 & 1. 62 & 1.74 & 2.26 & 1.85 \\
\hline 1840 & 2.00 & 1.75 & 1.51 & 1.70 & 2.07 & 1.95 & 1.90 & 2.11 & 2.06 & 1.74 \\
\hline 1850 & 1.77 & 2.33 & 1.66 & 1.36 & 1.39 & 1.50 & 1.70 & 1.77 & 1.99 & 1.45 \\
\hline 1860 & 1.63 & 2.12 & 1.37 & 1.76 & 1.61 & 1.79 & 1.78 & 1.75 & 2.33 & 1.55 \\
\hline 1870 & 1.67 & 1.32 & 1.25 & 1.04 & 1.76 & 1.73 & 1.49 & 1.21 & 1.97 & 1.58 \\
\hline 1890 & 2.23 & 1.68 & 1.97 & 1.15 & 1.68 & 0.93 & 1.49 & 1.73 & 1.50 & 2.37 \\
\hline 1890 & 2.04 & 2.31 & 2.76 & 2.11 & 2.75 & 1.23 & 1.38 & 2.01 & 2.11 & 1.06 \\
\hline 1900 & 1.19 & 1.35 & 1.61 & 1.79 & 1.43 & 1.38 & 1.39 & 1.25 & 1.13 & 1.20 \\
\hline 1910 & 1.51 & 0.95 & 1.76 & & & & & & & \\
\hline
\end{tabular}

Oregon group; 17 trees.

\begin{tabular}{|c|c|c|c|c|c|c|c|c|c|c|}
\hline A. D. & 0 & 1 & 2 & 3 & 4 & 5 & 6 & 7 & 8 & 9 \\
\hline 1710 & 4.21 & 4.04 & 3.91 & 4.30 & 4.44 & 4.81 & 5.21 & 4.30 & 3.63 & 4.38 \\
\hline 1720 & 4.57 & 4.08 & 4.31 & 4.10 & 4.06 & 4.21 & 3.84 & 3.84 & 3.62 & 3.67 \\
\hline 1730 & 3.69 & 3.39 & 3.63 & 3.49 & 3.14 & 2.80 & 2.89 & 2.74 & 2.97 & 3.46 \\
\hline 1740 & 2.34 & 2.19 & 2.02 & 2.16 & 2.29 & 2.17 & 1.91 & 2.09 & 2.14 & 2.36 \\
\hline 1750 & 2.29 & 2.57 & 2.52 & 2.67 & 2.17 & 1.92 & 2.00 & 1.98 & 1.90 & 1.99 \\
\hline 1760 & 2.33 & 2.18 & 2.33 & 2.28 & 2.49 & 2.18 & 2.27 & 2.33 & 2.26 & 2.32 \\
\hline 1770 & 2.69 & 3.16 & 3.15 & 3.01 & 3.32 & 2.85 & 3.22 & 2.84 & 3.04 & 3.25 \\
\hline 1780 & 3.15 & 3.23 & 2.72 & 2.52 & 2.62 & 3.05 & 3.58 & 3.35 & 2.58 & 3. 28 \\
\hline 1790 & 2.74 & 2.46 & $2.5 \theta$ & 2.74 & 3.00 & 2.78 & 2.59 & 2.36 & 2.29 & 2.50 \\
\hline 1800 & 2.45 & 2.44 & 2.57 & 2.61 & 2.65 & 2.81 & 2.97 & 2.52 & 2.57 & 2.31 \\
\hline 1810 & 2.37 & 2.31 & 2.06 & 2.11 & 2.35 & 2.71 & 2.77 & 2.62 & 2.48 & 2.54 \\
\hline 1820 & 2.99 & 2.72 & 1.96 & 2.36 & 2.10 & 2.38 & 2.37 & 2.54 & 2.22 & 2.05 \\
\hline 1830 & 2.19 & 2.21 & 2.06 & 2.80 & 2.72 & 2.29 & 2.53 & 2.15 & 2.21 & 2.35 \\
\hline 1840 & 2.22 & 2.00 & 1.82 & 1.88 & 1.52 & 1.86 & 2.08 & 2.42 & 1.93 & 1.94 \\
\hline 1850 & 1.33 & 1.66 & 1.74 & 1.75 & 1.76 & 1.84 & 2.05 & 2.11 & 1.93 & 1.77 \\
\hline 1860 & 1.88 & 2.24 & 2.32 & 1.84 & 1.92 & 1.81 & 1.76 & 1.88 & 2.31 & 2.01 \\
\hline 1870 & 1.76 & 1.61 & 1.56 & 1.60 & 1.66 & 1.75 & 2.07 & 2.08 & 2.13 & 2.15 \\
\hline 1880 & 2.12 & 1.88 & 1.62 & 1.50 & 1.08 & 1.09 & 1.16 & 1.44 & 1.34 & 1.88 \\
\hline 1890 & 1.54 & 1.25 & 1.62 & 1.84 & 1.68 & 1.68 & 1.48 & 1.19 & 0.98 & 1.62 \\
\hline 1900 & 1.54 & 1.89 & 1.78 & 1.61 & 1.87 & 1.77 & 1.31 & 1.28 & 1.39 & 1.34 \\
\hline 1910 & 1.11 & 1.11 & & & & & & & & \\
\hline
\end{tabular}

Sequoin recond: Group of $1918 ; 1$ to 4 trees.

\begin{tabular}{|c|c|c|c|c|c|c|c|c|c|c|}
\hline B. C. & $\mathbf{0}$ & $\mathbf{9}$ & $\mathbf{8}$ & $\mathbf{7}$ & $\mathbf{6}$ & $\mathbf{5}$ & $\mathbf{4}$ & $\mathbf{3}$ & $\mathbf{2}$ & $\mathbf{1}$ \\
\hline 1310 & $\ldots \ldots$ & $\ldots \ldots$ & $\ldots \ldots$ & $\ldots .2$ & $\mathbf{1} 1.10$ & 2.90 & 2.50 & 1.50 & 2.40 & 2.60 \\
1300 & 2.45 & 1.40 & 1.30 & 1.25 & $\mathbf{1 . 2 5}$ & $\mathbf{1 . 0 0}$ & 0.90 & 1.30 & 1.20 & 1.30 \\
1290 & 1.50 & 1.40 & 1.45 & 1.15 & 1.10 & 0.95 & 0.90 & 1.00 & 0.90 & 0.85 \\
1280 & 1.15 & 1.20 & 1.05 & 1.20 & 1.00 & 0.75 & 0.60 & 0.75 & 0.65 & 0.90 \\
1270 & 0.65 & 0.40 & 0.55 & 0.55 & 0.50 & 0.70 & 0.90 & 0.55 & 0.55 & 0.80 \\
1260 & 0.90 & 0.55 & 0.70 & 0.80 & 0.80 & 0.95 & 1.05 & 0.60 & 0.50 & 0.45 \\
1250 & 0.70 & 0.70 & 0.60 & 0.70 & 0.80 & 0.80 & 0.60 & 0.90 & 0.70 & 0.60 \\
1240 & 0.70 & 0.45 & 0.75 & 0.85 & 1.15 & 0.85 & 0.90 & 1.00 & 0.90 & 1.15 \\
1230 & 1.25 & 1.35 & 1.40 & 1.40 & 1.55 & 2.10 & 2.20 & 2.85 & 3.45 & 3.10 \\
\hline
\end{tabular}

1306 B. C. is incomplete. 
Sequoia record: Group of $1918 ; 1$ lo 4 trees-continued.

\begin{tabular}{|c|c|c|c|c|c|c|c|c|c|c|}
\hline B. C. & 0 & 9 & 8 & 7 & 6 & 5 & 4 & 3 & 2 & 1 \\
\hline 1220 & 3.25 & 3.45 & 2.85 & 3.00 & 3.50 & 3.65 & 4.55 & 3.50 & 3.80 & 3.35 \\
\hline 1210 & 3.35 & 3.95 & 3.10 & 4.20 & 4.00 & 3.90 & 2.95 & 2.75 & 3.20 & 2.20 \\
\hline 1200 & 2.50 & 3.20 & 2.80 & 3.35 & 3.75 & 3.25 & 2.85 & 3.35 & 3.35 & 4.30 \\
\hline 1190 & 3.35 & 2.90 & 3.65 & 3.95 & 3.95 & 3.05 & 3.05 & 3.00 & 3.45 & 4.25 \\
\hline 1180 & 4.10 & 3.95 & 4.00 & 3.10 & 3.25 & 3.75 & 4.40 & 3.70 & 5.00 & 4.20 \\
\hline 1170 & 3.60 & 3.10 & 2.50 & 2.85 & 3.65 & 4.10 & 3.15 & 3.50 & 3.10 & 2.40 \\
\hline 1160 & 2.30 & 2.65 & 2.80 & 3.10 & 2.65 & 2.30 & 2.30 & 2.30 & 3.15 & 2.50 \\
\hline 1150 & 2.20 & 2.55 & 3.10 & 3.05 & 3.80 & 2.85 & 2.75 & 2.80 & 2.80 & 3.10 \\
\hline 1140 & 3.25 & 2.50 & 2.50 & 2.75 & 2.65 & 2.90 & 3.50 & 3.15 & 2.40 & 2.35 \\
\hline 1130 & 2.80 & 2.45 & 3.00 & 2.75 & 2.55 & 3.50 & 3.25 & 2.35 & 2.18 & 2.59 \\
\hline 1120 & 2.26 & 2.12 & 2.09 & 1.71 & 1.86 & 2.04 & 2.09 & 2.54 & 1.76 & 2.06 \\
\hline 1110 & 1.72 & 1.99 & 2.42 & 2.23 & 1.98 & 1.90 & 1.55 & 1.85 & 2.04 & 2.23 \\
\hline 1100 & 2.15 & 2.30 & 2.58 & 2.53 & 2.42 & 1.84 & 1.99 & 1.93 & 2.32 & 2.14 \\
\hline 1090 & 1.55 & 1.67 & 1.78 & 1.69 & 1.91 & 1.78 & 1.62 & 1.44 & 1.59 & 1.68 \\
\hline 1080 & 1.68 & 1.66 & 1.51 & 1.64 & 1.48 & 1.77 & 1.88 & 2.72 & 2.71 & 2.66 \\
\hline 1070 & 2.04 & 2.76 & 1.01 & 1.08 & 1.30 & 0.97 & 1.18 & 1.14 & 1.34 & 1.43 \\
\hline 1060 & 1.34 & 1.38 & 1.22 & 1.32 & 1.74 & 1.76 & 1.77 & 1.54 & 1.31 & 1.13 \\
\hline 1050 & 1.34 & 1.31 & 1.53 & 1.69 & 1.63 & 1.41 & 1.45 & 1.60 & 1.59 & 1.31 \\
\hline 1040 & 1.79 & 1.41 & 1.45 & 1.27 & 1.23 & 1.25 & 1.29 & 1.01 & 1.68 & 1.68 \\
\hline 1030 & 1.66 & 1.92 & 1.65 & 1.74 & 1.53 & 1.56 & 1.50 & 1.19 & 1.09 & 1.33 \\
\hline 1020 & 0.99 & 1.22 & 1.27 & 1.24 & 1.67 & 1.33 & 1.66 & 1.92 & 2.12 & 2.10 \\
\hline 1010 & 1.87 & 1.64 & 1.22 & 1.29 & 1.12 & 1.08 & 1.24 & 1.44 & 1.39 & 1.33 \\
\hline 1000 & 1.29 & 1.28 & 1.28 & 1.20 & 1.24 & 1.24 & 1.29 & 1.65 & 1.31 & 1.29 \\
\hline 990 & 1.24 & 1.29 & 1.19 & 1.34 & 1.39 & 1.28 & 1.21 & 1.24 & 1.10 & 1.15 \\
\hline 980 & 1.06 & 1.14 & 1.00 & 1.38 & 1.21 & 1.25 & 1.12 & 1.20 & 1.24 & 1.32 \\
\hline 970 & 1.37 & 1.27 & 1.30 & 1.04 & 1.27 & 1.24 & 1.16 & 1.20 & 1.36 & 1.18 \\
\hline 960 & 1.25 & 1.30 & 1.32 & 1.43 & 0.76 & 0.83 & 1.03 & 0.93 & 1.10 & 1.07 \\
\hline 950 & 1.35 & 1.56 & 1.55 & 1.30 & 1.32 & 1.64 & 1.43 & 1.83 & 1.51 & 1.38 \\
\hline 940 & 1.44 & 1.16 & 1.50 & 1.37 & 1.63 & 1.91 & 2.35 & 2.20 & 2.17 & 1.74 \\
\hline 930 & 2.09 & 2.79 & 3.23 & 2.66 & 1.77 & 2.06 & 1.76 & 1.78 & 2.13 & 1.85 \\
\hline 920 & 2.14 & 2.02 & 1.69 & 1.71 & 1.70 & 1.22 & 1.46 & 1.71 & 1.88 & 1.64 \\
\hline 910 & 1.86 & 1.87 & 2.18 & 1.72 & 1.44 & 1.77 & 1.92 & 1.82 & 1.80 & 1.87 \\
\hline 900 & 2.25 & 2.35 & 2.29 & 1.98 & 2.10 & 2.37 & 2.32 & 2.07 & 2.45 & 2.10 \\
\hline 890 & 1.89 & 1.96 & 1.94 & 1.95 & 2.40 & 2.18 & 2.12 & 2.24 & 2.33 & 1.95 \\
\hline 880 & 2.17 & 2.29 & 2.48 & 2.13 & 2.11 & 2.33 & 1.99 & 1.77 & 1.83 & 1.67 \\
\hline 870 & 1.62 & 1.72 & 2.17 & 1.58 & 1.43 & 1.19 & 1.31 & 1.36 & 1.30 & 1.38 \\
\hline 860 & 1.30 & 1.42 & 1.33 & 1.25 & 1.14 & 1.13 & 1.09 & 1.15 & 1.11 & 0.74 \\
\hline 850 & 1.02 & 1.23 & 1.14 & 1.07 & 1.04 & 1.39 & 1.32 & 1.45 & 1.42 & 1.58 \\
\hline 840 & 1.32 & 1.51 & 1.54 & 1.40 & 1.40 & 1.36 & 1.40 & 1.43 & 1.44 & 1.28 \\
\hline 830 & 1.57 & 1.51 & 1.28 & 1.16 & 1.57 & 1.65 & 1.54 & 1.32 & 1.22 & 1.26 \\
\hline 820 & 1.06 & 1.12 & 1.11 & 0.97 & 0.97 & 1.00 & 0.98 & 1.11 & 1.00 & 1.01 \\
\hline 810 & 1.15 & 1. 25 & 1.30 & 1.04 & 1.18 & 1.10 & 0.88 & 1.07 & 1.13 & 1.20 \\
\hline 800 & 1.10 & 1.18 & 1.27 & 1.20 & 1.14 & 1.26 & 1.26 & 1.26 & 1.08 & 1.26 \\
\hline 790 & 1.10 & 1.04 & 1. 19 & 1.07 & 1.16 & 1.21 & 1.02 & 1.08 & 1.08 & 1.10 \\
\hline 780 & 1,03 & 1.21 & 1.16 & 0.92 & 0.91 & 1.12 & 1.23 & 1.08 & 0.89 & 1.03 \\
\hline 770 & 1.06 & 1.25 & 1.07 & 1.02 & 1.12 & 1.14 & 1.09 & 1.28 & 1.17 & 1.31 \\
\hline 760 & 1.27 & 1.22 & 1.41 & 1.04 & 1.22 & 1.12 & 1.08 & 1.06 & 1.23 & 1.27 \\
\hline 750 & 1.27 & 1.35 & 1.38 & 1.12 & 1.15 & 1.59 & 1.37 & 1.10 & 1.44 & 1.48 \\
\hline 740 & 1.53 & 1.33 & 1.30 & 1.25 & 1.46 & 1.29 & 1.32 & 1.30 & 1.47 & 1.28 \\
\hline 730 & 1.26 & 1.40 & 1.62 & 1.46 & 1.17 & 1.23 & 1.49 & 1.38 & 1.21 & 0.94 \\
\hline 720 & 1.52 & 1.46 & 1.39 & 1.02 & 1.19 & 1.20 & 1.34 & 1.30 & 1.22 & 1.44 \\
\hline 710 & 1. 37 & 1.43 & 1.58 & 1.52 & 1.72 & 1.32 & 1.51 & 1.26 & 1.60 & 1.33 \\
\hline 700 & 1.82 & I. 56 & 1.30 & 1.43 & 1.45 & 1.66 & 1.40 & 1.45 & 1.79 & 1.81 \\
\hline 690 & 1.78 & 1.75 & 1.79 & 1.78 & 1.36 & 1.46 & 1.42 & 1.52 & 1.28 & 1.40 \\
\hline 680 & 1.21 & 1.26 & 1.09 & 1.41 & 1.25 & 1.30 & 1.44 & 1.63 & 1.28 & 1.51 \\
\hline 670 & 1.25 & 1.38 & 1.06 & 1.20 & 1.30 & 1.25 & 1.34 & 1.70 & 1.44 & 1.15 \\
\hline 680 & 1.35 & 1.20 & 1.22 & 1.01 & 0.96 & 1.13 & 1.44 & 1.36 & 1.20 & 1.32 \\
\hline 650 & 1.18 & 1.22 & 0.86 & 1.18 & 0.97 & 1.03 & 1.12 & 0.98 & 1.01 & 1.14 \\
\hline 640 & 1. 14 & 1.32 & 1.17 & 1.08 & 1.12 & 1. 18 & 1.18 & 1.14 & 1.04 & 0.94 \\
\hline 630 & 1.22 & 1.02 & 0.98 & 1.02 & 1.00 & 1.24 & 1.21 & 1.18 & 1.10 & 1.39 \\
\hline 620 & 1.24 & 1.22 & 1.26 & 1.13 & 1.13 & 1.20 & 1.22 & 1.08 & 1.08 & 1.19 \\
\hline 610 & 1.08 & 0.90 & 1.02 & 0.95 & 1.07 & 1.15 & 1.05 & 1.04 & 0.96 & 1.21 \\
\hline
\end{tabular}


Sequoia record: Group of 1918,1 to 4 treeg-continued.

\begin{tabular}{|c|c|c|c|c|c|c|c|c|c|c|}
\hline B. C. & 0 & 9 & 8 & 7 & 6 & 5 & 4 & 3 & 2 & 1 \\
\hline 600 & 1.25 & 1.20 & 0.95 & 1.10 & 0.90 & 0.90 & 1.05 & 1.08 & 0.94 & 0.99 \\
\hline 590 & 0.94 & 1.06 & 0.83 & 0.82 & 0.97 & 0.92 & 0.60 & 0.64 & 0.45 & 0.68 \\
\hline 580 & 0.83 & 0.96 & 0.75 & 0.78 & 0.96 & 0.80 & 0.82 & 0.83 & 0.90 & 0.86 \\
\hline 570 & 0.76 & 1.02 & 0.91 & 0.74 & 0.86 & 0.93 & 0.93 & 0.86 & 0.78 & 0.81 \\
\hline 560 & 0.66 & 0.80 & 0.82 & 0.95 & 0.88 & 0.95 & 0.96 & 1.11 & 1.03 & 1.10 \\
\hline 550 & 1.21 & 1.44 & 1.38 & 1.32 & 1.29 & 1.26 & 1.10 & 1.18 & 1.34 & 1,19 \\
\hline 540 & 1.10 & 0.94 & 1.07 & 0.76 & 0.79 & 0.89 & 0.66 & 0.77 & 1.05 & 1.04 \\
\hline 530 & 1.00 & 0.88 & 0.90 & 1.01 & 0.81 & 0.90 & 0.80 & 0.82 & 0.88 & 0.94 \\
\hline 520 & 0.60 & 0.74 & 1.01 & 0.99 & 0.93 & 0.92 & 0.83 & 0.87 & 0.50 & 0.96 \\
\hline 510 & 1.08 & 0.96 & 0.91 & 1.02 & 1.06 & 1.12 & 1.04 & 1.01 & 1.10 & 1.29 \\
\hline 500 & 0.98 & 1.00 & 1.01 & 0.89 & 0.90 & 1.10 & 1.10 & 1.09 & 1.02 & 0.91 \\
\hline 490 & 1.14 & 1.10 & 1.06 & 1.03 & 0.90 & 0.92 & 1.00 & 0.94 & 1.05 & 1.12 \\
\hline 480 & 1.17 & 1.12 & 1.10 & 1.11 & 1.22 & 1.04 & 1.08 & 0.88 & 0.82 & 0.90 \\
\hline 470 & 0.91 & 1.03 & 0.99 & 1.01 & 1.16 & 0.76 & 0.96 & 0.80 & 0.82 & 0.94 \\
\hline 460 & 0.96 & 0.91 & 0.79 & 0.84 & 0.79 & 0.90 & 0.84 & 0.82 & 0.69 & 0.86 \\
\hline 450 & 0.84 & 0.60 & 0.66 & 0.79 & 0.83 & 0.86 & 0.77 & 0.78 & 0.86 & 0.77 \\
\hline 440 & 0.84 & 0.94 & 0.94 & 0.78 & 0.79 & 0.80 & 0.80 & 1.02 & 1.09 & 1.12 \\
\hline 430 & 1.16 & 0.81 & 0.97 & 0.86 & 0.82 & 0.75 & 0.88 & 0.69 & 0.63 & 0.58 \\
\hline 420 & 0.90 & 0.60 & 0.73 & 0.83 & 0.58 & 0.77 & 0.88 & 0.78 & 0.74 & 0.84 \\
\hline 410 & 0.89 & 0.59 & 0.82 & 0.90 & 1.05 & 0.93 & 0.82 & 0.90 & 0.83 & 0.83 \\
\hline 400 & 0.83 & 0.75 & 0.80 & 0.67 & 0.66 & 0.55 & 0.71 & 0.75 & 0.58 & 0.78 \\
\hline 390 & 0.90 & 0.74 & 0.66 & 0.77 & 0.80 & 0.76 & 0.69 & 0.99 & 0.83 & 0.80 \\
\hline 380 & 0.75 & 0.95 & 1.02 & 0.99 & 1.04 & 0.91 & 0.95 & 0.88 & 0.92 & 1.09 \\
\hline 370 & 1.00 & 1.00 & 0.90 & 0.97 & 0.92 & 1.01 & 0.87 & 0.81 & 0.67 & 0.87 \\
\hline 360 & 0.93 & 0.90 & 0.79 & 0.87 & 0.81 & 0.84 & 0.82 & 0.76 & 0.71 & 0.72 \\
\hline 350 & 0.66 & 0.68 & 0.69 & 0.73 & 0.82 & 0.69 & 0.73 & 0.70 & 0.59 & 0.73 \\
\hline 3 & 0.71 & 0.77 & 0.72 & 0.74 & 0.69 & 0.61 & 0.78 & 0.84 & 0.84 & 0.60 \\
\hline 330 & 0.68 & 0.67 & 0.72 & 0.68 & 0.54 & 0.70 & 0.38 & 0.54 & 0.64 & 0.85 \\
\hline 3. & 0.86 & 0.83 & 0.79 & 0.93 & 0.98 & 0.93 & 0.94 & 0.90 & 0.93 & 0.88 \\
\hline 310 & 0.82 & 0.69 & 0.72 & 0.87 & 0.86 & 0.89 & 0.97 & 0.78 & 0.88 & 0.84 \\
\hline & 0.92 & 0.88 & 0.93 & 0.95 & 0.74 & 0.84 & 0.78 & 0.72 & 0.81 & 6.73 \\
\hline & 0.82 & 0.86 & 0.69 & 0.76 & 0.82 & 0.73 & 0.70 & 0.85 & 0.83 & 0.62 \\
\hline 280 & 0.70 & 0.81 & 0.66 & 0.84 & 0.87 & 0.72 & 0.72 & 0.72 & 0.65 & 0.70 \\
\hline 270 & 0.65 & 0.70 & 0.84 & 0.77 & 0.70 & 0.74 & 0.72 & 0.68 & 0.67 & 0.86 \\
\hline 260 & 0.82 & 0.74 & 0.64 & 0.64 & 0.78 & 0.69 & 0.69 & 0.71 & 0.72 & \\
\hline
\end{tabular}

Sequoia record: Group of $1915 ; 11$ trees.

\begin{tabular}{|c|c|c|c|c|c|c|c|c|c|c|}
\hline B. C. & 0 & 9 & 8 & 7 & 6 & 5 & 4 & 3 & 2 & 1 \\
\hline 280 & & & & & & & 3. 82 & 4.38 & 3.78 & 2.87 \\
\hline 270 & 2.96 & 2.59 & 2.73 & 2.55 & 0.84 & 2.85 & 2.27 & 2.70 & 2.76 & 3.56 \\
\hline 260 & 3.16 & 3.08 & 3.71 & 2.92 & 2.54 & 2.41 & 2.20 & 2.16 & 2.37 & 2.73 \\
\hline 250 & 2.66 & 2.47 & 2.13 & 2.32 & 1.67 & 1.29 & 0.87 & 1.42 & 1.72 & 1.83 \\
\hline 240 & 1.53 & 1. 52 & 1.61 & 1.15 & 1.09 & 0.63 & 1.19 & 1. 19 & 1.51 & 1.05 \\
\hline 230 & 1. 30 & 1.22 & 1.29 & 1.22 & 1.12 & 1.48 & 1.55 & 1.40 & 1.06 & 1. 35 \\
\hline 220 & 1.55 & 1.52 & 1.64 & 1.75 & 1.26 & 1.21 & 1.25 & 1.65 & 2.06 & 1.77 \\
\hline 210 & 2.33 & 2.11 & 2.02 & 2.71 & 2.88 & 2.40 & 2.58 & 2.23 & 1.82 & 2.16 \\
\hline 200 & 2.19 & 2.23 & 2.40 & 2.61 & 2.35 & 2.38 & 2.62 & 2.72 & 2.02 & 2. 28 \\
\hline 190 & 3.10 & 2.85 & 2.80 & 3.15 & 3.01 & 2.98 & 2.17 & 2.48 & 1.92 & 1.86 \\
\hline 180 & 2.33 & 2.78 & 2.44 & 2.20 & 2.50 & 2.59 & 2.35 & 2.40 & 2.11 & 1.97 \\
\hline 170 & 1. 77 & 2.00 & 1.52 & 2.51 & 2.96 & 2.89 & 1.89 & 1.93 & 1.47 & 1.76 \\
\hline 160 & 1.20 & 1.10 & 1.42 & 1.77 & 2.02 & 2.00 & 2.20 & 2.14 & 1.90 & 2.87 \\
\hline 150 & 2.26 & 2.28 & 2.74 & 2.58 & 2.60 & 2.36 & 2.34 & 2.06 & 2.66 & 1.70 \\
\hline 140 & 2.78 & 2.54 & 2.25 & 2.42 & 2.28 & 2.07 & 2.20 & 2.34 & 2.36 & 2.52 \\
\hline 130 & 2.00 & 2.01 & 2.18 & 2.44 & 2.04 & 2.18 & 1.87 & 2.00 & 2.23 & 2.23 \\
\hline 120 & 2.20 & 2.48 & 2.66 & 2.34 & 2.16 & 2.29 & 2.54 & 2.33 & 2.15 & 2.28 \\
\hline 110 & 2.64 & 2.66 & 2.33 & 2.24 & 2.85 & 2.55 & 2.44 & 2.16 & 2.21 & 1.91 \\
\hline 100 & 1.62 & 2.08 & 2.22 & 1.96 & 1.85 & 1.75 & 1.65 & 1.85 & 1.90 & 1.80 \\
\hline
\end{tabular}


Sequoia record: Group of $1915 ; 11$ trees-continued.

\begin{tabular}{|c|c|c|c|c|c|c|c|c|c|c|}
\hline B. C. & 0 & 9 & 8 & 7 & 6 & 5 & 4 & 3 & 2 & 1 \\
\hline 90 & 1.74 & 1.80 & 1.89 & 1.68 & 1.68 & 1.56 & 1.80 & 1.37 & 1.92 & 2.27 \\
\hline 80 & 2.34 & 2.16 & 2.25 & 2.17 & 2.00 & 2.63 & 2.16 & 2.08 & 2.16 & 2.27 \\
\hline 70 & 2.26 & 1.85 & 2.20 & 2.13 & 2.18 & 1.87 & 2.43 & 2.22 & 1.64 & 1.70 \\
\hline 60 & 2.22 & 2.35 & 2.48 & 2.52 & 2.00 & 1.90 & 1.89 & 1.58 & 1.54 & 1.85 \\
\hline 50 & 1.75 & 1.58 & 1.42 & 1.31 & 1.24 & 1.60 & 1.81 & 1.78 & 1.72 & 1.66 \\
\hline 40 & 1.75 & 1.64 & 1.59 & 1.59 & 1.70 & 1.68 & 1.57 & 1.35 & 1.63 & 2.14 \\
\hline 30 & 1.86 & 1.71 & 1.50 & 1.62 & 1.50 & 1.54 & 1.34 & 1.62 & 1.79 & 1.38 \\
\hline 20 & 1.78 & 1.38 & 1.46 & 1.71 & 1.44 & 1.70 & 1.23 & 1.23 & 1.04 & 1.24 \\
\hline 10 & 1.44 & 0.98 & 1.38 & 1.52 & 1.44 & 1.42 & 1.40 & 1.29 & 1.56 & 1.60 \\
\hline A. D. & 0 & 1 & 2 & 3 & 4 & 5 & 6 & 7 & 8 & 9 \\
\hline 0 & 1.68 & 1.58 & 1.70 & 1.93 & 1.83 & 1.56 & 1.67 & 1.24 & 1.39 & 1.65 \\
\hline 10 & 1.92 & 1.60 & 1.30 & 1.21 & 1.33 & 0.89 & 1.24 & 1.72 & 1.96 & 1.58 \\
\hline 20 & 1.57 & 1.68 & 1.74 & 1.80 & 1.71 & 1.82 & 1.83 & 1.78 & 2.01 & 1.94 \\
\hline 30 & 1.87 & 1.76 & 1.76 & 1.74 & 1.80 & 2.06 & 2.39 & 1.74 & 1.69 & 2.00 \\
\hline 40 & 2.11 & 1.75 & 1.83 & 1.64 & 1.88 & 2.06 & 2.00 & 1.72 & 1.60 & 1.61 \\
\hline 50 & 1.44 & 1.27 & 1.19 & 1.40 & 1.44 & 1.45 & 0.98 & 1.00 & 1.42 & 1.54 \\
\hline 60 & 1.21 & 1.17 & 1.26 & 1.09 & 1.03 & 1.23 & 1.38 & 1.31 & 1.36 & 0.86 \\
\hline 70 & 1.42 & 1.20 & 1.49 & 1.55 & 1.41 & 1.33 & 1.25 & 1.21 & 1.27 & 1.32 \\
\hline 80 & 1.28 & 1.59 & 1.52 & 1.48 & 1.54 & 1.77 & 1.48 & 1.38 & 1.50 & 1.44 \\
\hline 90 & 1.50 & 1.42 & 1.46 & 1.35 & 1.15 & 1.15 & 1.25 & 1.33 & 1.06 & 1.23 \\
\hline 100 & 0.86 & 1.25 & 1.11 & 1.18 & 1.17 & 1.14 & 0.80 & 1.17 & 0.99 & 0.44 \\
\hline 110 & 1.04 & 1.28 & 1.82 & 1.85 & 1.26 & 1.16 & 1.26 & 1.38 & 1.31 & 1.38 \\
\hline 120 & 1.13 & 1.07 & 1.20 & 1.06 & 0.99 & 1.05 & 1.05 & 1.06 & 0.92 & 1.13 \\
\hline 130 & 0.98 & 0.96 & 0.92 & 0.90 & 0.92 & 0.93 & 1.19 & 1.14 & 1.12 & 1.07 \\
\hline 140 & 1.02 & 1.00 & 0.93 & 1.10 & 1.10 & 1.10 & 1.12 & 1.14 & 1.27 & 1.12 \\
\hline 150 & 1.01 & 0.98 & 0.59 & 0.99 & 1.16 & 0.92 & 1.19 & 0.93 & 1.08 & 1.10 \\
\hline 160 & 0.93 & 0.98 & 1.04 & 1.24 & 1.02 & 1.04 & 1.06 & 0.79 & 0.54 & 0.55 \\
\hline 170 & 0.81 & 0.99 & 0.79 & 0.74 & 1.00 & 1.20 & 1.01 & 1.17 & 0.87 & 0.91 \\
\hline 180 & 0.98 & 0.86 & 1.15 & 1.02 & 1.00 & 1.13 & 1.12 & 1.16 & 0.98 & 0.49 \\
\hline 190 & 0.87 & 1.29 & 1. 52 & 1.59 & 1.47 & 1.40 & 1.35 & 1.42 & 1.28 & 1.39 \\
\hline 200 & 1.25 & 1.42 & 1.37 & 1.58 & 1.58 & 1.81 & 1.68 & 1.19 & 1.18 & 1.30 \\
\hline 210 & 1.40 & 1.40 & 1.28 & 1.11 & 1.06 & 1.07 & 1.30 & 1.06 & 1.98 & 0.94 \\
\hline 220 & 0.82 & 1.10 & 1.09 & 1.04 & 1.10 & 0.90 & 0.77 & 1.00 & 1.15 & 0.92 \\
\hline 230 & 0.93 & 0.94 & 1.10 & 1.09 & 1.03 & 1.06 & 0.66 & 0.99 & 0.98 & 0.75 \\
\hline 240 & 0.98 & 1.07 & 0.88 & 0.91 & 1.02 & 0.94 & 1.06 & 1.04 & 0.98 & 0.97 \\
\hline 250 & 1.00 & 0.89 & 0.95 & 0.82 & 0.96 & 0.90 & 0.74 & 0.81 & 0.80 & 0.91 \\
\hline 260 & 1.02 & 1.00 & 0.92 & 0.97 & 1.01 & 0.95 & 0.89 & 1.02 & 1.03 & 1.01 \\
\hline 270 & 0.84 & 0.61 & 0.92 & 0.92 & 0.60 & 0.90 & 0.84 & 0.96 & 0.91 & 0.88 \\
\hline 280 & 1.04 & 0.85 & 0.95 & 0.98 & 0.94 & 0.88 & 0.98 & 0.96 & 0.92 & 0.99 \\
\hline 290 & 1.08 & 1.10 & 0.74 & 0.87 & 0.85 & 1.14 & 0.96 & 0.84 & 1.14 & 0.98 \\
\hline 300 & 0.91 & 1.08 & 1.00 & 1.03 & 0.96 & 0.56 & 0.60 & 0.76 & 0.87 & 0.96 \\
\hline 310 & 0.98 & 1.09 & 0.92 & 0.60 & 1.02 & 0.89 & 0.85 & 0.91 & 1.04 & 0.85 \\
\hline 320 & 0.92 & 0.82 & 0.99 & 0.86 & 0.89 & 0.87 & 0.83 & 0.85 & 1.04 & 0.78 \\
\hline 330 & 0.78 & 0.84 & 0.78 & 0.46 & 0.68 & 0.88 & 0.76 & 0.82 & 0.80 & 0.68 \\
\hline 340 & 0.62 & 0.75 & 0.91 & 0.81 & 0.54 & 0.78 & 0.74 & 0.82 & 0.97 & 0.68 \\
\hline 350 & 1.04 & 0.86 & 0.90 & 0.78 & 0.93 & 0.88 & 0.88 & 0.72 & 0.98 & 0.89 \\
\hline 360 & 0.91 & 0.80 & 1.00 & 1.05 & 1.21 & 1.12 & 1.35 & 1.32 & 1.07 & 0.74 \\
\hline 370 & 0.81 & 1.08 & 1.23 & 1.47 & 1.73 & 1.79 & 1.56 & 1.08 & 1.34 & 1.68 \\
\hline 380 & 1.83 & 1.89 & 1.95 & 1.82 & 1.79 & 1.75 & 1.13 & 1.30 & 1.60 & 1.62 \\
\hline 390 & 1.59 & 1.64 & 1.54 & 1.63 & 1.66 & 1.60 & 1.40 & 1.44 & 1.26 & 1.31 \\
\hline 400 & 1.79 & 1.92 & 1.88 & 1.53 & 1.43 & 1.76 & 1.77 & 1.62 & 1.61 & 1.68 \\
\hline 410 & 1.68 & 1.83 & 1.73 & 1.68 & 1.52 & 1.81 & 2.03 & 1.91 & 1.90 & 2.09 \\
\hline 420 & 2.19 & 1.92 & 1.92 & 1.82 & 1.64 & 1.76 & 2.14 & 2.34 & 2.19 & 2.12 \\
\hline 430 & 2.07 & 1.92 & 1.79 & 1.66 & 1.78 & 1.66 & 1.90 & 1.80 & 1.59 & 1.62 \\
\hline 440 & 1.68 & 1.89 & 1.27 & 1.55 & 1.58 & 1.89 & 1.69 & 1.48 & 1.20 & 1.39 \\
\hline 450 & 1.37 & 1.24 & 1.18 & 1.21 & 1.28 & 1.34 & 1.59 & 1.60 & 1.44 & 1.36 \\
\hline 460 & 1.38 & 1.32 & 1.26 & 1.35 & 1.30 & 1.39 & 1.21 & 1.29 & 1.29 & 1.30 \\
\hline 470 & 1.50 & 1.47 & 1.29 & 1.41 & 1.23 & 1.56 & 1.52 & 1.27 & 1.48 & 1.65 \\
\hline 480 & 1.57 & 1.61 & 1.67 & 1.73 & 1.76 & 1.66 & 1.70 & 1.68 & 1.54 & 1.76 \\
\hline
\end{tabular}


Sequoia record: Group of 1915; 11 tree-continued.

\begin{tabular}{|c|c|c|c|c|c|c|c|c|c|c|}
\hline A. D. & 0 & 1 & 2 & 3 & 4 & 5 & 6 & 7 & 8 & 9 \\
\hline 490 & 1.48 & 1.47 & 1.60 & 1.52 & 1.76 & 1.92 & 1.94 & 1.51 & 1.50 & 1.88 \\
\hline 500 & 1.55 & 1.48 & 1.44 & 1.61 & 1.85 & 1.70 & 1.52 & 1.31 & 1.47 & 1.62 \\
\hline 510 & 1.61 & 1.92 & 1.39 & 1.27 & 1.19 & 1.26 & 1.39 & 1.07 & 0.68 & 1.10 \\
\hline 520 & 0.94 & 1.33 & 1.45 & 1.14 & 1.02 & 1.15 & 1.08 & 1.11 & 1.24 & 1.29 \\
\hline 530 & 1.14 & 1. 27 & 1.24 & 1.26 & 1.18 & 1.27 & 1.30 & 1.33 & 1.21 & 0.78 \\
\hline 540 & 0.94 & 0.99 & 0.86 & 0.91 & 0.96 & 1.19 & 1.15 & 1.16 & 1.08 & 0.98 \\
\hline 550 & 0.97 & 1.03 & 0.72 & 0.48 & 0.45 & 0.82 & 1.09 & 0.79 & 1.07 & 1.34 \\
\hline 560 & 1.61 & 1.23 & 1.45 & 1.21 & 1.20 & 1.07 & 1.13 & 1.27 & 1.08 & 1.14 \\
\hline 570 & 0.84 & 0.98 & 1.03 & 1.08 & 1.16 & 1.04 & 0.99 & 0.92 & 0.94 & 1.09 \\
\hline 580 & 0.94 & 1.04 & 0.78 & 0.99 & 0.99 & 0.98 & 0.77 & 1.29 & 1.16 & 1.12 \\
\hline 590 & 1.16 & 0.95 & 1.22 & 1.09 & 1.06 & 1.10 & 1.27 & 1.00 & 0.98 & 0.95 \\
\hline 600 & 1.17 & 1.19 & 0.97 & 1.29 & 1.22 & 1.27 & 1.12 & 1.06 & 1.45 & 1. 30 \\
\hline 610 & 1.36 & 1.40 & 1.02 & 1.28 & 1.54 & 1.52 & 1.61 & 1.74 & 1.67 & 1.72 \\
\hline 620 & 1.28 & 1.46 & 1.62 & 1.71 & 1.35 & 1.30 & 1.23 & 1.54 & 1. 53 & 1.20 \\
\hline 630 & 1.28 & 1.24 & 1.28 & 1.24 & 1.47 & 1.35 & 1.36 & 1.28 & 1.26 & 1.14 \\
\hline 640 & 0.84 & 1.10 & 1.16 & 1.45 & 1.64 & 1.43 & 1.30 & 1.36 & 1.50 & 1.62 \\
\hline 650 & 1.22 & 1.07 & 1.38 & 1.52 & 1.49 & 1.57 & 1.31 & 1.27 & 1.46 & 1.03 \\
\hline 660 & 1.23 & 1.21 & 1.57 & 1.78 & 1.37 & 1.51 & 1.41 & 1.50 & 1.52 & 1.32 \\
\hline 670 & 1.54 & 1.39 & 1.49 & 1.44 & 1.49 & 1.51 & 1.21 & 1.10 & 1.41 & 1.07 \\
\hline 680 & 1.54 & 1.55 & 1.53 & 1.14 & 1.20 & 1.19 & 1.25 & 1.35 & 1.28 & 1.21 \\
\hline 690 & 1.33 & 1.15 & 1.53 & 1.67 & 1.49 & 1.36 & 1.17 & 1.22 & 1.38 & 0.55 \\
\hline 700 & 1.20 & 1.58 & 1.37 & 1.41 & 1.50 & 1.47 & 1.60 & 1.01 & 1.29 & 1. 30 \\
\hline 710 & 1.30 & 1.34 & 1.22 & 1.16 & 1.04 & 0.93 & 1.15 & 1.23 & 1.00 & 0.74 \\
\hline 720 & 1.08 & 1.18 & 0.97 & 1.09 & 0.96 & 1.25 & 1.19 & 1.08 & 0.80 & 1.14 \\
\hline 730 & 1.27 & 1.24 & 1.33 & 1.49 & 1.32 & 1.27 & 1.33 & 1.59 & 1.34 & 1.10 \\
\hline 740 & 1.25 & 1.22 & 0.84 & 1.41 & 1.31 & 1.51 & 1.13 & 1.22 & 1.08 & 1.24 \\
\hline 750 & 1.16 & 0.87 & 1.04 & 0.96 & 0.88 & 0.90 & 1.04 & 1.08 & 1.19 & 1. 20 \\
\hline 760 & 0.88 & 0.96 & 0.56 & 0.82 & 0.75 & 1.00 & 0.91 & 0.95 & 0.94 & 1.10 \\
\hline 770 & 1.16 & 1.39 & 1.48 & 1.29 & 1.20 & 1.50 & 1.34 & 1.39 & 1.47 & 1.17 \\
\hline 780 & 1.62 & 1.12 & 1.04 & 1.23 & 1.36 & 1.17 & 0.96 & 1.11 & 0.87 & 1.10 \\
\hline 790 & 1.40 & 1.13 & 1.16 & 1.12 & 0.99 & 1.18 & 1.39 & 0.75 & 1.17 & 1. 20 \\
\hline 800 & 1.19 & 1.11 & 1.18 & 1.19 & 0.88 & 1.01 & 1.42 & 1.04 & 1.11 & 0.73 \\
\hline 810 & 0.99 & 1.22 & 1.23 & 1.15 & 1.24 & 1.28 & 1.26 & 1.17 & 1.02 & 0.83 \\
\hline 820 & 1.10 & 1.17 & 1.32 & 0.89 & 1.09 & 1.08 & 1.25 & 1.30 & 1.29 & 1.16 \\
\hline 830 & 1.10 & 1.24 & 1.38 & 1.07 & 1.18 & 1.26 & 1.25 & 1.32 & 1.27 & 1.13 \\
\hline 840 & 0.99 & 1.10 & 1.10 & 1.35 & 1.19 & 0.97 & 1.21 & 0.92 & 1.23 & 1.23 \\
\hline 850 & 1.15 & 1.16 & 1.16 & 1.22 & 1.09 & 0.99 & 1.06 & 1.01 & 1.13 & 1.14 \\
\hline 860 & 1.19 & 1.00 & 1.04 & 1.04 & 1.12 & 0.67 & 1.23 & 1.20 & 0.63 & 1.14 \\
\hline 870 & 1.32 & 1.08 & 1.03 & 0.97 & 1.18 & 1.10 & 0.98 & 1.12 & 1.17 & 1.18 \\
\hline 880 & 1.24 & 1.35 & 1.41 & 1.13 & 1.22 & 1.53 & 1.42 & 1.08 & 1.29 & 1.15 \\
\hline 890 & 1.00 & 1.05 & 1.33 & 1.33 & 1.10 & 1.13 & 1.24 & 1.31 & 1.11 & 1.21 \\
\hline 900 & 1.03 & 1.25 & 1.10 & 1.07 & 1.12 & 1.13 & 1.03 & 1.01 & 1.10 & 1.00 \\
\hline 910 & 1.06 & 1.15 & 1.10 & 0.84 & 1.17 & 0.97 & 1.15 & 1.28 & 1.06 & 1.09 \\
\hline 920 & 1.20 & 1.08 & 1.24 & 1.05 & 0.87 & 1.04 & 1.09 & 1.09 & 1.03 & 0.90 \\
\hline 930 & 0.74 & 0.98 & 1.00 & 0.72 & 1.05 & 1.01 & 1.02 & 1.29 & 1.05 & 1.21 \\
\hline 940 & 1.24 & 1. 20 & 1.15 & 0.99 & 0.91 & 1.06 & 1.19 & 1.28 & 1.01 & 1.01 \\
\hline 950 & 1.20 & 1.09 & 0.94 & 0.97 & 0.47 & 0.91 & 1.08 & 0.71 & 0.89 & 1.07 \\
\hline 960 & 1.22 & 0.87 & 0.92 & 1.15 & 1.06 & 1.07 & 0.98 & 1.16 & 1.33 & 1. 28 \\
\hline 970 & 1.50 & 1.14 & 1.09 & 1.22 & 1.15 & 1.01 & 1.08 & 1.14 & 1.00 & 0.82 \\
\hline 980 & 0.62 & 0.76 & 0.92 & 0.96 & 1.19 & 1.36 & 1.15 & 1.24 & 1.21 & 1. 33 \\
\hline 990 & 1.28 & 1.41 & 1.36 & 1.40 & 1.17 & 1.04 & 1.04 & 1.39 & 1.42 & 1. 24 \\
\hline 1000 & 1. 30 & 1.44 & 1.45 & 1.55 & 1.35 & 1.20 & 1.46 & 1.36 & 1.35 & 1.31 \\
\hline 1010 & 1.11 & 1.34 & 1.22 & 1.20 & 1.20 & 1.37 & 1.58 & 1.54 & 1.36 & 1.60 \\
\hline 1020 & 1.49 & 1.38 & 1.38 & 1.56 & 1.56 & 1.10 & 1.31 & 1.32 & 1.16 & 1.13 \\
\hline 1030 & 1.14 & 1.08 & 0.98 & 1.10 & 1.19 & 1.08 & 1.12 & 1.22 & 1.21 & 1.06 \\
\hline 1040 & 1.00 & 1.23 & 1.28 & 1.03 & 0.99 & 1.20 & 0.99 & 0.88 & 0.93 & 0.95 \\
\hline 1050 & 1.02 & 1.02 & 0.76 & 0.70 & 0.79 & 0.84 & 0.94 & 0.81 & 0.82 & 0.58 \\
\hline 1060 & 0.58 & 0.91 & 0.89 & 0.92 & 1.19 & 1.17 & 1.08 & 1.25 & 1.36 & 1.13 \\
\hline 1070 & 0.90 & 1.24 & 0.99 & 1.08 & 1.21 & 1.32 & 1.30 & 1.15 & 1.08 & 1.16 \\
\hline
\end{tabular}


Sequoia record: Group of $1915 ; 11$ trees-continued.

\begin{tabular}{|c|c|c|c|c|c|c|c|c|c|c|}
\hline A. D. & 0 & 1 & 2 & 3 & 4 & 5 & 6 & 7 & 8 & 9 \\
\hline 1080 & 1.17 & 1.08 & 0.71 & 1.11 & 1.09 & 1.10 & 0.95 & 1.14 & 1.05 & 1.07 \\
\hline 1090 & 0.88 & 0.89 & 0.82 & 0.64 & 0.99 & 1.13 & 0.93 & 1.06 & 0.76 & 0.83 \\
\hline 1100 & 1. 11 & 1.04 & 1.05 & 0.92 & 0.90 & 1.00 & 0.87 & 0.84 & 0.86 & 1.05 \\
\hline 1110 & 0.93 & 0.96 & 0.96 & 1.01 & 1.00 & 1.10 & 1.24 & 1.17 & 1.24 & 1.07 \\
\hline 1120 & 1.18 & 1.17 & 1.11 & 0.93 & 1.02 & 1.19 & 0.57 & 0.70 & 0.99 & 1.00 \\
\hline 1130 & 1.00 & 0.88 & 0.90 & 0.91 & 0.90 & 0.97 & 1.11 & 0.96 & 0.95 & 0.94 \\
\hline 1140 & 0.92 & 0.92 & 1.08 & 0.96 & 0.89 & 0.83 & 0.89 & 0.97 & 0.89 & 1.07 \\
\hline 1150 & 0.88 & 0.76 & 0.52 & 0.63 & 0.83 & 0.84 & 0.34 & 0.65 & 0.85 & 0.99 \\
\hline 1160 & 1.00 & 0.93 & 0.80 & 1.06 & 0.87 & 1.00 & 1.02 & 1.05 & 0.85 & 1.12 \\
\hline 1170 & 0.84 & 0.81 & 0.87 & 0.82 & 0.91 & 0.63 & 0.72 & 0.60 & 0.80 & 0.89 \\
\hline 1180 & 0.88 & 1.06 & 0.92 & 0.71 & 0.99 & 0.87 & 1.06 & 0.93 & 1.12 & 1.10 \\
\hline 1190 & 1.00 & 1.00 & 0.98 & 0.90 & 1.04 & 1.06 & 0.91 & 0.98 & 0.94 & 1.04 \\
\hline 1200 & 1.09 & 1.08 & 0.96 & 0.94 & 1.00 & 1.04 & 0.79 & 0.85 & 0.82 & 1.02 \\
\hline 1210 & 0.98 & 0.86 & 0.93 & 0.92 & 1.06 & 0.86 & 0.96 & 0.84 & 0.74 & 1.00 \\
\hline 1220 & 0.93 & 0.83 & 0.82 & 0.87 & 0.87 & 0.91 & 0.82 & 0.73 & 0.91 & 0.97 \\
\hline 1230 & 0.95 & 0.73 & 0.83 & 0.91 & 0.80 & 0.78 & 0.64 & 0.62 & 0.78 & 0.79 \\
\hline 1240 & 0.84 & 0.86 & 0.76 & 0.74 & 0.77 & 0.64 & 0.93 & 0.87 & 1.04 & 0.80 \\
\hline 1250 & 0.57 & 0.70 & 0.84 & 0.84 & 0.70 & 0.71 & 0.99 & 0.88 & 0.97 & 1.00 \\
\hline 1260 & $0.9 \overline{7}$ & 0.85 & 0.80 & 0.57 & 0.54 & 0.85 & 0.92 & 0.86 & 0.79 & 0.70 \\
\hline 1270 & 0.97 & 0.99 & 0.96 & 0.81 & 1.06 & 1.05 & 0.87 & 0.97 & 1.10 & 0.72 \\
\hline 1280 & 0.83 & 0.91 & 0.94 & 1.00 & 0.74 & 0.58 & 0.86 & 0.94 & 0.85 & 0.87 \\
\hline 1290 & 1.00 & 1.00 & 0.71 & 0.85 & 0.98 & 0.74 & 0.48 & 0.85 & 0.78 & 1.01 \\
\hline 1300 & 0.91 & 0.97 & 1.03 & 1.01 & 1.17 & 1.20 & 1.21 & 1.27 & 1.15 & 0.95 \\
\hline 1310 & 1.17 & 1.06 & 1.22 & 1.28 & 1.14 & 1.24 & 0.85 & 1.03 & 1 & 1.20 \\
\hline 1320 & 1.03 & 1.07 & 1.12 & 1.17 & 1.04 & 0.92 & 1.24 & 1.34 & 1.19 & 1.18 \\
\hline 1330 & 1.35 & 1.31 & 1.02 & 1.05 & 1.16 & 0.90 & 1.14 & 1.20 & 12 & 1.14 \\
\hline 1340 & 1.25 & 1.26 & 1.16 & 1.09 & 1.15 & 1.17 & 1.11 & 1.06 & 1.01 & 1.26 \\
\hline 1350 & 1.03 & 0.93 & 0.6 & 0.97 & 0.96 & 1.10 & 1.27 & 1.09 & & 1.03 \\
\hline 1360 & 1.05 & 0.97 & 1.10 & 1.21 & 1.15 & 0.83 & 1.06 & 1.22 & 1.20 & 1.15 \\
\hline 1370 & 1.06 & 1.05 & 1.15 & 1.14 & 1.05 & 1.01 & 0.95 & 0.7 & & 1.04 \\
\hline 1380 & 1.21 & 1.21 & 1.03 & $\cdot 1.09$ & 1.04 & 1.09 & 1.04 & 0.97 & 1.00 & 1.13 \\
\hline 1390 & 0.81 & 0.87 & 0.98 & 1.03 & 1.01 & 0.87 & 0.81 & 0.91 & 0.90 & 0.92 \\
\hline 1400 & 0.84 & 0.86 & 0.74 & 0.80 & 0.86 & 0.88 & 0.88 & 0.84 & 0.76 & 0.91 \\
\hline 1410 & 0.72 & 0.89 & 0.94 & 0.75 & 1.05 & 1.10 & 1.1 & 1.10 & 1.11 & 1.05 \\
\hline 1420 & 1.27 & 1.02 & 1.25 & 1.16 & 1.13 & 0.92 & 0.70 & 0.9 & 0.8 & 0.90 \\
\hline 1430 & 0.83 & 0.81 & 0.83 & 0.85 & 0.81 & 0.78 & 0.84 & 0.8 & 0.8 & 0.79 \\
\hline 1440 & 0.80 & 0.81 & 0.74 & 0.72 & 0.75 & 0.88 & 0.79 & 0.74 & 0.78 & 0.71 \\
\hline 1450 & 0.77 & 0.75 & 0.66 & 0.74 & 0.71 & 0.77 & 0.7 & 0.68 & 0.75 & 0.78 \\
\hline 1460 & 0.77 & 0.78 & 0.81 & 0.76 & 0.70 & 0.74 & 0.7 & 0.84 & 0.66 & 0.77 \\
\hline 1470 & 0.91 & 0.76 & 0.72 & 0.61 & 0.7 & 0.71 & 0. & 0.8 & 0.8 & 0.57 \\
\hline 1480 & 0.77 & 0.86 & 0.88 & 0.94 & 1.00 & 0.78 & 0.8 & 0.82 & 0.94 & 0.94 \\
\hline 1490 & 0.88 & 0.87 & 0.84 & 0.86 & 0.8 & 1.00 & 0.8 & 0.82 & 0.89 & 0.66 \\
\hline 1500 & 0.63 & 0.85 & 1.06 & 0.9 & & 0. & 1.0 & 0.98 & 1.05 & 1.07 \\
\hline 15 & 0.8 & 0.86 & 1.0 & 1.0 & 0. & 0.8 & 0. & 0.93 & 0.66 & 0.91 \\
\hline 1520 & 0.94 & 0.9 & 0.8 & 0. & 1 & 1.1 & 1.0 & 0.8 & 1.03 & 0.60 \\
\hline 15 & 0.9 & 1 & 0 & 0.7 & 1 & 1.0 & 0. & 0.8 & 0.96 & 1.12 \\
\hline & 0.88 & 0. & & & & & & 1.0 & 0.73 & 0.94 \\
\hline 155 & 0.8 & 0. & 0 . & 0.9 & 0.7 & 0.8 & 0. & 0.85 & 0.89 & 0.82 \\
\hline 1560 & 0.87 & 0. & & & 0.90 & 0.87 & 0 . & 0.81 & 0.89 & 0.78 \\
\hline & 0.82 & 0.4 & 0.7 & 0.8 & 0.77 & 0.76 & 0. & 0.78 & 0.70 & 0.50 \\
\hline & 0 & 0.53 & 0. & 0.78 & & & & 0.80 & 0.75 & 0.87 \\
\hline & 0. & 0.7 & & 0.81 & & & 0. & 0.81 & 0.79 & 0.75 \\
\hline & 0. & & & 0. & & 0 & & 0.81 & 0.88 & 0.88 \\
\hline & & & & & & & & 0.94 & 0.84 & 0.79 \\
\hline & & & & & & & & 0.89 & 0.97 & 0.89 \\
\hline 16: & 0.91 & 0. & & & & & 0.93 & 0.66 & 0.81 & 0.92 \\
\hline & & & & & & & & & 0.91 & 0.94 \\
\hline 1650 & 0.77 & 0.86 & 0. & 0.74 & 0.52 & 0.58 & 0.78 & 0.75 & 0.84 & 0.74 \\
\hline 1660 & 0.83 & 0.83 & 0.79 & 0.81 & $\sigma .79$ & $\sigma .85$ & 0.86 & 0.67 & 0.82 & 0.70 \\
\hline
\end{tabular}


APPENDIX.

Sequoia recond: Group of $1915 ; 11$ trees-continued.

\begin{tabular}{|c|c|c|c|c|c|c|c|c|c|c|}
\hline A. D. & 0 & 1 & 2 & 3 & 4 & 5 & 6 & 7 & 8 & 9 \\
\hline 1670 & 0.68 & 0.73 & 0.81 & 0.86 & 0.89 & 0.91 & 0.77 & 1.03 & 0.89 & 0.85 \\
\hline & 0.94 & 0.78 & 0.73 & 0.82 & 0.76 & & 0.71 & & & 0.73 \\
\hline 16 & 0.7 & 0.54 & 0.78 & 0.76 & 0.79 & 0.79 & 0.73 & 0.79 & 0.65 & 0.67 \\
\hline 170 & 0.64 & 0.6 & 0.90 & 0.65 & 0.72 & 0.89 & 0.64 & 0.72 & & 0.95 \\
\hline 1710 & 0.74 & 0.67 & 0.68 & 0.76 & 0.73 & 0.70 & 0.84 & 0.88 & 0.74 & 0.71 \\
\hline 1720 & 0.86 & 0.70 & 0.7 & 0. & 0. & 0. & 0.91 & & & 0.48 \\
\hline 1730 & 0.85 & 0.89 & 0.97 & 0.9 & 1.01 & 0.5 & 0.86 & 0.91 & 0.98 & 0.73 \\
\hline 174 & 0.8 & 1.04 & 0.96 & 0.8 & 0.8 & 1. & 0.90 & 1.01 & 0.83 & 0.88 \\
\hline 175 & 1.11 & 0.99 & 0.96 & 0.8 & 0.9 & 0. & 0.69 & 0.79 & 0.93 & 1.00 \\
\hline 17 & 1.0 & 1.13 & 1.01 & 1. & 1.0 & 0. & 1.14 & 1.21 & 1.25 & 1.05 \\
\hline 17 & 1.10 & 1.16 & 1.16 & 1.0 & 1.1 & 1. & 0.85 & 0.48 & 0.73 & 0.90 \\
\hline 17 & 0.97 & 0.87 & 0.52 & 0.6 & 0.8 & 0. & 1.05 & 1. & 0.82 & 0.95 \\
\hline 12 & 1.0 & 1.03 & 1.07 & 0.8 & 0.8 & 0. & 0. & 1. & 1.14 & 1.10 \\
\hline 1800 & 1.06 & 1.13 & 1.09 & 1.0 & 0.8 & 0. & 0. & 0. & 0.83 & 0.81 \\
\hline & $0 . \varepsilon$ & 0.99 & 0.79 & 0.88 & 1.03 & 0. & 0.99 & 1. & 0.78 & 0.88 \\
\hline 18 & 0.88 & 0.84 & 0.74 & 0.75 & 0.71 & 0. & 0.94 & 0.78 & 0.77 & 0.55 \\
\hline 1 & 0.7 & 0. & 0. & 0. & 0. & 0. & 0.86 & 0. & 0 & 0.81 \\
\hline 184 & $0.7 ?$ & 0.52 & 0.7 & 0. & 0. & 0. & 0.90 & 7 & & 0.95 \\
\hline & 0.8 & & 0. & 1. & 0. & 0. & 0.79 & 0. & & 0.74 \\
\hline 186 & 0.91 & $0 . \varepsilon$ & 0.86 & 0.84 & 0. & 0. & 0.87 & 0 . & 0.88 & 0.80 \\
\hline & 0.7 & 0. & 0. & 0. & 0 . & 0. & 0.99 & 0. & 1.11 & 0.99 \\
\hline & 1.0 & 1.2 & 1. & 1. & 1. & 1. & 1.10 & 0 . & 1.12 & 1.16 \\
\hline & 1.2 & 1.1 & 0. & 1. & 1. & 1.11 & 1.09 & 1. 10 & 0.84 & 0.90 \\
\hline & 1.11 & 0.9 & 0.76 & 0. & 0.96 & 0.91 & 0.90 & 0.93 & 0.82 & 0.89 \\
\hline 1910 & 0.78 & 0.90 & 0.87 & 0.83 & 0.85 & & & 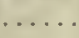 & & \\
\hline
\end{tabular}

Nots. - The dates in table 4 on page 45 should be altered by one year to agree with those in table 5 on page 52 . 


\section{BIBLIOGRAPHY.}

Anse, Cuevruavd. 1905. First report on relation between climate and crops. Bull. U. S. Weather Bureau 36.

ABвor, C. F. 1902. The relation of the sunspot cycle to meteorology. Mon. Wea. Rev. 1902, April: 179.

1911. The sun.

1913. Annals of astrophysical observatory of the Smithsonian Institution.

19132. The variation of the sun. Astroph. Jour. 38: 181, September 1913.

1918. On periodicity in solar variation. Smith. Misc. Coll. 69: No. 6, June 1918.

ANGOT, ALFRed. 1903. The simultaneous variations of the sunspots and terrestrial atmospheric temperatures. Ann. Soc., Met. France, June 1903. Transl. Mon. Wea. Rev., August 1903: 371 .

ANTEvs, ERNBx. 1917. Die Jahresringe der Holzgewächse und die Bedeutung derselben als klimatischer Indikator. Progressus Rei Botanicae, Fünfter Band.

Arctowsir, H. 1909. L'Enchatnement des variations climatique. Soc. Belg. Astron. 1909.

—. 1912. Studies on climates and crops; corn erops in the United States. Bull. Amer. Geog. Soc, Vol. XLIX: 745-760. October 1912.

1913. On some climatic changes recorded in New York City. Studies on climates and crops. Bull. Amer. Geog. Soo., Vol. XLV: 117-131. February 1913.

1914. About climatic variations. Amer. Jour. Sci., Vol, XXXVII: 305-315, April 1914. 1914. A study of the changes in the distribution of temperature in Europe and North America during the years 1900-1909. Ann. N. Y. Acad. Sci., Vol. XXIV: $39-113$.

. 1915. On storm frequency changes in the United States. Mon. Wea. Rev., August $1915,43: 379-389$.

1915. Notices sur quelques relations numériques entre facules et taches solaires. Mem. Soc. Spett. italiani, Vol. IV, Serie 2, 1915: 181-184.

19153. Recherches sur les variations du rapport entre facules et taches solaires. Mem. Soc. Bpett. italiani, Vol. IV, Serie 2, 1915: 185-190.

19154. Sur les faculea solaires. Comptes Rendus, t. 161, page 434, séance du octobre 1915.

1915. Sur les variations du rapport entre facules et taches solaires. Comptes Rendus, t. 161, page 485, seance du 26 octobre 1915 .

1916. Les variations de la latitude heliographique moyenne des taches solaires. Comptes Rendus, t. 162, page 501, séance du 3 avril 1916.

$1910^{2}$. De l'influence de la terre sur la fréquence et la latitude heliographique moyenne des taches solaires. Comptes Rendus, t. 162, page 593, séance du 17 avril 1916.

Baxkz, A. L. 1913. The effect of smoke and gases on vegetation. Proc. Iowa Acad. Sci., Vol. XX: $169-188$.

Brozsow, F. H. 1903. Studies on the circulation of the atmospheres of the sun and the earthII. Synchronism of the variations of the solar prominences with the terrestrial barometric pressures and the temperature. Mon. Wea. Rev., November 1903, Vol. 31: 509.

$1903^{2}$. Studies of the circulation of the atmospheres of the sun and earth $-V$. The variable action of the sun and its effect on terrestrial weather conditions. U. S. Weather Bureau.

1909. Important problems in climatology. Mon. Wea. Rev., 1909, 37: 979-982.

1910. Studies on the general circulation of the earth's atmosphere. Amer. Jour. Sei., Vol. XX1X, April 1910: 277-292.

$1810^{2}$. The circulations of the atmospheres of the earth and of the sun. Pop. Sci. Monthly, May 1910: 437-461.

1910. The inversion of temperature amplitudes and departures in the United States. Amer. Jour. Sci., Vol. XXX, August 1910: 115-127.

Boave, E. E. 1905. Annual rings of tree-growth. Mon. Wea. Rev, 33: 250. June 1905.

BRUCKNER, E. 1890. Klima-Schwankungen seit 1700. Wien, 1890.

Buchas, A. 1903. The rainfall of Scotland in relation to sunspots. Jour. Scot. Met. Soc., 12: 117. 1903.

Carpenter, F. A. 1914. Clouds of California. Los Angeles. U. S. Weather Bureau Office, 1914.

Chayton, H. H. 1884-85. A lately discovored cycle. Amer. Met. Jour., I, 130, 528.

- 1915. A study of the moving waves of weather in South America. Quart. Jour. Roy. Met. Boo, Vol. XII, No. 175, July 1915: 202-208.

Cunuentw, Frederic E. 1916. Plant succession: An analysis of the development of vegetation. Carnegie Inst. Wash. Pub. No. 242. 
Cuevenarn, J. F. 1913. The effect of soot in smoke on vegetation. Mellon Institute of Industrial Research and School of Specific Industries. Smoke Investigation Bull. No. 7.

Crovgr; H. W. 1905. Synchronous variations in solar and terrestrial phenomena. Astroph. Jour., 22: 42-75. July 1905.

Contie, A. L. 1913. The mode of propagation of the sun's influence in magnetic atorms. Mon. Not. Roy. Ast. Soc., 73: 539. May 1913.

Dovaus9s, A. E. 1909. Weather cycles in the growth of big trees. Mon. Wea. Rev., une 1909: 225-237.

1914. Method of estimating rainfall by the growth of trees. Bull. Amer. Geog. Soc., Vol. XLVI: 321-335, May 1914.

19142. A photographic periodogram of the sunspot numbers. Astroph. Jour., Vol. XL, No. $3 ; 326-331$, October 1914.

1914. A method of estimating rainfall by the growth of trees. The olimatic factor as illustrated in arid America, by E. Huntington. Carnegie Inst. Wash. Pub. No. 192, Chapter XI: 101-121.

1915. An optical periodograph. Astroph. Jour., Vol. XLI, No. 3: 173-186. April 1915. 19152. The Callendar sunshine recorder and some of the world-wide problems to which this instrument can be applied. Proc. 2d Pan-Amer. Sci. Cong., Sec. II: $570-579$.

1917. Climatic reeords in the trunks of trees. Amer. Forestry, December 1917: $732-735$.

Evmremp, John, Thomas RoYds, and S. Sitarama Aryzr. 1912. On the relative numbers of prominences observed on the eastern and western limbs. Kodaikanal Bull. 28: 509-516. 1912.

1913. The apparent effect of planets on the distribution of prominences. Kodaikanal Bull. 35: 37-43. 1913.

GrbB, David. 1914. The periodogram analysis of the variations of SS Cygni. Mon. Not. Roy. Ast. Soc, 74: 678. Juno 1914.

Gremsx, A. W. 1891. Irrigation and water storage in the arid regions. Report of the Chief Signal Officer to the House of Representatives.

Hale, G. E. 1908. Solar Vortices. Astroph. Jour., 28: 100, reprinted in Cont. Mt. Wilson Sol. Obs. No. 26.

19082. The study of stellar evolution. The University of Chicago Press.

1908. On the probable existence of a magnetic field in sunspota. Astroph. Jour., 28: 363.

1913. Preliminary researches of an attempt to detect the general magnetic field of the sun. Astroph. Jour., 38, July 1913, reprinted in Cont. Mt. Wilson Sol. Obs. No. 71.

and Frrotnand Ellerman, S. B. Nichoison, and A. H. Jot. 1919. The magnetic polarity of sunspots. Astroph. Jour., 49:153, April 1919.

HaNN, J. 1902. Die Schwankungen der Niederschlagsmengen in grosseren Zeiträumen.

Hellmann, G. 1906. Die Niederschläge in den norddeutschen Stromgebieten.

Heraetre, F. 1914. Le problème du desséchement de l'Asie intérieure. Annales Gógraphie, 15 janvier 1914: 1-30.

HrMphREYs, W. J. 1910. Solar disturbances and terrestrial temperatures. Astroph. Jour., $32: 07$.

Huntington, E. 1905. Explorations in Turkestan, by Raphael Pumpelly. Carnegie Inst. Wash. Pub. No. 26.

1911. Palestine and its transformation.

1912. The secret of the big trees. Harpers, July 1912: 292-302.

1914. The climatic factor as illustrated in arid America. Carnegie Inst. Wash. Pub. No. 192.

1918. The evolution of the earth and its inhabitants. Climate and the evolution of civilization, Yale University Press.

KapTerN, J. C. 1916. Tree-growth and meteorological factors.

KimsalL, H. H. 1908. Pyroheliometer and polarimeter observations. Bull. Mt. Weather Obsv., Vol. I, 2-4; Vol. II, 2.

1910. Solar radiation, atmospheric absorption, and sky polarization at Washington, D. C. Bull. Mt. Weather Obsv, Vol. III, 2.

1912. The dense haze of June 10-11, 1912. Bull. Mt. Weather Obsv., Vol. V, part 3: 161-165.

- , and MiLLer, E. R. 19122. The influence of clouds on the distribution of solar radiation. Bull. Mt. Weather Obsv., Vol. V, part 3: 166-183.

1913. The meteorclogical aspect of the smoke problem. Mellon Institute of Industrial Research and School of Specific Industries. Smoke Investigation Bull. No. 5 .

1914. The relation between solar radiation intensities and the temperature of the air in the northern hemisphere in 1912-13. Bull.Mt. Weather Obsv., Vol. VI, part 5: 205-220.

Kimura, H. 1913. On the harmonic analysis of sunspot relative numbers. Mon. Not. Roy. Ast. Soc., 73: 543, May 1913. 
Livingston, G. J. 1909. An annotated bibliography of evaporation. Mon. Wea. Rev., June, September, November, 1908; February, March, April, May, June, 1909.

Lock¥ER, W. J. S. 1902. On some phenomena which suggest a short period of solar and meteorological changes. Proc. Roy. Boc., Vol. 70: 500-503.

. 1905. The flow of the river Thames in relation to British pressure and rainfall changes. Proc. Roy. Boc., Vol. 76: 494-506. 1905.

1906. Barometric pressures of long duration over large areas. Proc. Roy. Soc., Vol. 78: 43-60. 1906.

19062. Some world weather problems. Science Progress No. 2, October 1906.

1908. Monthly rainfall averages for 37 stations. Solar Physics Obsv., South Kensington. 1909. Discussion of Australian meteorology. Solar Physics Obsv., South Kensington.

1910. Southern hemisphere surface air circulation. Solar Physies Obsv., South Kensington.

$1910^{\circ}$. The behavior of the short-period atmospheric pressure variation over the earth's surfsce. Proc. Roy. Soc., Vol. 73: 457-470.

stations. Solar Physics Obsv., South Kensington, 1908.

Maunder, E. W. 1909. Notes on cyclones of the Indian Ocean, 1856-67, and their association with solar rotation. Mon. Not. Roy. Ast. Soc, 70, No. 1, November 1909.

- 1913. Distribution of sunspots in heliographic latitude, 1874-1913. Mon. Not. Roy. Ast. Soc., $74: 112$. December 1913.

Mrchelson, A. A. 1913. Determination of periodicities by the harmonic analyzer with an application to the sunspot cycle. Astroph. Jour., 38: 268. 1913.

MiLl, H. R. 1915. Tree-growth as a measurement of rainfall. Symons's Met. Mag., March 1915: 21-23.

MiLlish, D. C. 1916. The science of musical sounds.

-. 19162. The Henrici harmonic analyzer and devices for extending and facilitating its use. Jour. Franklin Institute, September 1916: 285-322.

Mrusen, E. R. 1912. See Kimball, H. H. 1912,

McAdw, A. 1903. Climatology of California. W. B. Bull. I.

McCratchis, A. J., and J. E. CorT. 1909. Relations of weather to crops and varieties adapted to Arizons conditions, Univ, of Arizons Agr. Exp. Ste. Bull. No, 61.

Moore, W. I. 1910. The influence of forests on climate and on floods. Report to House Com. on Agr.

Nordmann. 1903. Periodicity of sunspots and the variations of the mean annual temperatures of the atmosphere. Comptes Rendus. June 1903. Transl. Mon. Wea. Rev., August 1903: 371 .

Prarson, G. A. 1918. Studies of the yield and reproduction of western yellow pine in Arizona and New Mexico. Jour. of Forestry, March 1918: 273-293.

Pencr, A. 1914. The shifting of the climatic belts. Scot. Geog. Mag., 30:281, No. 6. June 1914.

Pexterison, OTto. 1912. The connection between hydrographical and meteorological phenomena. Qtly. Jour. Roy. Met. Boo, 38, No. 163, Juiy 1912.

Picrerine, W. H. 1910. The orbits of meteorites. Pop. Astr., No. 175: 1-15.

-. 1910". Two types of comets' tails. Pop. Astr., No. 175.

… 1910. The size of meteors. Astroph. Jour., Vol, XXI, No. 1: 88. January 1910.

Poskrs, P. 1910. Cycles du temps dans l'accroissement des grands arbres. Ciel et Terre. Bull. Soc. belge d'Astron., November 5, 1910.

Rosven, W. H. 1914. Design and theory of mechanism for illustrating certain systems of lines of force and stream lines. Bull. Mt. Wea. Obsv., 6: 195. August 1914.

Russzr, H. C. 1876. Notes on climate of New South Wales. Jour. Roy. Soc. N. S. W., 10: 151.

Sampson, R. A. 1914. On Professor Turner's theory of a sunspot swarm of meteors associated with the Leonids. Mon. Not. Roy. Ast. Soc., 75: 82. December 1914.

Schorme, G. 1917. Larken. Och. dess betydelse for svensk skogshushallning. Skogsvårdsforeningens Tidskrift.

Scramber, P. 1903. Die Schwankungen der jahrlichen Niederschlagshohen und deren Beziehungen zu den Relativzahlen für die Sonnenflecken. Heft. VII, Das Klima des Kön. Sachsen." Chemnitz.

BchUster, A. 1897. On lunar and solar periodicities of earthquakes. Proc. Roy. Boc., Vol. 61: $455-465$.

1898. On the investigation of hidden periodicities with application to a supposed 26day period of meteorological phenomena. Ter. Mag., 3, March 1898: $13-41$.

1899. On the periodogram of magnetic declination at Greenwich. Camb. Philos. Soc. Trans, 18: 107-135. 
Scrustre, A., 1906. The periodogram and its optical analogy. Proc. Roy. Soc. A., Vol. 77:136-140 19062. On the periodicities of the sunspots. Philos. Trans. Roy. Soc. A., Vol. 206: 69-100.

SHREVE, FORREST. 1915. The vegetation of a desert mountain range as conditioned by climatic factors. Carnegie Inst. Wash. Pub. No. 217.

SpilluaN, W. J. 1915. A theory of gravitation and related phenomena, Washington, D. C. September.

Stockman, W. B. 1905. Periodic variation of rainfall in the arid region. Wea. Bur. Bull. N. W. B. No. 326.

STratToN, F. J. M. 1911. On possible phase relations between the planets and sunspot phenomena. (Papers of the I. U. S. R. Computing Bureau, No. VII.) Mon. Not. Roy. Ast. Soc. 72: 9. November 1911.

St. John, Chartes E. 1913. Radial motion in sunspots. Astroph. Jour., 37: 322, reprinted in Cont. Mt. Wilson Sol. Obs. No. 69; continued in Astroph. Jour., vol. 38; reprinted in Cont. Mt. Wilson Sol. Obs. No. 74.

STörmgr, CARL. 1916. Researches on solar vortices. Astroph. Jour., vol. 43. reprinted Cont. Mt. Wilson Sol. Obs. No. 109.

TURNER, H. H. 1913. On the harmonic analysis of Wolf's sunspot numbers, with special reference to Mr. Kimura's paper. (Papers of the I. U. S. R. Computing Bureau, No. IX.) Mon. Not. Roy. Ast. Soc., 73: 549, May 1913.

$1913^{2}$. On the expression of sunspot periodicity as a Fourier sequence, and on the general use of a Fourier sequence in similar problems. (Papers of the I. U. S. R. Computing Bureau, No. X.) Mor. Not. Roy. Ast. Boo., 73: 714. November 1913.

$1913^{3}$. Further remarks on the expression of sunspot periodicity as a Fourier sequence. (Papers of the I. U. S. R. Computing Bureau, No. XII.) Mon. Not. Roy. Ast. Soo., 74: 16. November 1913.

$1913^{4}$. On a simple method of detecting discontinuities in s series of recorded observations, with an application to sunspots, suggesting that they are caused by a meteor swarm due to successive encounters of the Leonids with Saturn, which has been more than once considerably perturbed by the Leonid swarm. (Papers of the I. U. S. R. Computing Bureau, No. XIII.) Mon. Not. Roy. Ast. Soo., 74: 82. December 1913.

1915. Reply to Professor Sampson's objections to the hypothesis of a sunspot swarm. Mon. Not. Roy. Ast. Soc., 75: 138. January 1915.

VArt, C. E. 1917. Lithologic evidence of climatic pulsations. Science, N. S., Vol. XLVI, No. 1178: 90-93. July 27, 1917.

VERY, F. W. 1898. The variation of solar radiation. Astroph. Jour., Vol. VII, No. 4: 255-272.

- . 1901. The solar constant. U. 8. Dept. of Agr., Wea. Bur., No. 254.

-1904. The absorption of radiation by the solar atmosphere and the intrinsic radiation of that atmosphere. Astroph. Jour., Vol. XIX, 2.

Vinson, A. E. 1914. The effect of elimatic conditions on the rate of growth of date palms. Bot. Gas., Vol. LVII, No. 4: 324-327.

Woures, A. 1917. Astronomische Mitteilungen gegründet von Dr. Rudolf Wolf. No. CVI. 



QK

745

D62

v. 1

cop.2

Biolugical

\& Medical
Douglass, Andrew Ellicott

Climatic cycles and tree-growth

PLEASE DO NOT REMOVE

CARDS OR SLIPS FROM THIS POCKET

UNIVERSITY OF TORONTO LIBRARY 
